\title{
Characterization of infield duty cycles and exhaust emissions from diesel powered off-road heavy-duty equipment
}

Jeremiah Christopher Rohrbaugh

West Virginia University

Follow this and additional works at: https://researchrepository.wvu.edu/etd

\section{Recommended Citation}

Rohrbaugh, Jeremiah Christopher, "Characterization of infield duty cycles and exhaust emissions from diesel powered off-road heavy-duty equipment" (2002). Graduate Theses, Dissertations, and Problem Reports. 1289.

https://researchrepository.wvu.edu/etd/1289

This Thesis is protected by copyright and/or related rights. It has been brought to you by the The Research Repository @ WVU with permission from the rights-holder(s). You are free to use this Thesis in any way that is permitted by the copyright and related rights legislation that applies to your use. For other uses you must obtain permission from the rights-holder(s) directly, unless additional rights are indicated by a Creative Commons license in the record and/ or on the work itself. This Thesis has been accepted for inclusion in WVU Graduate Theses, Dissertations, and Problem Reports collection by an authorized administrator of The Research Repository @ WVU. For more information, please contact researchrepository@mail.wvu.edu. 
Characterization of Infield Duty Cycles and Exhaust Emissions from Diesel Powered Off-Road Heavy Duty Equipment

Jeremiah C. Rohrbaugh

Thesis submitted to the

College of Engineering and Mineral Resources at West Virginia University in partial fulfillment of the requirements for the degree of

Master of Science

in

Mechanical Engineering

Mridul Gautam, Ph.D., Chair

Committee Members:

Dr. Gregory Thompson

Dr. W. Scott Wayne

Department of Mechanical and Aerospace Engineering Morgantown, WV

2002

Keywords: Off-Road Equipment, Diesel Emissions 


\title{
Characterization of Infield Duty Cycles and Exhaust Emissions from Diesel Powered Off-Road Heavy Duty Equipment
}

\author{
Jeremiah C. Rohrbaugh
}

\begin{abstract}
The objective of study was to design, develop, and evaluate techniques to measure exhaust emissions from non-road equipment representative of major off-road diesel emissions contributors. Emissions data was collected from an excavator powered by a 1987 Komatsu 266 hp engine with mechanical fueling control, and a track-type tractor powered by a 2001 Caterpillar $850 \mathrm{hp}$ engine with electronic fueling control.

For the excavator, data was logged during in-field operation, and then representative in- field cycles were created on an engine test bed using this data. The Komatsu excavator engine was exercised over these new cycles in the WVU Engine and Emissions Research Laboratory, and brake-specific emissions of $\mathrm{CO}, \mathrm{NO}_{\mathrm{x}}$, total $\mathrm{HC}$, total $\mathrm{PM}$, and $\mathrm{CO}_{2}$ were determined. For the tractor, on-board emissions measurement equipment, namely the Mobile Emissions Measurement System (MEMS) and the Reat time Particulate Mass Monitor, RPM 100 were employed to collect in- use mass emissions rates of $\mathrm{CO}_{2}, \mathrm{NO}_{\mathrm{x}}$, and $\mathrm{PM}$.

Brake-specific emissions data collected while operating the excavator engine on the transient cycles and an 8-Mode test schedule highlighted the vast differences between
\end{abstract}


the results. Brake-specific $\mathrm{HC}, \mathrm{CO}, \mathrm{CO}_{2}, \mathrm{NO}_{\mathrm{x}}$, and $\mathrm{PM}$ emissions from the transient cycles were $50 \%, 65 \%, 10 \%, 35 \%$, and $50 \%$ lower than the weighted 8 -Mode results, respectively. Data collected from one exhaust stack on the tractor during a 360 second test cycle was $5062 \mathrm{~g} /$ cycle $\mathrm{CO}_{2}, 67.7 \mathrm{~g} /$ cycle $\mathrm{NO}_{\mathrm{x}}$, and $0.349 \mathrm{~g} /$ cycle DPM.

The study concluded that exhaust emissions are vehicle and task specific in nature, and while the ISO 8-Mode test cycle used for engine certification provides a benchmark for comparison of engine performance, it lacks the ability to provide a realistic estimation of actual in- field, in- use engine emissions. Therefore, emissions data collected over the 8-mode cycle is not recommended for use in emissions inventory models. 


\section{ACKNOWLEDGEMENTS}

Most of my life to this point has involved educational institutions, so as I near the end of my college career I have to wonder what not going to class on a regular basis will feel like. At this point it is hard to imagine life without Ramen noodles and $4 \times 4$ day at Kroger, but these are just a few of the simple pleasures that many a college grad will remember with a warm place in their heart. One of the best aspects of pursuing a graduate degree is that you get to meet some very sharp, hardworking people. I would like to take this time to recognize those who have helped me reach a goal that I set nearly two years ago.

First and foremost, I would like to thank Dr. Mridul Gautam, my advisor and friend, for all of the guidance and insight you have offered; and for the occasional shot in the arm when it became necessary to stir some motivation. Even though I can't have any french fries when you are in the vicinity, you have given me a great opportunity to further my education and for that I am truly appreciative.

When I think of the greatest influence in my life and those who have helped me the most, they are without question my parents. God has blessed me with a wonderful family whose support and love is without question. Dad, thanks for believing in yourself and walking out of that coal mine to create a company that not only kept me from having to say "do you want fries with that," but more importantly instilled the value of hard work and sparked a desire to pursue a mechanical engineering degree. I can't thank you enough for the valuable common sense experience that I have gathered while working with you, even if I do neglect to use it at times. How can one possibly express with 
words the thanks his mother deserves? Mom thank you for taking the time to be what a mother should be, your love is always felt, and though it may not seem at times like I listen at all to what you and dad have taught me about right and wrong, you have always provided an excellent example of what intelligent, moral, responsible people should do. Mike and Kris, you guys are both meat-heads, but you are some pretty cool brothers. No matter how good you may get at football, basketball, or golf, remember that big brother can still put a whuppin on ya!

I have also been very fortunate to have grandparents and aunts and uncles that have shown their love and support. From sparking an interest in flying to learning the finer points of fishing, or even sometimes the mischief that dad tries to steer you away from, granddads always teach you about the important stuff in life that they seem to have a vast amount of knowledge about. Grandmothers will never let you leave their presence without offering you some kind of food, which is very important to a growing boy. Scott, you are more like a big brother than an uncle, how else could I have learned to perform an all-star WWF body-slam or ddt without wrestlemania in the front yard? Thanks also for the tips on how to survive life in Morgantown. Lori, you were the twin sister I never had. Now that I'll be home more often you and Garrett better get those Artic Cats ready to breathe Polaris smoke! To all of my family, I apologize for not thanking each of you individually, but you are all very special to me, and I thank you for everything that you have done for me.

Life would be difficult if not impossible to survive without good friends. Some friends you know for just a short time and some you have known since you can remember. Ray is one such friend that I have known since kindergarten, it's a wonder we 
haven't killed each other with all the stuff we have done, from three wheeler wrecks to brush cutting accidents, to testing steel toe boots, we gave our guardian angels a workout for sure. Best of luck to you and Aimee, the only woman that rides snowmobile faster than I do; I wish you many happy years together. Aaron and especially Jaime, thanks for all the great meals and for knowing who to come to when you needed a hammer mechanic! I have enjoyed many fun times with you guys, thanks for being there when times weren't so good either. You have a wonderful baby boy too, I hope Micheala is as healthy and cool as James, but the camera is going to ha ve to go, I can't be caught holding two kids at the same time! I have many friends that I should mention, people that I have worked with that have taught me many things (good and bad), thanks to all of you. Sometimes we unfortunately lose our friends too. Ron Dolan and Shawn Radcliff were two friends whose lives were cut tragically short, and will be sorely missed.

One of the great things about graduate school is that you have the privilege of working with a high quality group of people that make you a better person. Dan Carder certainly stands out as one of the elite, whether working on an engineering solution or looking for a good bow, Dan can offer sound advice. Thanks for all of your help, especially for when you didn't have to, and probably should have been elsewhere. Wes Riddle, the human clock, can always tell when lunchtime is or when it is time to make a run to Jordan's for parts, and there are few people that are as enjoyable to work with. Ryan Barnett thanks for all the free lessons, whether it was getting destroyed at Quake or testing engines through the early morning hours, your work made finishing the project much easier. 
I certainly must thank all those who helped with this project, especially Dr. Greg Thompson, Tom Spencer, and Aaron Barnett, who braved the elements in Mt. Storm and some wreckless driving to help test the dozer. Thanks to Richard Atkinson for helping with lab programming, and for offering sound advice on anything electrical. Jared Knight, Brad Bane, and Jason Snyder are three of the many graduate students that I have enjoyed working with, I wish you all the best of luck. Ben Shade, Eric Meyer, and Andy Fuller also deserve credit, as their work was instrumental in creating the MEMS system that was used to complete this project. Thank you also to Dr. Scott Wayne for serving as one of my committee members.

Special thanks to Buffalo Coal Corp. and in particular, Mr. Chuck Howdershelt, Mr. Gerald Rammsburg, and Mr. John Geroski for allowing us to make your dozer look like the space shuttle. Your help was very much appreciated. I would also like to thank the California Air Resources Board for funding this project.

Last but certainly not least I would like to thank God for all of the blessings he has given me throughout my life. It sometimes disturbs me that we often forget God's name until we encounter tragedy in our lives, he deserves credit when things go well.

Well I should end this before it begins to look like an acceptance speech. I apologize for anyone that I have forgot to mention, but after many hours of writing, your mind sometimes goes blank. With deadlines approaching I should probably focus my remaining energy to finishing this monstrosity of a thesis. 


\section{TABLE OF CONTENTS}

ABSTRACT.

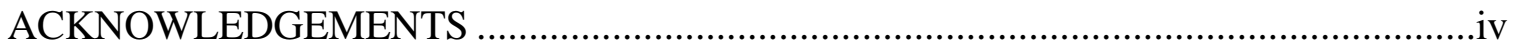

TABLE OF CONTENTS ..................................................................................... vii

LIST OF TABLES ………………….................................................................. xii

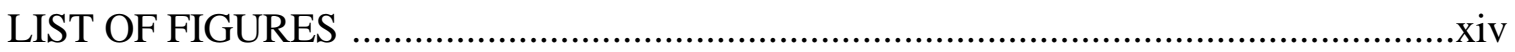

NOMENCLATURE .......................................................................................

CHAPTER 1 - INTRODUCTION ...................................................................... 1

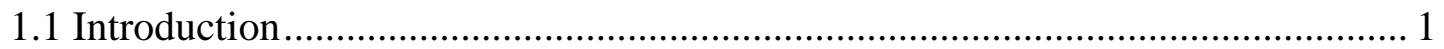

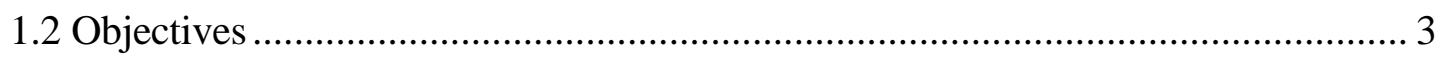

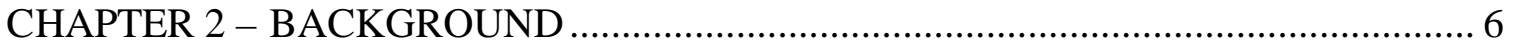

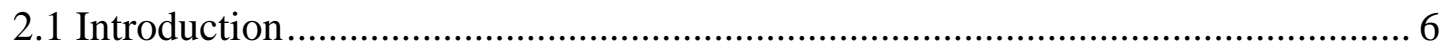

2.2 Previous Off-road Emissions Testing ………………................................... 12

2.2.1 Northeast States for Coordinated Air Use Management - 1997.................. 12

2.2.2 United States Coast Guard - 1997.............................................................. 13

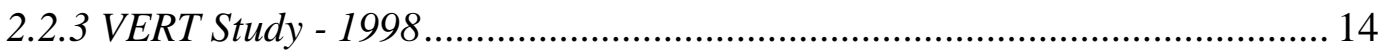

2.2.4 West Virginia University - 1999 .............................................................. 15

2.2.5 West Virginia University - 2001 ............................................................ 15

2.3 Previous On-board Emissions Testing Devices …………………………......... 16

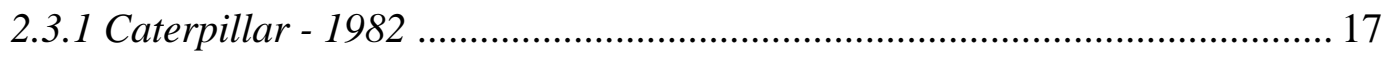

2.3.2 Southwest Research Institute - 1992 ............................................................. 17

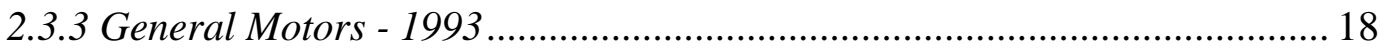

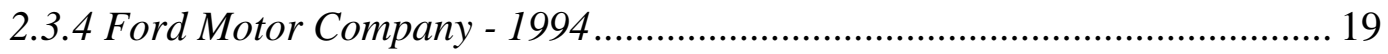

2.3.5 University of Pittsburgh - 1997................................................................. 20

2.3.6 Flemish Institute for Technological Research - 1997 .................................. 20

2.3.7 United States Environmental Protection Agency - 1999 .............................. 21

2.3.8 Ford Motor Company / WPI Microprocessor Systems, Inc. - 1999 ............ 22

2.3.9 West Virginia University - 2000 ................................................................... 22

2.4 Mobile Source Technical Review Subcommittee Meeting - 2002 ....................... 24

CHAPTER 3 - EXPERIMENTAL EQUIPMENT AND PROCEDURES ....................... 26

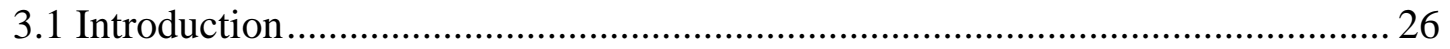




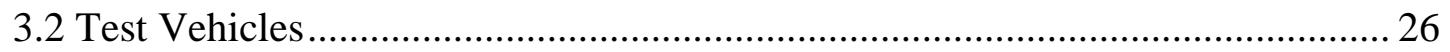

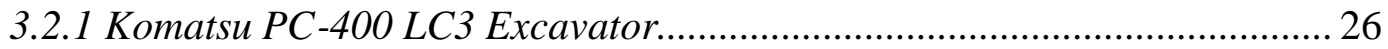

3.2.2 Caterpillar D-11R CD Track-type Tractor .................................................. 28

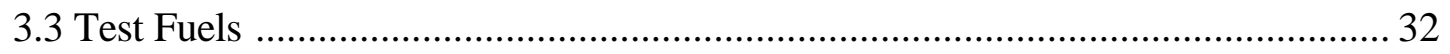

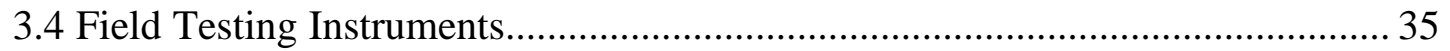

3.4.1 Sensor's AMB-II Microbench ................................................................ 35

3.4.1.1 Sample Collection and Conditioning....................................................... 36

3.4.1.2 Engine Speed Measurement ................................................................... 38

3.4.2 Mobile Emissions Measurement System (MEMS) ……………………..... 39

3.4.2.1 MEMS Exhaust Mass Flow Measurement ................................................... 41

3.4.2.2 MEMS Engine Torque and Speed Measurement...................................... 41

3.4.2.3 MEMS Emissions Analyzers Component................................................. 42

3.4.2.4 MEMS Emissions Sample Conditioning System....................................... 43

3.4.2.5 MEMS Data Acquisition, Reduction, and Archival System........................... 44

3.4.3 MARI Real-time Particulate Mass Monitor (RPM 100) ………................... 45

3.4.3.1 Quartz Crystal Microbalance ................................................................... 46

3.4.3.2 Sampling Conditioning System................................................................ 49

3.5 Laboratory Testing Equipment, WVU EERL.................................................... 55

3.5.1 Full-flow Exhaust Dilution Tunnel ........................................................... 57

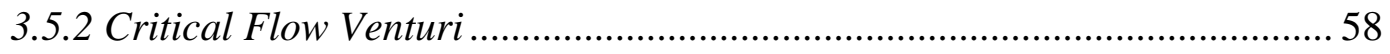

3.5.3 Gaseous Emission Sampling System ……………………………………... 58

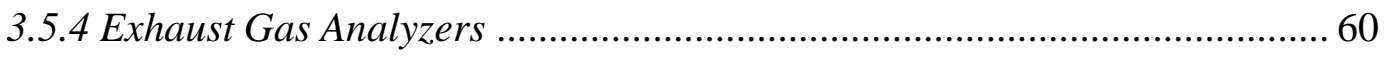

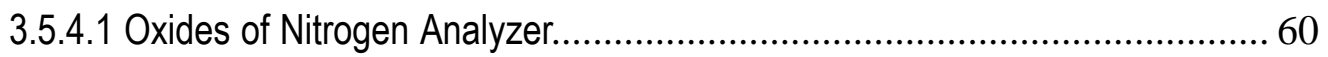

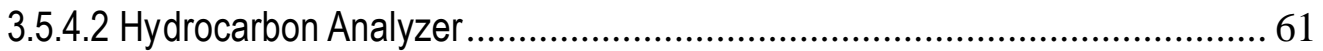

3.5.4.3 Carbon Monoxide/Carbon Dioxide Analyzers.............................................. 61

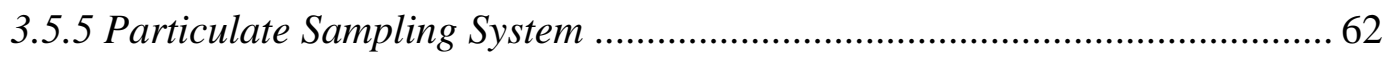

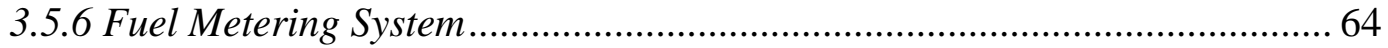

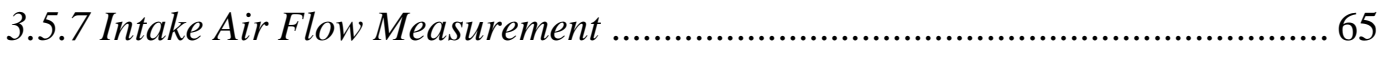

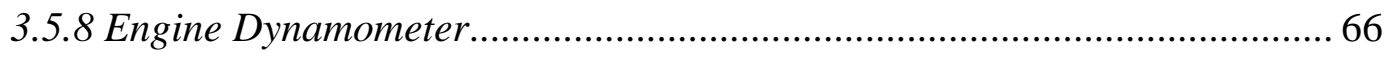

3.5.9 Instrumentation Control / Data Acquisition ................................................... 67

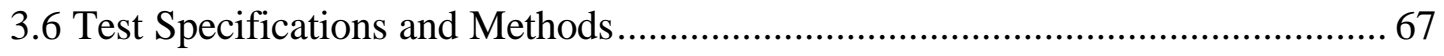




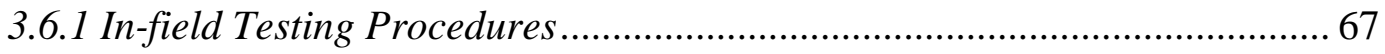

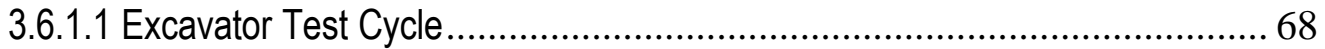

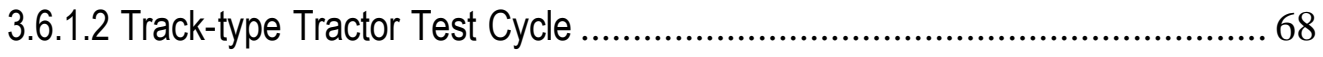

3.6.2 Laboratory Testing Procedures .............................................................. 71

3.6.2.1 Transient Test Operating Conditions.......................................................... 72

3.6.2.2 Steady-state Operating Conditions............................................................ 74

3.6.3 MEMS System Qualification for In-field Testing ........................................ 75

3.6.3.1 Exhaust Stack Sampling Section Design and Qualification.......................... 75

3.6.3.2 Preparation of MARI RPM 100 for In-field Testing ..................................... 80

CHAPTER 4 - RESULTS AND DISCUSSION............................................................ 83

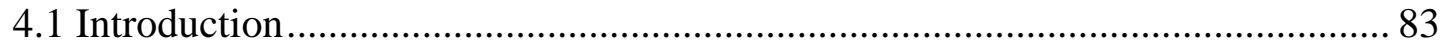

4.2 Considerations Relative to In-field Emissions Measurement .............................. 83

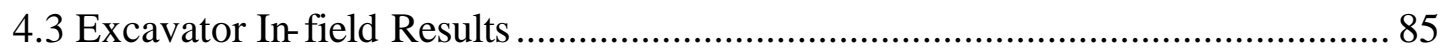

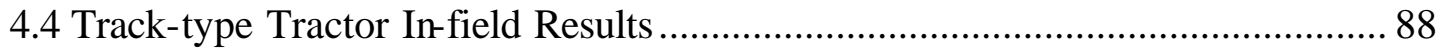

4.4.1 Vehicle Instrumentation and Test Conditions............................................. 88

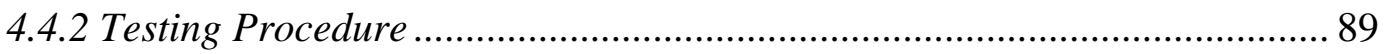

4.4.3 Emissions Test Results ............................................................................. 91

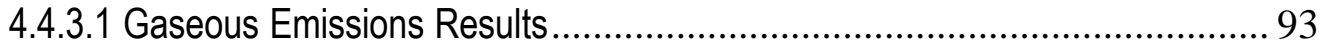

4.4.3.2 Particulate Matter Emissions Results ........................................................ 93

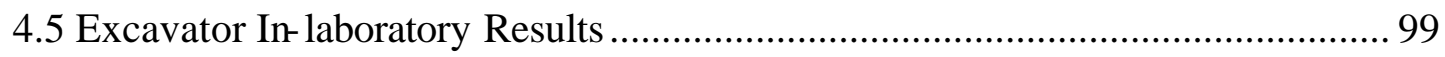

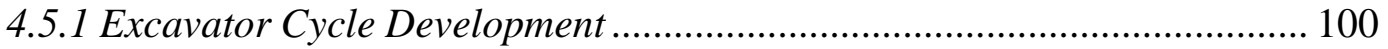

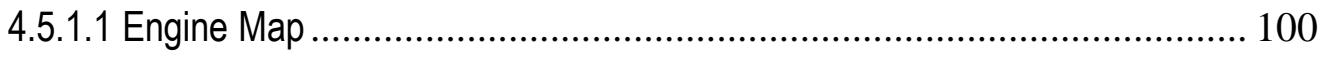

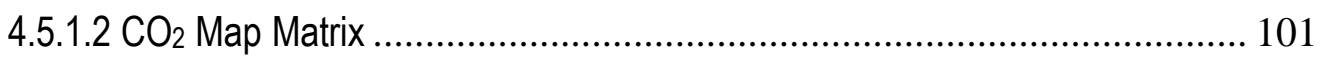

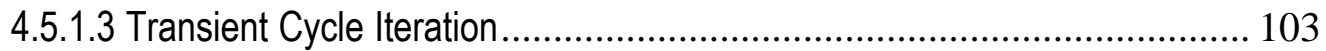

4.5.2 Excavator Transient Cycle Laboratory Emissions Results......................... 116

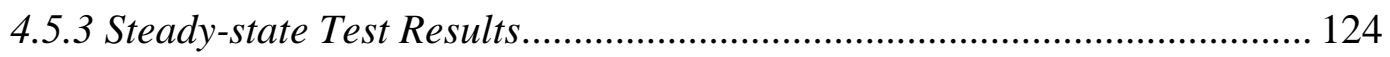

4.5.4 Comparison of Test Cycle Emissions Results: WVU Off-road Transient

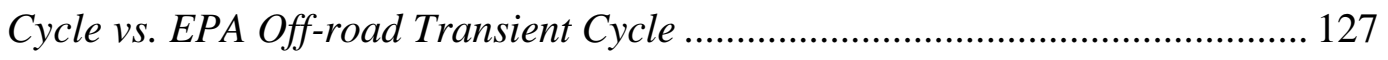

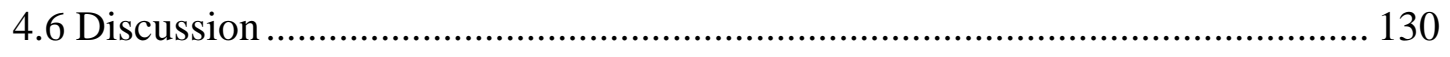

4.6.1 Engine Load and Speed Factors ............................................................... 131

4.6.2 Characterization of Transient Test Cycles ................................................ 143 
4.6.2.1 Transient Cycles Used on Komatsu PC400-LC3 Excavator. 143

4.6.2.2 Transient Cycle Characterization Relative to Caterpillar D-11R CD Track-type

Tractor. 154

4.6.3 Evaluation of 8-Mode Weighting Factors............................................. 161

CHAPTER 5 - CONCLUSIONS AND RECOMMENDATIONS ............................. 165

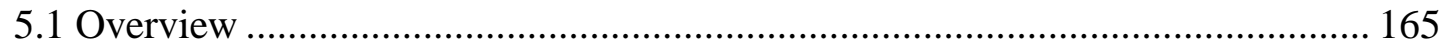

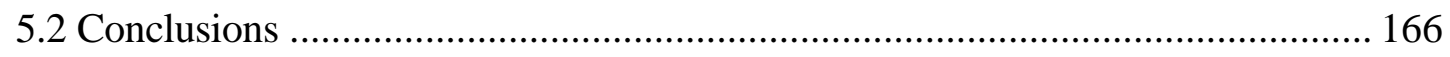

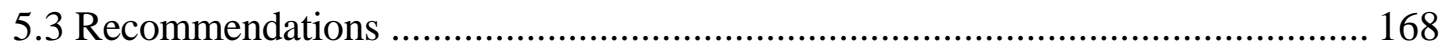

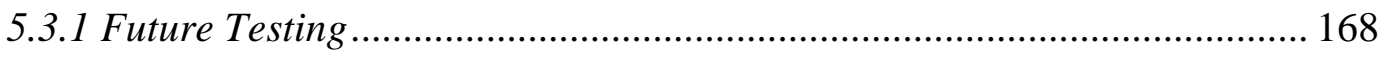

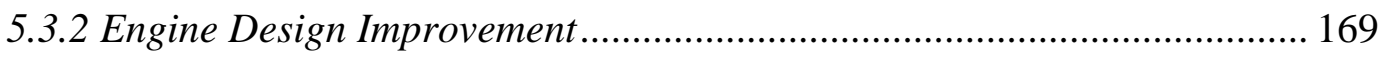

APPENDIX A - ADDITIONAL BRAKE-SPECIFIC LABORATORY TRANSIENT

CYCLE TESTING DATA FOR KOMATSU S6D125-1 (g/Bhp-Hr).......................... 173 


\section{LIST OF TABLES}

Table 1 Tier 1 Emissions Standards for Engine Power Classes Evaluated for this Study.. 2

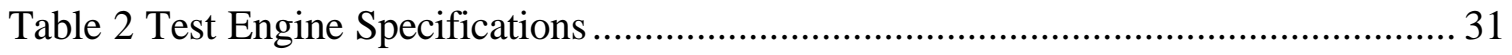

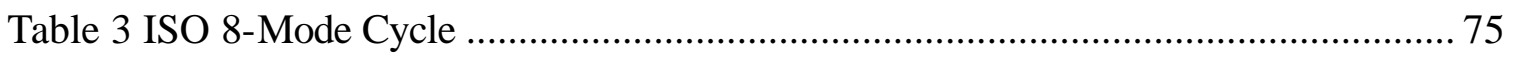

Table 4 Gravimetric PM Comparisons between the MARI RPM 100 and the Full-flow

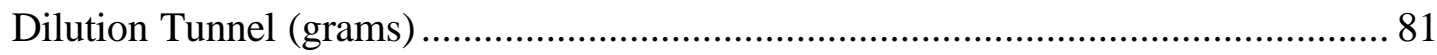

Table 5 Matrix for the Komatsu S6D125-1 Excavator Engine .................................... 102

Table 6 Transient Cycle Brake-Specific Exhaust Emissions Results for the Komatsu S6D125-1 Excavator Engine Operating According to the WVU Excavator Test Cycle \#1 (Loading) (g/Bhp-hr).

Table 7 Brake-Specific Transient Cycle Exhaust Emissions Results for the Komatsu S6D125-1 Excavator Engine Operating According to the WVU Excavator Test Cycle \#2 (Transport) (g/Bhp-hr).

Table 8 Transient Cycle Emissions Results for the Komatsu S6D125-1 Excavator Engine Operating According to the WVU Excavator \#3 (Trenching) Test Cycle (g/Bhp-hr)

Table 9 Excavator 8-Mode Engine Speed/Load Set Points 124

Table 10 Average 8-Mode Results for the Komatsu S6D125-1 Excavator Engine (g/Bhphr)

Table 11 Comparison of Weighted 8-Mode Results with Average Transient Test Results for the Komatsu S6D125-1 Excavator Engine (g/Bhp-hr)..... 126

Table 12 Emissions Results for the Komatsu S6D125-1 Excavator Engine Operating

According to the EPA Excavator Test Cycle (g/bhp-hr).

Table 13 Comparison of Brake-specific Exhaust Emissions Results for the Komatsu

S6D125-1 Excavator Engine Operating According to the WVU Excavator Test

Cycles and the EPA Excavator Test Cycle (g/Bhp-hr)

Table 14 Average Load Factor and Cycle Time for the Laboratory Transient Test Cycles

Table 15 Comparison of Mode 2 Results with Transient Test Results (g/bhp-hr) 161

Table 16 Comparison of Weighted 8-Mode Results with Transient Cycle Results after the Removal of Mode 8 from the Weighting Process 162 
Table 17 Comparison of Weighted 8-Mode Results with Transient Cycle Results after the Removal of Mode 4 from the Weighting Process.................................................. 162 Table 18 Comparison of Weighted 8-Mode Results with Transient Cycle Results after the Removal of Modes 4 and 8 from the Weighting Process..................................... 163 Table 19 Comparison of Weighted 8-Mode Results with Transient Cycle Results after the Removal of Mode-8 and the Adjustment of Weighting Factors ............................ 164

Table 20 Comparison of Steady-state Dynamometer Test Results with the Current Off-

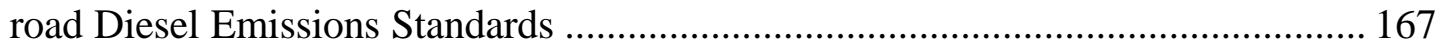

Table 21 Comparison of Brake-Specific Emissions from First and Final Iterations of Excavator Cycle 1 (Digging Cycle)

Table 22 Comparison of Brake-Specific Emissions from First and Final Iterations of Excavator Cycle 2 (Hauling Cycle)

Table 23 Comparison of Brake-Specific Emissions from First and Final Iterations of

Excavator Cycle 3 (Trenching Cycle)..... 


\section{LIST OF FIGURES}

Figure 1 Komatsu PC400LC3 Excavator …………………………………………..... 27

Figure 2 Komatsu S6D125-1 Engine in Excavator......................................................... 27

Figure 3 Engine Map for Komatsu Excavator ............................................................ 28

Figure 4 Caterpillar D-11R CD Track-Type Tractor Operating at Buffalo Coal Test Site

Figure 5 Caterpillar D-11R CD Track-Type Tractor Outfitted with WVU's Mobile

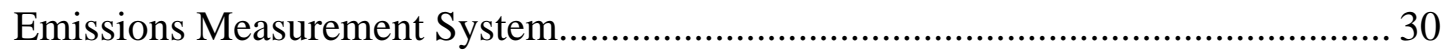

Figure 6 Caterpillar 3508 Engine Lug Curve (As Reported by Caterpillar)..................... 31

Figure 7 Test Fuel Analysis Results Provided by CARB Southern Laboratory Branch.. 33

Figure 8 Test Fuel Analysis Results Provided by CORE Laboratories ............................. 34

Figure 9 Sensors Inc. AMB-II Multigas Analyzer........................................................ 36

Figure 10 Sample Probe, Line, and Filter Used for Excavator In-field Testing ............... 37

Figure 11 Exhaust Sample Line and Probe on Excavator .................................................. 37

Figure 12 WVU MEMS Gaseous Sample Conditioner and Analyzer Container............. 39

Figure 13 MEMS System Components ....................................................................... 40

Figure 14 Exhaust Sampling System of the First Generation MEMS............................... 44

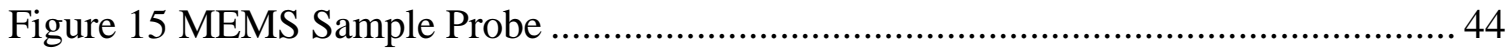

Figure 16 MARI Real-Time Particulate Mass Monitor (RPM 100) in a Weatherproof

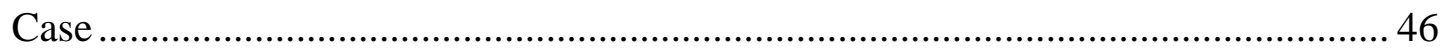

Figure 17 Internal Component View of the MARI Real-Time Particulate Mass Monitor

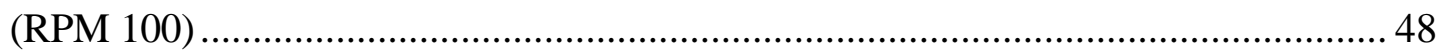

Figure 18 Schematic of the Sampling System ......................................................... 51

Figure 19 Schematic of the Sample Conditioning System ............................................... 52

Figure 20 Schematic of WVU EERL Laboratory Setup ..................................................... 56

Figure 21 Gaseous Emissions Analyzer Bench at WVU EERL....................................... 59

Figure 22 EPA Crawler Tractor Normalized Speed and Load Set-point Cycle ................ 70

Figure 23 Komatsu S6D125-1 Engine Mounted on GE DC Dynamometer Test Bed ..... 72

Figure 24 EPA Excavator Cycle Percentage Load Setpoints ............................................. 74

Figure 25 Test Section for Track-type Tractor In-field Testing ........................................ 77 
Figure 26 Dynamometer Test Cycle Designed to Evaluate the On-board Emissions

Testing System in the Laboratory 79

Figure 27 Comparison of Mass Emissions Rates of $\mathrm{NO}_{\mathrm{x}}$ over a Transient Cycle Designed

to Mimic In-field Dozer Operation - MEMS Results and Laboratory Results 79

Figure 28 Comparison of Mass Emissions Rates of $\mathrm{CO}_{2}$ over a Transient Cycle Designed

to Mimic In-field Dozer Operation - MEMS Results and Laboratory Results ......... 80

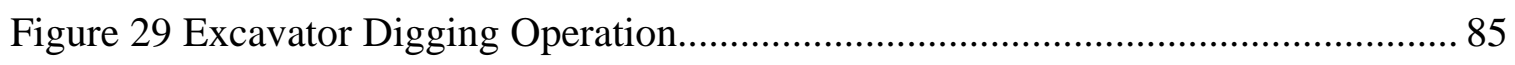

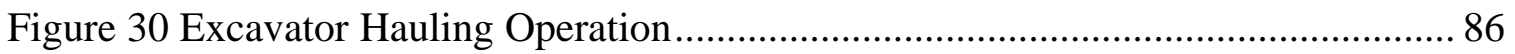

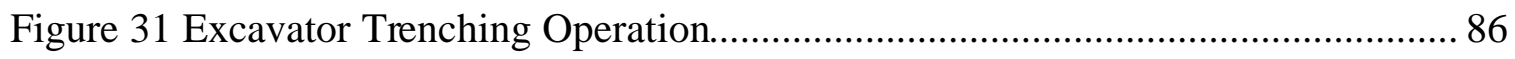

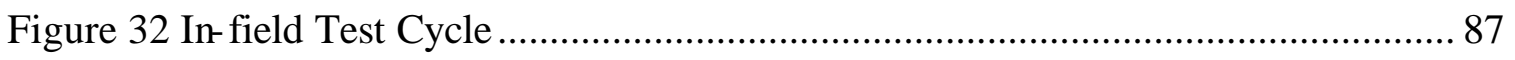

Figure 33 Caterpillar D-11R CD Track-type Tractor with On-board Emissions

Measurement Equipment 89

Figure 34 Caterpillar D-11R CD Track-type Tractor Operating with On-board Emissions

Measurement Equipment . 90

Figure 35 Engine Speed and Power Data Collected by Caterpillar during Track-type

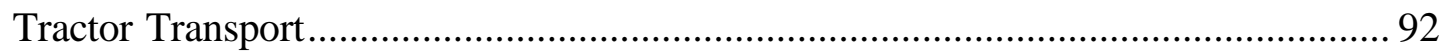

Figure $36 \mathrm{CO}_{2}$ Mass vs. Time for the First Track-type Tractor Test (Full Cycle) ........... 94

Figure $37 \mathrm{CO}_{2}$ Mass vs. Time for the First Track-type Tractor Test (Cycle Shortened to

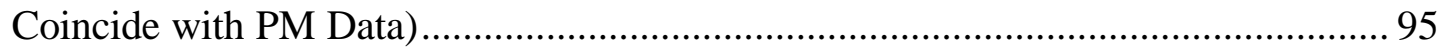

Figure $38 \mathrm{NO}_{\mathrm{x}}$ Mass vs. Time for the First Track-type Tractor Test (Full Cycle) .......... 95

Figure $39 \mathrm{NO}_{\mathrm{x}}$ Mass vs. Time for the First Track-type Tractor Test (Cycle Shortened to

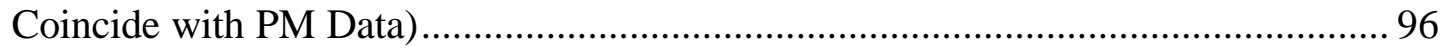

Figure $40 \mathrm{NO}_{\mathrm{x}}$ and PM Concentration Data for the First Track-type Tractor Test ..........97

Figure $41 \mathrm{CO}_{2}$ Mass vs. Time for the Second Track-type Tractor Test ......................... 98

Figure $42 \mathrm{NO}_{\mathrm{x}}$ Mass vs. Time for the Second Track-type Tractor Test ......................... 99

Figure 43 Komatsu S6D125-1 Engine Mounted on GE DC Dynamometer Test Bed ... 100

Figure 44 Komatsu S6D125-1 Engine Map........................................................... 101

Figure 45 Test Cycle 1 First Approximation Results ............................................... 104

Figure 46 Test Cycle 1 Final Test Results .............................................................. 105

Figure 47 Continuous $\mathrm{CO}_{2}$ Traces $(0-200$ s) from Cycle Iterations used to Produce Final

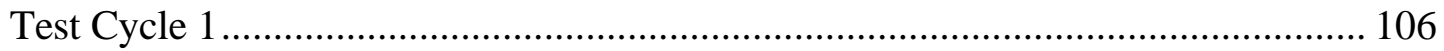


Figure 48 Continuous $\mathrm{CO}_{2}$ Traces $(200-400$ s) from Cycle Iterations used to Produce

Test Cycle 1 .

Figure 49 Continuous $\mathrm{CO}_{2}$ Traces $(400-600 \mathrm{~s})$ from Cycle Iterations used to Produce

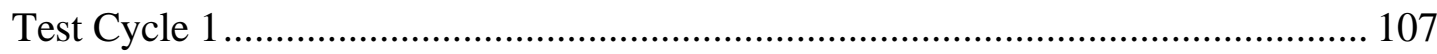

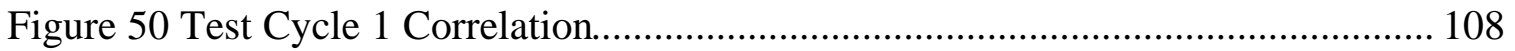

Figure 51 Comparison of Average Brake-specific Emissions Results from the First and

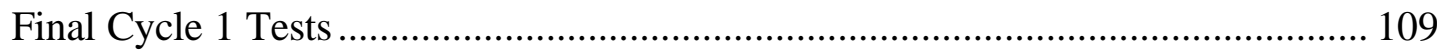

Figure 52 Test Cycle 2 First Approximation Results ............................................... 110

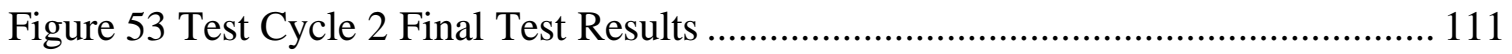

Figure 54 Test Cycle 2 vs. In-field $\mathrm{CO}_{2}$ Correlation ............................................. 112

Figure 55 Comparison of Average First and Final Cycle 2 Iteration Brake-specific

Emissions

Figure 56 Test Cycle 3 First Approximation Results ............................................. 114

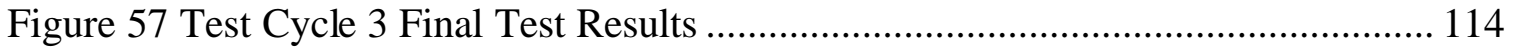

Figure 58 Correlation of $\mathrm{CO}_{2}$ Data from Final Test and In-field Results..................... 115

Figure 59 First and Final Cycle 3 Iteration Average Brake-specific Emissions

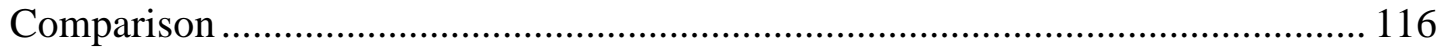

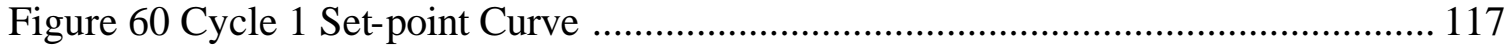

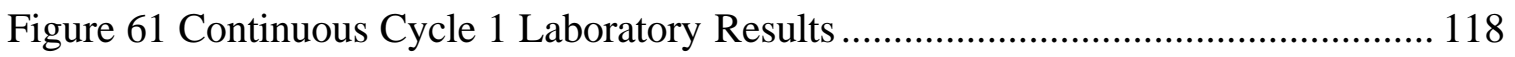

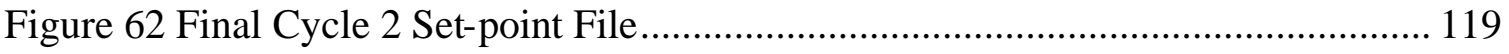

Figure 63 Continuous Cycle 2 Laboratory Results ................................................... 120

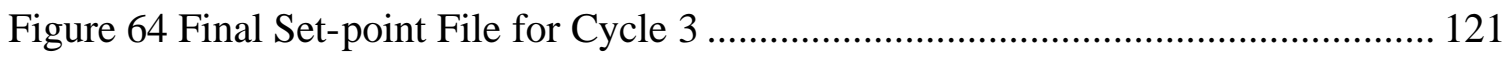

Figure 65 Cycle 3 Final Laboratory Results ......................................................... 122

Figure 66 Average Laboratory Results Comparison for the Three Excavator Transient Cycles (g/Bhp-hr)

Figure 67 Average of 8-Mode Results for the Komatsu S6D125-1 Engine (g/Bhp-hr). 125

Figure 68 Average Weighted 8-Mode Emissions for the Komatsu S6D125-1 Engine

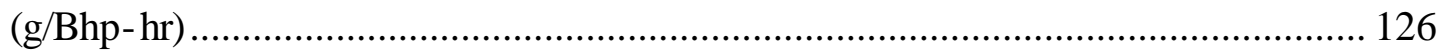

Figure 69 Set-point Torque and Speed for EPA Cycle ........................................... 128

Figure 70 EPA Cycle Continuous Laboratory Results ............................................. 129

Figure 71 Average Load and Speed Factors for All Vehicles and Te st Cycles.............. 132 
Figure 72 Normalized Load and Speed Curve for the WVU Loader Cycle 133

Figure 73 Normalized Load and Speed Curve for the WVU Street Sweeper Cycle ...... 134 Figure 74 Normalized Load and Speed Curve for the Street Sweeper on Loader Cycle 134 Figure 75 Normalized Load and Speed Curve for the WVU Excavator Cycle 1 .......... 136 Figure 76 Normalized Load and Speed Curve for the WVU Excavator Cycle 2 .......... 137 Figure 77 Normalized Load and Speed Curve for the WVU Excavator Cycle 3 ........... 138

Figure 78 Normalized Load and Speed Curve for the EPA Excavator Cycle 139 Figure 79 Normalized Load and Speed Curve for the Track-type Tractor Transport Test

Figure 80 Normalized Engine Speed Data for Track-type Tractor Digging Cycle 1 .... 141 Figure 81 Normalized Engine Speed Data from Track-type Tractor Second Digging Test

Figure 82 Speed Range Characterization for Excavator Cycle 1 (Digging) .................. 144

Figure 83 Load Range Characterization for 1900-2000 rpm Speed Range ................... 145

Figure 84 Load Range Characterization for 2000-2100 rpm Speed Range ................... 145

Figure 85 Speed Range Characterization for Excavator Cycle 2 (Hauling) .................. 146

Figure 86 Load Range Characterization for 1900-2000 rpm Speed Range for Excavator

Cycle 2 ..

Figure 87 Load Range Characterization for 2000-2100 rpm Speed Range for Excavator

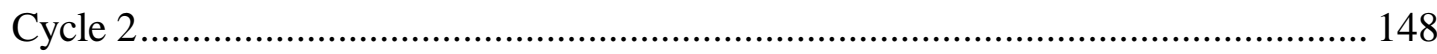

Figure 88 Speed Range Characterization for Excavator Cycle 3 (Trenching) ............... 149

Figure 89 Load Range Characterization for 1900-2000 rpm Speed Range for Excavator

Cycle 3 .

Figure 90 Load Range Characterization for 2000-2100 rpm Speed Range from Excavator

Cycle 3. 150

Figure 91 Speed Range Characterization for EPA Transient Excavator Test Cycle ...... 151 Figure 92 Load Range Characterization for 2000-2100 rpm Speed Range for EPA Excavator Cycle 152

Figure 93 Load Range Characterization for 1200-1400 rpm Speed Range for EPA

Excavator Cycle 153

Figure 94 Speed Range Characterization for Track-type Tractor Transport Test 154 
Figure 95 Load Factor Characterization for Track-type Tractor Transport Test in 19002000 rpm Speed Range

Figure 96 Engine Speed Characterization for In-field Digging Transient Test Cycle \#1

Figure 97 Engine Speed Characterization for Track-type Tractor In-field Digging Transient Test \#2

Figure 98 Speed Range Characterization for EPA Crawler Tractor Cycle 158 Figure 99 Load Factor Characterization for EPA Crawler Tractor Cycle 1300-1600 rpm Speed Range 159

Figure 100 Laboratory Qualification Test Cycle Speed Range Characterization........... 159

Figure 101 Load Range Characterization for Laboratory Qualification Testing Cycle . 160 


\section{NOMENCLATURE}

\begin{tabular}{|c|c|}
\hline $\mathrm{ADC}$ & Analog-to-Digital Conversion \\
\hline CARB & California Air Resources Board \\
\hline CFR & Code of Federal Regulations \\
\hline $\mathrm{CFV}$ & Critical Flow Venturi \\
\hline $\mathrm{CO}$ & Carbon Monoxide \\
\hline $\mathrm{CO}_{2}$ & Carbon Dioxide \\
\hline CVS & Constant Volume Sampler \\
\hline $\mathrm{DC}$ & Direct Current \\
\hline DPM & Diesel Particulate Matter \\
\hline ECU & Engine (Electronic) Control Unit \\
\hline EERL & Engine and Emissions Research Laboratory \\
\hline EGS & Electrochemical Gas Sensor \\
\hline FTIR & Fourier Transform Infrared \\
\hline FTP & Federal Test Procedure \\
\hline G & Force of Gravity \\
\hline GCS & Governed Central Speed \\
\hline GE & General Electric \\
\hline GPS & Global Positioning System \\
\hline $\mathrm{HC}$ & Hydrocarbon \\
\hline HFID & Heated Flam Ionization Detector \\
\hline I.D. & Inner Diameter \\
\hline LFE & Laminar Flow Element \\
\hline MARI & Mid-Atlantic Research Institute \\
\hline MEMS & Mobile Emissions Measurement System \\
\hline MFC & Mass Flow Controller \\
\hline NDIR & Non-dispersive Infrared \\
\hline NDUV & Non-dispersive Ultra-violet \\
\hline NESCAUM & Northeast States for Coordinated Air Use Management \\
\hline NIST & National Institute for Standards and Technology \\
\hline NO & Nitric Oxide \\
\hline
\end{tabular}




$\begin{array}{ll}\mathrm{NO}_{2} & \text { Nitrogen Dioxide } \\ \mathrm{NO}_{\mathrm{x}} & \text { Oxides of Nitrogen } \\ \mathrm{O}_{2} & \text { Oxygen } \\ \mathrm{O}_{3} & \text { Ozone } \\ \mathrm{OBE} & \text { On-board Emissions (measurement device) } \\ \mathrm{PPM} & \text { Parts Per Million } \\ \text { PREVIEW } & \text { Portable Realtime Emission Vehicular Integrated Engineering } \\ & \text { Workstation } \\ \text { PSI } & \text { Pounds per Square Inch } \\ \text { QCM } & \text { Quartz Crystal Microbalance } \\ \text { QC/QA } & \text { Quality Control / Quality Assurance } \\ \text { RCI } & \text { Richard Construction Inc. } \\ \text { ROVER } & \text { Real-time On-road Vehicle Emissions Recorder } \\ \text { RPM 100 } & \text { Real-time Particulate Mass Monitor } \\ \text { RTD } & \text { Resistive Temperature Device } \\ \text { SCFM } & \text { Standard Cubic Feet per Minute } \\ \text { SCS } & \text { Sample Conditioning System } \\ \text { SO } & \text { Sulfur Dioxide } \\ \text { TEOM } & \text { Tapered Element Oscillating Microbalance } \\ \text { TTL } & \text { Transistor-Transistor Logic } \\ \text { UDDS } & \text { Urban Dynamometer Driving Schedule } \\ \text { US EPA } & \text { United States Environmental Protection Agency } \\ \text { VEOM } & \text { Vito on-the Road Emission and Energy Measurement } \\ \text { WV } & \text { West Virginia } \\ \text { WVU } & \text { West Virginia University } \\ \text { ZrO } & \text { Zirconium Oxide } \\ & \end{array}$




\section{CHAPTER 1 - INTRODUCTION}

\subsection{Introduction}

Internal combustion engines have become an essential part of today's society. The energy developed by these engines moves people, products, and portions of the earth itself. The by-products of the combustion process, however, leave us searching for ever cleaner ways to produce this energy. A great deal of research and design effort has been devoted to on-highway engines, which has produced more energy efficient and cleaner burning vehicles. Compression-ignition or diesel engines are of particular concern due to the high levels of particulate matter $(\mathrm{PM})$, oxides of nitrogen $\left(\mathrm{NO}_{\mathrm{x}}\right)$, and volatile organic compounds that they produce. During the past few decades, the U.S. Environmental Protection Agency (EPA) and the California Air Resources Board (CARB) have introduced increasingly tighter standards regarding exhaust emissions from various sources. An area of particular concern is the pollution created by both onhighway and non-road diesel engine powered vehicles. The current exhaust emissions regulations for diesel engines concentrate on four major exhaust components: HC, PM, $\mathrm{CO}$, and $\mathrm{NO}_{\mathrm{x}}$. The production of $\mathrm{CO}_{2}$ is also coming under scrutiny as a greenhouse gas on a global scale.

The health concerns regarding direct human exposure to these exhaust emissions are heightened for many of the off-road diesel applications due to poorly ventilated work areas and direct exhaust plume exposure to the equipment operator and immediate coworkers. Attention is now shifting to off-highway vehicles in order to curb emissions from traditionally "dirty" engines. The 1996 Statement of Principles between EPA, California Air Resource Board (CARB), and off-highway engine manufacturers, phases 
in emissions standards that become increasingly more stringent through the year 2008

[1]. Currently, Tier 1 standards are in effect for new production engines of the 175-300 hp class and the $>750 \mathrm{hp}$ class. Engines have been separated by power rating in the creation of these standards, the power classes evaluated under this study and the current standards for exhaust emissions are listed in Table 1.

Table 1 Tier 1 Emissions Standards for Engine Power Classes Evaluated for this Study

\begin{tabular}{|c|c|c|c|c|}
\hline Power Rating & NOx & HC & CO & PM \\
\hline (hp) & (g/bhp-hr) & (g/bhp-hr) & (g/bhp-hr) & (g/bhp-hr) \\
\hline \hline $\mathbf{1 7 5}-\mathbf{3 0 0}$ & 6.9 & 1 & 8.5 & 0.4 \\
\hline$>\mathbf{7 5 0}$ & 6.9 & 1 & 8.5 & 0.4 \\
\hline
\end{tabular}

$\mathrm{CARB}$ is also in the process of updating its emissions inventory models with information on in-use emissions data from off-highway vehicles as these inventories have often been inaccurate in the estimation of emissions from mobile sources, especially from diesel-powered equipment. Emissions databases from off-road diesel powered equipment suffer immensely from insufficient realworld activity data and, more so, from the fact that emissions standards regulating such equipment have only been in existence since 1996. Current testing procedures for off-road engine emissions quantification modeling do not mimic actual duty cycles experienced by the engine in a vehicle. An engine will produce vastly different exhaust emission levels when operating on different duty cycles, especially between the traditional steady state ISO $8178 \mathrm{C} 18$-mode, (which is the current qualification standard) and a "real world" transient test [2]. Standardized transient tests do not exist and their development is complex and laborious. While the steady state 8- 
Mode test provides a benchmark by which engines can be compared and certified, the vast differences in transient operations performed by a given engine creates the problem of developing a cycle that produces an accurate representation of in-field emissions production. Determination of actual duty cycles, either by in-laboratory cycle recreation or in-use emissions measurement would be a logical answer to understanding actual inuse emissions. In-use emissions measurement utilizes equipment capable of producing laboratory grade data to record raw exhaust component concentrations as the vehicle performs normal operations. These devices are well suited to modern electronically controlled engines as information can easily be gathered from engine control units (ECU) to calculate brake-specific emissions. Laboratory cycle recreation uses data measured infield, usually engine speed and data from which torque can be determined, to create and modify a cycle that is exercised on the engine in laboratory until the engine produces the same data that was recorded in-field. The focus of this study was to fill the current void in off-road equipment testing cycles and the consequent lack of "reat-world" emissions data that is needed to accurately model emissions inventories. Thus, the necessary knowledge will be available to enact appropriate standards for off-highway mobile sources such that air quality standards can be maintained.

\subsection{Objectives}

The global objective of this study was to develop and validate techniques to record data that represent actual emissions for diesel powered off-highway vehicles. Due to a lack of existing standardized transient cycles it was determined that in-field duty cycles should be recorded and reproduced in the laboratory. State-of-the-art equipment was developed and modified to accomplish the task of recording in- use emissions on 
non-road equipment. West Virginia University procured four vehicles for four engine horsepower classes. An Elgin Pelican Streetsweeper with a John Deere 4039TF Engine (51-120 hp), a John Deere 444D End Loader with a 6058D engine (121-250 hp), a Komatsu PC400LC3 Excavator with a S6D 125-1 Engine (251-500 hp) and a Caterpillar D11R CD Track-type Tractor with a 3508 engine (500-750 hp). The particular focus of this study is on the excavator and the tractor. Barnett (2001) presented data and detailed analysis of emissions from the streetsweeper and the wheel loader.

The specific objectives of this study included procurement of the vehicles necessary for testing, developing techniques to measure in- use emissions data, measuring emissions while the vehicle performed infield operations, and producing, from this data, emissions data relative to in- use duty cycles. For the excavator engine, engine speed and raw $\mathrm{CO}_{2}$ concentrations were recorded during field operation. The engine was then removed from the vehicle and placed on a dynamometer test bed where an iterative process was used to develop a transient test cycle that produced the same engine speed and $\mathrm{CO}_{2}$ data as the infield measurements. The emissions results from these tests were compared to emissions produced on the ISO $8178 \mathrm{C} 1$ test cycle. The in- use emissions data collected from the track-type tractor during in-field operation were measured using WVU's Mobile Emissions Measurement System (MEMS), which is a portable, on-board unit capable of providing measurements of mass emissions of $\mathrm{NO}_{\mathrm{x}}$ and $\mathrm{CO}_{2}$. Gravimetric exhaust PM measurements were made using the Mid-Atlantic Research Institute's (MARI) portable Real-time Particulate Mass Monitor (RPM100) that is capable of providing in-field, on-board realtime particulate mass information. This report presents: a review of published literature on in-use emissions measurements and non-road 
equipment emissions, details of the equipment and vehicles used, in field and in lab testing procedures and transient cycle development, results and comparisons of said tests, and conclusions and recommendations. 


\section{CHAPTER 2 - BACKGROUND}

\subsection{Introduction}

Exhaust emissions from diesel-powered equipment is a significant source of particulate matter, oxides of nitrogen, and carbon dioxide, with trace amounts of hydrocarbons and carbon monoxide. The regulations of diesel exhaust emissions are aimed at limiting the serious health effects caused by diesel exhaust constituents. When inhaled, $\mathrm{NO}_{\mathrm{x}}$ and $\mathrm{CO}$ readily bond to the hemoglobin in blood and reduce the oxygen carrying capacity to cells. If exposure levels are high enough, death from suffocation may result. $\mathrm{NO}_{\mathrm{x}}$ plays a significant role in the formation of photochemical smog, which is an unsightly and unhealthy problem for many cities [3]. The semi-volatile and heavier HC components of diesel exhaust, which adsorb and condense onto the PM, are of great concern since these compounds have been shown to exhibit carcinogenic or mutagenic properties in biological testing at the cellular level [3]. PM found in the exhaust stream can be inhaled deeply into the lung, remaining due to impaction or sedimentation depending on particle size, and may cause severe respiratory problems. It is known, that older individuals suffering from chronic respiratory and cardiac diseases are at greatest risk and that fine $\mathrm{PM}(<2.5 \mu \mathrm{m}$ in diameter $)$ has a greater effect than do the larger size fractions. Of particular concern are the ultrafine particles $(<0.3 \mu \mathrm{m}$ in diameter $)$ that may not contribute to the mass concentration, but may pose the greatest health risk because of the higher number count. Much effort has been made to reduce the levels of hazardous emissions from on- highway vehicles, but until recently little attention has been paid to off-highway equipment. Significant reductions in particulate mass in dieselpowered engines have occurred in the past twenty years through intercooling, high boost 
pressures, centralized injector nozzle positioning, much higher injection pressures, lower combustion chamber swirl, and piston bowl refinement measures. However, it was determined in a study [4] that while overall particulate emissions have been reduced to only $10 \%$ of the prevalent levels of 15 to 20 years ago, the very fine nano-particle count was actually increased by these technologies at all load points, sometimes by as much as a factor of six. The focus is now shifting to reduce the emissions from these vehicles as Tier 1, 2, and 3 standards set by EPA, CARB, and several equipment manufacturers have been set to phase in through this decade. On a national scale, off-road engines are estimated to emit nearly $20 \%$ of all $\mathrm{NO}_{\mathrm{x}}$ and about half of all fine PM pollution from mobile sources. Current projections indicate that the $\mathrm{NO}_{\mathrm{x}}$ emissions from non-road engines will surpass those of on-road engines by the year 2005 [5].

Testing procedures and emissions inventories for off-highway equipment are also in the process of reevaluation. With the many different forms of off-highway equipment performing many different tasks it is clear that one test cannot give an accurate representation of the emissions being produced while engines are in operation. Many variables also affect the emissions rates such as percent loading, age of the engine, operator habits, location of operation, and fuel used. The current qualification standard is the ISO $8178 \mathrm{C} 1$ test consisting of eight steady state modes of operation. Most off road equipment is rarely operated at a steady state and in fact is quite transient in some cases. A considerable amount of diesel engine emissions research involving on-highway vehicles has been directed toward the development of standardized transient testing cycles that accurately represent real-world operating conditions for these vehicles. This cycle development process provides a performance benchmark to assist in developing 
standardized emissions regulations and an evolutionary approach to cleaner, more efficient engine designs. With increasing attention being focused on the reduction of emissions from off-road sources, the development of representative testing cycles for these vehicles is a high priority.

Previous research has used fuel rack position as a means of estimating engine torque to produce transient cycles for lab research. Some equipment however operates at full rack and powers hydraulic pumps that operate the vehicle. It is therefore not feasible to use this method on machines of this type. Engine dynamometer test bed or vehicle chassis dynamometer testing has traditionally been the method of choice for brakespecific exhaust emissions measurement. Engine dynamometer test beds require that the engine is removed from a vehicle and fitted with many components needed to make it operate, thus the method is expensive and time consuming, as well as inconvenient to the equipment owner. In placing an engine on a dynamometer test bed, care must be taken to create similar systems for air, fuel, electrical, and exhaust, as are seen by the engine invehicle. Chassis dynamometer testing is a simpler way of measuring the engine's operating characteristics in- vehicle, but it is also plagued with problems that make a search for a better method desirable. These problems include but are not limited to: an operator is required to perform specified tasks with the vehicle, thus making exact repeatability and set-point achievement accuracy improbable due to human error, an operator's characteristic tendencies will skew results, and, most existing chassis dynamometer setup's are incapable of handling the size and properly loading the operating systems of most off-highway equipment. An emissions measurement system that could be utilized on the vehicle as it operated in its normal environment would be a 
device that could prove paramount to understanding the in- use emissions of off-highway diesel-powered equipment. In the event that such a device would be considered for use in this arena, test protocols for on-board exhaust emissions measurements would need to be developed.

Two methods may be employed for the collection of in- use emissions data. Tedlar bags may be used to collect gaseous emissions over a test span, and then have their contents analyzed at a later time with laboratory analyzers. This method provides for integrated exhaust emissions data for the test cycle. This would be a cheap and simple method for the collection of in- use emissions data. It would have limitations in that the determination of the effects of transient events on the engine's emission rates would be impossible. Alternately, an on-board emissions measurement system that would continuously measure engine emissions in a fashion similar to the laboratory would provide real-time emissions data for the evaluation of transient effects on exhaust emission rates, and the data could be reduced for the formulation of integrated results for the test cycle. This method requires much more effort and is more expensive than using gas collection bags, but it also has the capability to accommodate instruments for the measurement of particulate matter on a realtime basis, which is becoming highly desirable.

Equipment exists that can be used to sample raw exhaust for emissions measurement while the engine operates in- vehicle as the machine performs normal duties. Parameters needed for the relation of raw exhaust emissions levels to mass emission rates can be easily measured. For instance, magnetic sensors placed near the flywheel, or tapping the alternator to monitor the frequency of the unregulated signal it 
produces can be used to determine engine speed, thermocouples can easily be placed to monitor intake and exhaust temperatures, and pressures can be determined with miniaturized pressure transducers such that intake and exhaust flow rates can be quantified.

Traditionally, emissions have been reported on a brake-specific basis, that is, on a work-output basis. While this format provides for a more direct emissions comparison for engines with different power output levels, it requires a very accurate determination of engine work. To do this with in-field data, a means of determining engine load as the machine operates is necessary. This is by far the most challenging aspect of producing meaningful emissions data from in-field testing. Devices that are placed in the driveline can be used for the measurement of torque; however, they are very expensive and difficult to use. Off-highway equipment presents more complication as the driveline is usually enclosed for protection and difficult to access, and some machines directly drive hydraulic pumps with no driveshaft at all. Also, equipment owners tend to be cautious about modification to the machine, and often refuse to allow for the use of such a device. If, instead of a brake-specific approach, a fuel-specific approach to reporting emissions were used, it would be far easier to report in-field emissions measurements in a manner that engines could be compared. Fuel use is directly related to power output. While the argument does exist that high fueling rates could provide misleading results by lowering the fuel specific emissions rates, the likelihood of intentional manufacturer tampering here is unlikely as fuel economy is important to equipment owners.

As the determination of engine load is a complicated task, indirect methods for inferring torque, such as the measurement of the engine-fueling rate, have been 
commonly used. On mechanically injected engines, the rack displacement in the injection pump has been measured with a linear position sensor in order to estimate engine fuel consumption for the calculation of load. Problems with this approach include measurement inaccuracies, difficulties with the instrumentation of the injection pump, and vibration-induced sensor malfunctions. Furthermore, installing the linear position sensor often requires the disassembly and modification of the injection pump, which is labor intensive and often not permitted by the owner of the test vehicle.

On modern engines with electronically controlled fuel injection pumps, an interface can be used to retrieve fueling rate data from the ECU (Engine Control Unit), which is calculated based upon fuel pressure and injector pulse-width. As a vehicle ages, component degradation and algorithm inaccuracies will provide small sources of error in this method. Electronic injection is a new technology that has only recently been implemented into off-highway equipment; therefore the use of this method would be limited to a small percentage of the vehicles that are currently in operation. However, as the current inventory of equipment is replaced by more modern electronically injected machinery, this could become the most desirable method for power prediction inferred from engine fueling rates.

During this study, another method was developed for the inference of engine torque. This method used raw exhaust $\mathrm{CO}_{2}$ concentrations and engine speed data to interpolate torque from a matrix of load vs. $\mathrm{CO}_{2}$ output developed when the engine was placed on a laboratory dynamometer. The engine was then operated according to these dynamometer set points while raw exhaust $\mathrm{CO}_{2}$ emissions were recorded using the same methodology that was used during in-field testing. The raw $\mathrm{CO}_{2}$ trace recorded from the 
engine operating according to the dynamometer test cycle was compared to the $\mathrm{CO}_{2}$ trace recorded during in-field testing. The dynamometer set points were then optimized as necessary until convergence criteria were achieved. The excavator testing was performed using this method. A portable on-board emissions measurement and engine speed logging system were utilized to collect $\mathrm{CO}_{2}$ and engine speed data during normal vehicle operating conditions. For the track-type tractor testing, the engine load factor was recorded from the ECU during in- field operation.

\subsection{Previous Off-road Emissions Testing}

This section reviews exhaust emissions testing that has been performed on offhighway engines. There has been some testing performed on off-highway engines, especially in the laboratory, but in-use testing while the engine is in the vehicle has been limited by the equipment available to perform this type of testing.

\subsubsection{Northeast States for Coordinated Air Use Management - 1997}

A study was performed by The Northeast States for Coordinated Air Use Management (NESCAUM) to determine how exhaust aftertreatment devices affected emission levels [6]. Four devices were tested on five vehicles: oxidation catalysts, fuel borne catalysts, and active as well as passive particulate filters.

Test cycles were derived from in-field data that was collected while the machines were operating. The parameter measured was exhaust gas temperature, and the exhaust temperatures were monitored during laboratory tests to maintain adherence to the in-field test cycles. The sample was diluted using a mini-dilution tunnel, and integrated bag samples and gravimetric PM data were collected. During the testing raw exhaust constituent concentrations were continuously monitored with a compact multigas 
analyzer, but the researchers concluded that response times made all measurements except $\mathrm{CO}_{2}$ unreliable. The $\mathrm{CO}_{2}$ data was used to determine vehicle fuel consumption during the test procedure. This project illustrated one attempt to derive representative testing cycles for off-road vehicles, and exhibited that methods were available to correlate the laboratory test cycle with an in-field operation cycle.

\subsubsection{United States Coast Guard - 1997}

For research purposes related to the 1990 Clean Air Act for non-highway mobile source air pollution, the United States Coast Guard developed a system to measure the exhaust emissions from three 82-ft. U.S. Coast Guard Cutters (powered by Caterpillar D3412 engines of 750-800hp ratings)[7,8]. This system used an Enerac 2000E emissions measurement system to measure nitric oxide $(\mathrm{NO})$, nitrogen dioxide $\left(\mathrm{NO}_{2}\right)$, carbon monoxide $(\mathrm{CO})$, sulfur dioxide $\left(\mathrm{SO}_{2}\right)$, oxygen $\left(\mathrm{O}_{2}\right)$, and hydrocarbon $(\mathrm{HC})$ levels in the raw exhaust stream. $\mathrm{CO}_{2}$ concentrations were inferred from the other gaseous component levels. Intake air flow rates were monitored digitally with the Electronic Flo whood manufactured by Shortridge Instruments, and fuel consumption was measured with Hedland in-line flow meters. Engine torque was measured with driveshaft-mounted strain gauges that broadcast strain quantity through radio frequency. While this system successfully measured exhaust emissions and proved the ability to measure torque infield with strain gauges, it was rather complex and cumbersome to use.

Test procedures were derived from the ISO 8178. A number of variables were investigated to determine their effects on exhaust emissions, these included water depth, effect of towing another boat, water current, sea state, and wind direction. Emissions rates were determined quantitatively as a function of power and fuel consumption, but it 
was ultimately concluded that propeller shaft speed was the most significant factor related to exhaust emissions levels.

\subsubsection{VERT Study - 1998}

A study was conducted to evaluate the effects of exhaust aftertreatment devices on emissions levels at European tunnel construction sites [4]. Ventilation at these sites is often poor, and workers can be exposed to high levels of air pollutants from construction equipment. It is therefore paramount to develop methods of reducing harmful pollutants to improve air quality for worker safety. The study investigated thirty-two particulate traps of various types from different manufacturers. The study focused on PM emissions, but $\mathrm{CO}, \mathrm{CO}_{2}$, and $\mathrm{HC}$ levels were also monitored.

The Switzerland VRV 59A smoke opacity test for free acceleration and a full-load exhaust blackening test were used to estimate PM emission levels. For the smoke opacity test, the engine was operated at steady load conditions and a sharp transient speed change was administered. The change in opacity of the engine exhaust was used to identify the amount of diesel soot being emitted. Although the test results for vehicles outfitted with particulate traps were near the lower limits detectable by the opacity meters, the results could be used to indicate trap failure during testing. The blackening measurements at full load were taken on construction vehicles equipped with torque converters, which allowed two to three minutes in the stalled condition such that sufficient time existed for an exhaust opacity test. Gaseous emissions were monitored only during steady-state loading conditions with computer-controlled instruments operating on the principles of electrochemical reaction and IR absorption (NDIR). 


\subsubsection{West Virginia University - 1999}

West Virginia University in cooperation with the WV Diesel Commission tested four engines commonly used in underground mining equipment to evaluate the performance of existing exhaust aftertreatment devices for emissions control [9]. The engines tested were a MWM D-916-6, a Lister Petter LPU-2, an Isuzu C240, and a Caterpillar 3306. All engines were tested in laboratory on a dynamometer test bed according to the ISO 8178 8-Mode test. The study also investigated other methods for emissions control such as low sulfur fuels, reducing engine fueling rate, and different combinations of catalysts and PM traps to reduce overall emissions. In the end the study concluded that small reductions in fuel sulfur produce significant reductions in PM emissions and that the use of catalysts for the reduction of exhaust emissions is risky as it can produce high levels of nitrogen dioxide, sulfates, and aerosols of sulfuric acid, which are highly toxic.

\subsubsection{West Virginia University-2001}

WVU was contracted by CARB to provide emissions data for off-highway diesel powered equipment that represented actual in-use emissions such that CARB could update emissions inventories relative to the contributions of the se engines to air pollution [2]. The vehicles were selected to represent major off-highway mobile source contributors in California and were classed by engine power rating. Both pre- and post1996 vehicles were selected to evaluate the adherence to the Tier 1 emissions standards implemented in 1996. Techniques were developed to use raw exhaust $\mathrm{CO}_{2}$ concentrations and coinciding engine speed data to infer engine torque such that in- use emissions could be estimated. 
A John Deere 444 end loader with a 6059 D engine and an Elgin Pelican streetsweeper with a John Deere 4039T engine were tested in-field. Raw $\mathrm{CO}_{2}$ and engine speed data were recorded during the tests. The engines were removed from the vehicles and tested in laboratory. Transient test cycles were developed from the in-field data and iterated until laboratory speed and $\mathrm{CO}_{2}$ traces satisfactorily matched the field data. The engines were also operated on the ISO $8178 \mathrm{C}$ 8-Mode test. Brake-specific emissions results from the weighted 8 -Mode data were $100-500 \%$ higher in value than the results of transient tests. The brake-specific $\mathrm{CO}_{2}$ emissions among transient cycle iterations differed by no more than $1 \%$, and when the cycle developed for the loader was exercised on the streetsweeper engine, brake-specific $\mathrm{CO}_{2}$ emissions were $10 \%$ higher than the results of the cycle developed for the streetsweeper. This showed that cycle nature has the greatest effect on brake-specific emissions results

Methods were examined to correlate 8-Mode data and transient test results by adjusting the 8-Mode weighting factors to give more weight to modes that represented torque and speed levels at which the engine operated more often. In doing this, the amount of difference was greatly reduced.

\subsection{Previous On-board Emissions Testing Devices}

A number of emissions measurement systems have been developed for in-field data acquisition. The ultimate goal of such devices is to provide laboratory grade emissions data while the engine operates in-field such that a better understanding is gained of the pollution caused by mobile sources. For cycle development work, a system is needed that can be entirely contained on the vehicle being tested, thus these devices 
must be compact in nature. This section describes a number of systems previously used for on-board exhaust emissions measurements.

\subsubsection{Caterpillar - 1982}

Caterpillar developed and used a portable bag collection system to collect gaseous emissions such that in-use $\mathrm{NO}_{\mathrm{x}}$ emissions from diesel engines could be quantified. This testing was done as part of the Point-of-Use Control program that required verification of in-field compliance to emissions regulations [10]. The measurement systemconsisted of an exhaust probe, a prefilter, a sample line, a pump, an air-cooled condensing coil (for sample humidity control), and two gas collection bags. This system was operated remotely by the driver and used its own on-board power supply. The study concluded that valid data could only be obtained during fully loaded operation, as this was where $\mathrm{NO}_{\mathrm{x}}$ concentrations from the on-board system were within $10 \%$ of laboratory analyzers.

\subsubsection{Southwest Research Institute - 1992}

Southwest Research Institute developed a mobile system to measure gaseous diesel exhaust emissions and PM as part of a study initiated to develop methods for exhaust emissions testing that did not require the use of a dynamometer [11]. Raw gaseous measurements of $\mathrm{CO}, \mathrm{CO}_{2}, \mathrm{NO}_{\mathrm{x}}$, and $\mathrm{O}_{2}$ were made using an Energy Efficiency Systems, Inc. Enerac 2000E from integrated bag samples collected during engine operation. A mini-dilution tunnel was employed for the collection of PM. The system was used for inspection and maintenance of buses, and the data was compared with transient cycle emissions data taken by the EPA while the buses operated on a chassis dynamometer. The tests were limited to being performed on vehicles equipped with 
automatic transmissions, as the test sequence required 30 -second load operations on the vehicle at various throttle positions while the vehicle was held stationary through locked brakes. The testing results showed that measurement of $\mathrm{CO}, \mathrm{O}_{2}$, and $\mathrm{NO}_{\mathrm{x}}$ were within $5 \%$ of measurements made by laboratory grade analyzers

\subsubsection{General Motors - 1993}

General Motors Corporation outfitted a Pontiac Bonneville SSE passenger car with a gasoline-fueled 3.8-liter engine with emissions instrumentation and tested it over numerous driving routes to obtain representative in- use emissions data [12]. The system was capable of measuring $\mathrm{HC}, \mathrm{CO}_{2}, \mathrm{CO}$, and $\mathrm{NO}$ using a variety of NDIR analyzers. A Horiba MEXA-311GE analyzer was used to measure concentrations of $\mathrm{CO}_{2}$ and $\mathrm{CO}$, while measurements of $\mathrm{HC}$ and $\mathrm{CO}$ were performed with a MEXA-324GE. A Siemens Ultramat-22P analyzer was also used to make $\mathrm{HC}$ and $\mathrm{CO}$ measurements, and a Siemens NO analyzer was also used. A Draeger electrochemical gas sensor (EGS) cell was used to also measure $\mathrm{CO}$ buildup levels within the vehicle's driver compartment. An icecooled water trap was used to condition sample humidity to acceptable levels. A Kurz flow meter was used for exhaust gas flow rate measurements, while the intake air flow rates were monitored using the stock air meter. A relationship between intake and exhaust flows was derived to illustrate the effects of intake flow on exhaust flow. The tests consisted of driving routes during high-traffic rush-hour conditions as well as during lighter traffic conditions to study different operating conditions. For comparative purposes, emissions rates of $\mathrm{HC}$ and $\mathrm{CO}$ were recorded while the vehicle was tested using the Urban Dynamometer Driving Schedule (UDDS) on a chassis dynamometer. 
Due to slow analyzer response times, the system was unable to record transient events, and only one vehicle was tested. However, the research did demonstrate that useful on-board emissions data could be collected from a spark-ignited gasoline-fueled vehicle during normal operation.

\subsubsection{Ford Motor Company - 1994}

Ford Motor Company developed an emissions sampling system that was tested on three spark-ignited vehicles $[\mathbf{1 3}, \mathbf{1 4}, \mathbf{1 5}, \mathbf{1 6}]$, a 1992 Aerostar van, a 1991 Taurus station wagon, and a 1991 flex-fueled Taurus sedan. The objective of the study was to compare real-time emissions measurements made with the on-board Ford system with those obtained with remote equipment. Each vehicle's system was capable of monitoring and controlling various engine parameters, but only the van and the wagon were equipped with the ability to monitor real-time emissions.

The Aerostar van was equipped with an On-Board Emissions (OBE) system comprised of a dilution tunnel and a Fourier Transform Infrared (FTIR) analyzer. $\mathrm{CO}_{2}$, $\mathrm{NO}_{\mathrm{x}}, \mathrm{CO}$, and $\mathrm{HC}$ emissions measurements were recorded, and the data collected using the OBE system were compared with those obtained from tests performed at a chassis dynamometer laboratory. The results reported showed differences of $2 \%$ for $\mathrm{CO}_{2}, 10 \%$ for $\mathrm{NO}_{\mathrm{x}}, 3 \%$ for $\mathrm{CO}$, and $7 \%$ for $\mathrm{HC}$, and it was also determined that the FTIR analyzer's had inadequate response time for transient emissions testing.

The Taurus wagon was equipped with an infrared analysis system capable of measuring $\mathrm{CO}_{2}, \mathrm{NO}_{\mathrm{x}}, \mathrm{CO}$, and $\mathrm{O}_{2}$ emissions. A non-dispersive ultraviolet (NDUV) analyzer was used for NO measurement. The results from the NDUV analyzer and a 
laboratory grade chemiluminescent analyzer were correlated and showed favorable results (slope of 0.8 and an $R^{2}$ value of 0.97 ).

\subsubsection{University of Pittsburgh - 1997}

The University of Pittsburgh developed a system to measure emissions from 20 natural gas powered passenger vans using an RG240 multigas analyzer produced by OTC SPX for the detection of $\mathrm{CO}, \mathrm{NO}_{\mathrm{x}}, \mathrm{CO}_{2}, \mathrm{HC}$, and $\mathrm{O}_{2}$ [17]. The system used $12 \mathrm{v} \mathrm{DC}$ vehicle power and also employed stand-alone engine diagnostic equipment to monitor engine parameters. The exhaust sample was collected using a 12 in. probe in the exhaust stream, and it was conditioned with coalescing filters. Total exhaust flow rate was inferred from intake and fuel mass flow data collected by the engine diagnostic equipment. Data collection was performed with a laptop computer using software developed by the University of Pittsburgh.

Problems were reported with data time alignment, slow analyzer response times, mass emission rates measurement, and random analyzer auto zeroing. Also, since the analyzer unit was originally developed for testing gasoline-fueled vehicles and not natural gas powered vehicles, $\mathrm{HC}$ measurement bias was encountered. However, the system did successfully provide on-board emissions data from naturat gas fueled vehicles operating in reat world applications.

\subsubsection{Flemish Institute for Technological Research - 1997}

The Flemish Institute for Technological Research (VITO) developed an on-board emissions measurement system and tested gasoline-fueled passenger cars and dieselfueled buses. The VITO On-the Road Emission and Energy Measurement (VEOM) 
utilized NDIR technology for $\mathrm{CO}$ and $\mathrm{CO}_{2}$ measurement, an HFID for $\mathrm{HC}$ measurement, and a chemiluminescent analyzer for the detection of $\mathrm{NO}_{\mathrm{x}}$. The exhaust sample was diluted by means of a nitrogen-driven ejector located in the vehicle tailpipe, and heated sample lines were implemented to prevent the loss of heavy hydrocarbons from the sample stream. Emissions were reported in either $\mathrm{g} / \mathrm{s}$ or $\mathrm{g} / \mathrm{km}$ format by combining dilute sample amounts collected with data on fuel consumption, lambda values, and engine speed. Results showed that the VEOM data differed from chassis laboratory data by $25 \%$ for $\mathrm{HC}, 20 \%$ for $\mathrm{CO}$, and less than $10 \%$ for $\mathrm{CO}_{2}$ and $\mathrm{NO}_{\mathrm{x}}$. The VEOM system weighed approximately $500 \mathrm{lbs}$, making it difficult to set up on any given vehicle, and thus impractical for acquiring in- use data.

\subsubsection{United States Environmental Protection Agency - 1999}

The Office of Mobile Sources of the United States Environmental Protection Agency (US EPA) developed a mobile emissions testing system to measure emissions from gasoline vehicles. The system was named the Real time On-road Vehicle Emissions Recorder (ROVER), and was later modified to extend its capabilities to the emissions analysis of diesel fueled vehicles. A differential pressure device was used to determine exhaust flow rate, while a Snap-On Model MT3505 emissions analyzer was used for the determination of $\mathrm{CO}, \mathrm{CO}_{2}, \mathrm{HC}$, and $\mathrm{NO}$ (there was no converter for $\mathrm{NO}_{\mathrm{x}}$ determination). Vehicle speed was determined with a global positioning system (GPS) and an interface with the vehicle's ECU. Results were reported on a distance-specific basis; grams of pollutant emitted per mile the test vehicle traveled (g/mile). 


\subsubsection{Ford Motor Company / WPI Microprocessor Systems, Inc. - 1999}

Ford Motor Company and WPI-Microprocessor Systems, Inc. had developed a system known as the Portable Real-Time Emission Vehicular Integrated Engineering Workstation (PREVIEW) [18]. PREVIEW was capable of measuring wet exhaust and compact enough to fit into the passenger compartment of a sport-utility vehicle.

PREVIEW used NDIR technology to measure $\mathrm{CO}_{2}, \mathrm{CO}$, and $\mathrm{HC}$, while $\mathrm{NO}_{\mathrm{x}}$ was detected with ultra-violet sensors. A number of sensors could be used by the system for recording of up to forty additional engine parameters, such as various engine temperatures or air/fuel ratio sensing devices. Control of the PREVIEW system was accomplished with a laptop computer and software that recorded and displayed data simultaneously at a $1 \mathrm{~Hz}$ frequency.

Testing performed with the system included transient FTP cycle tests as well as Highway Fuel Economy tests in a laboratory setting. Comparative results with a chassis dynamometer laboratory showed that the PREVIEW system obtained results within $1.5 \%$ for $\mathrm{CO}_{2}, 12.3 \%$ for $\mathrm{HC}, 0.4 \%$ for $\mathrm{NO}_{\mathrm{x}}$, and $3.4 \%$ for $\mathrm{CO}$, of the laboratory-grade analyzers. Also of interest was that the instantaneous mass measurements for $\mathrm{NO}_{\mathrm{x}}$ with the PREVIEW system actually exhibited faster response times than the laboratory analyzer. No further information on this system could be found in published literature.

\subsubsection{West Virginia University - 2000}

West Virginia University developed a system for the on-board measurement of inuse emissions from heavy-duty on-road vehicles [19]. The Mobile Emissions Measurement System (MEMS) provided realtime, on-board brake-specific measurement of $\mathrm{NO}_{\mathrm{x}}$ and $\mathrm{CO}_{2}$, and was comprised of the three primary components: an exhaust flow 
measurement apparatus, emissions measurement equipment, and a data acquisition device.

The MEMS was extensively tested and reviewed by the US EPA. EPA approved the use of MEMS for in-use emissions testing of heavy duty trucks during Phase III of the Consent Decrees work, which is being conducted by West Virginia University.

Engine exhaust flow was measured with an Annubar ${ }^{\mathrm{TM}}$, multi-port Pitot-tube averaging differential pressure device. This device provided a low-restriction of the exhaust and proved to be very robust. The emissions sampling component consisted of a heated, filtered, and humidity-controlled sample conditioning system, a Horiba COM-11 $\mathrm{NO}_{2}$ converter, Horiba BE-140 NDIR analyzer, a Horiba MEXA-120 NO electrochemical NO cell. The data acquisition components of the MEMS were comprised of a National Instruments PXI-1025 computer, signal conditioning hardware, data acquisition, ECU-interface, and control software. The system provided records of a variety of signals from thermocouples, pressure transducers, emissions analyzers, and numerous ECU outputs. Engine torque output and speed was recorded with the aid of manufacturer-supplied ECU interfaces, and vehicle speed was measured with a Global Positioning System (GPS).

When compared to laboratory-grade analyzers during chassis-dynamometer testing, the MEMS was reported to be capable of providing brake-specific $\mathrm{CO}_{2}$ data which differed from the laboratory data by $2.54 \%$, and brake-specific $\mathrm{NO}_{\mathrm{x}}$ data that differed by $11.54 \%$ (MEXA-120) and 5.68\% (electrochemical cell). This system was by far one of the most usable devices available for the determination of laboratory grade emissions data during in-field vehicle operation. 


\subsection{Mobile Source Technical Review Subcommittee Meeting - 2002}

A meeting was held on February 13, 2002, between representatives of EPA, $\mathrm{CARB}$, and various research institutions and portable emissions measurement device manufacturers. The nature of this meeting was to discuss the directions and strategies that need to be implemented for future in- use exhaust emissions measurement and the possibility of using in- use testing for certification of engine compliance to emissions standards. The EPA was particularly concerned with monitoring engines in-use to ensure that adherence to standards is met, finding defeat devices used to get an engine through a certification test such that the devices can be identified and eliminated, and further using the information to aid in future rulemaking. The information presented herein was gathered through personal correspondence with Dr. Mridul Gautam, an attendee of said meeting.

Representatives from CARB reported that diesel PM made up nearly $70 \%$ of the entire toxins in the air. The current regulations show DPM emissions of 30,000 tons per year. The standards set to take effect in the future reduce this to slightly less than 20,000 tons per year. Off-road mobile sources are the largest contributor to these figures, accounting for more than on-road mobile sources and stationary sources put together. In September 2000, CARB adopted a Diesel Risk Reduction Plan with the goal of reducing risk of DPM exposure to near zero, applying PM controls to all diesel engines, and integrating these systems with $\mathrm{NO}_{\mathrm{x}}$ reduction efforts. Using this plan, CARB hopes to reduce DPM emissions and exposure risk by nearly $75 \%$ by the year 2020 as compared to the allowances of the current standards. The elements of the plan include reducing 
emissions from new engines, using ultra- low sulfur ( $<15 \mathrm{ppm})$ fuel, in-use emissions testing to ensure compliance, and retrofitting existing engines with PM filters.

Reports on some of the research done with the ROVER system showed the evolution of the system from the early designs to the current capabilities of the system and the wide variety of vehicles and engines tested. Also, the MEMS system was discussed, highlighting the versatility and high quality data recording capabilities of the system. Discussion of these systems also focused on the challenges surrounding in- use emissions measurement, such as determination of engine torque for a brake-specific emissions reporting approach, the different emissions that occur due to different test cycles, and the amount of time and effort spent to instrument a test vehicle. A portable real-time PM monitor was also discussed as an option to in- use PM determination. More discussion on this system follows in Chapter 3.

Sensors, Inc. and Horiba, two manufacturers of emissions measurement equipment, presented information on new portable systems that are more versatile and user friendly than past systems. These systems were reported to be capable of providing full emissions data that are very close to the results obtained with a CVS system. It was not clear how the systems performed during a full transient test, and no information was available on the accuracy and preciseness of continuous (second-by-second) data over short time windows (say, 30 seconds long).

This meeting served as evidence that the technology exists to start making in- use emissions measurement a tool that can be used to reduce vehicle emissions and thus improve air quality everywhere. 


\section{CHAPTER 3 - EXPERIMENTAL EQUIPMENT AND PROCEDURES}

\subsection{Introduction}

This chapter discusses the test vehicles and experimental equipment used during this investigation. Attention is also given to the manner in which tests were conducted. All laboratory testing was performed at the West Virginia University Engines and Emissions Research Laboratory (WVU EERL). Field testing was performed at various construction sites in West Virginia.

\subsection{Test Vehicles}

The vehicles tested under this study were selected to represent the major offhighway diesel emissions contributors in California. For the study, engines were classed by power rating. The two vehicles presented herein were used to satisfy testing requirements for a 250-500 hp class engine and a >500 hp class engine.

\subsubsection{Komatsu PC-400 LC3 Excavator}

A 1987 Komatsu PC400 LC3 Excavator with a turbo-charged in-line six-cylinder model S6D125-1 engine was selected for the 250-500 hp class engine testing requirement. Richard Construction, Incorporated (RCI), leased the vehicle to WVU for the duration of field and laboratory testing. RCI also provided operators for the field portion of testing. The lease commenced on the seventh day of May 2001. Figure 1 shows the excavator while Figure 2 illustrates the engine as configured on the machine. Detailed specifications for the S6D125-1 engine are listed in Table 2. 


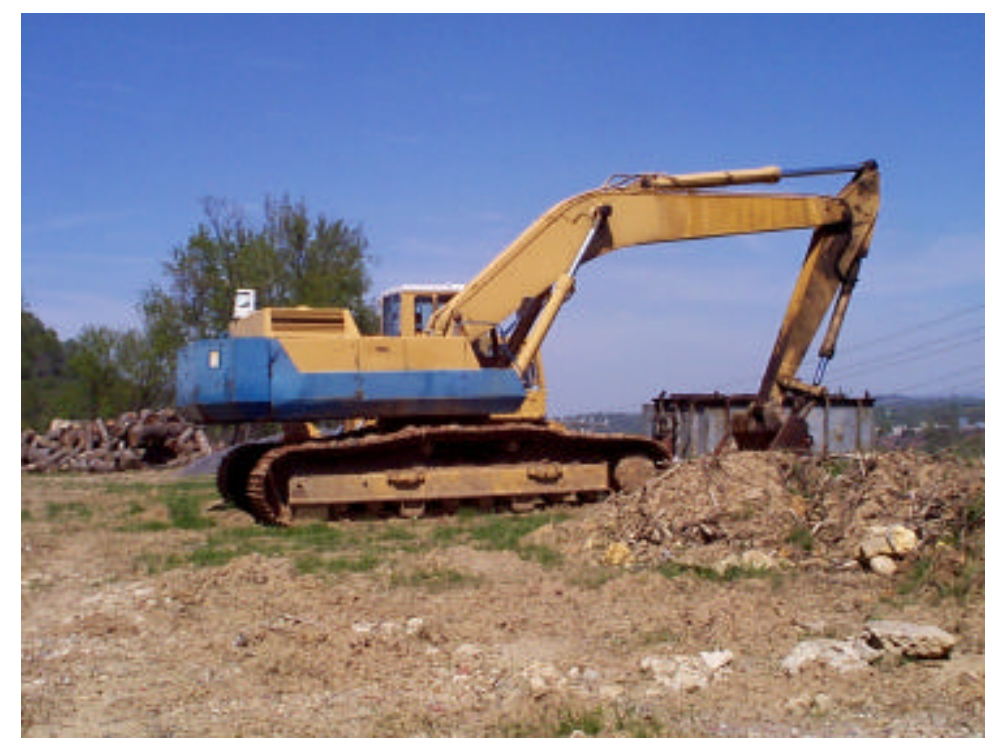

Figure 1 Komatsu PC400LC3 Excavator

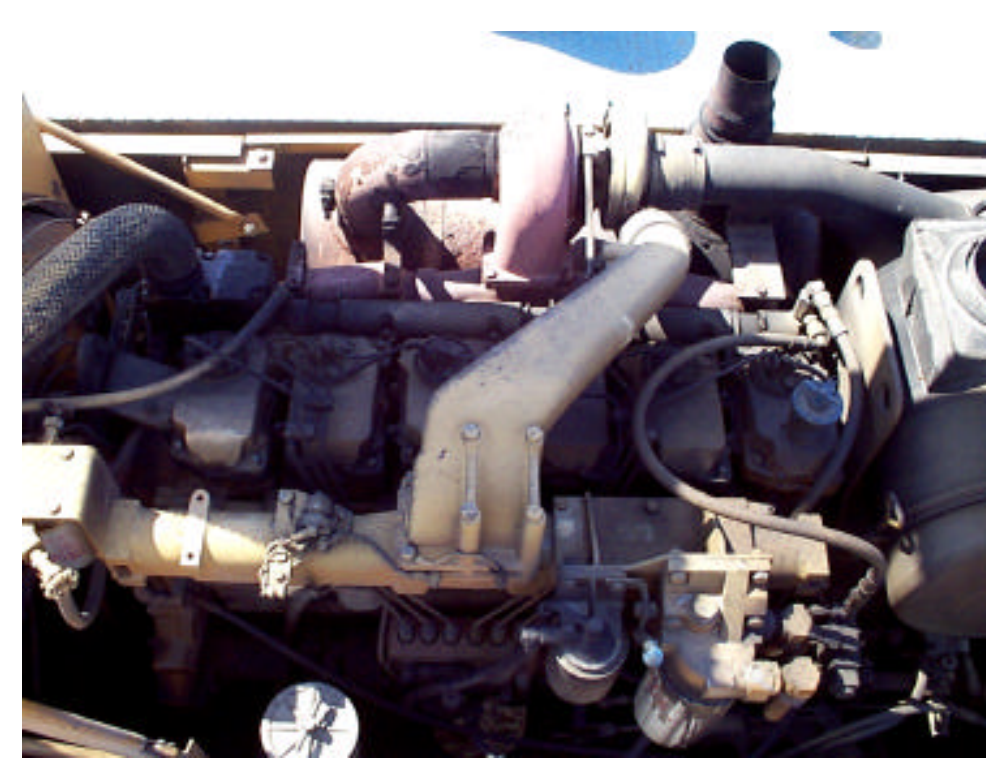

Figure 2 KomatsuS6D125-1 Engine in Excavator

The S6D125-1 engine is rated at $266 \mathrm{hp}$ at $2000 \mathrm{rpm}$. Each cylinder is $4.92 \mathrm{in}$.

bore $x 5.91$ in. stroke giving a total engine displacement of $674 \mathrm{in}^{3}(11.05 \mathrm{~L})$. Laboratory testing produced the following engine map (see Figure 3) showing the peak power to be $250 \mathrm{hp}$ at $1800 \mathrm{rpm}$ and the peak torque to be $745 \mathrm{ft}-\mathrm{lb}$ at $1350 \mathrm{rpm}$. 


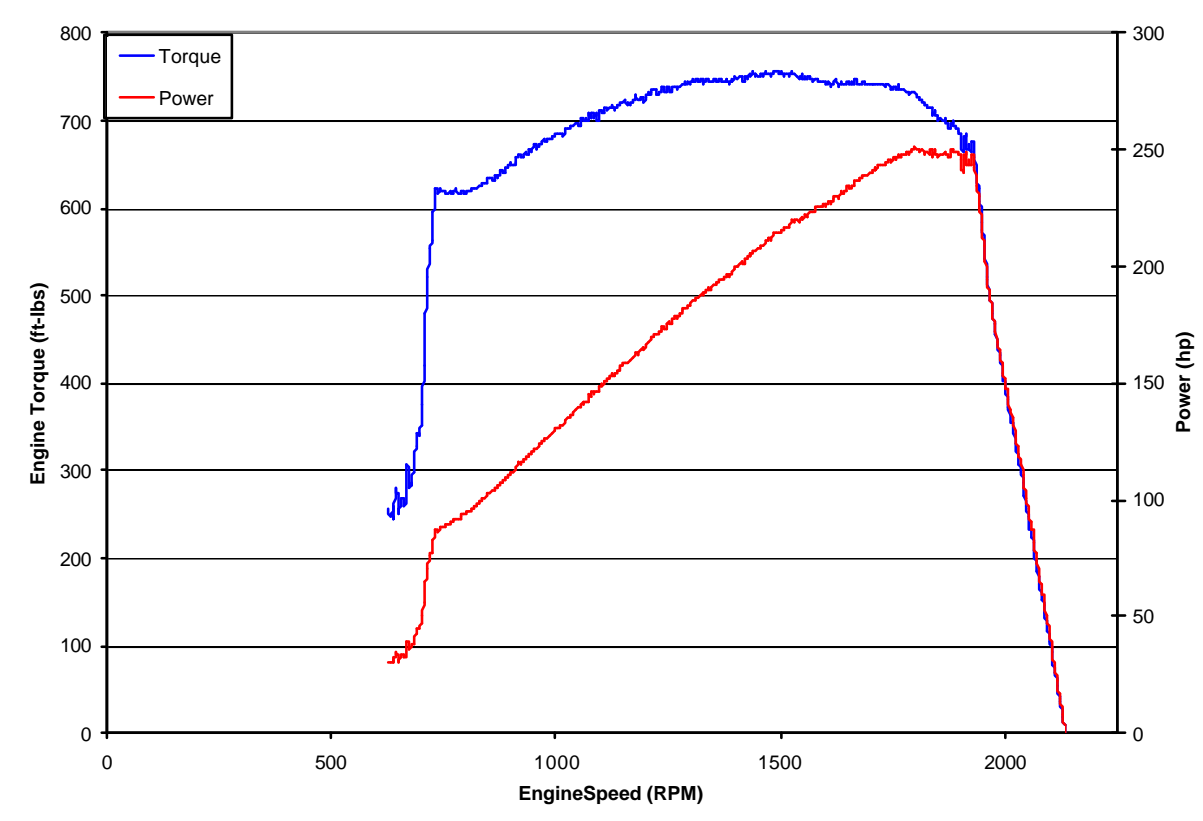

Figure 3 Engine Map for Komatsu Excavator

\subsubsection{Caterpillar D-11R CD Track-type Tractor}

WVU procured the use of a 2001 Caterpillar model D-11R CD track-type tractor outfitted with a 3508B TA, Vee-8, four-stroke diesel, electronically controlled direct unit injection engine for the $>500$ horsepower engine class testing. The tractor is the property of Buffalo Coal Corp., and testing was performed on the company's A34 strip mine site near Mt. Storm, WV. The operator was an employee of Buffalo Coal.

The model 3508 engine was rated for $950 \mathrm{bhp}$ at $1800 \mathrm{rpm}$. The bore and stroke of the each cylinder was $6.7 \mathrm{in}$. $7.5 \mathrm{in}$. giving a total displacement of $2105 \mathrm{in}^{3}$ (35L). 


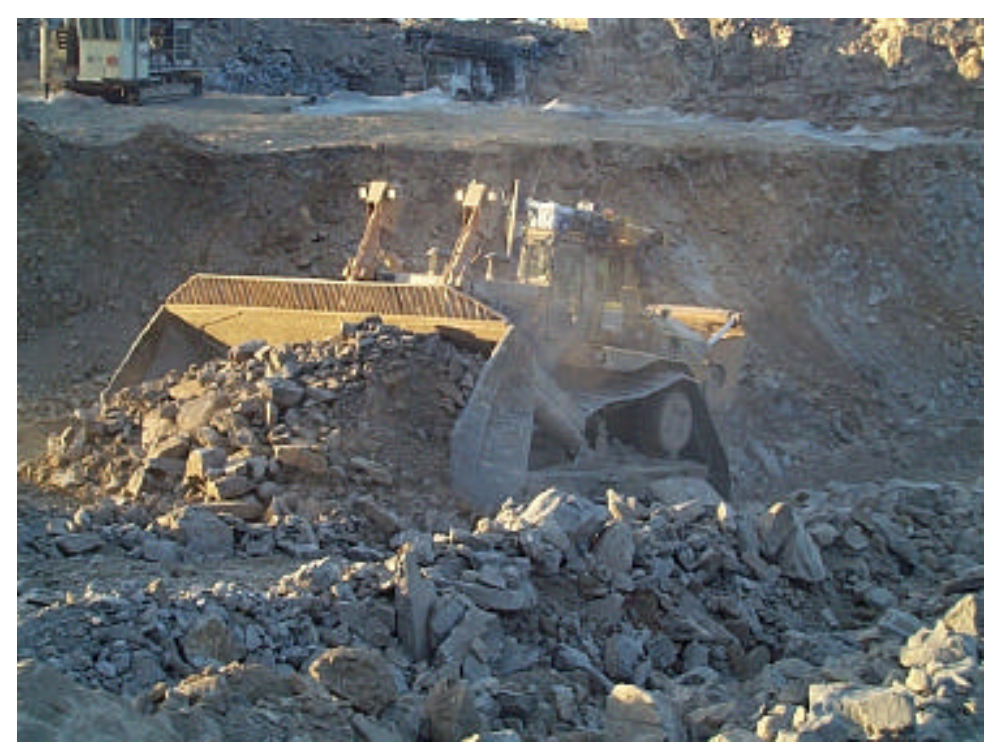

Figure 4 Caterpillar D-11R CD Track-Type Tractor Ope rating at Buffalo Coal Test Site

WVU was unable to remove the engine from the dozer in order to perform emissions tests in the dynamometer laboratory. Not only did the engine output power exceed the dynamometer's load capabilities, but Buffalo Coal would not permit the extended downtime or potential damage that could have been caused by engine removal and dynamometer testing. As a result, WVU proposed to CARB, and received approval that emissions and vehicle activity data collected in the field would be sufficient to satisfy this part of the project. To do so, WVU's Mobile Emissions Measurement System (MEMS) was employed to record mass emissions rates of $\mathrm{CO}_{2}$ and $\mathrm{NO}_{\mathrm{x}}$, while the MidAtlantic Research Institute's RPM-100 was used to provide real-time, on-board, gravimetric particulate mass emissions measurements.

The MEMS system is capable of logging engine control unit data streams for the inference of engine torque, but the Caterpillar D-11R CD engine control unit did not publicly broadcast the necessary engine load data stream. Therefore, a representative 
from Caterpillar logged engine speed and estimated load, using a proprietary Caterpillar ECU-interface. The correlation of the MEMS with a full-flow CFV-CVS system operating according to CFR 40, Part 86, Subpart N [20] was established before the unit was installed on the Caterpillar D-11R CD dozer for in-field testing. Further details regarding the design, use, and correlation with a full-flow laboratory of the MEMS will be discussed in Section 3.6.3.1.

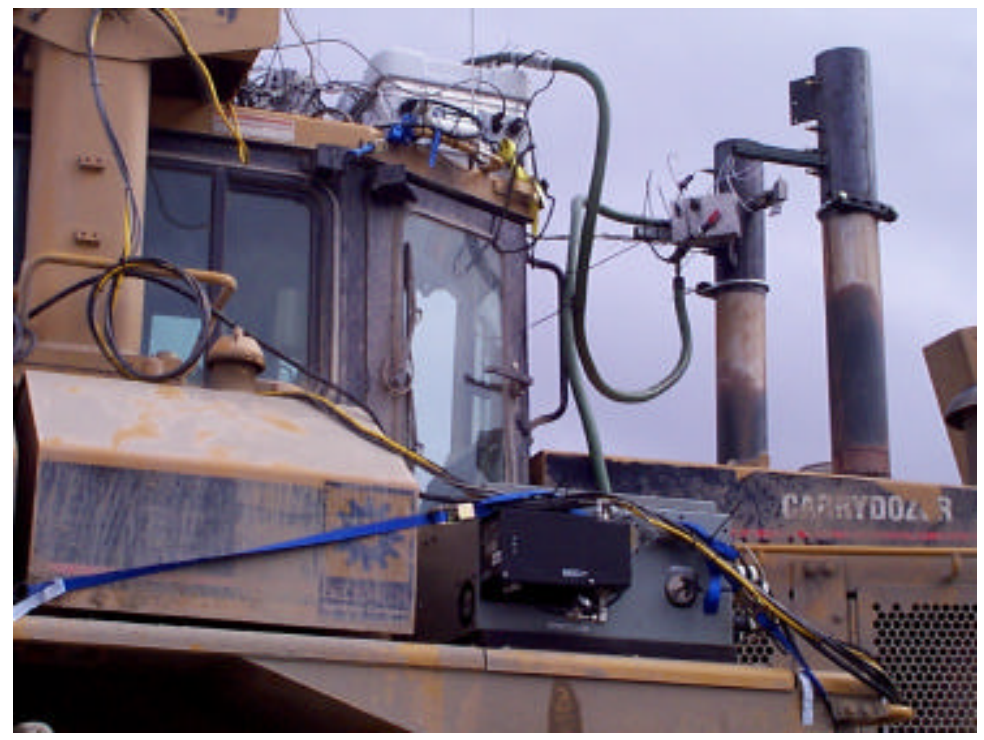

Figure 5 Caterpillar D-11R CD Track-Type Tractor Outfitted with WVU's Mobile Emissions Measurement System

Although laboratory testing was not performed on this engine, Caterpillar provided a lug-curve (see Figure 6), showing the power production of this engine. 


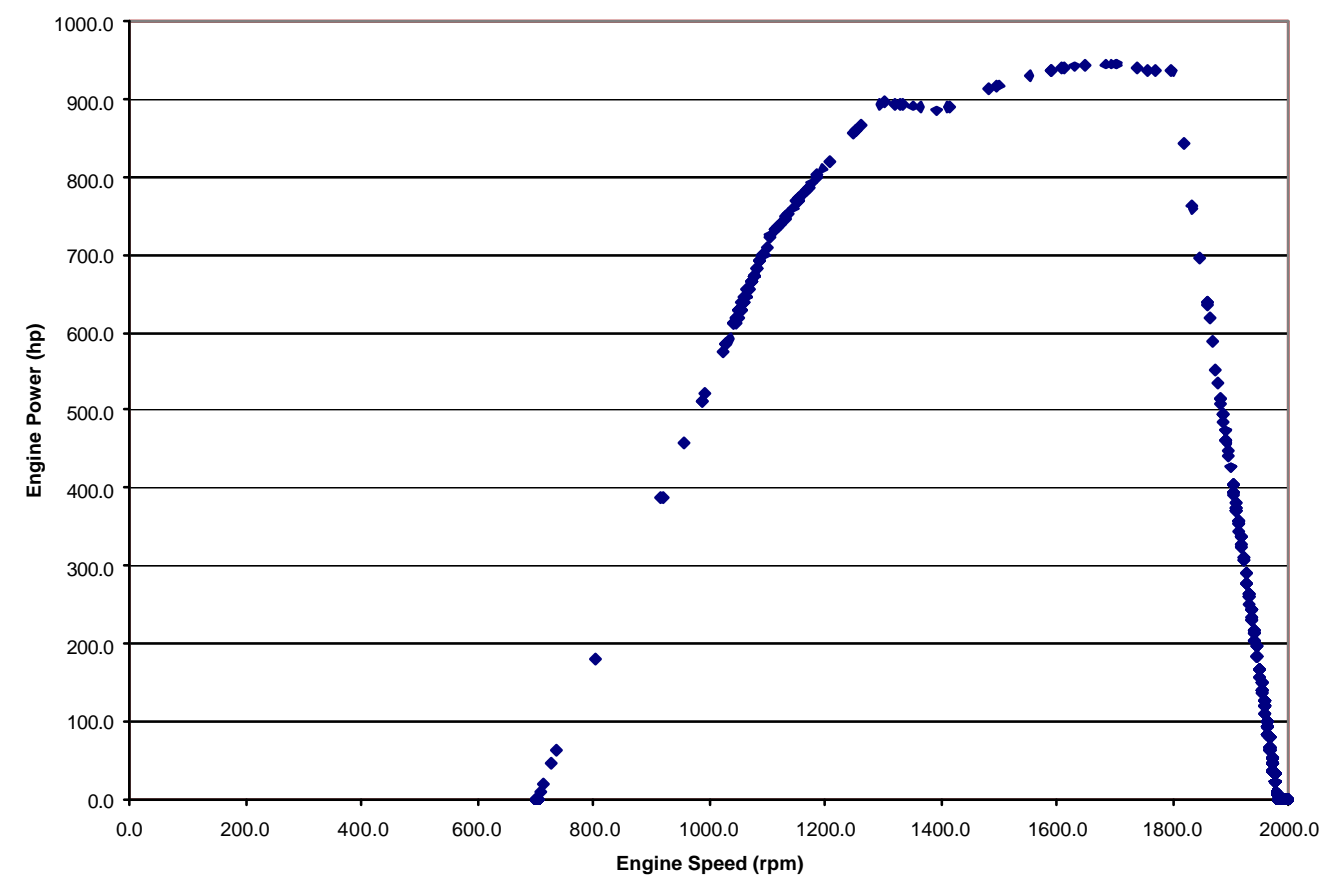

Figure 6 Caterpillar 3508 Engine Lug Curve (As Reported by Caterpillar)

Table 2 Test Engine Specifications

\begin{tabular}{|c|c|c|}
\hline Vehicle & $\begin{array}{c}\text { Komatsu PC400LC3 } \\
\text { Excavator }\end{array}$ & $\begin{array}{c}\text { Caterpillar D11R CD } \\
\text { Track-Type Tractor }\end{array}$ \\
\hline Engine Manufacturer & Komatsu & Caterpillar \\
\hline Engine Model & S6D125-1 & $3508 \mathrm{~B}$ TA \\
\hline Displacement & $674 \mathrm{in}^{3}(11.05 \mathrm{~L})$ & $2105 \mathrm{in}^{3}$ (35 L) \\
\hline Power Rating & $250 \mathrm{hp} @ 1800 \mathrm{rpm}$ & $950 \mathrm{hp} \mathrm{@} \mathrm{1800} \mathrm{rpm}$ \\
\hline Torque Rating & $745 \mathrm{ft}-1 \mathrm{lbs} @ 1350 \mathrm{rpm}$ & $3600 \mathrm{ft}-\mathrm{lbs} @ 1300 \mathrm{rpm}$ \\
\hline Configuration & In- line 6 cylinder, 4-stroke & Vee-8 cylinder, 4-stroke \\
\hline Bore x Stroke & 4.92 in. $x$ 5.91 in. & 6.7 in. $x$ in. \\
\hline Induction & Turbocharged & Turbocharged \\
\hline Injection & Direct-Mechanical Control & Direct- Electronic Control \\
\hline
\end{tabular}




\subsection{Test Fuels}

The test fuel used for the engine emissions tests performed in the laboratory was a market blend of three commercially available diesel fuels in California. The fuel analysis results for this blend are included in

Figure 7 and Figure 8. The pump diesel fuel that the vehicles normally operate with was used for the in-field, on-board emissions tests, which was Federal Diesel no. 2. 
LABORATORY ANALYSIS REPORT

FUEL ANALYSIS AND METHODS EVALUATION SECTION

CALIFORNIA AIR RESOURCES BOARD

Project ID: WVU/CARB 98-317

Submitted by: Haviside Heastings Inc.

\begin{tabular}{|c|c|c|c|c|c|c|c|c|c|}
\hline \multirow{2}{*}{\multicolumn{2}{|c|}{$\begin{array}{l}\text { ANALYTICAL } \\
\text { LABORATORY } \\
\text { METHOD }\end{array}$}} & \multicolumn{8}{|c|}{$\begin{array}{l}\text { Fuel Analysis \& Methods Evaluation Section (FAME) } \\
\text { Monitoring and Laboratory Division, CARB }\end{array}$} \\
\hline & & \multicolumn{3}{|c|}{$\begin{array}{l}\text { ASTM D5186 } \\
\text { SFC/FID }\end{array}$} & \multicolumn{3}{|c|}{$\begin{array}{l}\text { ASTM D86 } \\
\text { Automatic }\end{array}$} & $\begin{array}{l}\text { ASTM D5453 } \\
\text { Antek }\end{array}$ & $\begin{array}{l}\text { ASTM D4052 } \\
\text { Density Mtr }\end{array}$ \\
\hline \multicolumn{2}{|c|}{ Analysis Date } & \multicolumn{3}{|c|}{$5 / 26 / 00$} & \multicolumn{3}{|c|}{$5 / 24 / 00$} & $5 / 24 / 00$ & $5 / 24 / 00$ \\
\hline \multicolumn{2}{|c|}{ Analyst } & \multicolumn{3}{|c|}{$\mathrm{JC}$} & \multicolumn{3}{|c|}{ MM } & JS & JS \\
\hline $\begin{array}{l}\text { Sample } \\
\text { I.D. }\end{array}$ & $\begin{array}{c}\text { Sample } \\
\text { Date }\end{array}$ & $\begin{array}{c}\text { Total } \\
\text { Aromatics } \\
\text { (vol \%) }\end{array}$ & $\begin{array}{c}\text { Total } \\
\text { Aromatics } \\
\text { (mass } \%) \\
\end{array}$ & $\begin{array}{c}\text { Polycyclic } \\
\text { Aromatics } \\
\text { (mass\%) }\end{array}$ & $\begin{array}{r}T 10 \\
(\operatorname{deg} C) \\
\end{array}$ & $\begin{array}{c}T 50 \\
(\operatorname{deg} C) \\
\end{array}$ & $\begin{array}{c}\text { T90 } \\
(\operatorname{deg} C)\end{array}$ & $\begin{array}{l}\text { Sulfur } \\
(\mathrm{ppm})\end{array}$ & $\begin{array}{l}\text { Density } \\
(a) 60 F \\
(\mathrm{~g} / \mathrm{mL})\end{array}$ \\
\hline $98-317-1$ & & 15.2 & 15.2 & 2.91 & 198 & 235 & 307 & 173 & 0.8268 \\
\hline $98-317-2$ & & 15.5 & 15.4 & 2.93 & 198 & 234 & 304 & 197 & 0.8262 \\
\hline $98-317-3$ & & 15.4 & 15.4 & 2.97 & 197 & 235 & 305 & 187 & 0,8266 \\
\hline & & & & & & & & & \\
\hline & & & & & & & & & \\
\hline & & & & & & & & & \\
\hline & & & & & & & & & \\
\hline & & & & & & & & & \\
\hline & & & & & & & & & \\
\hline & & & & & & & & & \\
\hline & & & & & & & & & \\
\hline & & & & & & & & & \\
\hline & & & & & & & & & \\
\hline & & & & & & & & & \\
\hline
\end{tabular}

Approved by:

NR: Not Requested

Date: $\mathbf{5 / 2 6 / 0 0}$

Figure 7 Test Fuel Analysis Results Provided by CARB Southern Laboratory Branch 


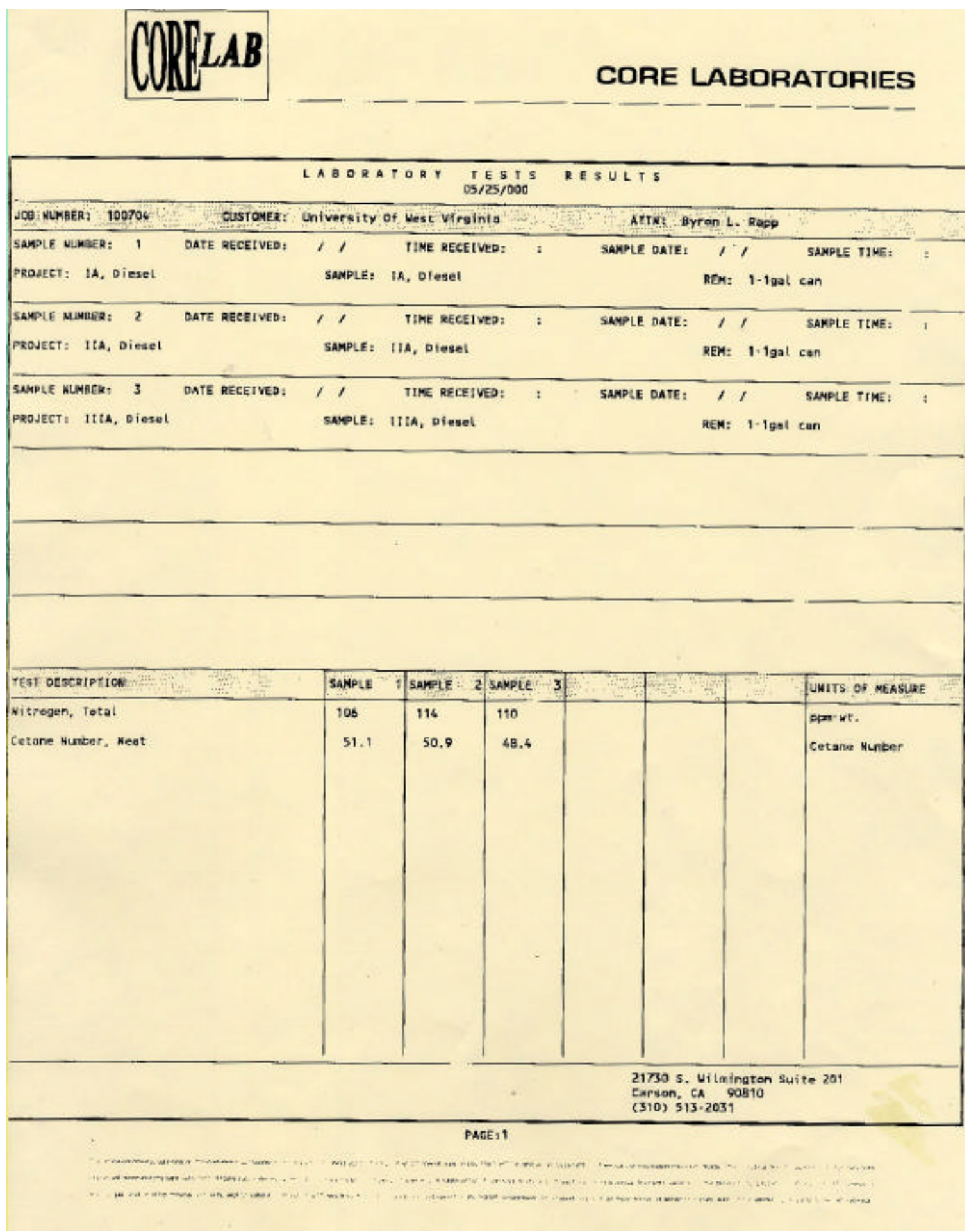

Figure 8 Test Fuel Analysis Results Provided by CORE Laboratories 


\subsection{Field Testing Instruments}

This section discusses the emissions measurement devices used during field testing of the vehicles selected for this experiment. $\mathrm{CO}_{2}$ and engine speed data were recorded from the excavator testing and full emissions data were collected for the tracktype tractor.

\subsubsection{Sensor's AMB-II Microbench}

Raw exhaust concentration measurement, for the excavator, was collected with a five gas repair-grade micro-bench on a continuous basis. This micro-bench will be referred to as an analyzer in this text. Generally a gas analyzer consists of a micro-bench (core of the analyzer), controls, and some limited sample conditioning. The analyzer, shown in Figure 9, is an AMB-II manufactured by Sensors, Inc. The AMB-II is a solidstate NDIR device that measures $\mathrm{CO}_{2}, \mathrm{CO}$, and $\mathrm{HC}$. The theory behind NDIR technology is that each constituent gas is known to have a waveband within the infrared spectrum where it has significant absorption above other background gases. Optical band pass filters are placed before a thermocouple detector. These filters pass only wavelength specific electromagnetic energy. The effect of overlapping absorption is reduced and the overall resolution increased by the use of these filters. Infrared detectors are used to measure the reduction in transmitted infrared energy across a gas filled cell. This measurement is made for the waveband of each gas. Temperature and pressure variations are compensated for by the bench's microprocessor. The ranges measurable for each gas with this device are $0-20 \%$ for $\mathrm{CO}_{2}, 0-15 \%$ for $\mathrm{CO}$, and 0-2000ppm for $\mathrm{HC}$ (Hexane). The analyzer communicates with an onboard laptop computer via serial cable. Software supplied by Sensors, Inc. was used to control the calibration and data acquisition 
functions of the unit. General modifications to the system were made by WVU in order to prepare it for the rigors of the off-highway arena, and to expedite the collection of pertinent field data that would be used for test cycle development. Power for the system was obtained through a 12 volt power outlet on the excavator.

It should be noted that WVU chose not to use the AMB-II micro-bench in the MEMS due to several inherent time-stamping related problems. For purposes of cycle recreation, as described below, the AMB-II was employed in this study.

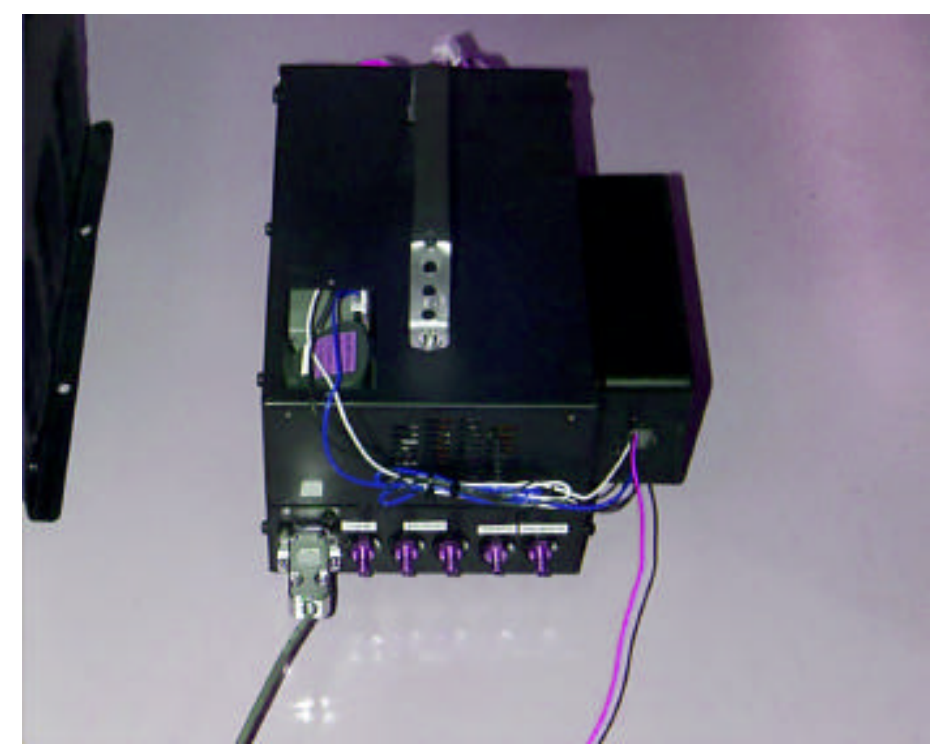

Figure 9 Sensors Inc. AMB-II Multigas Analyzer

\subsubsection{Sample Collection and Conditioning}

A stainless steel exhaust probe was used to sample from the vehicle's raw exhaust stream. The sample probe was affixed directly to the exhaust outlet and drew the sample from within the exhaust stack to avoid losses due to any number of atmospheric phenomena. The sample was passed through a non-heated sampling line and a coalescing, high-temperature glass microfiber filter before it was introduced into the gas analyzer to prevent damage to the system by removing PM and some water. The micro- 
bench has a sample pump and an additional water removal filter. Figure 10 shows the sample probe, line and filter housing, while Figure 11 shows the probe as mounted on the excavator.

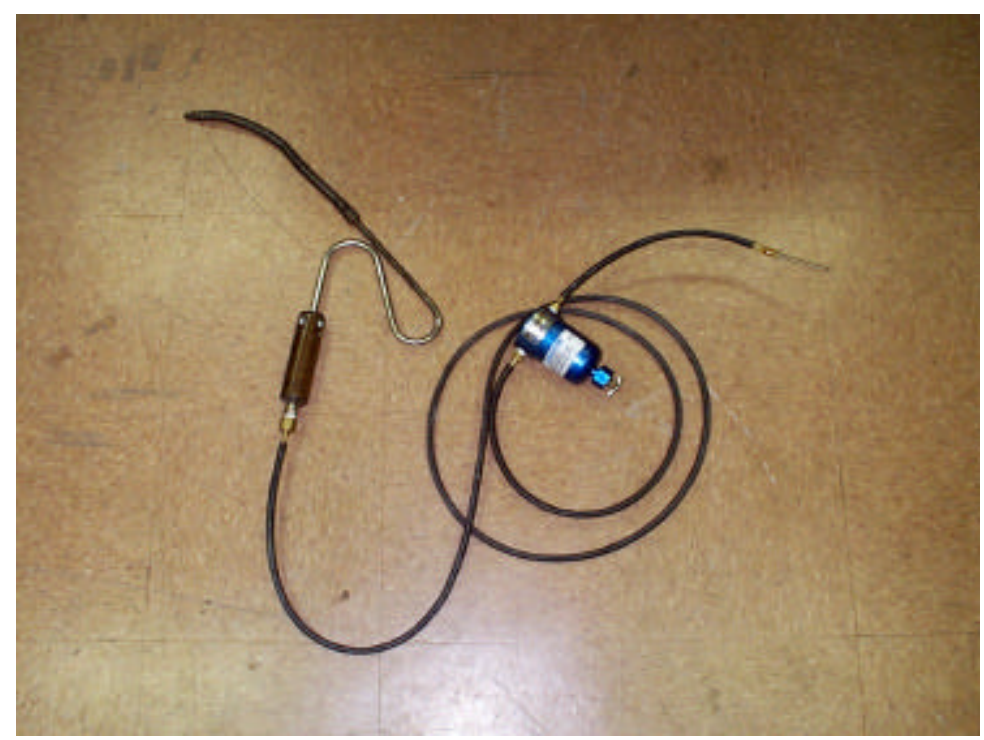

Figure 10 Sample Probe, Line, and Filter Used for Excavator In-field Testing

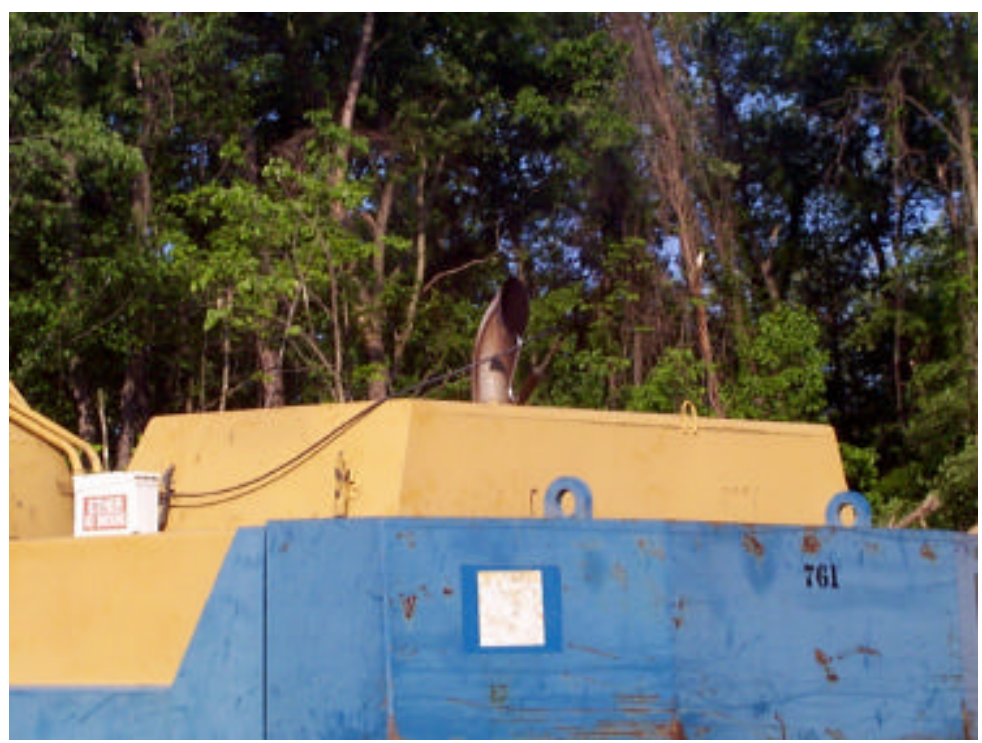

Figure 11 Exhaust Sample Line and Probe on Excavator 


\subsubsection{Engine Speed Measurement}

In order to collect engine speed data, the vehicle alternator was tapped in order to record a signal that could be used by the emissions measurement system. The voltage of the signal alternates between a value near zero volts and an upper limit near one volt. The Sensors AMB-II has the capability of measuring a transistor-transistor-logic (TTL) signal, so the alternator signal was used to trip a field voltage that registered a count each time it was passed such that a TTL like signal was generated for the analyzer to record. However, a problem was encountered due to the noise contained in the alternator signal. The signal was observed with an oscilloscope and it was found that it contained many very short duration spikes that were close enough to one volt that they were counted as a pulse. The signatconditioning device constructed basically chopped the top of the signal off (voltages near one volt) and nullified the noise spikes that were significantly less than one volt, thus producing a substantially cleaner signal. The signal conditioner was mounted to the side of the AMB-II analyzer. As the engine speed changes, the frequency of the alternator signal will change, and by knowing the number of poles and the alternator pulley to crankshaft pulley ratio, the amount of sinusoidal pulses per engine revolution can be determined. Ultimately to check this estimation, the engine speed recorded from this signal was compared to the dynamometer's speed encoder across the engine's operating range. Using the data collected during this operation, appropriate conversion factors were determined to relate the value recorded by the microbench to actual engine speed. 


\subsubsection{Mobile Emissions Measurement System (MEMS)}

The MEMS System was developed by WVU to test highway vehicles in operation. Some modifications were made to the system to accommodate the size of the engine in the D-11R and the environmental extremes in which it operates. Due to limitations in the flow measurement devices used, it was decided to test each exhaust stream separately. The major component of the first generation MEMS, the exhaust sample conditioner and analyzer container, is shown in Figure 12.

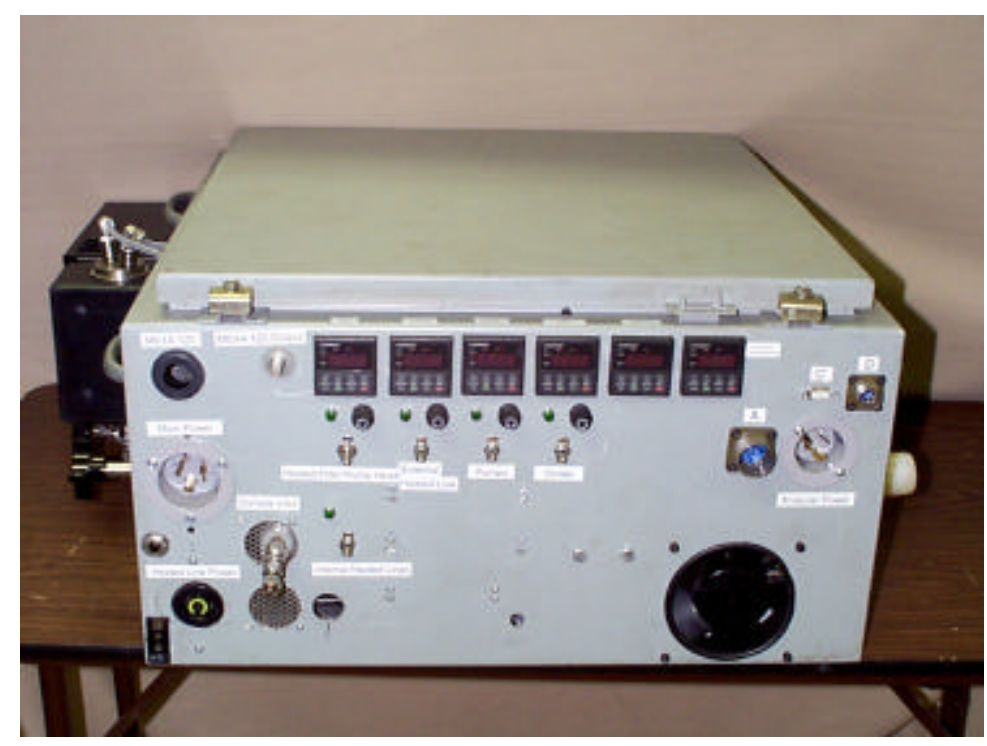

\section{Figure 12 WVU MEMS Gaseous Sample Conditioner and Analyzer Container}

In order to achieve accurate in- use brake-specific mass emissions, an on-board emissions measurement system must not only be portable, but also be capable of accurately measuring several parameters in a repeatable manner with the highest level of precision. These include engine speed, engine torque, exhaust mass flow rates, and exhaust constituent concentrations. The MEMS was developed after an extensive evaluation of available technologies as they relate to these issues. The MEMS has recently been approved by the US EPA for use in Phase III work of the "In-Use Testing Program" 
under the Consent Decrees. The MEMS is capable of measuring in-use brake-specific emissions of $\mathrm{NO}_{\mathrm{x}}$ and $\mathrm{CO}_{2}$ from diesel-powered vehicles operated under real-world conditions. The major sub-systems of MEMS include:

i. $\quad$ Exhaust mass flow measurement system

ii. Engine torque and speed measurement system

iii. Exhaust emissions analyzers

iv. Exhaust gas sampling, and sample conditioning systems

v. Vehicle speed and distance measurement system

vi. Data acquisition, reduction, and archival system

For illustration purposes, Figure 13 shows a flowchart of this system. The systems are discussed in more detail in the subsections that follow.

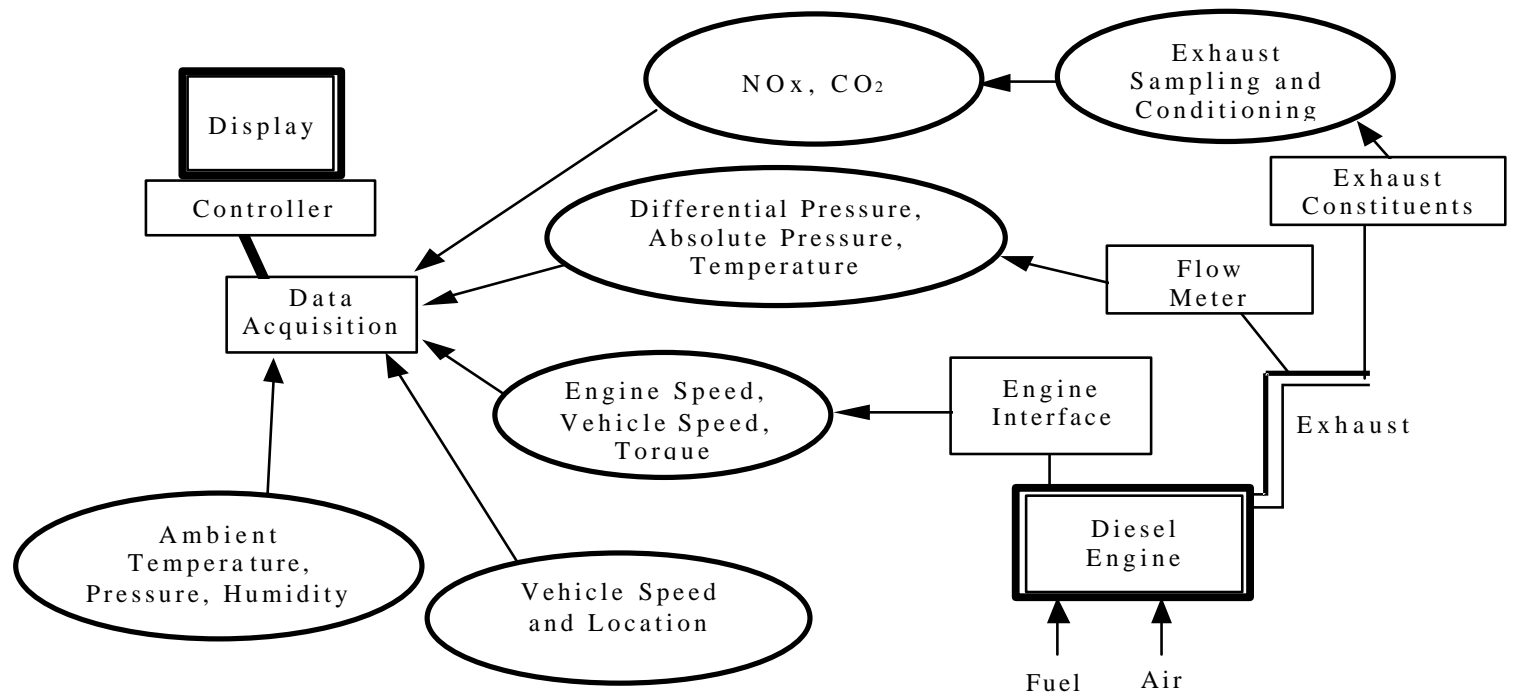

Figure 13 MEMS System Components 


\subsubsection{MEMS Exhaust Mass Flow Measurement}

To gather data for the calculation of exhaust flow rate, MEMS uses an Annubar ${ }^{\mathrm{TM}}$ cross-sectional averaging flow meter. This device was chosen for its ability to counteract the effects of pulsation in the exhaust stream that are produced by an internal combustion engine, which cause measurement error. When used in the same nominal pipe size as the vehicle's exhaust system, a minimal additional backpressure is placed on the engine. A Validyne P55D differential pressure transducer, Omega PXI213 absolute pressure transducer, and J-type thermocouples were used to record the necessary data from the Annubar ${ }^{\mathrm{TM}}$ device for calculation of exhaust mass flow rate. For this testing, a 6 inch Annubar $^{\mathrm{TM}}$ device was used. The exhaust stack on the D-11R measures 6.875 inches I.D., which tested the limits of the 6 inch Annubar ${ }^{\mathrm{TM}}$ device. In order to determine that this device would provide accurate measurements, a series of tests were performed with the device in a section of pipe sized to the dimensions of the D-11R exhaust stack. A more thorough description of this testing and the results follows in Section 3.6.3.1 Exhaust Stack Sampling Section Design and Qualification.

\subsubsection{MEMS Engine Torque and Speed Measurement}

In its simplest form, engine torque production can be inferred from the fuel consumption of the engine. Many modern diesel engines use electronically controlled injection strategies to maximize power output and fuel efficiency. These modern systems provide the ability to interface with them to allow the determination of the amount of fuel injected during each engine cycle. With the aid of sensors determining parameters such as intake pressure and temperature, exhaust backpressure, coolant and fuel temperatures, 
and intake air humidity, an accurate estimate of torque can be acquired. Since the engines that were removed for dynamometer testing were mechanically fuel injected, this method was not an option for this research. However, this would be the method of choice for future torque determination on modern ECU-controlled vehicles. The MEMS is capable of monitoring engine torque and speed via an ECU protocol adaptor through an RS232 interface with the data acquisition system. Engine torque is inferred from the ECU's broadcast signal of the percent load, the measured curb no-load percent load, and the manufacturer supplied lug curve. The Caterpillar D-11R CD used for this study did not broadcast ECU data that could be interpreted with a standardized public protocol adaptor as used with the MEMS. Therefore Caterpillar provided a representative and an interface to collect the ECU data.

The engine speed signal was divided at the magnetic pickup and monitored by the MEMS acquisition system as well as the Caterpillar system in order to provide a common means of data alignment. Caterpillar provided engine speed and load information (estimated from fueling information) so that engine work could be integrated to provide brake-specific emissions results.

\subsubsection{MEMS Emissions Analyzers Component}

The MEMS employs an NDIR solid-state detection device for the inference of $\mathrm{CO}_{2}$, (as well as $\mathrm{CO}$ and $\mathrm{HC}$ ), whereas a $\mathrm{ZrO}_{2}$ sensor is used for $\mathrm{NO}_{\mathrm{x}}$ determination. An electrochemical cell is employed as a quality control/quality assurance (QC/QA) measure, due to the limited in-field performance data associated with the $\mathrm{ZrO}_{2}$ sensor that serves as the primary $\mathrm{NO}_{\mathrm{x}}$ measurement device. It should be noted that although the 
NDIR system is capable of measuring $\mathrm{HC}$ and $\mathrm{CO}$, the resolution of the microbench is substandard for diesel applications.

\subsubsection{MEMS Emissions Sample Conditioning System}

In collecting an exhaust sample for emissions evaluation, there are several aspects that must be considered to provide accurate meaningful results. Removal of particulate matter, sample temperature control, and minimization of water interference are three key issues for which the MEMS system compensates. Two ways of controlling water interference are to prevent condensation or remove the water vapor present in the sample stream. MEMS uses heated sampling lines to prevent condensation, and a thermoelectric chiller immediately upstream of the emissions measurement devices removes water from the sample stream and lowers the sample temperature to analyzer manufacturer's specifications.

A schematic of the sampling system for MEMS is shown in Figure 14. The generalized system consists of a sampling probe, a heated line, a heated filter, a heatedhead pump, an external $\mathrm{NO}_{2}$ converter, and a thermoelectric chiller. The MEMS sampling probe is designed in accordance with the Code of Federal Regulations (CFR) 40 Part 89.412.96 [20]. A 0.25-inch diameter stainless steel tube with nine sampling holes was used as the sampling probe. The design of the probe is shown in Figure 15. The multiple sampling ports on the probe provide a means of collecting an average exhaust flow sample in order to increase accuracy relative to changes in composition with changes in flowrate. A differential pressure regulator and a flow meter with a needle valve for flow control are used to provide for a stable flow rate. All components of this 
system have been designed according to manufacturer specification for the emissions analyzers used by MEMS.

MEMS Sample Flow Schematic

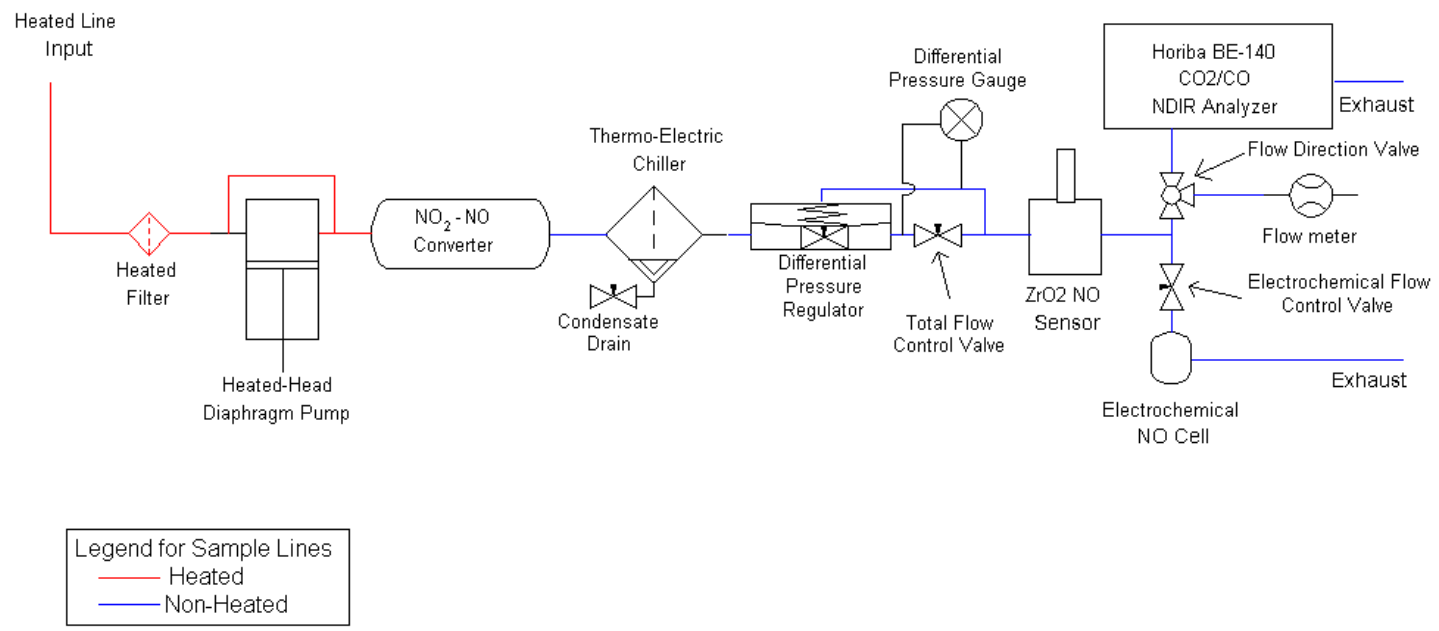

Figure 14 Exhaust Sampling System of the First Generation MEMS.

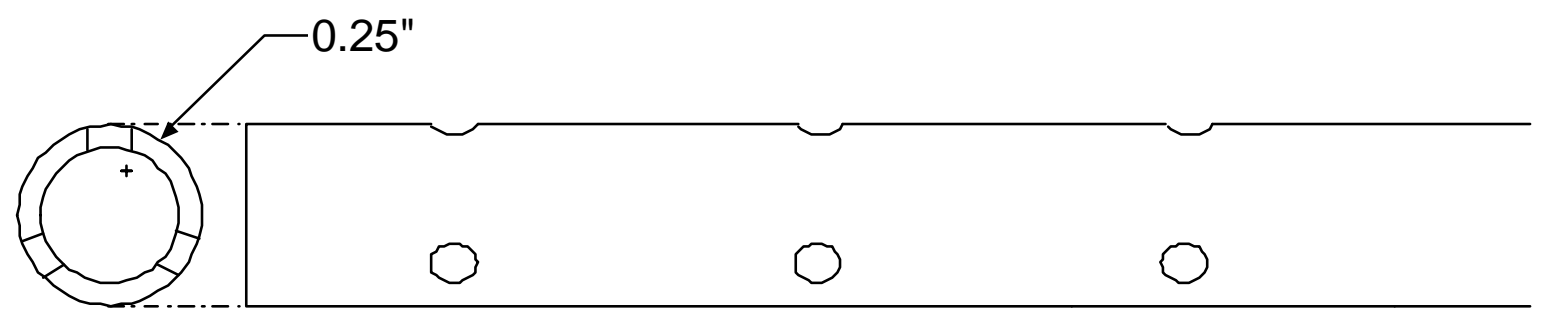

Figure 15 MEMS Sample Probe

\subsubsection{MEMS Data Acquisition, Reduction, and Archival System}

The first generation MEMS used a National Instruments PXI-1025 as its computer platform, due to its inherent ruggedness and expandability. The configuration consisted of a National Instruments multifunction 6071E data acquisition card that 
interfaced with a signal conditioning box, a National Instruments Temperature/Voltage 4351 card, and a RS-232 serial card. A National Instruments PXI-8156B embedded computer was used to allow access to two serial ports, a USB port, a GPIB interface, as well as hard, floppy, and CD drives. The portable platform utilized a built-in monitor and keyboard. This system was attached to the test vehicle chassis, and required minimal setup effort. A customized software package was used, which was capable of a minimum sampling rate of $5 \mathrm{~Hz}$. MEMS employed a portable generator set to power all components with a battery back-up for the data acquisition system and emissions analyzers.

\subsubsection{MARI Real-time Particulate Mass Monitor (RPM 100)}

A prototype Mid-Atlantic Research Institute LLC. (MARI) Real-time Particulate Mass Monitor RPM 100 (see Figure 16 and Figure 17) was used for the measurement of total particulate matter emissions for the testing of the Caterpillar D-11R CD track-type tractor. This device uses a quartz crystal microbalance (QCM) along with a sample conditioning system to extend the usability of the QCM for engine exhaust measurements. The RPM 100 has undergone evaluations under the US EPA Heavy-duty Engine FTP schedules. In addition, the units have been used extensively for on-road, onboard vehicle applications, chase studies, and cabin air quality studies. For a better understanding of this system, the following sections describe the theory of operation of the unit. The RPM 100 was fitted in a weatherproof enclosure for the track-type tractor field testing. Figure 16 shows this enclosure. The port at the center of the top of the enclosure is the sample inlet. The sample is drawn through an exhaust probe and a heated line to this inlet. The heated line controller is also included in the enclosure. The 
enclosure was designed to operate on a single 120 volt ac power supply. A power inverter was used to supply the 12 volt dc needed by the RPM 100 and the pumps used to control sample and dilution flows. A serial connection is used to connect the RPM 100 to a computer that is used to control the system (i.e. dilution ratios, corona current, sample flows). All pumps and filters used by this system were also included in the enclosure. A problem was encountered with system overheating, thus a cooling fan was incorporated into the enclosure.

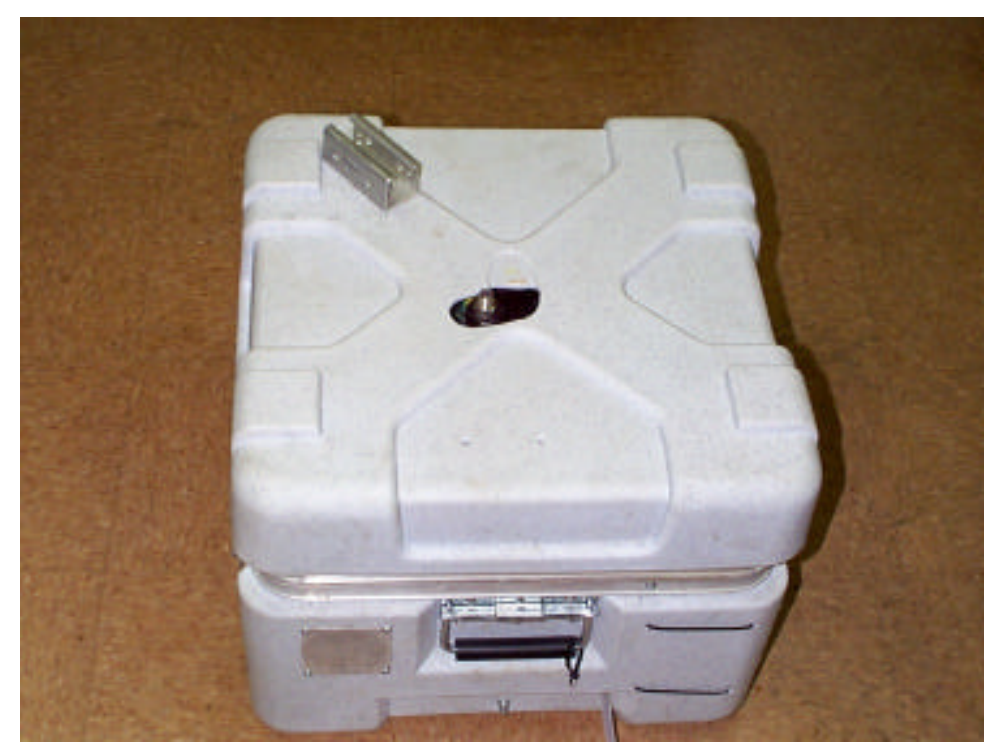

Figure 16 MARI Real-Time Particulate Mass Monitor (RPM 100) in a Weatherproof Case

\subsubsection{Quartz Crystal Microbalance}

Quartz crystal microbalances were popular in the 1970's and 1980's, but as the devices continually load with PM and exceed their operating range rather quickly, the $\mathrm{TEOM}^{\circledR}$ and beta gauges became dominant for continuous ambient $\mathrm{PM}_{10}$ dust monitoring. However, recent advances in improving the sensitivity of quartz crystals have brought QCM technology to the forefront of ultra- low PM mass emission 
measurement applications. Additionally, the ultra-low PM mass emissions from modern catalyzed trap equipped diesel engines are readily measured by the QCM. As the QCM is a simple and rugged device, unaffected by vibration or temperature, and has greater resolution (100-1000 times more sensitive to mass) than other harmonic oscillator systems, it is better suited for measuring low particle concentration levels. In the past, quartz crystal microbalances suffered from diffusion losses, long residence times, and inability to hold particles to the collection surface. However, since the 1980's, major technological advancements have been made in the area of collection and measurement of very low masses of PM.

Preliminary data from heavy-duty engine dynamometer studies clearly show the benefits of the technique as opposed to other commercially available microbalances. Tests conducted with the MARI RPM 100 on a heavy-duty engine dynamometer have shown the PM mass emissions data to be within $10 \%$ of the CVS-based gravimetric method. 


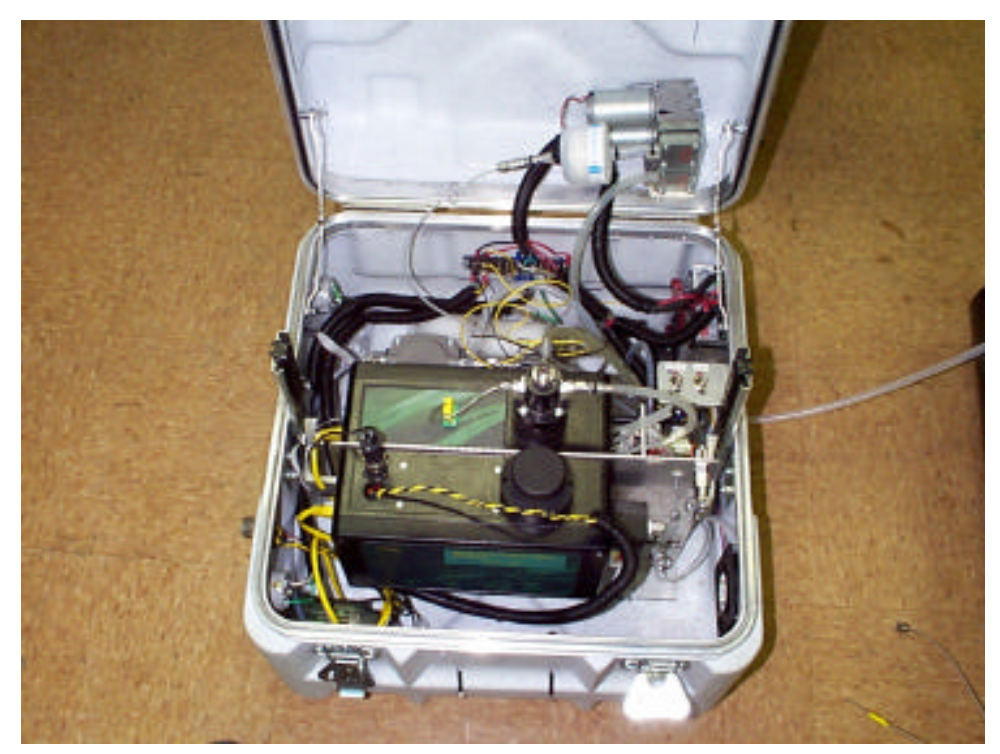

\section{Figure 17 Internal Component View of the MARI Real-Time Particulate Mass Monitor (RPM 100)}

The MARI RPM 100 uses a piezoelectric crystal, measuring $14 \mathrm{~mm}$ in diameter, as a sensitive microbalance. A point-to-plane electrostatic precipitator provides a very efficient means for collection of aerosol particles on the surface of the piezoelectric crystal, especially in the sub micrometer particle size range. The precipitator generates a corona field that charges particles to ensure deposition on the oppositely charged crystal. The diameter of the electrode is $6.4 \mathrm{~mm}$, and the active area on the crystal is usually 0.32 $\mathrm{cm}^{2}$. The piezoelectric quartz crystal is externally driven and excited to its natural frequency, which decreases with increasing mass load on its surface, by an electronic oscillator attached to two metal plates (usually deposited by vacuum evaporation) placed on both sides of the quartz blank. Thus, the particulate mass collected on the crystal can be determined by measuring the change in the crystal's natural frequency. When the crystal has been fully loaded, it can usually be cleaned, or replaced if necessary. 
The RPM 100 is insensitive to the pressure fluctuations caused by the pulsating flow of the internal combustion engine. The resonant frequency of the QCM used is normally $5 \mathrm{MHz}$ but can be varied depending on the application. Also, the MARI RPM 100 is insensitive to workplace vibrations typically encountered in on-board vehicle applications, which is critical for continuous PM mass measurement applications.

To manage the lifetime of the crystal (maximum loading typically less than $30 \mu \mathrm{g}$ after which it needs to be cleaned), the RPM 100 uses a high-performance dilution system. The integration of the unique diluter with the QCM (currently integrated by utilizing a CAN network) offers a fully flexible automated system that can both manage the crystal lifetime and moreover potentially offer an automatic and traceable route for determining the volatility component of the exhaust particulates- a prerequisite for good equivalency performance.

The microbalance can measure particles of the size range from 0.01 to $2.5 \mu \mathrm{m}$ in diameter, and depending on the crystal limitations and the averaging time, the unit can handle concentrations of $2-10,000 \mu \mathrm{g} / \mathrm{m}^{3}$.

\subsubsection{Sampling Conditioning System}

The sampling of exhaust emissions for PM (both raw exhaust and from dilution tunnels) requires the careful consideration of both the needs of the particulate measurement instrumentation, and the changes that may occur to characteristics of the sampled exhaust (i.e. changes to the particulate size and composition), due to the nature of the sampling equipment. The RPM 100 is retrofitted with a sample conditioning system for diluting the raw exhaust samples [21]. 
Sampling uncertainties may arise from source to receptor changes to the physical and chemical nature of the aerosol, sampling effects, temporal behavior, volatility, humidity and temperature effects, changes to the aerosol components, and field use robustness. For example, it has been well documented that in the presence of volatile material in the exhaust, changes in dilution ratio can affect the size distribution and concentration of the sampled aerosol. To overcome this phenomenon, various research projects have employed thermal denuders to remove volatiles from the sample.

Similarly, current particulate matter emissions measurement instrumentation has uncertainties arising from problems relating to transfer of the sample to the analyzer, which include pressure fluctuations at the inlet caused by pressure changes in the raw exhaust or dilution tunnel, sample concentration extremes outside of the performance range of the analyzer, and temperature and humidity effects.

The sampling conditioning system employed for this PM measurement system accounts for many of the aforementioned variables. The configuration of the system has been designed to minimize particle losses, provide great flexibility for measurement, avoid pressure fluctuations at the instrument inlets and improve measurement repeatability and reproducibility by having a "fixed" and "well-defined" sampling geometry. With reference to Figure 18, the Sampling Conditioning System (4) includes 12 v DC pump(s) (7, 12), an optional thermal denuder (13), a filter (6), automated minor and major flow controllers $(8,9)$, and control options/valves $(3,14,15,16$, and 17) for the selection of the "most-appropriate" sampling configuration. Key features of the system include a computer controlled SCS (diluter) that can dilute the aerosol proportionally, or to pre-programmed levels (range 3:1 - 3000:1 - comprising selectable 
ranges using laminar flow capillaries), a sample dilution accuracy of better than 5\%, atmospheric pressure sampling for correcting the particulate instrumentation, adaptive provisions for accommodating filters for mass-based regulatory measurements, minimized particle losses and bias to size distribution, and a HEPA filter and Carbon Capsule filter connected to the inlet (via a control value) to enable base-line measurements [21].

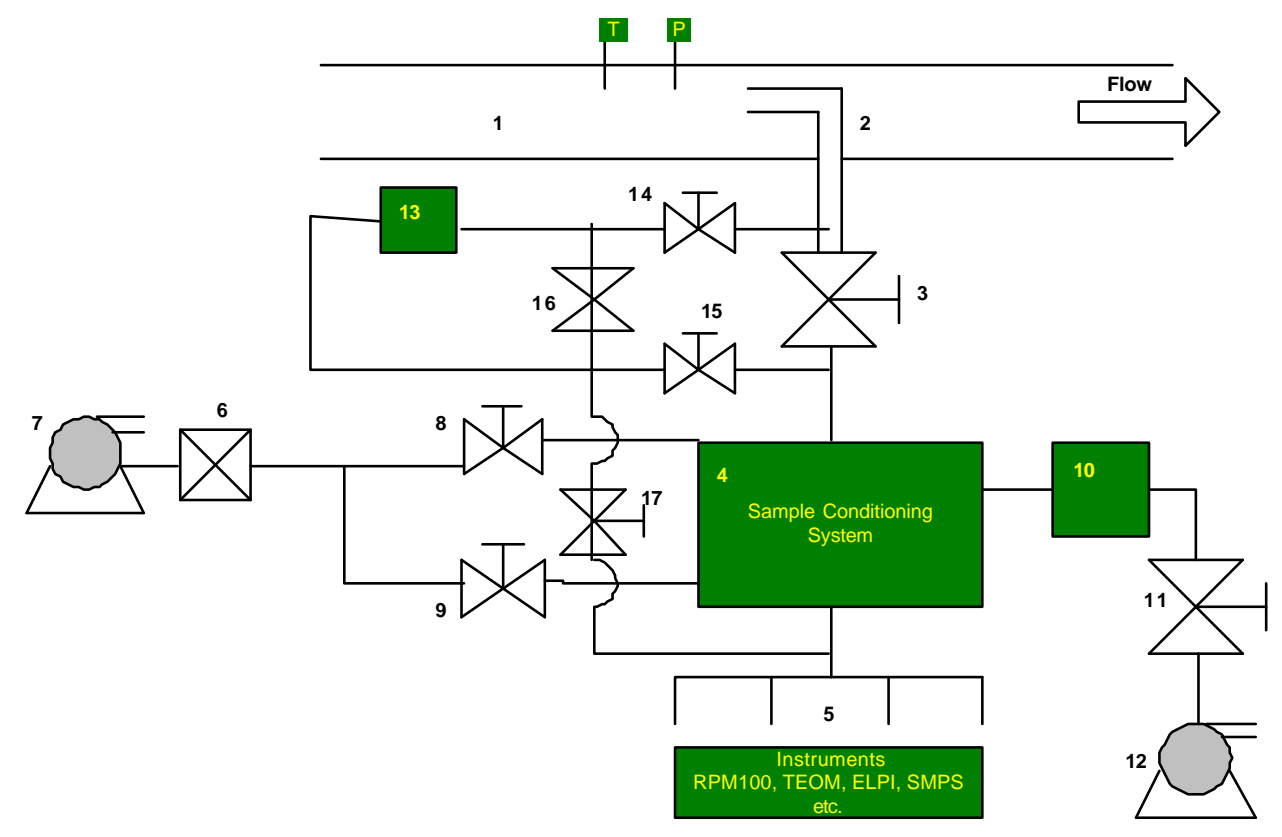

Figure 18 Schematic of the Sampling System

The parameters of flow that the SCS can operate with are as follows. The total flow can be varied from 20 to $40 \mathrm{lpm}$ with minor flow varying from 1 to $10 \mathrm{lpm}$ depending upon the dilution ratio. The sample inlet pressure can be varied from $0-2$ $\mathrm{kPa}$ and the maximum dilution air pressure is $100 \mathrm{kPa}$. The dilution air is pulled from ambient air and passes through HEPA grade filters to ensure that the sample is not 
contaminated. The temperature of sample gases can be as high as $200^{\circ} \mathrm{C}$, and the process is very fast, taking typically less than $50 \mathrm{~ms}$ for sample conditioning.

The Sampling Conditioning System is based on the work published by Brockmann et al. [22], which describes a diluter that was designed for sampling high concentrations $\left(\sim 10^{10} \mathrm{~cm}^{-3}\right)$ of ultrafine aerosols $(<0.3 \mu \mathrm{m}$ in diameter $)$. In its design particular care was taken to minimize the effects of coagulation and diffusional deposition within the diluter. Moreover, the diluter was also designed so that the effects of these processes on the size distribution of the sampled aerosol could be calculated and minimized.

Figure 19 shows a schematic diagram of the diluter within the Sampling Conditioning System. The sample is extracted through a needle and immediately mixed with the primary dilution flow. This diluted sample or aerosol then flows through a second transport tube to the throat of a venturi where it mixes with the secondary dilution air. The venturi is used to create the suction needed to draw the sample through the system. This allows the diluted sample to be delivered at atmospheric pressure.

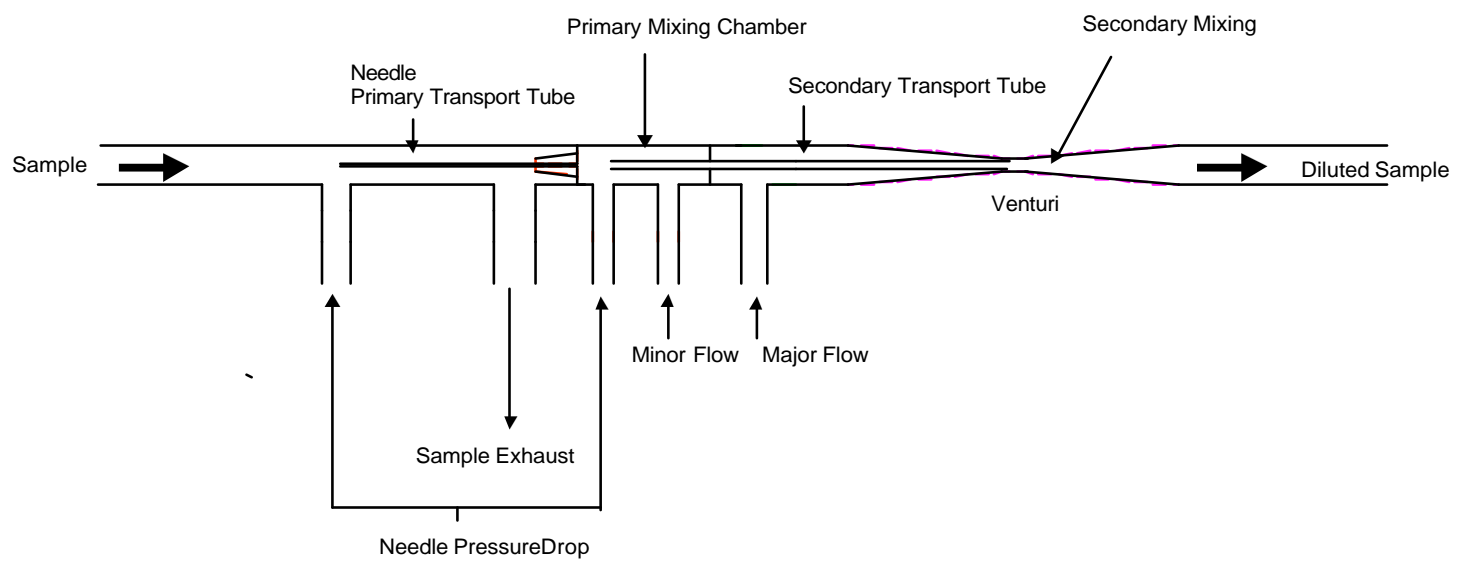

Figure 19 Schematic of the Sample Conditioning System 
Using Bernoulli's equation, the pressure balance for the diluter can be expressed

as:

$$
\mathrm{P}_{\mathrm{s}^{-}}\left(\mathrm{P}_{\mathrm{E}}-1 / 2 \rho \mathrm{V}_{\mathrm{t}}^{2}\right)=\Delta \mathrm{P}_{1}+\Delta \mathrm{P}_{2}
$$

Equation 1

Where,

$$
\begin{aligned}
& \mathrm{P}_{\mathrm{S}}=\text { static pressure at the sample point } \\
& \mathrm{P}_{\mathrm{E}}=\text { static pressure at the exhaust point } \\
& \Delta \mathrm{P}_{1}=\text { pressure drop across the sample capillary (primary transport tube) } \\
& \Delta \mathrm{P}_{2}=\text { pressure drop across the transport capillary (secondary transport tube) } \\
& V_{\mathrm{t}}=\text { gas velocity (average) at venturi throat } \\
& \rho=\text { gas density }\left(\mathrm{g} / \mathrm{cm}^{3}\right)
\end{aligned}
$$

Note that if the pressure at the sample and exhaust points are equal (assumptions that are often valid in practical situations), Equation (1) reduces to

$$
\Delta \mathrm{P}_{1}+\Delta \mathrm{P}_{2}=1 / 2 \rho \mathrm{V}_{\mathrm{t}}^{2}
$$

\section{Equation 2}

The pressure drops in the sample $\left(\Delta \mathrm{P}_{1}\right)$ and the transport $\left(\Delta \mathrm{P}_{2}\right)$ capillaries are functions of volumetric flow rates, $\mathrm{Q}$, through the capillaries. In fully developed laminar tube flow, pressure drop is linearly related to volumetric flow rate. However, if the flow develops from a flat velocity profile, as is the case in the sample and transport capillaries, the pressure drop has an additional contribution equal to $0.58 \rho \mathrm{u}^{2}[\mathbf{2 3}]$. Therefore, for flow through the capillary tubes, pressure drop $\Delta \mathrm{P}$ and volumetric flow rate $\mathrm{Q}$ are related by

$$
\Delta \mathrm{P}=\mathrm{aQ} \mathrm{Q}^{2}+\mathrm{bQ}
$$

Equation 3

Where, 


$$
a=8(1.16) \rho /\left(\pi^{2} d^{4}\right)
$$

\section{Equation 4}

And,

$$
b=128 \mu 1 /\left(\pi d^{4}\right)
$$

Equation 5

Where,

$$
\begin{aligned}
& \rho=\text { gas density } \\
& d=\text { capillary diameter } \\
& \mu=\text { gas absolute viscosity } \\
& 1=\text { capillary length }
\end{aligned}
$$

The overall dilution ratio $\mathrm{R}$ is then given by:

$$
\mathrm{R}=\left(\mathrm{Q}_{2} / \mathrm{Q}_{1}\right)\left(\mathrm{Q}_{3} / \mathrm{Q}_{2}\right)
$$

Equation 6

where the subscripts 12 and 3 respectively refer to the flow rates through the sample capillary tube, the transport capillary tube, and the venturi.

The sample flow rate $\mathrm{Q}_{1}$ depends on $\mathrm{P}$, which in turn depends on $\mathrm{Q}_{2}, \mathrm{Q}_{3}$, and the dimensions of the capillary tubes and venturi. The relationship between $Q_{1}$ and these parameters is determined by substituting Equation (3), for both capillary tubes, into Equation (2).

Brockmann et al. [22] found that the agreement between the experiment and Schlichting's equation was excellent, and the experimentally determined diameter values fell within the manufacturing tolerance limits. The experimental results were subsequently used to determine flow rates. Because the expression for pressure drop is applicable only so long as the capillary length exceeds the entrance. This is supplied by Schlichting [23]: 


$$
1_{10 \%}=0.29 \operatorname{Re}^{*} \mathrm{~d}
$$

Equation 7

where $1_{10 \%}$ is the length required for the flow centerline velocity to approach to within $10 \%$ of fully developed centerline velocity, and Re is the Reynolds number.

The equations presented above provide the basis for the design of this diluter, and indeed the design of any sample extraction device using venturi suction and capillary flow metering.

\subsection{Laboratory Testing Equipment, WVU EERL}

The laboratory testing for the project was performed at the West Virginia University Engines and Emissions Research Laboratory in Morgantown, WV. This laboratory has been in operation since 1993 and adheres to guidelines set by CFR 40, Part 86, Subpart N [20]. This laboratory uses a CFV-CVS (Critical Flow Venturi-Constant Volume Sampler) System. The following sections outline the components of this system. A schematic of the laboratory testing setup is shown in Figure 20. 


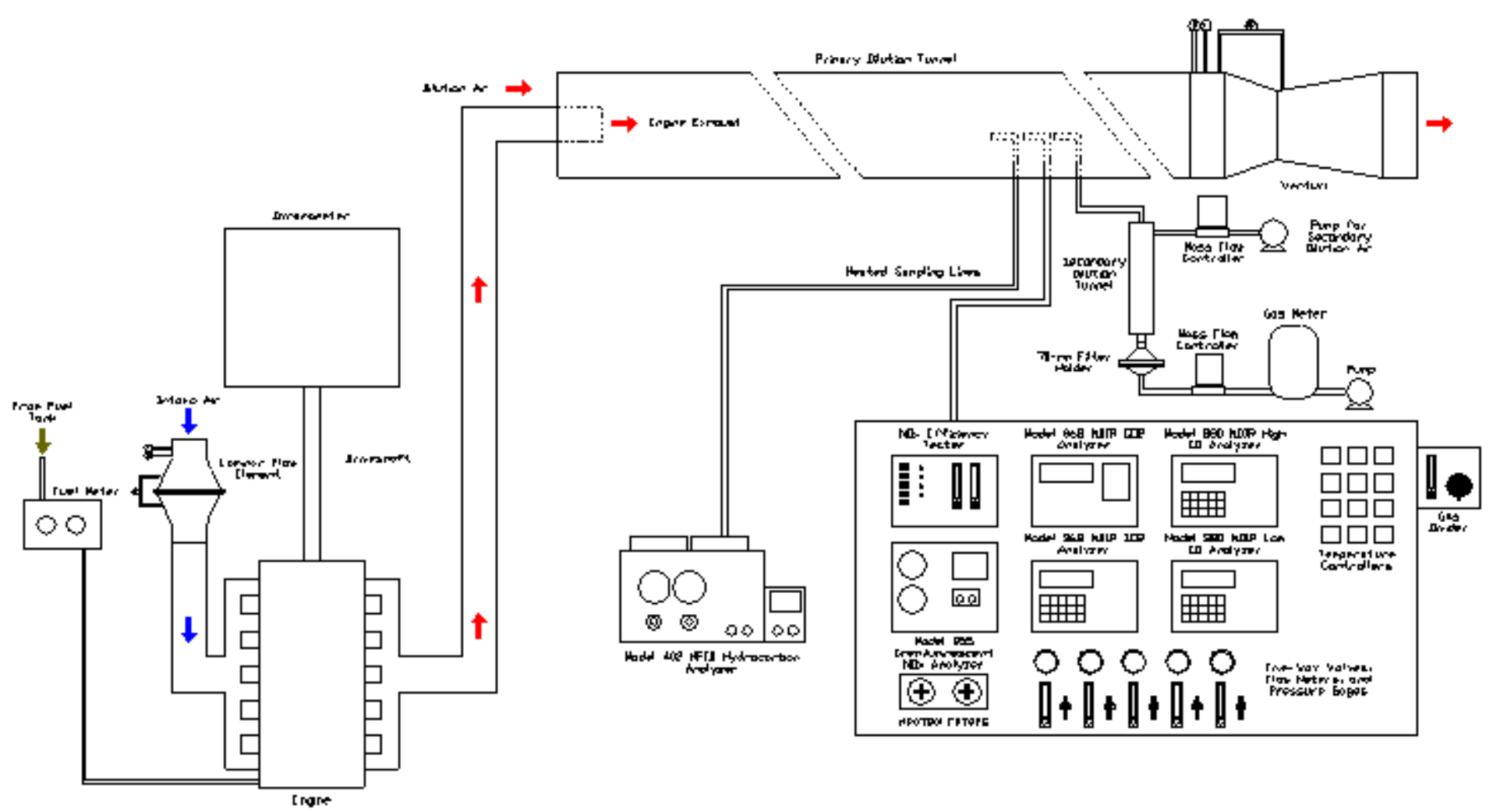

Figure 20 Schematic of WVU EERL Laboratory Setup 


\subsubsection{Full-flow Exhaust Dilution Tunnel}

The goal of engine emissions testing is to gain understanding of the constituents of engine exhaust and the way these constituents act in the atmosphere. In order to simulate in the laboratory the atmospheric mixing that occurs once the exhaust leaves the stack, the exhaust stream is mixed with ambient air. Other benefits of this process include lowering of the dew point temperature of the exhaust stream, which prevents condensation in sample lines, and stoppage of post combustion reactions. Water is a primary enemy of gaseous measurement as it can harm instruments and absorb exhaust gases such as $\mathrm{NO}_{2}$ and some components of PM.

The dilution tunnel at WVU EERL is 18 inches in diameter and 40 feet long, and it is constructed of stainless steel. Three critical flow venturis are available, one 400 SCFM and three 1000 SCFM venturis, which can be opened or closed to allow for 4003400 SCFM tunnel flow. A 75 hp blower pulls air through the tunnel and venturi(s). In order to ensure the exhaust mixes thoroughly with the dilution air, a mixing orifice, which is 8 inches in diameter, is placed three feet downstream of the tunnel inlet. The exhaust line is centered at the tunnel inlet using a honeycomb bracing. Exhaust gases begin mixing with dilution air at this point. The gaseous analyzer sample probes are placed 15 feet downstream of the orifice plate. The probes are connected with electrically heated sample lines to the analyzers. Downstream of the gas probes is a secondary dilution tunnel that is 4 inches in diameter and is used to draw off a portion of the mixed stream to collect PM samples. Additional air can be injected into this system to keep temperatures below $125^{\circ} \mathrm{F}$ at the collection filter, and the entire flow is MFC controlled. 


\subsubsection{Critical Flow Venturi}

Per the standards of CFR 40, Part 86, Subpart N, [20] the WVU EERL utilizes a constant volume sampling (CVS) system to regulate the flow of diluted exhaust. Four critical flow venturis are used to keep a constant total flow rate. This is accomplished by creating sonic flow conditions to maintain constant mass flow rate of the gas across the venturis. This mass flow rate can be calculated with the following equation.

$$
\mathrm{Q}=\mathrm{K}_{\mathrm{v}}(\mathrm{P} / \mathrm{v} \mathrm{T})
$$

Equation 8

$\mathrm{Q}$ is the mass flow rate in scfm, $\mathrm{K}_{\mathrm{v}}$ is a calibration coefficient, $\mathrm{P}$ is the absolute pressure at the venturi in $\mathrm{kPa}$, and $\mathrm{T}$ is the absolute temperature of the gas at the venturi inlet, measured in degrees Kelvin. Pressure data is collected with a Viatran model 1042 AC3AAA20 pressure transducer, while a resistive temperature device, or RTD, records temperature.

The venturis were calibrated with a subsonic venturi traceable to the standards set forth by the National Institute of Standards and Technology (NIST).

\subsubsection{Gaseous Emission Sampling System}

The gaseous sampling system consists of heated probes located in the dilution tunnel, and heated sampling lines connecting the probes with the gas analyzer bench. A picture of the gas analyzer bench can be seen in Figure 21. There are three heated sampling probes located ten tunnel diameters, approximately 180 in., downstream of the origin of the mixing zone, which ensures that complete turbulent mixing of the exhaust gases with the dilution air has occurred. The probes are oriented so that their opening is directed upstream toward the entrance of the tunnel. The connection between the sampling probes and the analyzers is made with electrically heated sampling lines. The 
$\mathrm{HC}$ sampling line is maintained at a temperature of $375^{\circ} \mathrm{F} \pm 10^{\circ} \mathrm{F}$ using a Fuji model No. 223-1806 temperature controller. This prevents the high molecular weight hydrocarbons from condensing in the sample line. The sample lines and probes for the $\mathrm{NO}_{\mathrm{x}}$ and $\mathrm{CO} / \mathrm{CO}_{2}$ sampling systems are kept at $235^{\circ} \mathrm{F} \pm 10^{\circ} \mathrm{F}$ in order to prevent the condensation of water in the line, which could induce measurement error as well as cause damage to the analyzers. The $\mathrm{CO} / \mathrm{CO}_{2}$ sample is pumped through a Hankinson compressed air dryer to provide for more moisture removal. Samples are flow controlled via needle valves and flows are measured using two devices to ensure that the sample rate is adequate for each analyzer.

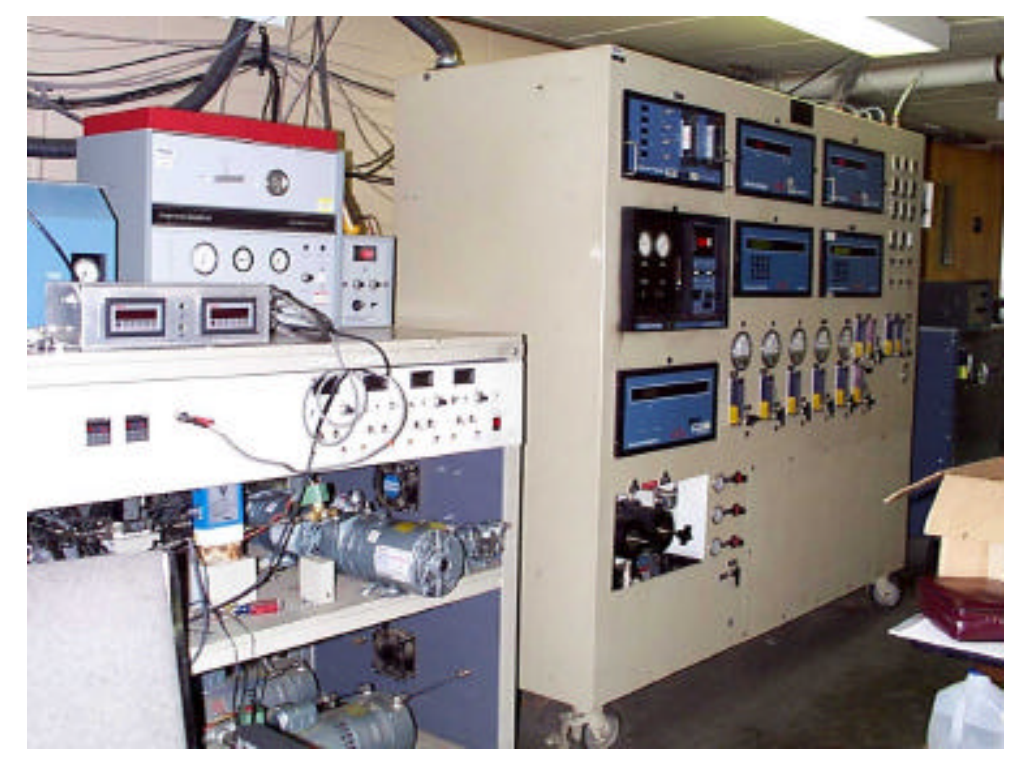

Figure 21 Gaseous Emissions Analyzer Bench at WVU EERL

There are two 80-liter Tedlar bags used in the EERL's sampling system. One bag is used to collect a diluted exhaust gas sample to allow a cycle averaged gas analysis for each test, and the other bag is used to collect a sample of the dilution air to account for any trace gas concentrations that might be contained in it. This allows for the 
background concentrations contained in the dilution air to be subtracted from the analyzer measurements to quantify actual exhaust stream concentrations. The primary reason for using the dilute sample bag is to allow comparison between it and the integrated sample for a quality control/quality assurance check.

\subsubsection{Exhaust Gas Analyzers}

This section gives a brief description of each gaseous analyzer used at WVU EERL and its components, as well as the theory of operation behind each analyzer. A more in depth look into operational theory can be found in the Rosemount analyzer operation manuals.

\subsubsection{Oxides of Nitrogen Analyzer}

The $\mathrm{NO} / \mathrm{NO}_{\mathrm{x}}$ analyzer used for testing is a Rosemount Model 955 chemiluminescent analyzer, which can measure $\mathrm{NO}_{\mathrm{x}}$ concentrations in ranges of 10, 25, $100,250,1000,2500$, and $10000 \mathrm{ppm}$. The analyzer is capable of detecting the concentration of $\mathrm{NO}$ or $\mathrm{NO}$ and $\mathrm{NO}_{2}$ together, which is commonly referred to as $\mathrm{NO}_{\mathrm{x}}$. When measurement of $\mathrm{NO}$ is desired, the sample $\mathrm{NO}$ is converted into $\mathrm{NO}_{2}$ by gas-phase oxidation with molecular ozone $\left(\mathrm{O}_{3}\right)$. During this reaction, about $10 \%$ of the $\mathrm{NO}_{2}$ becomes electrically excited, followed by an immediate return to the non-excited state. This phenomenon is known as photon emission. A photomultiplier tube is used to detect the photon emission quantity, which is proportional to the amount of NO present in the sample. For the detection of $\mathrm{NO}_{\mathrm{x}}$, the sample is first passed through a $\mathrm{NO}_{\mathrm{x}}$ converter that converts the $\mathrm{NO}_{2}$ into $\mathrm{NO}$, which is then measured in the same manner as previously described. If the determination of NO concentration only is desired, the sample can bypass the converter and be measured directly by selecting the NO mode of the analyzer. 
In the case of $\mathrm{NO}_{\mathrm{x}}$ detection, the total analyzer response would determine the amount of NO present in the original sample, as well as the NO created through the dissociation of $\mathrm{NO}_{2}$ in the converter. $\mathrm{A} \mathrm{NO}_{\mathrm{x}}$ efficiency tester made by the Beckman Co. is used to ensure that the converter in the Model $955 \mathrm{NO}_{\mathrm{x}}$ analyzer is operating above $90 \%$ converter efficiency, as is mandated by the CFR 40, Part 86, Subpart N [20].

\subsubsection{Hydrocarbon Analyzer}

The Rosemount Model 402 Heated Flame Ionization Detector (HFID) analyzer is used for the determination of hydrocarbon emissions. The counting of the elemental carbon atoms in the sample is used to determine the amount of hydrocarbon levels in the exhaust stream. The sample gas flow is regulated and flows through a hydrogen/helium fueled flame that causes the production of ions. These ions are collected with polarized electrodes in the analyzer. This absorption of ions by the electrodes produces a current flow in the analyzer's measurement circuitry, which is quantified and related to the number of carbon atoms contained in the sample. The measurement range of the Model $402 \mathrm{HC}$ analyzer is up to $250,000 \mathrm{ppm}$ with a linear full-scale output. A multiplier switch located on the front of the Model 402 allows selection of measurement ranges to achieve the best resolution for the gas concentration being sampled.

\subsubsection{Carbon Monoxide/Carbon Dioxide Analyzers}

The concentrations of $\mathrm{CO}$ and $\mathrm{CO}_{2}$ are determined with Horiba AIA-210 LE and Rosemount Model 868 analyzers respectively. Both of the analyzers utilize NDIR technology for gas measurement. An NDIR analyzer operates using the principle of infrared light absorption. In its simplest form, the NDIR analyzer uses the fact that a particular gas will absorb a certain wavelength of light somewhere within the infrared 
spectrum, with the other spectral wavelengths still being able to transmit through the gas. The analyzer detects the amount of infrared energy able to pass through the sample gas and uses it in the determination of the amount of the measured absorbent gas in the sample stream. An NDIR analyzer does not produce a linear output, so calibration curves are generated for the analyzers before each testing session. The range of the $\mathrm{CO}_{2}$ analyzer is from $0-5 \%$ and from $0-20 \%$. The range of the $\mathrm{CO}$ analyzer is $0-25 \mathrm{ppm}$ to $500 \mathrm{ppm}$.

\subsubsection{Particulate Sampling System}

The mass emission rates of particulate matter were determined by sampling total particulate matter emissions and performing a gravimetric analysis. Total particulate matter is defined as the material collected on a specified filter medium after diluting exhaust gases to a temperature of less than or equal to $125^{\circ} \mathrm{F}$. Diesel PM consists of primarily carbon, condensed hydrocarbons, sulfates, metal from engine wear, and associated water.

The particulate sampling system housed at the EERL incorporates a secondary dilution tunnel to provide a double dilution, proportional-sampling method for particulate matter collection and analysis. This system draws a diluted exhaust sample from the sampling region of the primary full-flow dilution tunnel into a secondary dilution tunnel. The flow rate through the secondary dilution tunnel is maintained by mass flow controllers throughout the emissions test in order to draw a proportional sample across the length of the test. Dilution in the second tunnel is adjusted to the amount necessary to reduce the face temperature of the sample filter to less than $125^{\circ} \mathrm{F}$. The amount of PM emitted by the engine during a test cycle can then be determined with a gravimetric 
analysis. The PM sampling system was designed to reduce thermophoretic losses of particulate matter.

In detail, the PM sampling system draws the diluted sample through a 0.5 in. diameter transfer tube, $7 \mathrm{in}$. in length, which links the secondary dilution tunnel to the sampling region of the primary dilution tunnel. The secondary dilution tunnel is constructed exclusively of stainless steel and is $3 \mathrm{in}$. in diameter and approximately $30 \mathrm{in}$. long. The secondary tunnel was designed in order to provide a sufficient residence time to allow the exhaust to thoroughly mix with dilution air to cool it to the desired $125^{\circ} \mathrm{F}$ standard. The sample flow exits the secondary tunnel and passes through a stainless steel filter holder that contains two (a primary and a secondary) Pallflex 70mm Model T60A20 flourocarbon-coated glass microfiber filters used for maximum PM extraction from the sample stream. The total secondary dilution flow is maintained by two Gast Model 1023101Q-583X rotary vane pumps each governed by a single Sierra 740-L-1 mass flow controller. The total possible flow through this system is 0-6 scfm with $0-3 \mathrm{scfm}$ maximum dilution air able to be injected. The Sierra mass flow controllers are routinely recalibrated by the manufacturer and additionally checked with a Merriam Instruments laminar flow element (LFE) rated at 0-8 scfm.

A controlled environmental chamber, maintained at $50 \% \mathrm{RH}$ and $70^{\circ} \mathrm{F}$, is used to condition filters before and after sampling. The filters are weighed before and after each test in a calibrated Cahn C-32 microbalance that has an accuracy of .1 $1 \mu \mathrm{g}$. The balance is recalibrated periodically during filter weighing to ensure measurement consistency. The difference in pre-test and post-test weights of the filters is then equated to total PM emissions. 


\subsubsection{Fuel Metering System}

In order to create accurate exhaust dilution ratios, it is necessary to determine total tunnel flow rates and engine exhaust mass flow rates. The total tunnel flow rate is determined with the CFV-CVS system, as described earlier. The determination of raw exhaust mass flow rates presents a problem in that there are a number of factors that inhibit a direct measurement of the exhaust flow rate, such as engine backpressure limits, high temperatures, and high particulate matter concentrations. An alternative approach to estimating exhaust mass flow rate is to use the intake airflow rate along with engine fuel consumption rate to calculate the exhaust flow.

The fuel consumption rate is accurately metered and monitored with a Max Flow Media 710 Series Fuel Measurement System. The fuel supplied to the engine is first drawn from the storage tank through a filter and into a vapor elimination device that maintains a constant pressure of $30 \mathrm{psi}$ with the system's transfer pump. The fuel then encounters a bypass system where excess supply fuel is routed via a pressure regulator through a heat exchanger and back to the storage tank. The heat exchanger uses the bypass supply fuel to cool the engine return fuel. Fuel that is not returned to the tank enters a Model 214 piston-displacement flowmeter. From there the metered fuel supply enters a level-controlled tank. In this tank the metered fuel is mixed with the unused engine return fuel that has been cooled by the internal heat exchanger. The volume of the tank is kept constant, so the fuel used by the engine is equal to the amount of metered fuel entering the tank during a given test period. The fuel is drawn from the tank with a secondary fuel pump in order to increase the pressure of the fuel to the operating levels required by high-pressure diesel injection systems. A bubble detector eliminates any 
vapors in the system by controlling a solenoid valve that connects the engine's supply and return lines. The removal of any vapor bubbles in the system is necessary to prevent any engine performance problems or metering inaccuracies. After exiting the solenoid valve, the fuel enters an external heat exchanger that maintains a constant fuel temperature with cooling water and a Fuji Model 223-1806 temperature controller.

\subsubsection{Intake Air Flow Measurement}

An LFE manufactured by Meriam Instruments, Model 50MC2-6, is used for quantification of intake airflow rates. This LFE measures 6 in. I. D. on the input and output, and is capable of flowing a maximum of $1007 \mathrm{cfm}$ at 8 in. water pressure. The LFE is made up of a series of small capillary tubes oriented parallel to the direction of airflow. The purpose of the capillary matrix is to remove turbulence and produce a laminar flow. A pressure drop is created in the LFE from the friction of the air passing through the tiny capillaries. Meriam Instruments supplies a calibration equation and coefficients that are unique to each LFE unit. Meriam determines these coefficients with a flow meter that is traceable to NIST standards. The absolute temperature and pressure upstream of the capillary matrix and the pressure downstream of the matrix are the only parameters needed for volume flow determination. The equation used for this calculation is:

$$
\underset{\text { Actual }}{\dot{V}}=\left[B \times(\Delta P)+C \times(\Delta P)^{2}\right] \times\left(\frac{\mu_{\text {std }}}{\mu_{\text {flow }}}\right)
$$

Where,

$$
\underset{\text { Actual }}{\dot{V}}=\quad \text { volume flow rate of air through LFE }
$$




$$
\begin{array}{lll}
\mathrm{B} & = & \text { coefficient supplied by Meriam Instruments } \\
\mathrm{C} & = & \text { coefficient supplied by Meriam Instruments } \\
\mu_{\text {std }} & = & \text { standard kinematic viscosity } \\
\mu_{\text {flow }} & = & \text { actual flow kinematic viscosity } \\
\Delta P & = & \text { differential pressure across LFE }
\end{array}
$$

A correction factor is used to account for viscosity variations and is as follows:

$$
\text { CorrectionFactor }=\left(\frac{529.67}{459.67+T\left({ }^{o} F\right)}\right) \times\left(\frac{181.87}{\mu g}\right)
$$

Equation 10

Where,

$$
\mu g=\frac{14.58+\left(\frac{459.67+T\left({ }^{o} F\right)}{1.8}\right)^{1.5}}{110.4+\left(\frac{459.67+T\left({ }^{o} F\right)}{1.8}\right)}
$$

These parameters are measured with an Omega PX653-10 DSV differential pressure transducer, a Viatran 1042 ACA absolute pressure transducer, and a RTD. A butterfly valve is used to set the manufacturer recommended intake restriction for each engine.

\subsubsection{Engine Dynamometer}

The dynamometer used to apply load to the engine in laboratory is a General Electric model DYC 243, fan-cooled, direct current dynamometer. This device is capable of absorbing a $550 \mathrm{hp} \mathrm{load} \mathrm{or} \mathrm{producing} 500 \mathrm{hp}$ to "motor" an engine. Torque is inferred from the force measurement of a load cell attached to an arm of known length holding the motor in the rotational axis of the driveshaft. This cell is calibrated by hanging known 
weights from an arm of known length mounted opposite to the cell so as to provide tension in the cell equal to the span values of force reachable by the dynamometer. Engine speed is recorded with an internal digital speed encoder. The dynamometer attaches to the engine flywheel using a driveshaft, and a bonded-rubber coupling link, which provides dampening.

\subsubsection{Instrumentation Control / Data Acquisition}

All laboratory data collected during the testing undertaken in this study was acquired using software and hardware previously developed and installed in the WVU EERL. The laboratory uses an RTI-815F data acquisition board for data collection as well as rack-mounted, Analog Devices Model 3B signal conditioning units. All data is recorded in $\mathrm{ADC}$ codes and later converted to the proper engineering units with a reduction program developed in-house at WVU.

\subsection{Test Specifications and Methods}

This section describes the testing procedures used to collect emissions data from the vehicles tested during this study. Also included herein is information on preliminary testing performed to qualify the test equipment before it was used for in-field engine exhaust emission measurements.

\subsubsection{In-field Testing Procedures}

The following is a description of the in-field test cycles and procedures exercised on the off-highway vehicles used for this study. 


\subsubsection{Excavator Test Cycle}

Data for the operation of the excavator was collected while it performed specified earthmoving activities that simulated the most common uses of this vehicle. The in-field test site is located in Star City, WV. Three primary operations were performed: stationary digging/backfilling, tracking/hauling, and trench digging. Stationary digging involves digging from the dirt removal area, swinging the boom to another location, and dumping the dirt into a pile. Backfilling is the opposite procedure, and the bucket may be used to compress the dirt as it is placed back into the area from which it was removed. A tramming/hauling operation is performed when the excavator is moved in order to transport dirt from one location to another that is not within the reach of the boom. Trenching/digging is an operation by which a line of dirt is removed, with the removed dirt placed near the trench for ease of backfilling. In this operation, the bucket digs out the desired amount of material, dumps near the edge of the trench, the machine tracks to the next position and the process repeats. Several repeats of each test were exercised to determine repeating trends in each operation. Due to the inability for any person but the operator to safely ride the vehicle while in operation, test equipment had to be checked and calibrated between tests. Once the trends of each operation were determined, the testing cycle was modified to include three ten- minute sections of each operation. This test design was repeated for QC/QA measures, and designated as the cycle that would be recreated once the engine was in-laboratory. In-field emissions data can be found in Section 4.3.

\subsubsection{Track-type Tractor Test Cycle}

The tractor tested in this study is used to remove overburden from coal seams after it has been blasted from the high-wall, and then to recover the area after coal has been 
extracted. The average duty cycle involves starting from one side of a pit, pushing down into the center and then up the other side of the pit removing earth at a rate of 30-40 cubic yards per cycle. The tractor then reverses and repeats the removal process. Occasionally when sandstone has not been sufficiently demolished by blasting, a ripper is used to move large rocks that cause the tractor blade to skip over an area and not remove the desired amount of material. In recovery operations, the tractor pushes the pile of material removed to expose coal back into the pit. As the job is completed, the tractor sculpts the landscape to designed parameters. For the in-field testing data recorded during this study, the tractor was only used to remove overburden, and was not employed for landscape recovery. As the engine could not be removed and tested in laboratory, the test cycle was determined by operator tendencies and the amount of material being moved by the tractor. The EPA has published normalized test cycles for off-highway equipment that may be fitted to any off-highway engine that is used in the particular vehicle class. The normalized load and speed set-point cycle for crawler tractors is shown in Figure 22 


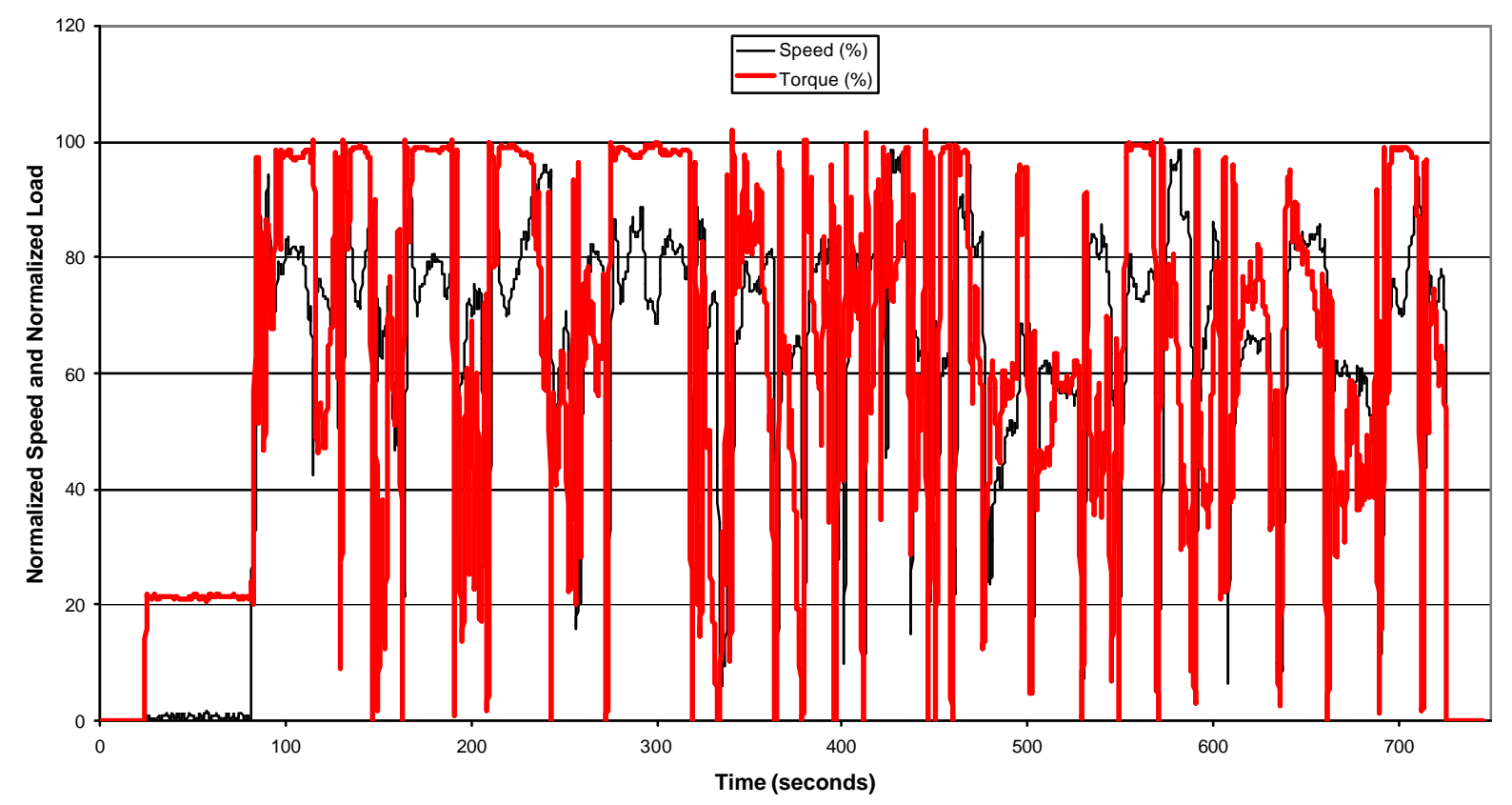

Figure 22 EPA Crawler Tractor Normalized Speed and Load Set-point Cycle

Recreation of this cycle as the tractor operated in- field would have been rather impossible. In lieu of not being able to recreate this cycle, the data collected from the field testing is compared to this cycle in the discussion section of Chapter 4.

Prior to testing, the engine oil, and the oil, fuel, and air filters were changed as part of routine maintenance. The exhaust stack caps were removed so that exhaust flow measurement devices could be affixed to the stack. The Caterpillar inlet air pre-filter system was disabled prior to testing the vehicle, due to its inherent entrainment of excess ambient air into the exhaust stream. This technique would have invalidated the PM concentrations that were sampled from a slip-stream, since an accurate account of exhaust dilution air amounts could not have been readily obtained. Due to proprietary issues, a Caterpillar representative was on site to collect engine speed and power data from the engine controller. The WVU MEMS is capable of interrogating engine control 
units that broadcast public information data streams, but this particular Caterpillar system did not operate according to these standardized communication protocols. Therefore, the WVU system could not parse the collected data stream. WVU could have undertaken the task, but representatives from Caterpillar were unwilling to provide WVU with the requisite ECU interface tools. The information collected here would be useful in calculating engine load and thus the duty cycle, and to provide a check on the emissions analyzers. Engine speed was recorded directly from a magnetic pickup. The signal was divided between the Caterpillar ECU interface, the MEMS gaseous emissions system, and the MARI RPM100. This common data stream provided for necessary time alignment information. The emissions testing equipment was securely mounted to the external surfaces of the dozer, and thus exposed to environment and vibration. Vibration damping material was used to protect against vibration and shock loading, and strainrelief was applied to sample lines and cables in order to reduce the likelihood of component failure. Heated sample lines were used to transfer the exhaust sample to the analyzers. Vehicle information pertaining to identification numbers and overall vehicle condition was also collected via manual inspection. Once all emissions testing equipment was secured and operational, the testing procedure began. The in-field emissions results can be found in Section 4.4.3.2.

\subsubsection{Laboratory Testing Procedures}

This section describes the procedures used to perform emissions testing on the Komatsu S6D125-1 engine in laboratory for the purpose of cycle recreation and 8-Mode testing. The engine was removed from the excavator in early summer 2001, and moved to the laboratory testing facility. Various small repairs and an extensive cleaning were 
performed before the engine was mounted onto the dynamometer test bed. The most significant of these repairs was to the turbo flange on the exhaust side as it had corroded away. This repair was necessary to eliminate the possibility of an exhaust leak for the determination of mass emission rates. The field testing was unaffected by these exhaust leaks as only concentration measurements of $\mathrm{CO}_{2}$ were made. The condition of this engine may be representative of a large number of off-road equipment owned by smaller businesses. A sampling port for the Sensor's measurement device was placed in the exhaust line at approximately the same distance downstream as was used in-field.

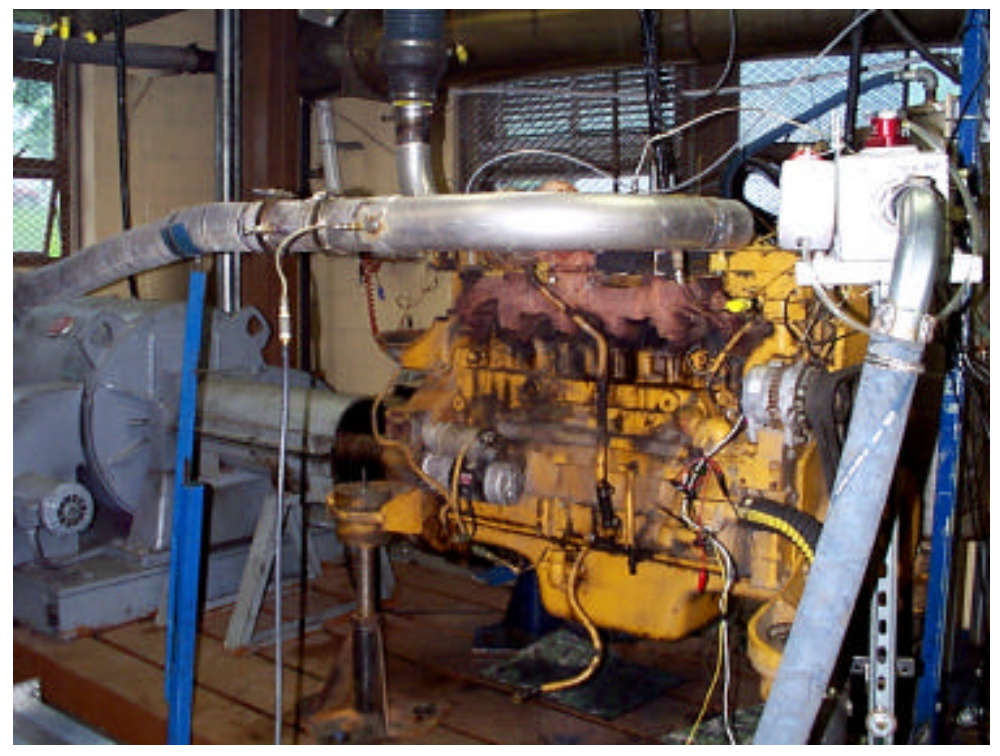

Figure 23 Komatsu S6D125-1 Engine Mounted on GE DC Dynamometer Test Bed

\subsubsection{Transient Test Operating Conditions}

The engine was operated according to a series of discretized engine maps in order to provide information regarding the specific dependence of $\mathrm{CO}_{2}$ emissions on engine load and speed. During these tests engine speed was increased in $100 \mathrm{rpm}$ increments from curb idle to maximum governed speed while raw $\mathrm{CO}_{2}$ emissions were recorded. 
Each of these operating points was held for 30 seconds in order to provide an asymptotic $\mathrm{CO}_{2}$ measurement. Three separate series of tests were performed in which the engine was loaded at 0,50 , and 100 percent of maximum torque at the given engine speed according to the engine maps. The data recorded from these $\mathrm{CO}_{2}$ maps were used to develop the first transient cycles using a simple linear interpolation from the previously collected in-field data.

Upon conference with CARB regarding vehicle activity, it was decided that three identified operations - digging/loading (cycle 1), transport (cycle 2), and trenching (cycle 3) - would be investigated as separate test cycles. By doing so, the emissions results and vehicle activity could be combined so as to be most representative of actual vehicles in a given study area. The continuous $\mathrm{CO}_{2}$ data from the first cycles was compared to the field data, and the iterative approach, similar to that discussed earlier in the report, was used to arrive at an acceptable correlation between laboratory and in-field data.

As another cycle comparative measure for insight into the methods used for development of transient dynamometer test cycles, the engine was exercised on a cycle derived from research performed by the EPA for excavator engines. A test cycle was developed using information published by the EPA. These tests were 30 minutes in length and encompassed a range of operations normally performed by this class of engine. Figure 24 shows the normalized set-points used to develop this cycle. 


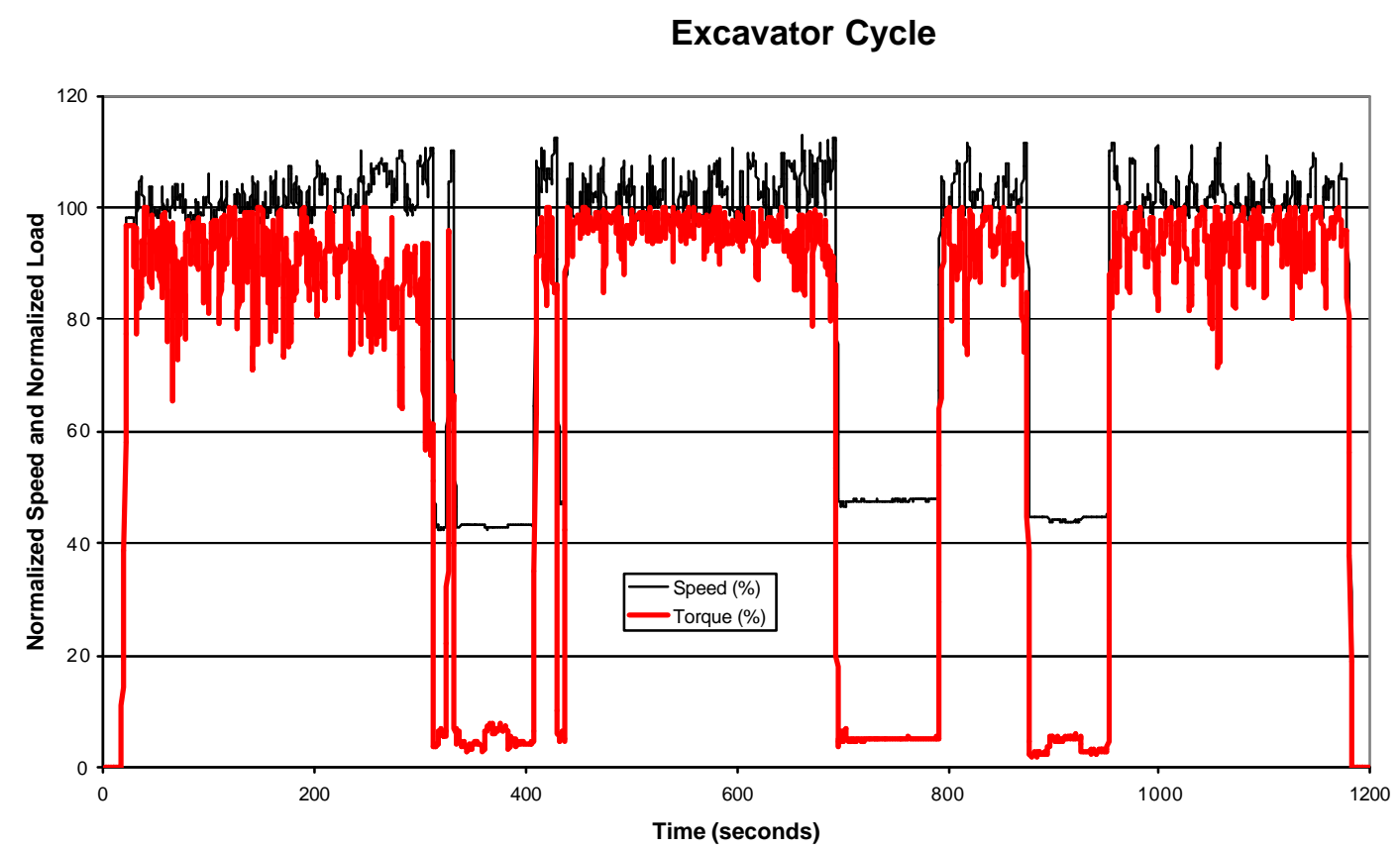

Figure 24 EPA Excavator Cycle Percentage Load Setpoints

\subsubsection{Steady-state Operating Conditions}

Steady-state tests were performed to provide data relative to the certification tests for off-highway engines. This data was compared to data collected from the transient test cycles. Table 3 shows the engine speed and load factors for the 8-Mode steady state test as well as the weighting factors that were used to produce the weighted 8-mode data given in Chapter 4 of this document. 
Table 3 ISO 8-Mode Cycle

\begin{tabular}{|c|c|c|c|}
\hline Mode Number & Engine Speed & $\begin{array}{c}\text { Load Factor } \\
\text { (Percent Load) }\end{array}$ & Weighting Factor \\
\hline $\mathbf{1}$ & Rated & 100 & 0.15 \\
\hline $\mathbf{2}$ & Rated & 75 & 0.15 \\
\hline $\mathbf{3}$ & Rated & 50 & 0.15 \\
\hline $\mathbf{4}$ & Rated & 10 & 0.10 \\
\hline $\mathbf{5}$ & Intermediate & 100 & 0.10 \\
\hline $\mathbf{6}$ & Intermediate & 75 & 0.10 \\
\hline $\mathbf{7}$ & Intermediate & 50 & 0.10 \\
\hline $\mathbf{8}$ & Idle & 0 & 0.15 \\
\hline
\end{tabular}

\subsubsection{MEMS System Qualification for In-field Testing}

This section describes the procedures used to prepare the MEMS System and the MARI RPM 100 for the field testing of the Caterpillar D-11R CD. Many considerations involved preparing the emissions equipment to provide quality data in the extreme environment in which the tractor operates. The vehicle operates in an environment that tests the reliability and durability of any equipment, for example the vehicle itself is designed to withstand $10 \mathrm{G}$ vertical loadings. As the dozer removes material, it digs through layers of sandstone that cause substantial amounts of vibration. High levels of dust become airborne as the dozer moves material. The climate of the area is also very extreme with high wind s, inclement weather, and extremely cold temperatures. The weather on the day of the test was windy with brief scattered rain showers and temperatures around $40^{\circ} \mathrm{F}$.

\subsubsection{Exhaust Stack Sampling Section Design and Qualification}

In order to collect emissions information from the Caterpillar D-11R CD in a nonintrusive manner that would not cause irreversible changes to the tractor, a small section 
of pipe, that housed all emissions sampling probes and the Annubar ${ }^{\mathrm{TM}}$ flow measurement device, was built and tested. The size of the test section tested the accuracy limits of the flow measurement device, so a series of flow tests were performed to determine the effects of the flow section on flow measurement. The test setup fed compressed air through an intercooler to avoid excessive temperatures. After being cooled, the air continued through a venturi upstream of the test section and a Laminar Flow Element downstream of the section to compare the flow rates registered by all devices under the same flow. Temperature was recorded upstream and downstream of the devices to compensate for its effects on flowrate. Due to the high winds and a desire to keep the weight of the test section at a minimum, various configurations involving placement of the Annubar ${ }^{\mathrm{TM}}$ device with respect to entrance and exit of the test section were evaluated in order to shorten the test section to the minimum acceptable length that would not distort flow measurement. The exhaust stack on the D-11 R CD has a three lobed venturi that it uses to create vacuum for the cleaning of dust from the primary intake filter screens. A stack section was also placed upstream of the test section in order to investigate the possibility of wake effects that may distort flow measurements.

Once this testing was completed and a suitable test section, shown in Figure 25, was developed, the exhaust section and the test section were placed in the exhaust line of a Detroit Diesel Corporation D-60 series 12.7 liter engine that was mounted on the dynamometer test cell at the WVU EERL. The characteristics of this engine were believed to mimic the exhaust flowrates of one exhaust stack on the Caterpillar 3508 engine in the D-11 R. A transient test cycle, that was designed to mimic the cycle performed by the dozer, was developed and repeated several times such that the MEMS 
system could be compared to laboratory grade analyzers using the test section setup for the in-field testing.

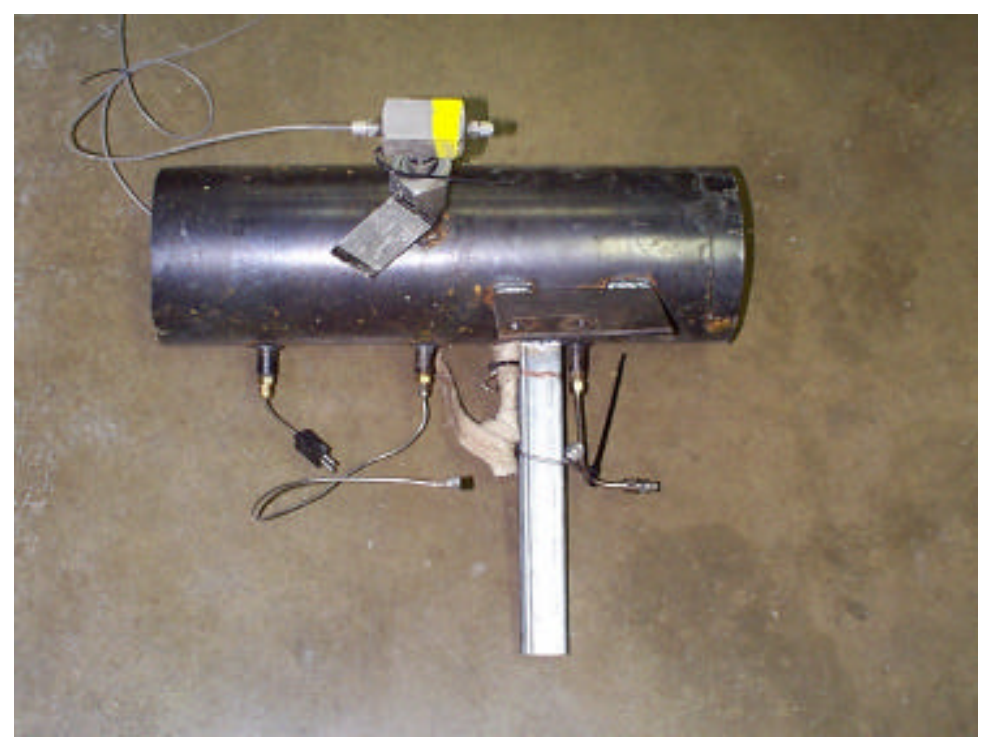

Figure 25 Test Section for Track-type Tractor In-field Testing

The testing results indicated that measurements were inaccurate at higher flow rates. These errors were attributed to the wake effects created by the exhaust venturi, which affected the Annubar ${ }^{\mathrm{TM}}$ pressure readings, and therefore induced a $20 \%$ error in the calculated flow rate and the mass emission rates of $\mathrm{CO}_{2}$ and $\mathrm{NO}_{\mathrm{x}}$. In order to combat this problem, tests were performed to determine correction coefficients that could be applied to the Annubar ${ }^{\mathrm{TM}}$ flow rate calculations. The engine was operated at steady-state setpoints for sufficient time to stabilize the pressure readings, and the gaseous emissions concentrations were measured with the MEMS. The calculated mass emissions rates were compared to those recorded by the full-flow dilution tunnel and laboratory emissions analyzers. The Annubar ${ }^{\mathrm{TM}}$ flow rate equation coefficients were adjusted accordingly in order to provide adequate correlation. After these correction factors were 
applied, emissions measurements were again performed, and the MEMS data were compared with data gathered by the laboratory's full-flow dilution tunnel.

Emissions data collected from the dozer cycle test using the MEMS System, the RPM 100, and the laboratory are presented below. Figure 26 shows the test cycle exercised on the D-60 engine while Figure 27 is included as a comparison of $\mathrm{NO}_{\mathrm{X}}$ mass emissions rates and Figure 28 compares $\mathrm{CO}_{2}$ mass emissions rates between MEMS and the laboratory analyzers. Review of Figure 26 shows that the dynamometer was operated in torque mode. Speed was set at a constant value near the speed at which peak power production of the Caterpillar 3508 occurs. The loading cycle was set to the best estimate of the nature of the cycle that would be encountered in-field. This cycle was used for the qualification of all equipment used for the in-field emissions testing of the track-type tractor. 


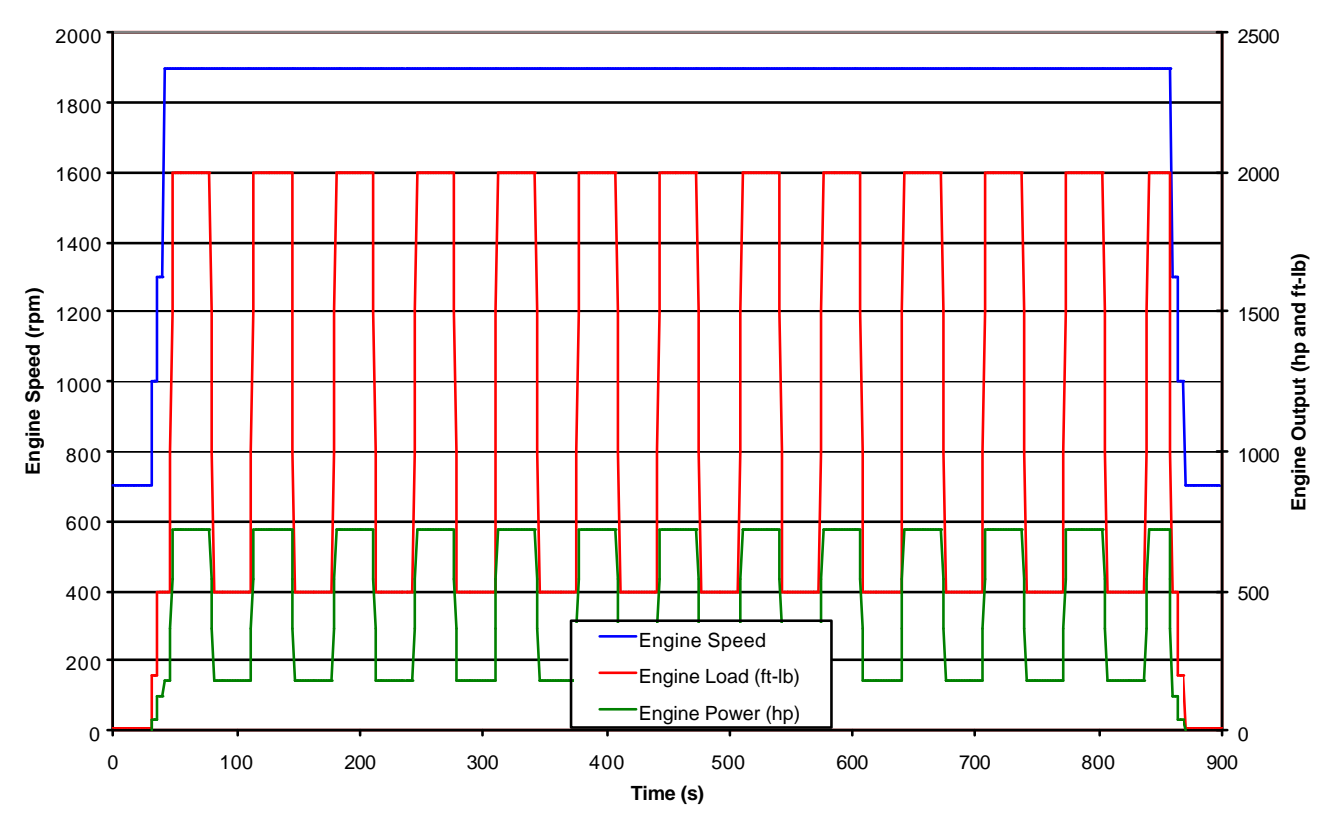

Figure 26 Dynamometer Test Cycle Designed to Evaluate the On-board Emissions

Testing System in the Laboratory

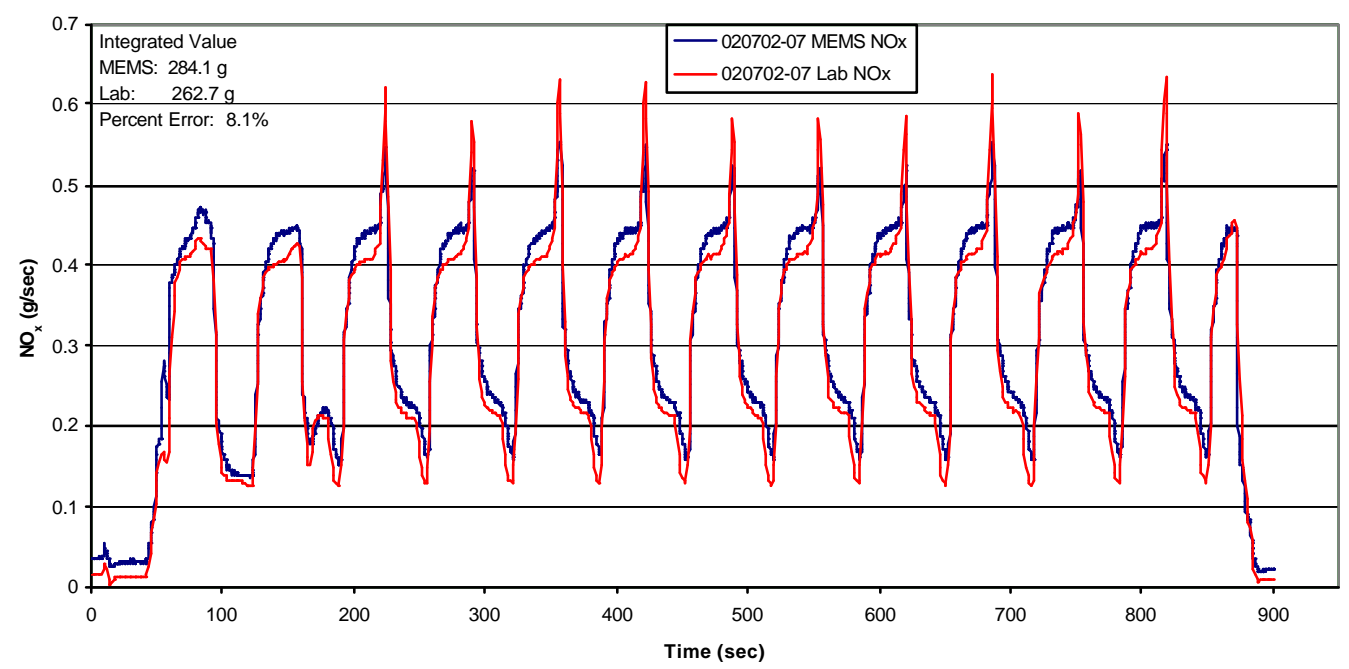

Figure 27 Comparison of Mass Emissions Rates of $\mathrm{NO}_{\mathrm{x}}$ over a Transient Cycle Designed to Mimic In-field Dozer Operation - MEMS Results and Laboratory Results 
Figure 27 shows the continuous $\mathrm{NO}_{\mathrm{x}}$ results from the lab qualification testing for the MEMS device. The continuous traces of the MEMS device closely match those recorded by the laboratory analyzer with small variances in peak values. Integrated results are also shown, and they are within $10 \%$ error.

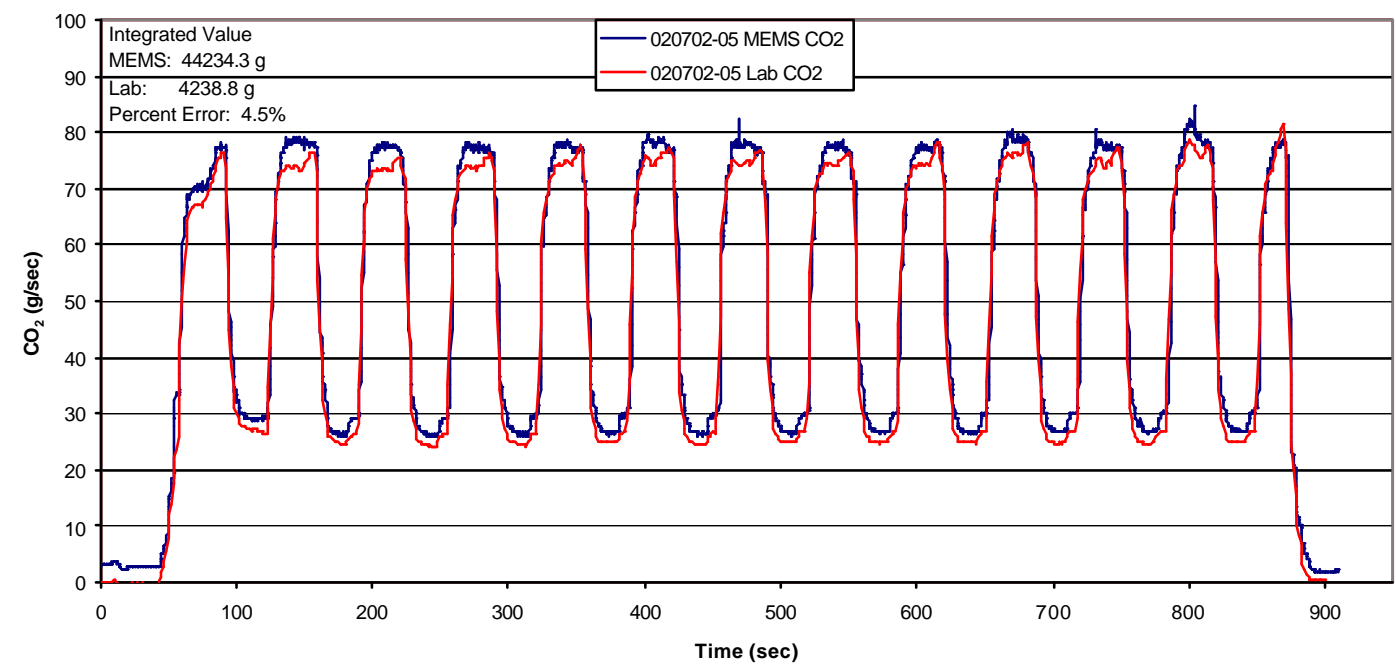

Figure 28 Comparison of Mass Emissions Rates of $\mathrm{CO}_{2}$ over a Transient Cycle Designed to Mimic In-field Dozer Operation - MEMS Results and Laboratory Results

Figure 28 shows the continuous $\mathrm{CO}_{2}$ results recorded by the MEMS and the laboratory analyzer during the qualification testing. The integrated results are within 5\% error.

\subsubsection{Preparation of MARI RPM 100 for In-field Testing}

Coinciding with the validation of MEMS equipment was the adaptation of the MARI RPM 100 for use as an on-board measurement system for off-road vehicles. As explained earlier, the RPM 100 provides for fully arbitrary control of the dilution of a slip-stream sample from the raw exhaust stream, and measures PM mass with a quartz 
crystal microbalance. The inherent system properties of compact size, robustness, and resistance to vibration made the RPM 100 well suited for on-board testing of the tractor. However, provisions had to be made to enclose the system in order to protect it from possible inclimate weather and less-than-optimal mounting locations. As a result, the system was mounted in an independent enclosure. In addition, modifications to the sample probe design were implemented in order to accommodate the anticipated exhaust pressures and flow rates that are characteristic of engines in the class used in the D11 R CD. When the dilution ratio, particulate concentration, and total engine exhaust flow rate are combined, engine-out particulate mass emissions rates can be calculated. The RPM 100 data was compared against the full-flow dilution tunnel laboratory. The total mass results in grams from the qualification testing performed on the RPM 100 using the Detroit Diesel Corporation D-60 series engine and the estimated dozer transient cycle are displayed in Table 4. It should be noted that the resultant error is an integration of all error sources in the emissions measurement system (raw exhaust flow rate measurements, mass measurements, inherent data acquisition errors, and general errors related to test procedures).

Table 4 Gravimetric PM Comparisons between the MARI RPM 100 and the Fullflow Dilution Tunnel (grams)

\begin{tabular}{|l|l|l|l|}
\cline { 2 - 4 } \multicolumn{1}{c|}{} & Test 01 & Test 02 & Test 03 \\
\hline MARI RPM 100 Integrated PM Mass & 0.74 & 1.97 & 1.73 \\
\hline $\begin{array}{l}\text { Full-Flow Dilution Tunnel Gravimetric Integrated PM } \\
\text { Mass }\end{array}$ & 0.71 & 1.75 & 1.79 \\
\hline Percent Difference (\%) & 4.2 & 12.6 & -3.4 \\
\hline
\end{tabular}

These results indicate that the RPM 100 can provide reliable PM data within $10 \%$ difference of gravimetric PM results. A problem was encountered with oxidation 
occurring from arcing between the tungsten electrode and the gold casing of the quartz crystal. This proved to be significant as the oxidation caused an increase in mass at a rate that skewed PM results. This was compensated for by recording 10 minutes of data before and after each emissions test in which clean air (ambient air drawn through a HEPA filter) was fed to the sampling system to determine the rates of oxidation buildup. 


\section{CHAPTER 4 - RESULTS AND DISCUSSION}

\subsection{Introduction}

The global objective of this study was to collect real-world activity data from offhighway diesel engine powered vehicles. In order to satisfy this objective, equipment modifications were made and methods were developed to collect high quality emissions data during in-field operation. Vehicles were tested in the condition they were found, with no modifications made to affect the engine performance or exhaust emissions. Manufacturer certified mechanics were employed to make any adjustments needed to accommodate emissions measurement equipment, and to remove the engine from the excavator for dynamometer testing. The data collected during this study was submitted to the California Air Resources Board in order to satisfy the project contract requirements.

This chapter is divided to separate the emissions results from the two vehicles. Emissions are presented in $\mathrm{g} / \mathrm{Bhp}-\mathrm{hr}$. Continuous sampling gas data is either presented in percent (volume) of span value or ppm. Additional test data is shown in the Appendix.

\subsection{Considerations Relative to In-field Emissions Measurement}

With the objective of this project being to provide emissions data relative to transient operation of the off-highway vehicles involved, and the lack of appropriate representative cycles for testing, it was necessary to determine in-field duty cycles in order to produce a cycle that accurately represented the actual operation cycle. Therefore a means of determining speed and torque of the cycle became an evident need. From testing done previously it had been established that engine speed and raw $\mathrm{CO}_{2}$ data can 
be used to infer torque within $5 \%$ error. This system was used for the testing of the 250 hp class excavator engine.

For the track-type tractor test, the engine size and power rating exceeded the available capabilities of the laboratory. As the engine was electronically controlled and fueling data was broadcast by the ECU, it was determined that load could be inferred from the engine speed and fuel consumption (given the appropriate fueling curve would be made available). A mobile emissions measurement device capable of producing continuous mass emissions data was utilized on this machine. An on-board PM measurement device was also used to provide realtime total PM emissions data from the actual in-field cycles.

Differences between the actual field testing and laboratory testing exist in the way that the exhaust sample is collected. In-field measurements are made from a sample of the raw stack exhaust. The laboratory uses a dilution system to mix clean air with the raw exhaust to simulate the effects of the exhaust entering the atmosphere. Laboratory emissions measurements can thus be affected by changing ambient conditions, such as operation of internal combustion engines within close range of the dilution tunnel inlet. Raw exhaust sampling suffers from higher concentrations of water and particulate matter that must be filtered to protect instruments from harm. These filters must be replaced frequently to avoid clogging. The other consideration is test repeatability. The electronically controlled laboratory dynamometer can usually reproduce a test cycle exactly. An operator in the field would find this to be nearly impossible to accomplish, therefore, larger differences are going to be seen during in-field test repeats largely due to this fact. 


\subsection{Excavator In-field Results}

The first test was a stationary digging operation in which the first half of the test was digging and the second half of the test was spent back-filling. This operation is common in construction situations like digging a basement, or burying a culvert or a storage tank. The continuous $\mathrm{CO}_{2}$ map from this test was used for the development of the first transient test cycle.

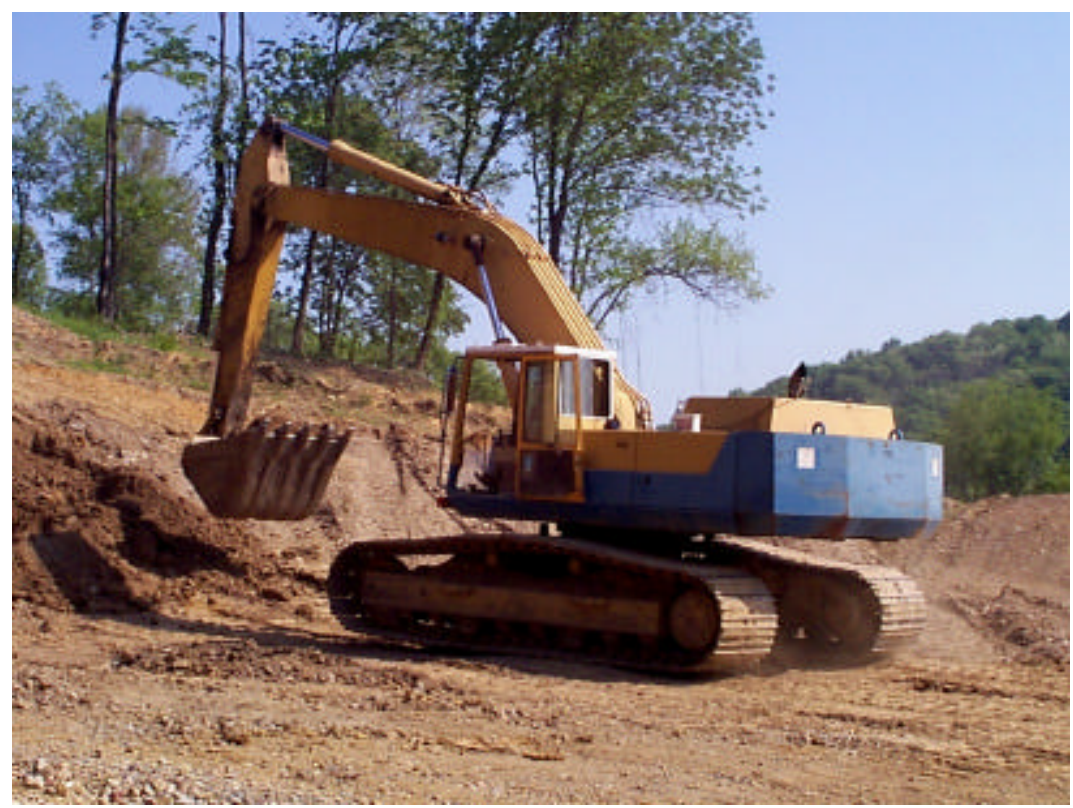

Figure 29 Excavator Digging Operation

The second test simulated hauling or tramming. A tramming/hauling operation is performed when the excavator is moved in order to transport dirt from one location to another that is not within the reach of the boom. The second test cycle was derived from this in-field activity. 


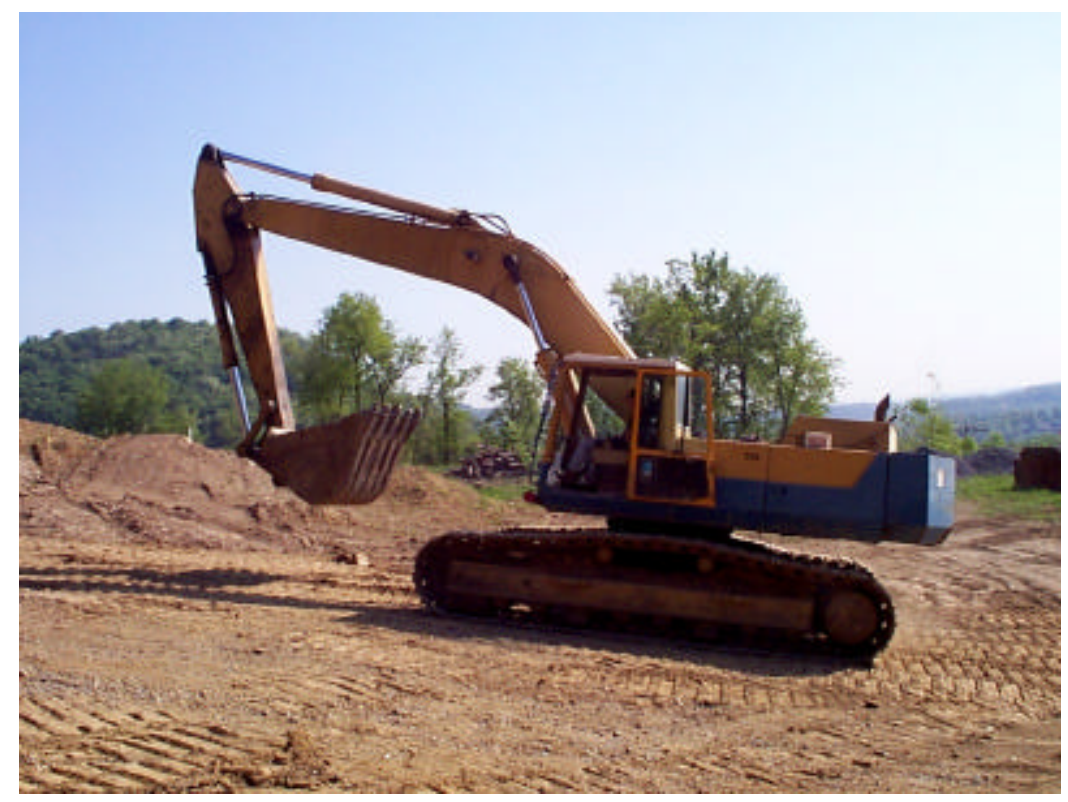

Figure 30 Excavator Hauling Operation

For the third test a trench was dug and then filled. This is probably the most common industrial use of the excavator. Trenching is used when cables or pipelines are to be buried and in digging building footers. Cycle three was developed from this data.

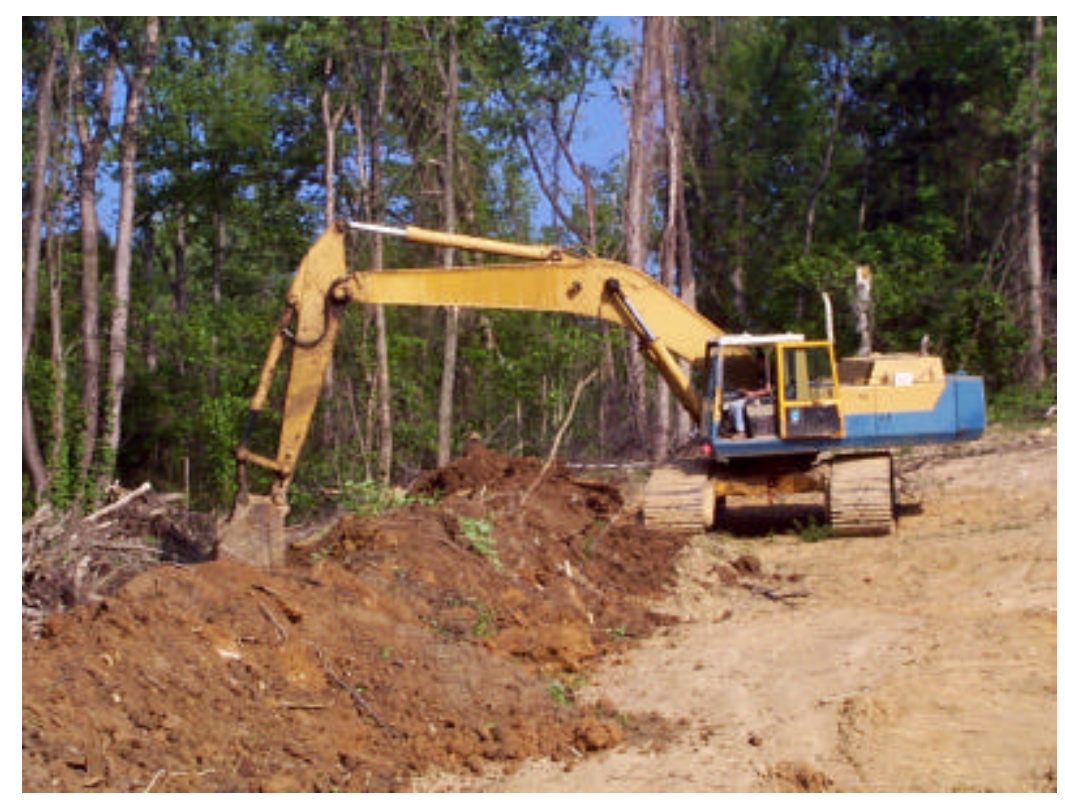

Figure 31 Excavator Trenching Operation 
Testing continued through early summer 2001. The three tests were combined into one operation for $\mathrm{CO}_{2}$ measurement. The final test of the combined cycles was used as the ultimate source for the laboratory test cycles. The test started with digging for ten minutes followed by hauling for ten minutes and finished with trenching for the last ten minutes. The following graph shows the $\mathrm{CO}_{2}$ levels recorded during this test.

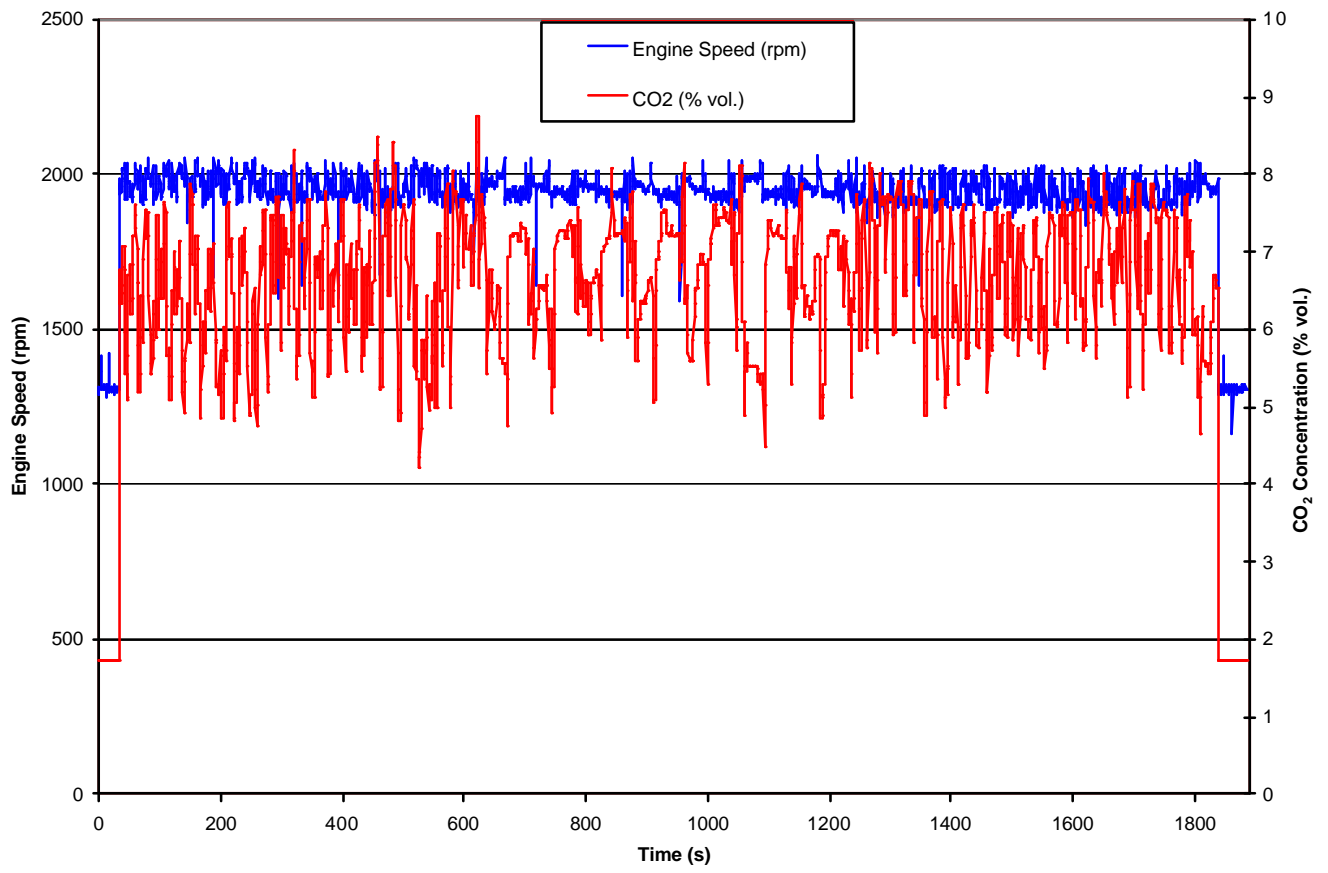

Figure 32 In-field Test Cycle

The first 600 seconds of this cycle are the digging cycle, the next 600 seconds are the hauling cycle, and the final 600 seconds are the trenching operation. The differences in the cycles are plainly visible in the nature of the speed and $\mathrm{CO}_{2}$ traces. Digging and trenching are two similar operations; therefore the characteristic engine speed and $\mathrm{CO}_{2}$ continuous emissions are nearly equivalent. These cycles are the result of testing performed with one machine and one operator, while this provided a control; it also limits the applicability of this data to other excavators. 


\subsection{Track-type Tractor In-field Results}

This section describes in detail the data collected from a Caterpillar D-11R CD Track-type Tractor with a 3508 engine as it operated in-field. The testing took place on the property of Buffalo Coal Corp. at a strip mine site designated as A34.

\subsubsection{Vehicle Instrumentation and Test Conditions}

The testing of the D-11R CD was performed in early 2002 and was performed infield only. The WVU MEMS system was employed to collect $\mathrm{CO}_{2}$ and $\mathrm{NO}_{\mathrm{x}}$ concentration levels as well as engine speed data, and information used to calculate exhaust flow rates. The MARI RPM 100 was used to collect particulate matter data. Modifications were made to the device to incorporate engine speed measurement such that PM data could be time aligned with MEMS data. Engine speed was recorded directly from a magnetic pickup. The signal was divided between the Caterpillar ECU interface, the MEMS gaseous emissions system, and the MARI RPM 100. 


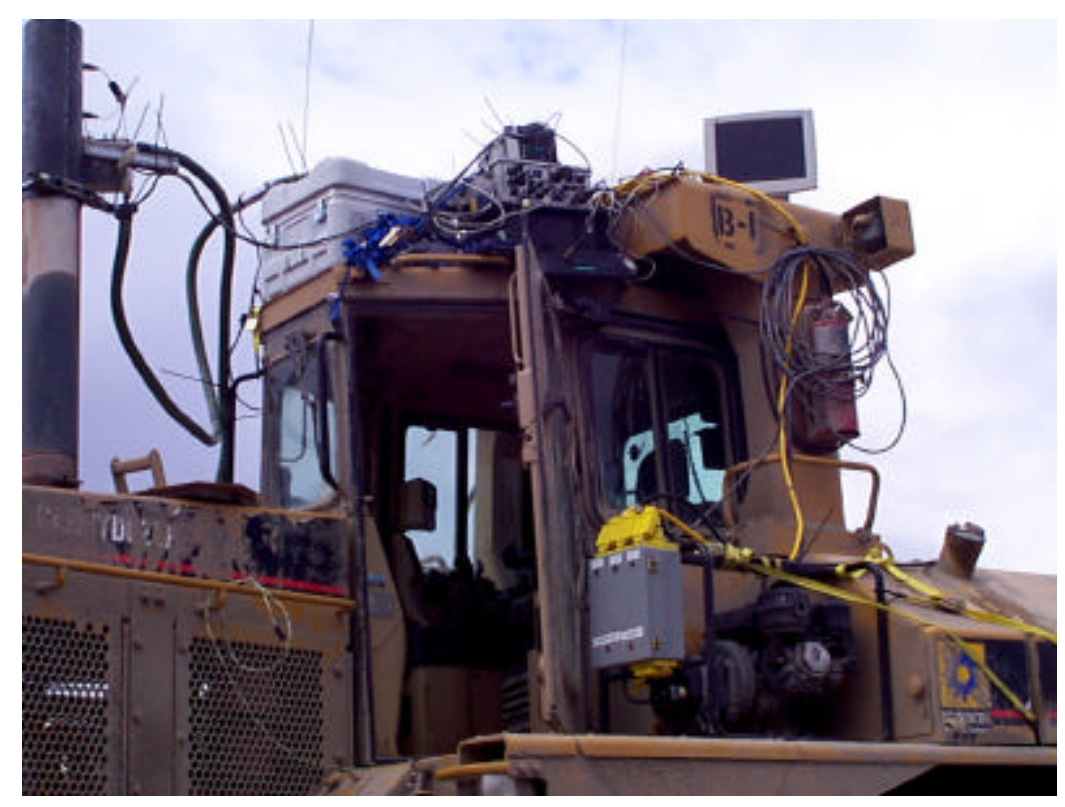

\section{Figure 33 Caterpillar D-11R CD Track-type Tractor with On-board Emissions Measurement Equipment}

Vibration damping material was used to protect against vibration and shock loading, and strain-relief's were applied in order to reduce the likelihood of component failure. Heated sample lines were used to transfer the exhaust sample to the analyzers. Vehicle information pertaining to identification numbers and overall vehicle condition was also collected via manual inspection. Once all emissions testing equipment was secured and operational, the testing procedure began.

\subsubsection{Testing Procedure}

The first test was a transport operation where the vehicle moved from the set-up site to the digging site. This operation was used as preliminary check of the emissions measurement equipment to ensure that it was functioning properly and mounted securely to the tractor. Once at the digging site, the emissions measurement system was calibrated. This procedure was also repeated between each test. As the test commenced, 
there was a short idle period, then the vehicle moved into the area from which material was to be removed. The digging operation consisted of pushing down from one side of a pit and pushing material across and piling it over the area where coal had been previously removed. When the operator reached a point where material had been sufficiently moved from the area, the vehicle reversed to the original starting point and pushed another load across the pit. This cycle repeats itself until the loose material is removed to the point where excavators and end loaders can finish the last removal of overburden and extract coal. During normal operation the vehicle will operate like this for 10 hours, after which the vehicle is refueled, lubricated, and inspected. The machine is usually stopped for one hour while this process takes place.

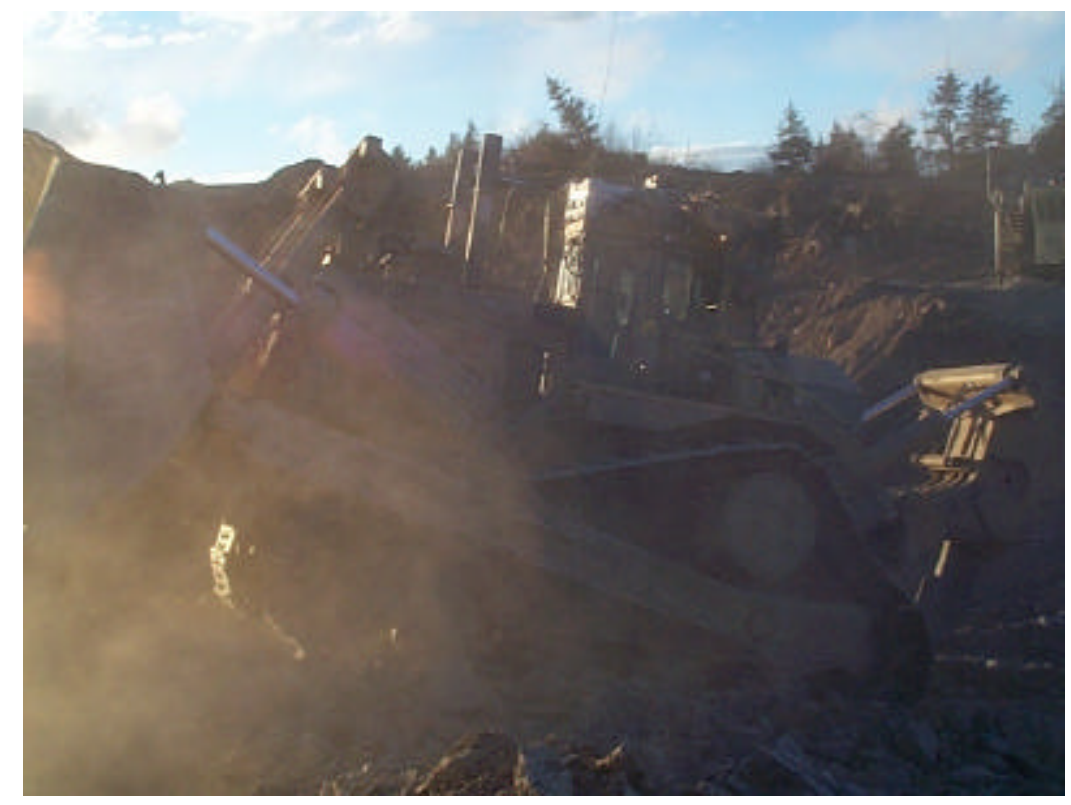

Figure 34 Caterpillar D-11R CD Track-type Tractor Operating with On-board Emissions Measurement Equipment

For the purposes of this testing, data collection was scheduled to coincide with operating cycles that were approximately 30 minutes in length. This test plan provided adequate cycle information, without risking the introduction of errors due to 
instrumentation drift, etc. In addition, it was anticipated that problems could be addressed without expending large amounts of time on voided tests. During the testing process, numerous problems were encountered that shortened the amount of data collected. Ultimately, a power generator failure, which was quickly rectified, and time scheduling constraints ended the in-field testing, but not before a sufficient amount of emissions data was collected.

\subsubsection{Emissions Test Results}

Due to engine size restrictions as well as reluctance of the vehicle's owner to modify the production exhaust system, the test plan was to measure the mass emissions of exhaust constituent emitted from the individual exhaust stacks. The Vee configuration and the exhaust system design, which incorporated an exhaust manifold equalization crossover, provided a means to independently measure the mass emissions from each stack. During the tests, each exhaust stack was outfitted with the short test sections in order to avoid significant backpressure differentials, and hence exhaust flow rate differences, between the two exhaust streams.

Mr. Pat Jones, from Caterpillar, installed a Caterpillar data-link and the unit was initialized to log the necessary engine speed and load information that is paramount to providing brake-specific mass emissions results. At the test-site it was indicated that the data collected using the data-link had been truncated. After further consultation during the week following the in-field tests, the researchers learned that Caterpillar would only be able to provide WVU with a limited amount of information that was recorded during the transportation of the tractor from the instrumentation set-up/tractor storage location to the actual mining test-site. It was originally decided that this operation would be used as 
a "shakedown" exercise; therefore no exhaust emissions data was collected. However, the data collected by Caterpillar is included in Figure 35. Since Caterpillar provided no engine loading information for the remaining tests, detailed brake-specific fuel consumption data was requested from Caterpillar, but due to its proprietary nature, this data was not released. As a result, the emissions data presented herein for the in-field testing of the D11R CD are in a mass-per-unit-time $(\mathrm{g} / \mathrm{s})$ basis.

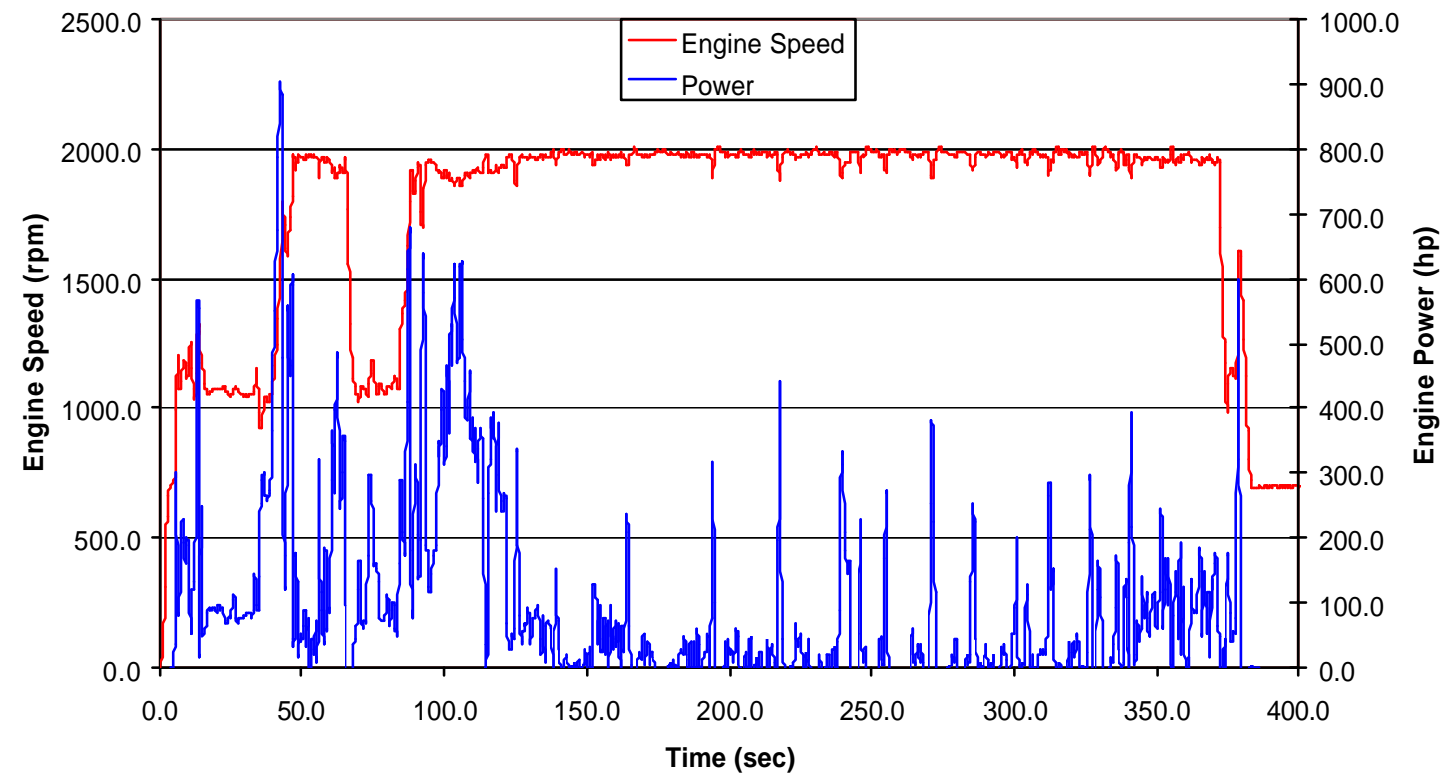

\section{Figure 35 Engine Speed and Power Data Collected by Caterpillar during Track- type Tractor Transport}

This figure shows the characteristics of transport mode. The engine operates at high idle and the loading is relatively low. The large spike at the 50 second mark indicates the point at which the blade was lifted. The smaller peaks along the test cycle are most likely the result of steering loads imposed as the dozer locks one track while the other continues motion. The cycle involved moving along a relatively level plane until about 125 seconds at which point the dozer started traveling down a grade into the mine 
pit. The engine seems also to idle at a higher rate when it is not warm as indicated by the engine idle speeds at the beginning and end of the test cycle.

\subsubsection{Gaseous Emissions Results}

The results presented herein were collected during the in-field testing of the D11R CD Track Type Tractor. Due to a data acquisition problem encountered during the first digging test, PM data was only collected for a portion of the full test. The gaseous results of this test have been presented in two formats. First the data is shown for the length of the test that PM data was collected such that integrated gaseous results can be compared to PM results. Secondly, the full gaseous test results are reported in their entirety. Figure 36 shows the full engine speed and raw $\mathrm{CO}_{2}$ data recorded by the MEMS during the first digging test, whereas Figure 37 illustrates the shortened results of the first digging test that coincide with the PM data collected during this test. Similarly, Figure 38 shows the full engine speed and $\mathrm{NO}_{\mathrm{x}}$ data as recorded by the MEMS during the first digging cycle, whereas Figure 39 illustrates the shortened version of these results that provide for comparison with PM results. The second test (a repeat of the operations from the first test) was performed after a zero/span verification of the emissions testing equipment. Figure 41 presents the continuous engine speed and $\mathrm{CO}_{2}$ results recorded by the MEMS during this second digging test, while Figure 42 shows the $\mathrm{NO}_{\mathrm{x}}$ results from this test.

\subsubsection{Particulate Matter Emissions Results}

Gravimetric PM data was collected during the tractor in-field operation, and PM data is presented for a 360 second portion of the first test. The operation consisted of approximately 260s of idle data, with the remainder of the test being comprised of 
transport and digging. Figure 40 presents the $\mathrm{NO}_{\mathrm{x}}$ mass rate $(\mathrm{g} / \mathrm{s})$ and $\mathrm{PM}$ concentration $\left(\mathrm{mg} / \mathrm{m}^{3}\right)$ for the test cycle. As stated earlier, since Caterpillar was unable to provide the necessary engine speed and load data, the data for the in- field tests are presented on a mass rate basis. As Figure 40 indicates, the integrated PM mass emissions for the test cycle (360 seconds long) were $0.349 \mathrm{~g}$. The engine speed spike near the 100 second mark of this test appears to be a noise anomaly that can be disregarded and has no real effect on the rest of the cycle. Note the corresponding $\mathrm{CO}_{2}$ and $\mathrm{NO}_{\mathrm{x}}$ dips during this time, which also ind icate that this period is to be considered an outlier. In the figures showing full test length, a few momentary spikes are observed that are most likely the result of noise or vibration. Again the engine idles at different speeds from the beginning to the end of the test, this is something that should be considered a design aspect of the engine, and is not reason for suspect of data logging equipment.

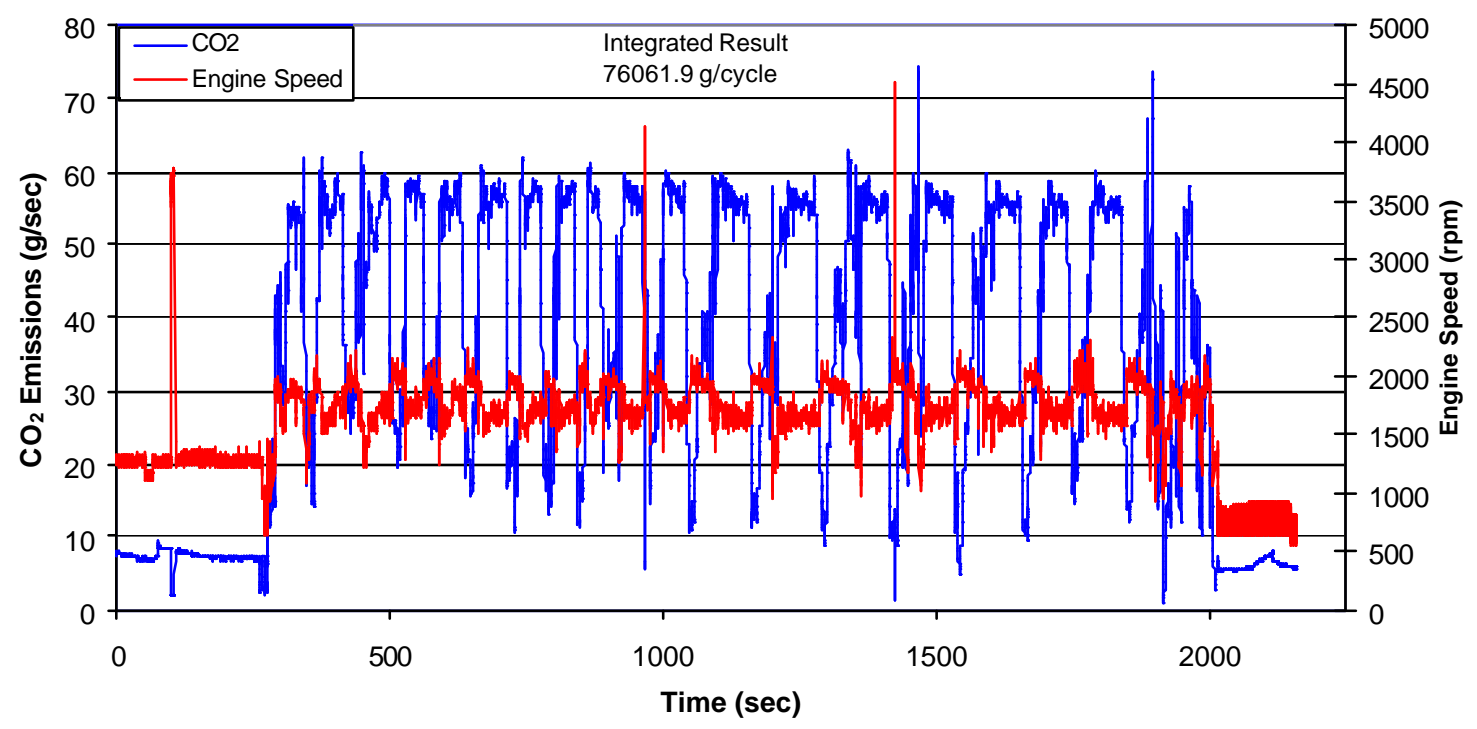

Figure $36 \mathrm{CO}_{2}$ Mass vs. Time for the First Track-type Tractor Test (Full Cycle) 


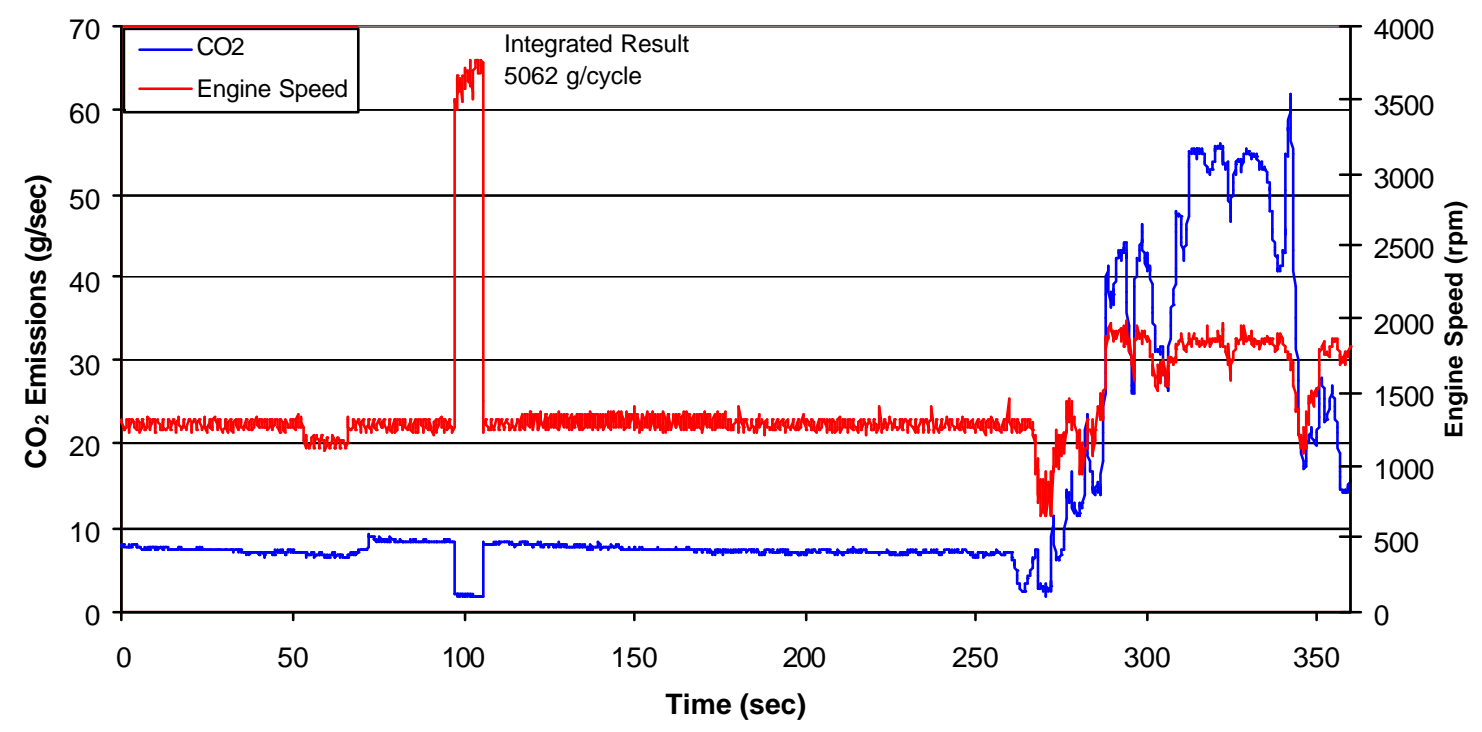

Figure $37 \mathrm{CO}_{2}$ Mass vs. Time for the First Track-type Tractor Test (Cycle Shortened to Coincide with PM Data)

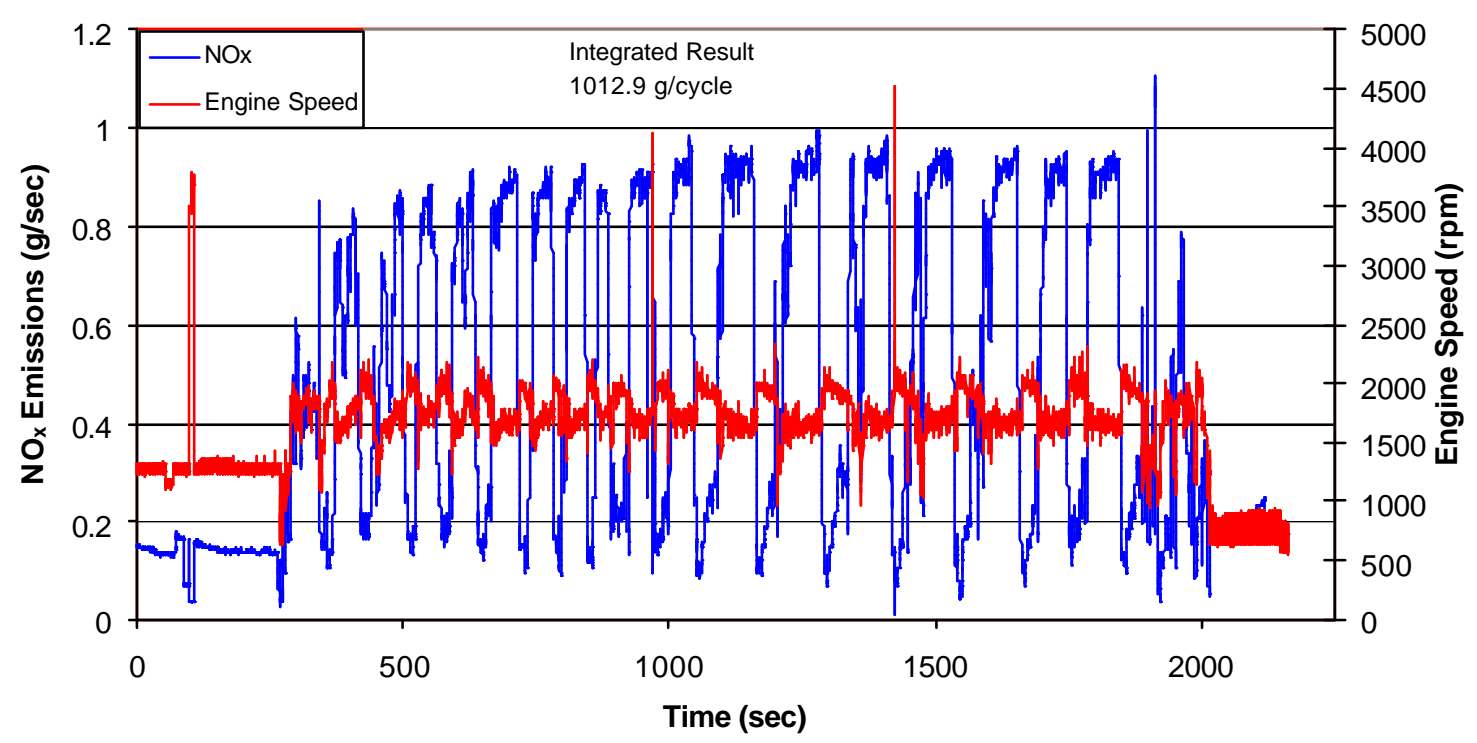

Figure $38 \mathrm{NO}_{\mathrm{x}}$ Mass vs. Time for the First Track-type Tractor Test (Full Cycle) 


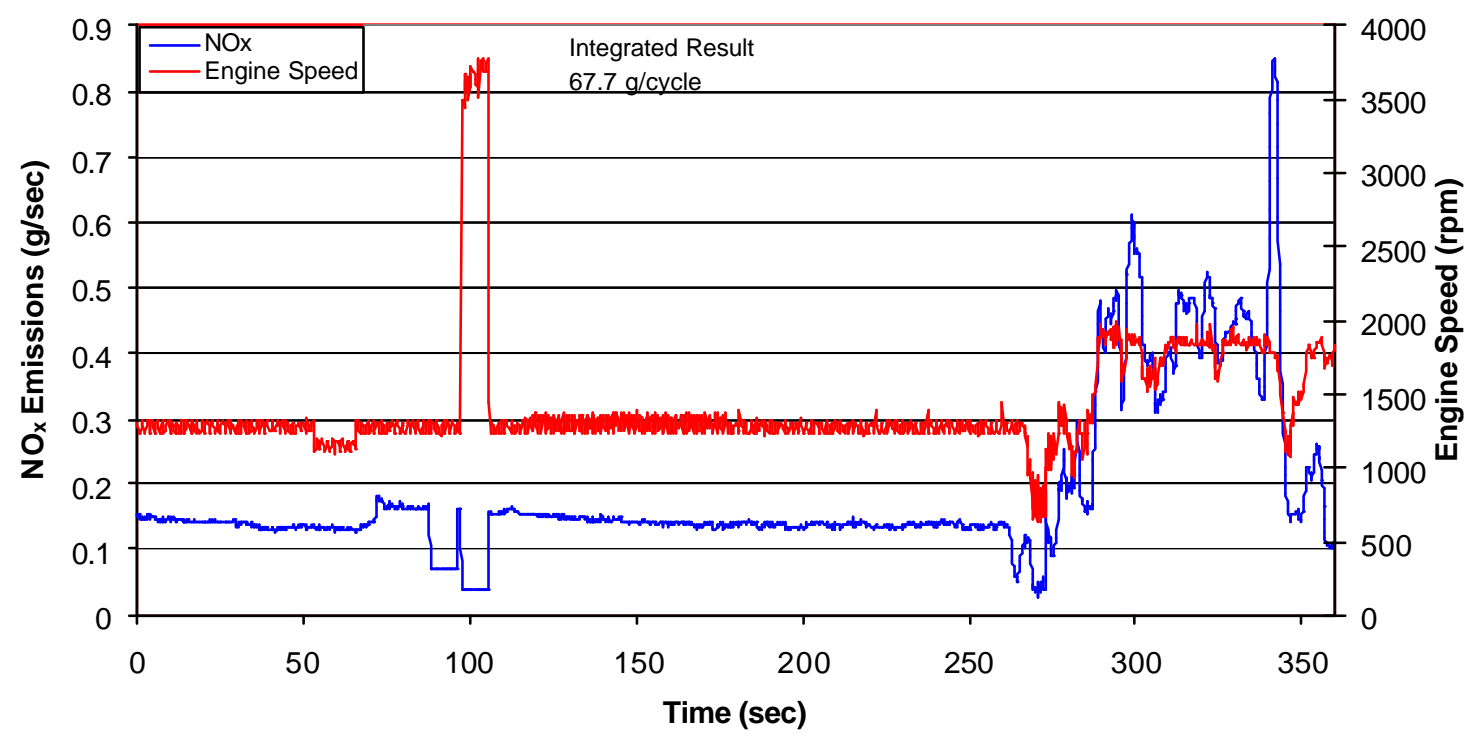

Figure $39 \mathrm{NO}_{\mathrm{x}}$ Mass vs. Time for the First Track-type Tractor Test (Cycle Shortened to Coincide with PM Data)

The periods of high engine speed indicate the transport of the tractor to the starting point, and the lower speed and higher emission peaks indicate the production run of the machine as it moves material across the pit. These figures illustrate that the duty cycle of the engine is very repeatable in nature. The initial cycle peak from idle, which occurs near 250 seconds, is the result of a transport up a steep grade over loose material as the tractor was moved into position to begin the first digging cycle. At the end of the test, the tractor was moved back down this grade to a point where the test equipment could be serviced and calibrated. 


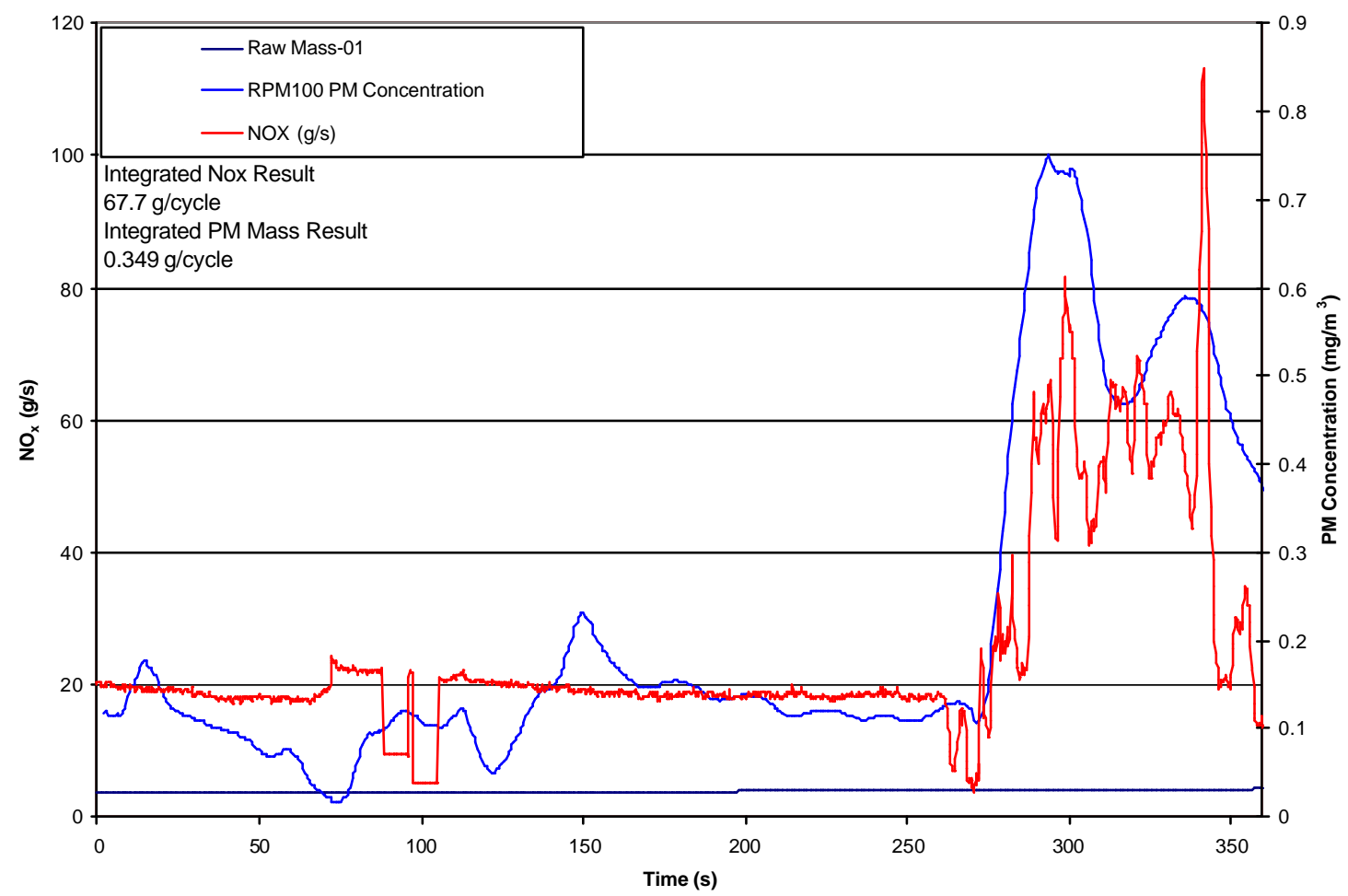

Figure $40 \mathrm{NO}_{\mathrm{x}}$ and PM Concentration Data for the First Track-type Tractor Test

The continuous PM concentration data is shown in Figure 40, the data of most interest starts at 250 seconds. The trend here shows a smooth increase in PM concentration with increasing engine speed and load, which is expected. The reasons that this curve appears smooth relative to the $\mathrm{NO}_{\mathrm{x}}$ data could be in the speed of data recording, or it may be due to the continuo us adjustments made by the RPM 100 to the sample, which dampen instantaneous effects. Over the entire cycle, the tractor produced 0.349 grams of PM that was recorded by the RPM 100.

After the first digging test, it was observed by the Caterpillar representative that the ECU data had not been recorded. During the time between tests, an attempt was made to find and fix the problem. This process continued through the first part of test two, which is visible in the following figures as the speed of the engine changes near the 
300 second mark. This is due to the changing of engine speed to determine if Caterpillar's data logging equipment was functioning properly. The test was shortened by an equipment failure, but it is evident by review of Figure 41 that the engine duty cycle is very repeatable in nature.

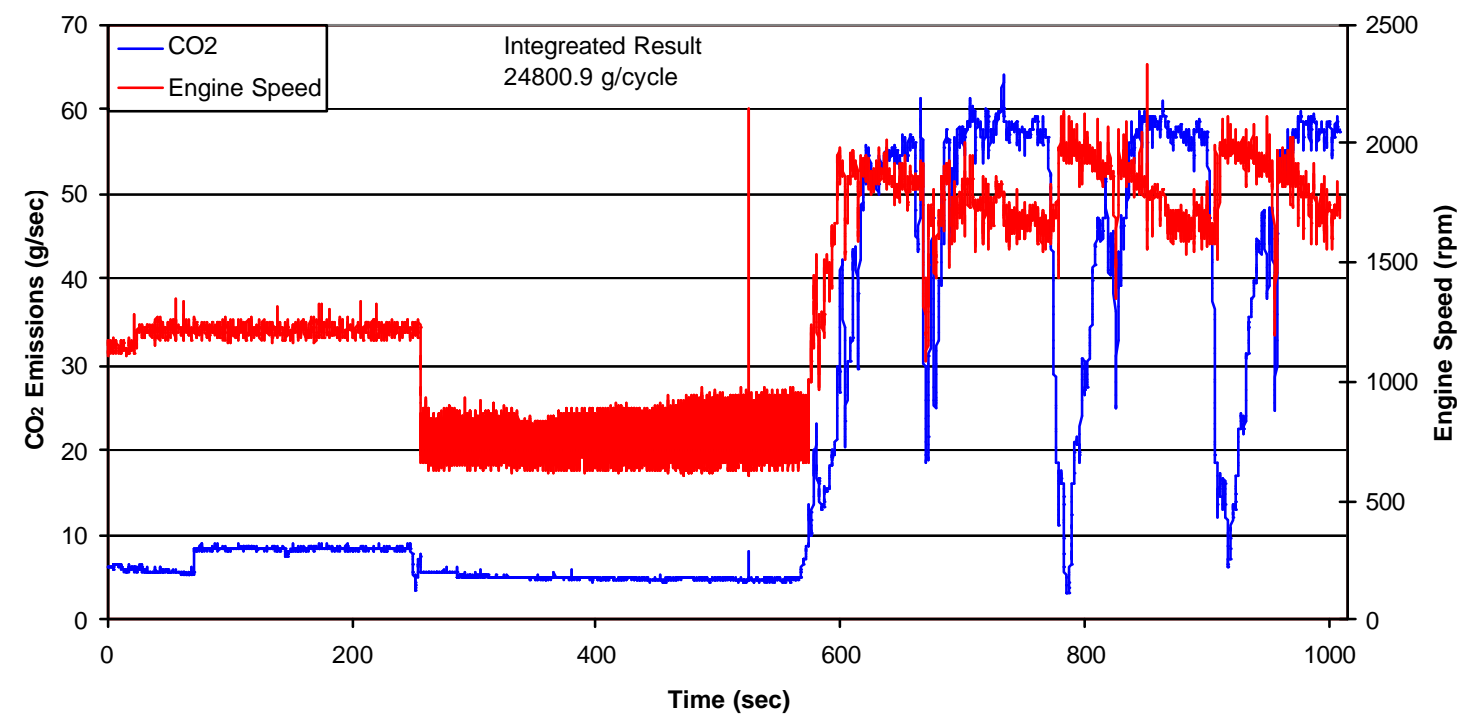

Figure $41 \mathrm{CO}_{2}$ Mass vs. Time for the Second Track-type Tractor Test

Again noise spikes can be observed in the data, which is most likely the result of vibration. The engine at full load tends to produce nearly 60 grams of $\mathrm{CO}_{2}$ per second, as recorded from one stack, which agrees with the data from the first digging test. Figure 42 shows that the full load continuous production of $\mathrm{NO}_{\mathrm{x}}$ was recorded as nearly 0.9 grams per second from one stack, which is also in agreement with data from the first test. 


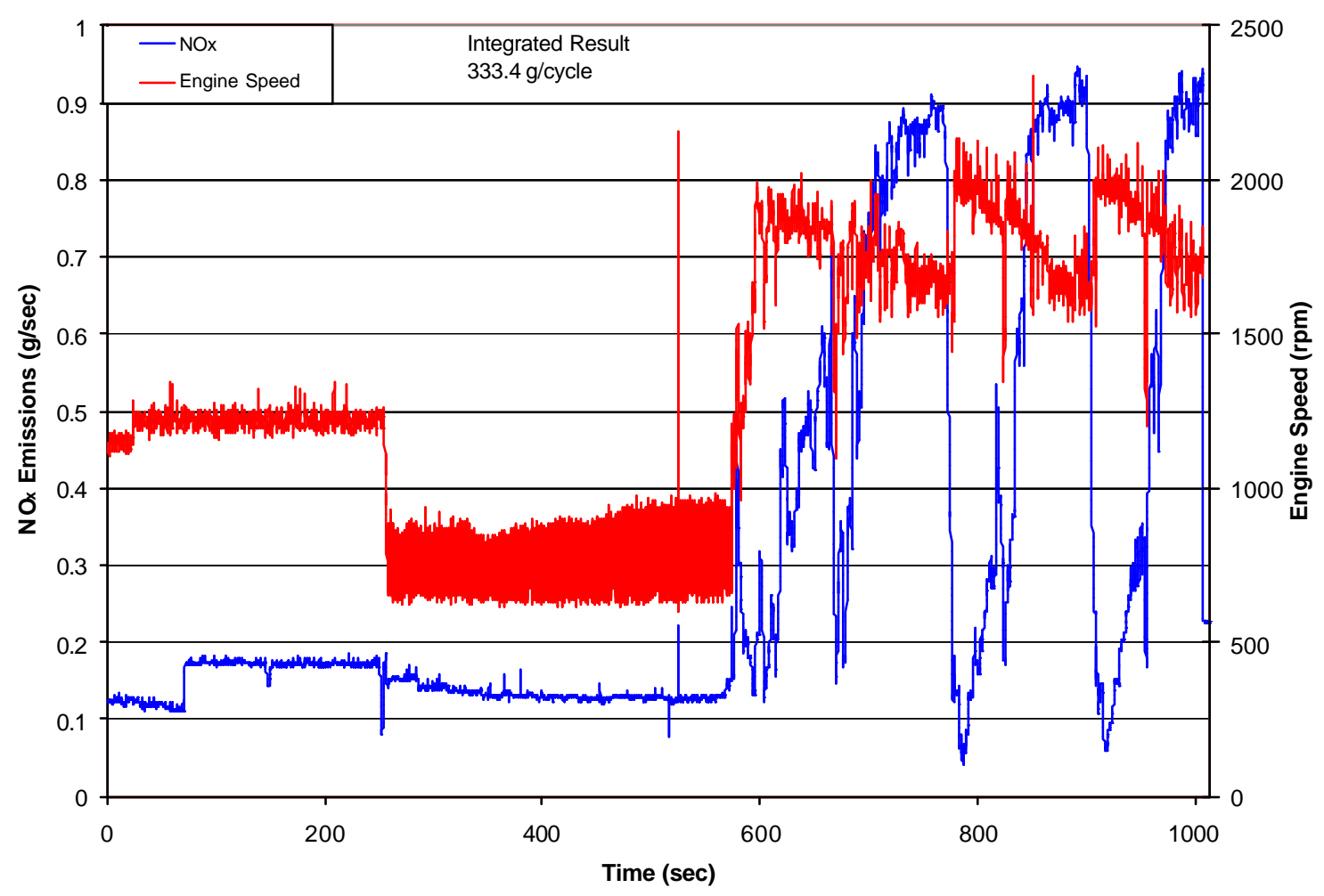

Figure 42 NO$_{x}$ Mass vs. Time for the Second Track-type Tractor Test

\subsection{Excavator In-laboratory Results}

The engine was removed from the excavator in early summer 2001, and moved to the laboratory testing facility. Various small repairs and an extensive cleaning were performed before the engine was mounted onto the dynamometer test bed. The most significant of these repairs was to the turbo flange on the exhaust side as it had corroded away. This was necessary in order to ensure that all engine exhaust entered the full flow dilution tunnel to produce accurate mass emission results. The condition of this engine may be representative of a large number of off-road equipment owned by smaller businesses. A sampling port for the Sensor's measurement device was placed in the exhaust line at approximately the same distance downstream as was used in-field. 


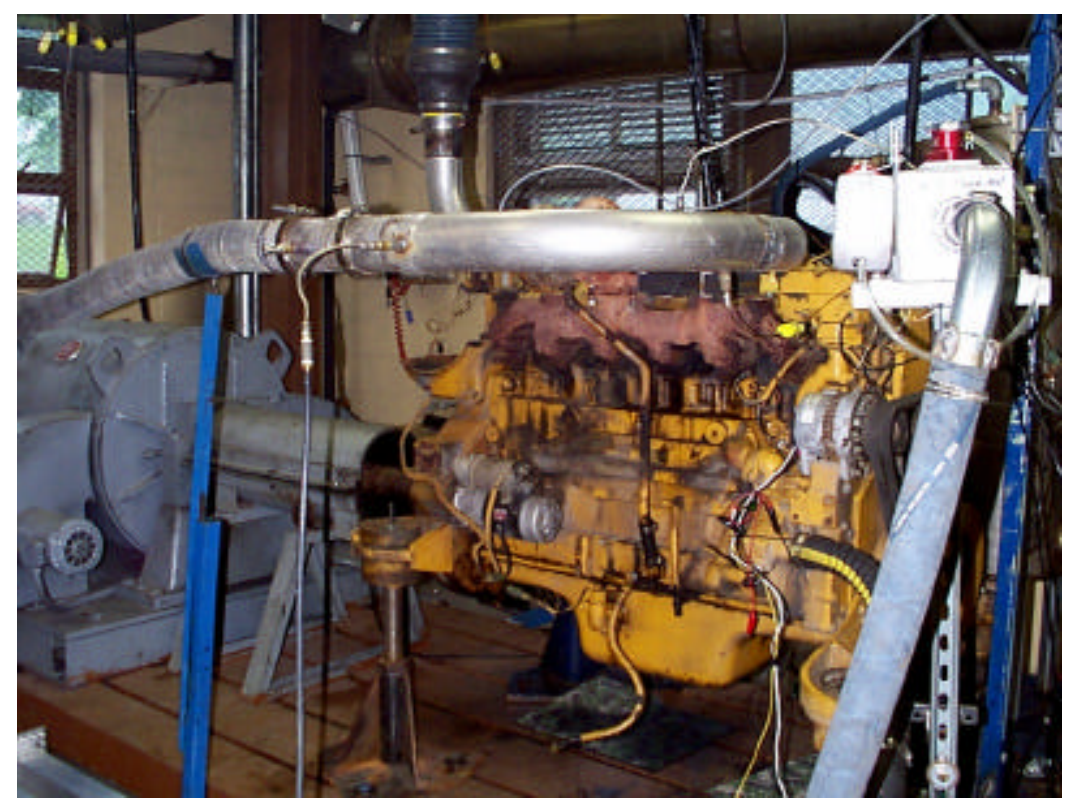

Figure 43 Komatsu S6D125-1 Engine Mounted on GE DC Dynamometer Test Bed

\subsubsection{Excavator Cycle Development}

This section describes in detail the procedures used and the results obtained during the laboratory testing of the Komatsu S6D125-1 Excavator Engine to determine the appropriate transient cycle relative to the results of in-field testing.

\subsubsection{Engine Map}

An engine mapping procedure, outlined in the CFR 40 Part 86 Subpart N [20], was performed on the Komatsu S6D125-1 engine to determine at what engine speeds the horsepower peak (rated speed) and torque peak (intermediate speed) occur, and what the respective values were. Quantifying these two speeds is necessary to determine the set points to be used for the steady-state 8-mode cycle and to allow the compilation of the $\mathrm{CO}_{2}$ map matrix used for development of the transient cycle. The resultant lug curve for the Komatsu S6D125-1 (Figure 44) indicated that peak horsepower was approximately 
$250 \mathrm{hp}$ at $1800 \mathrm{rpm}$, while the torque peak occurred at $1010 \mathrm{rpm}$ and was approximately $745 \mathrm{ft}-\mathrm{lbs}$.

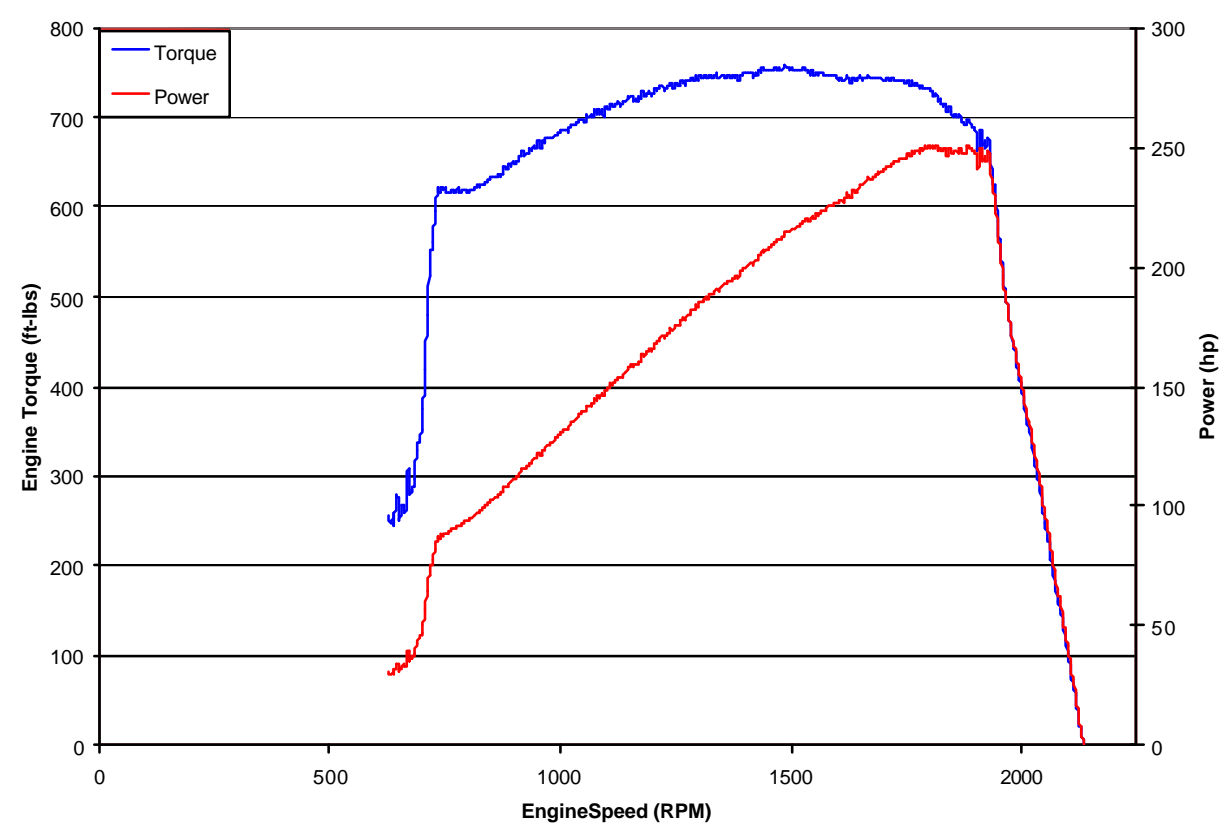

Figure 44 Komatsu S6D125-1 Engine Map

\subsubsection{2 $\mathrm{CO}_{2}$ Map Matrix}

The engine was operated according to a series of discretized engine maps in order to provide information regarding the specific dependence of $\mathrm{CO}_{2}$ emissions on engine load and speed. During these tests engine speed was increased in $100 \mathrm{rpm}$ increments from curb idle to maximum governed speed (650-2250 rpm), while raw $\mathrm{CO}_{2}$ emissions were recorded. Each of these operating points was held for 30 seconds to ensure that the $\mathrm{CO}_{2}$ data had time to reach a value of at least $90 \%$ of the fully stabilized steady-state value. Re sults from this procedure are summarized in Table 5. Three separate series of tests were performed in which the engine was loaded at 0,50 , and 100 percent of maximum torque at the given engine speed according to the engine maps. The data 
recorded from these $\mathrm{CO}_{2}$ maps were used to develop the first transient cycles by inputting the previously collected in-field data into a computer matrix interpolation program developed during the testing of the loader and streetsweeper engines (Barnett 2001) [2].

Table 5 Matrix for the Komatsu S6D125-1 Excavator Engine

\begin{tabular}{|c|c|c|c|}
\hline $\begin{array}{c}\text { Engine Speed } \\
(\mathbf{r p m})\end{array}$ & $\begin{array}{c}\mathbf{C O}_{\mathbf{2}} \text { (\% vol) @ 10\% } \\
\text { Engine Load }\end{array}$ & $\begin{array}{c}\mathbf{C O}_{\mathbf{2}} \text { (\%vol) @ 50\% } \\
\text { Engine Load }\end{array}$ & $\begin{array}{c}\mathbf{C O}_{\mathbf{2}} \text { (\%)vol) @ 100\% } \\
\text { Engine Load }\end{array}$ \\
\hline $\mathbf{6 5 0}$ & 1.12 & 1.09 & 1.13 \\
\hline $\mathbf{7 5 0}$ & 2 & 5.95 & 12.23 \\
\hline $\mathbf{8 5 0}$ & 2.12 & 5.98 & 11.86 \\
\hline $\mathbf{9 5 0}$ & 2.2 & 6.18 & 11.35 \\
\hline $\mathbf{1 0 5 0}$ & 2.33 & 6.34 & 11.04 \\
\hline $\mathbf{1 1 5 0}$ & 2.4 & 6.44 & 10.66 \\
\hline $\mathbf{1 2 5 0}$ & 2.55 & 6.57 & 10.33 \\
\hline $\mathbf{1 3 5 0}$ & 2.6 & 6.48 & 9.84 \\
\hline $\mathbf{1 4 5 0}$ & 2.65 & 6.29 & 9.63 \\
\hline $\mathbf{1 5 5 0}$ & 2.64 & 6.05 & 9.1 \\
\hline $\mathbf{1 6 5 0}$ & 2.7 & 5.93 & 8.66 \\
\hline $\mathbf{1 7 5 0}$ & 2.79 & 5.89 & 8.4 \\
\hline $\mathbf{1 8 5 0}$ & 2.72 & 5.82 & 8.14 \\
\hline $\mathbf{1 9 5 0}$ & 2.65 & 5.24 & 7.42 \\
\hline $\mathbf{2 0 5 0}$ & 2.43 & 3.44 & 4.95 \\
\hline $\mathbf{2 1 5 0}$ & 1.19 & 1.32 & 1.38 \\
\hline $\mathbf{2 2 5 0}$ & 1.19 & 1.32 & 1.38 \\
\hline
\end{tabular}

Raw exhaust $\mathrm{CO}_{2}$ data from the field was used by the program to develop a torque estimate by interpolating the data collected in the laboratory. $\mathrm{CO}_{2}$ data was again recorded during the first iteration of the cycle and was compared to the in- field data and a correlation of the results was performed. A manual process was then used to adjust the speed and load set points of the previous transient cycle iteration to make the $\mathrm{CO}_{2}$ data match the in-field $\mathrm{CO}_{2}$ data more accurately. 


\subsubsection{Transient Cycle Iteration}

Upon conference with CARB regarding vehicle activity, it was decided that the three identified operations - digging/loading (cycle 1), transport (cycle 2), and trenching (cycle 3) - would be investigated as separate test cycles. By doing so, the emissions results and vehicle activity could be combined so as to be most representative of actual vehicles in a given study area. The continuous $\mathrm{CO}_{2}$ data from the first cycles was compared to the field data, and largely due to experience in torque inference from previous testing, the first laboratory approximations of the in-field cycle provided $\mathrm{CO}_{2}$ traces that were relatively close to those collected in-field. First cycle results are shown in Figure 45, Figure 52, and Figure 56, for test cycles 1, 2, and 3, respectively.

Visual inspection of the cycle data revealed, during in-field testing, that the operation of the excavator varies from highly transient to nearly steady-state loading. As all drive and subsystems on the excavator operate via hydraulics, the engine speed will remain relatively constant and the engine load will change as more or less power demand is placed on the shaft mounted hydraulic pump. The fueling is controlled by a handoperated lever, or by governing actuators that mount to the pump rack in order to bring engine speed up to meet loading demands to avoid stalls. As the normal operation of the excavator entails full throttle position, the cycle recreation process was thus simplified, as varying throttle position was not present to induce error.

The iterative approach of adjusting the set-point load to recreate the $\mathrm{CO}_{2}$ trace recorded in- field was then used to arrive at an acceptable correlation between laboratory and in-field data. A graphical representation of $\mathrm{CO}_{2}$ data for the first and final iterations of the recreated in-laboratory cycle for the excavator can be seen in the following figures, 
along with correlations between the in-field and laboratory data. The correlation graphs are shown in Figure 50, Figure 54, and Figure 58, for cycles 1, 2, and 3, respectively.

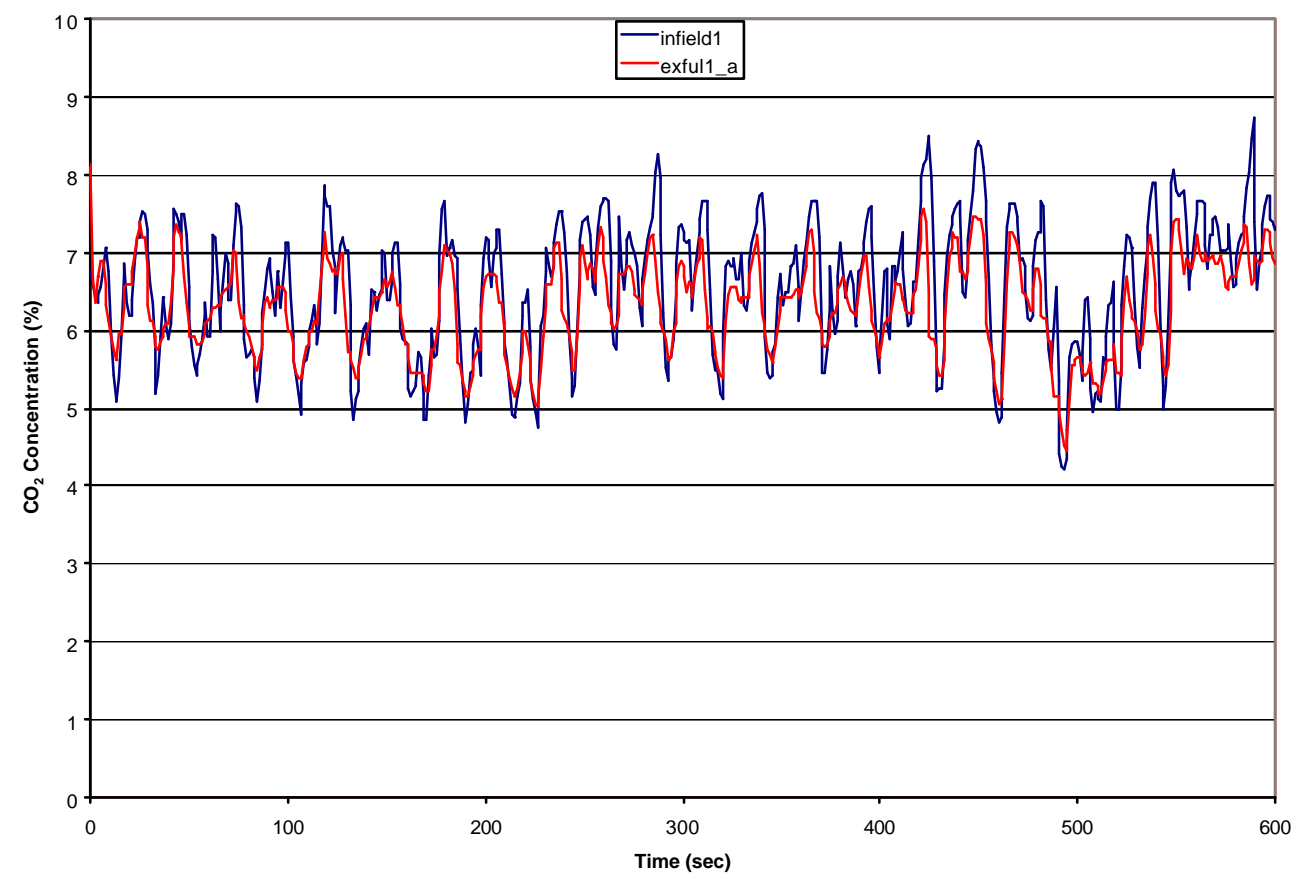

Figure 45 Test Cycle 1 First Approximation Results

The results of the first transient test showed generally good recreation of in-field $\mathrm{CO}_{2}$ concentration levels. A process of iteration was then used to adjust the cycle to get peak values in more agreement with each other. 


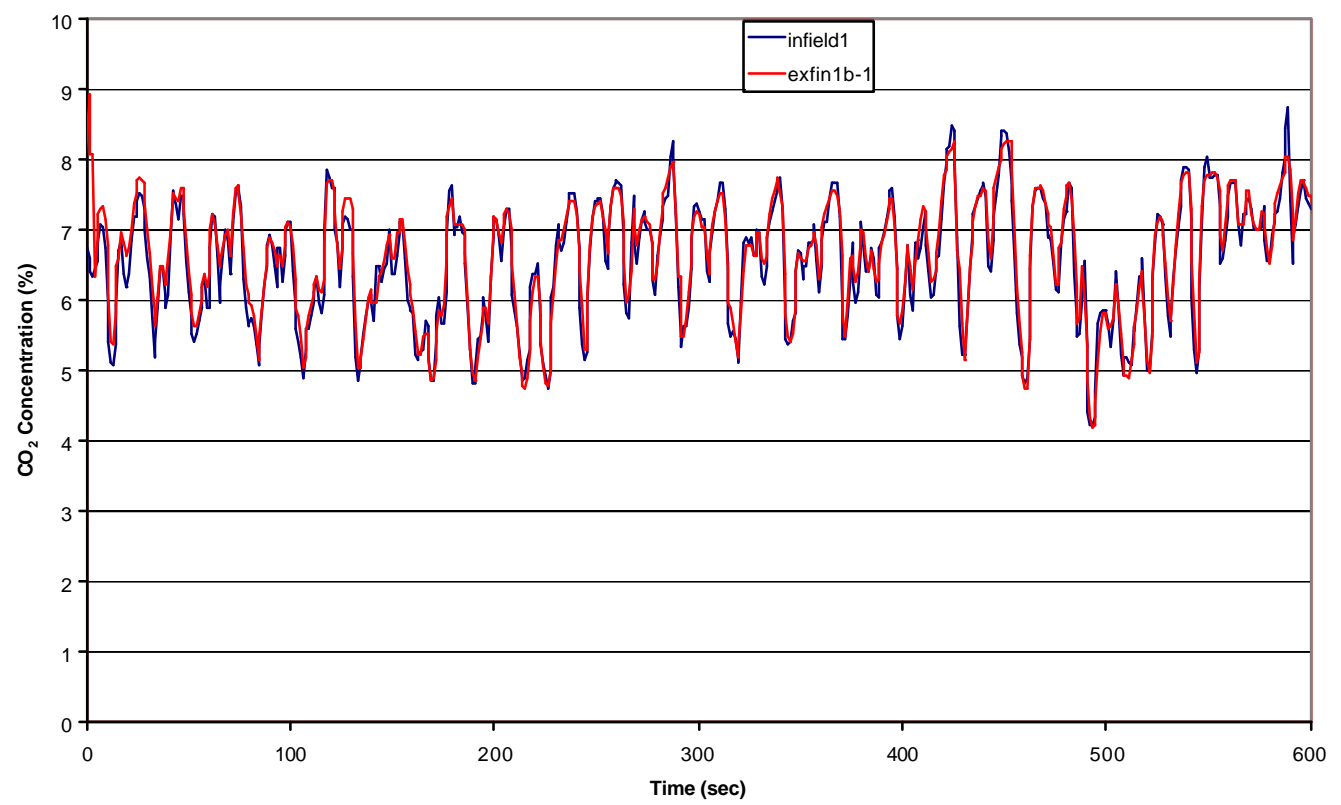

Figure 46 Test Cycle 1 Final Test Results

It is inherently evident that the final in-lab test cycle follows in-field continuous $\mathrm{CO}_{2}$ data with more accuracy than the first test, thus it is more indicative of the sharp transient events that may have occurred during vehicle operation. The process of iteration, however, is rather tedious and time consuming, and it's overall effect on brake specific emissions is relatively small, as is shown in Figure 51. For the purpose of illustration, the following figures show the continuous $\mathrm{CO}_{2}$ results from the cycle iterations that were exercised enroute to producing the final test cycle. Figure 47 shows the first 200 seconds of the cycle while Figure 48 shows the 200 to 400 second portion of the cycle and Figure 49 shows the last 200 seconds of the test cycle. In reference to the legend, infield 1 is the data recorded from the field testing of the excavator where exful_a,_b,_c, and _d3 represent successive iterations of the test cycle. The difference in continuous data is rather evident between the infield and exful_a data, but cycles b, c, and 
d3 show relatively little change in respect to the effort required to alter the cycle to produce another iteration.

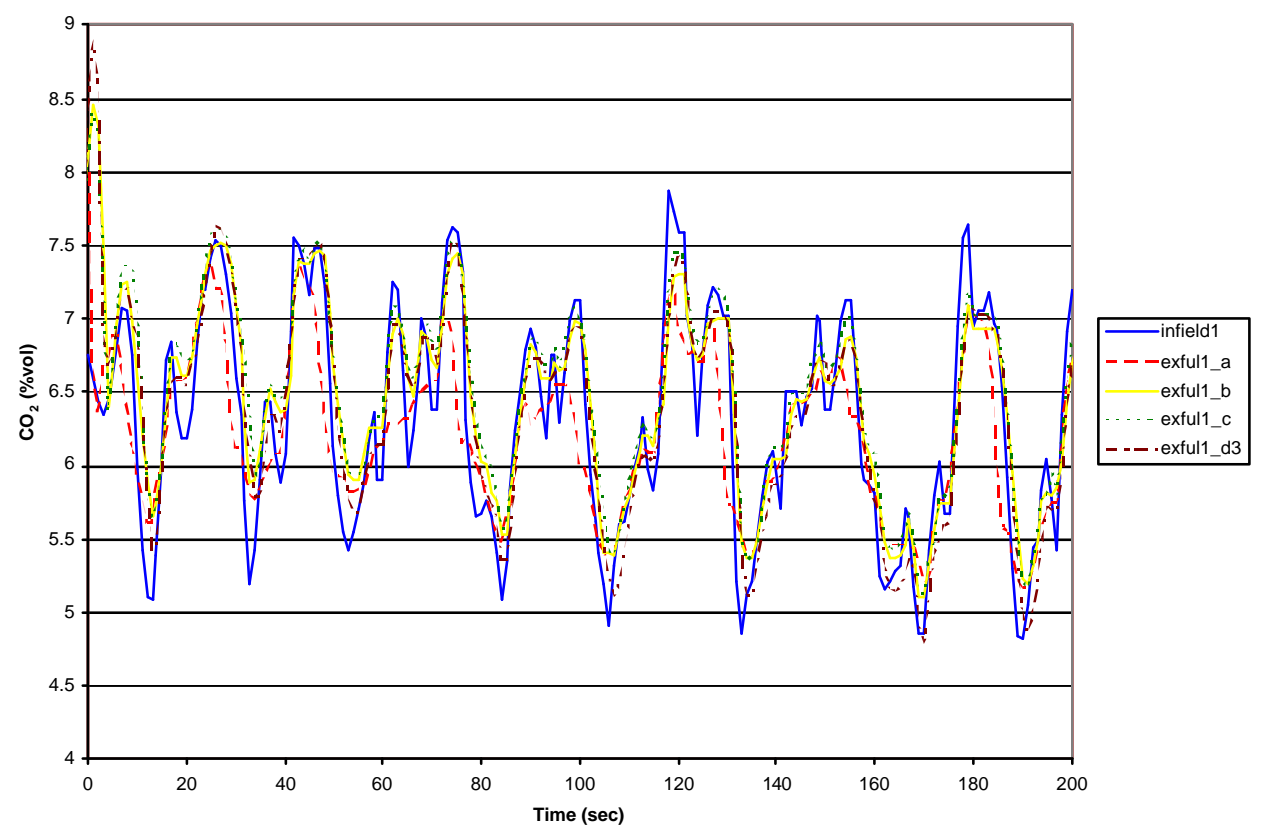

Figure 47 Continuous $\mathrm{CO}_{2}$ Traces $(0$ - 200 s) from Cycle Iterations used to Produce Final Test Cycle 1 


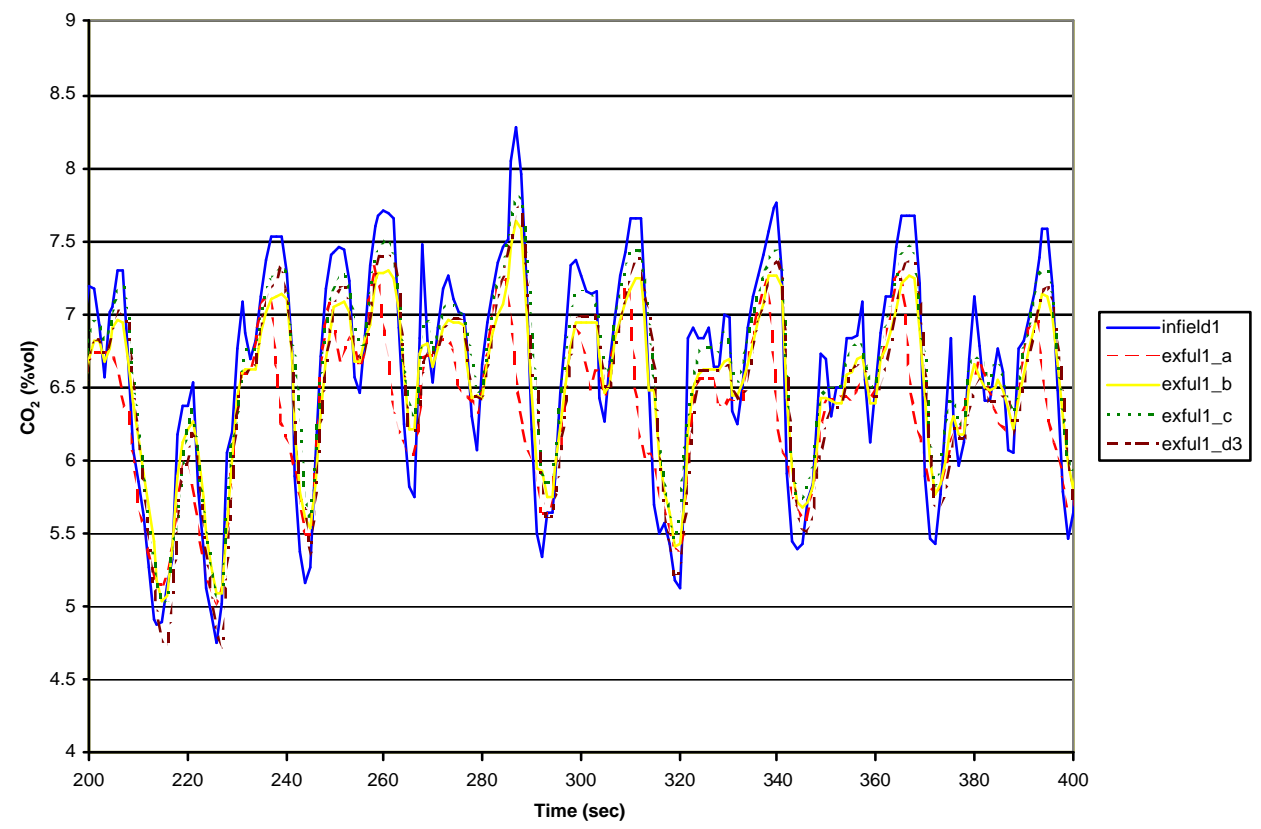

Figure 48 Continuous $\mathrm{CO}_{2}$ Traces $(200-400$ s) from Cycle Iterations used to Produce Test Cycle 1

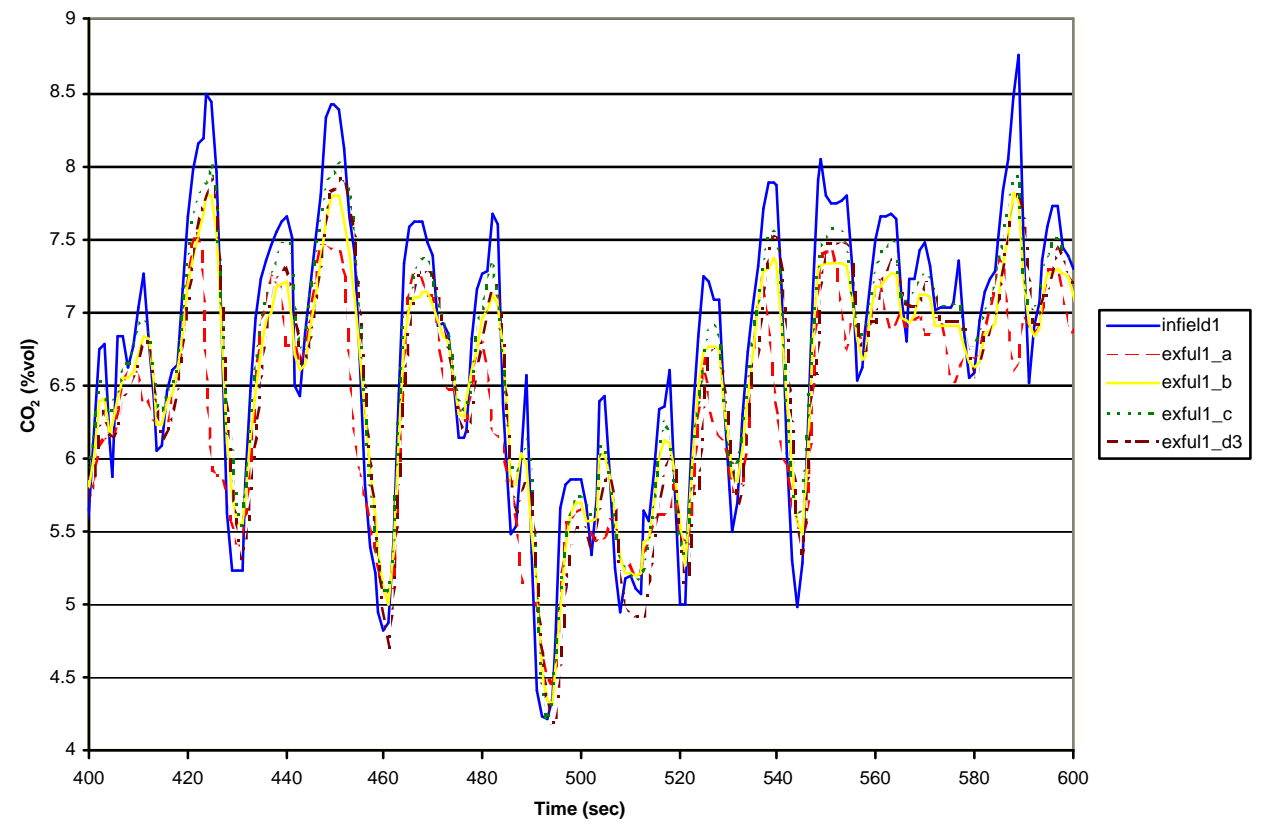

Figure 49 Continuous $\mathrm{CO}_{2}$ Traces $(400$ - 600 s) from Cycle Iterations used to Produce Test Cycle 1 
The nature of this cycle shows peaks that coincide with engine loading as it digs a load of material. Heavy engine loads, which occur if the excavator encounters a large rock that is embedded in the material being moved, are demonstrated by the uncharacteristically high peaks. The swells in the cycle represent times when the excavator swings and unloads the material in another location. This cycle shows that the nature of operation is very repeateable, depending largely on the nature of material, and operator tendencies.

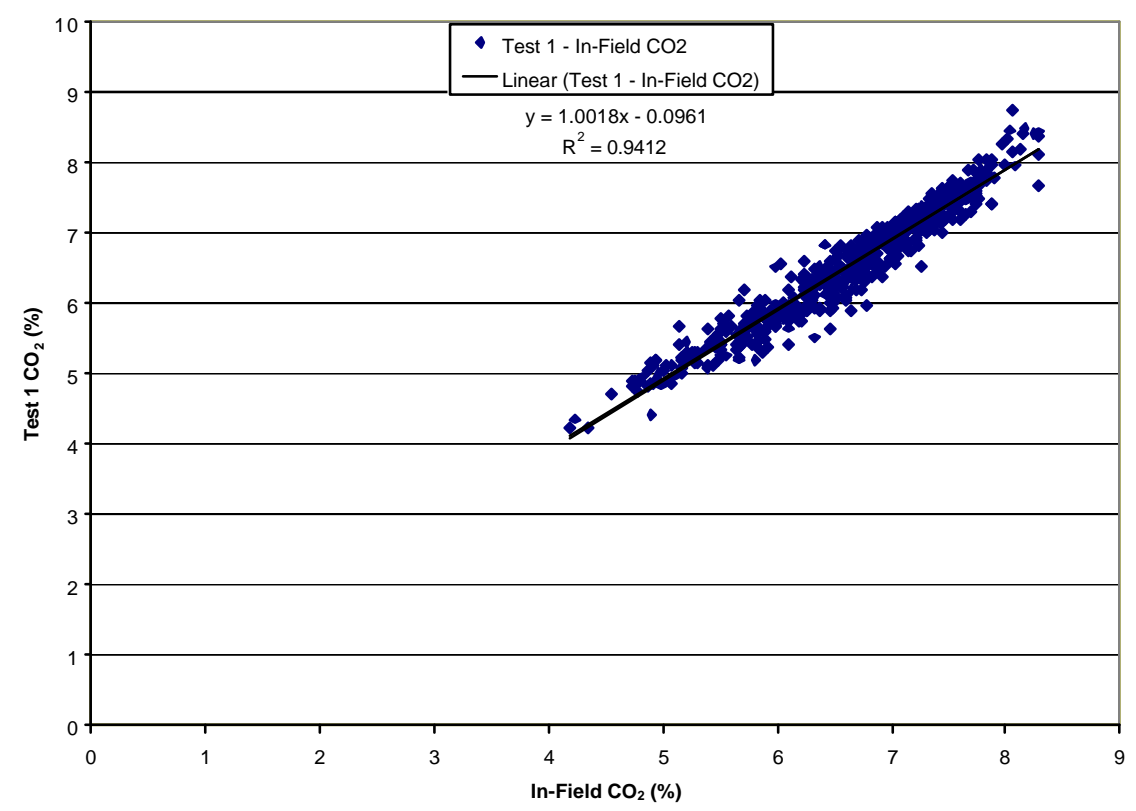

Figure 50 Test Cycle 1 Correlation

Review of this figure suggests excellent correlation between the final test cycle and in-field raw $\mathrm{CO}_{2}$ measurements. The correlation returned a slope very near to 1 and an intercept very near to zero. The $\mathrm{R}^{2}$ value for this regression is 0.9412 , indicating very close correlation. This correlation was simply performed by time aligning the $\mathrm{CO}_{2}$ data 
from the in-field and the final test cycle iteration, and then plotting them against each other. In theory the data should be a straight line $(y=x)$ for perfect results.

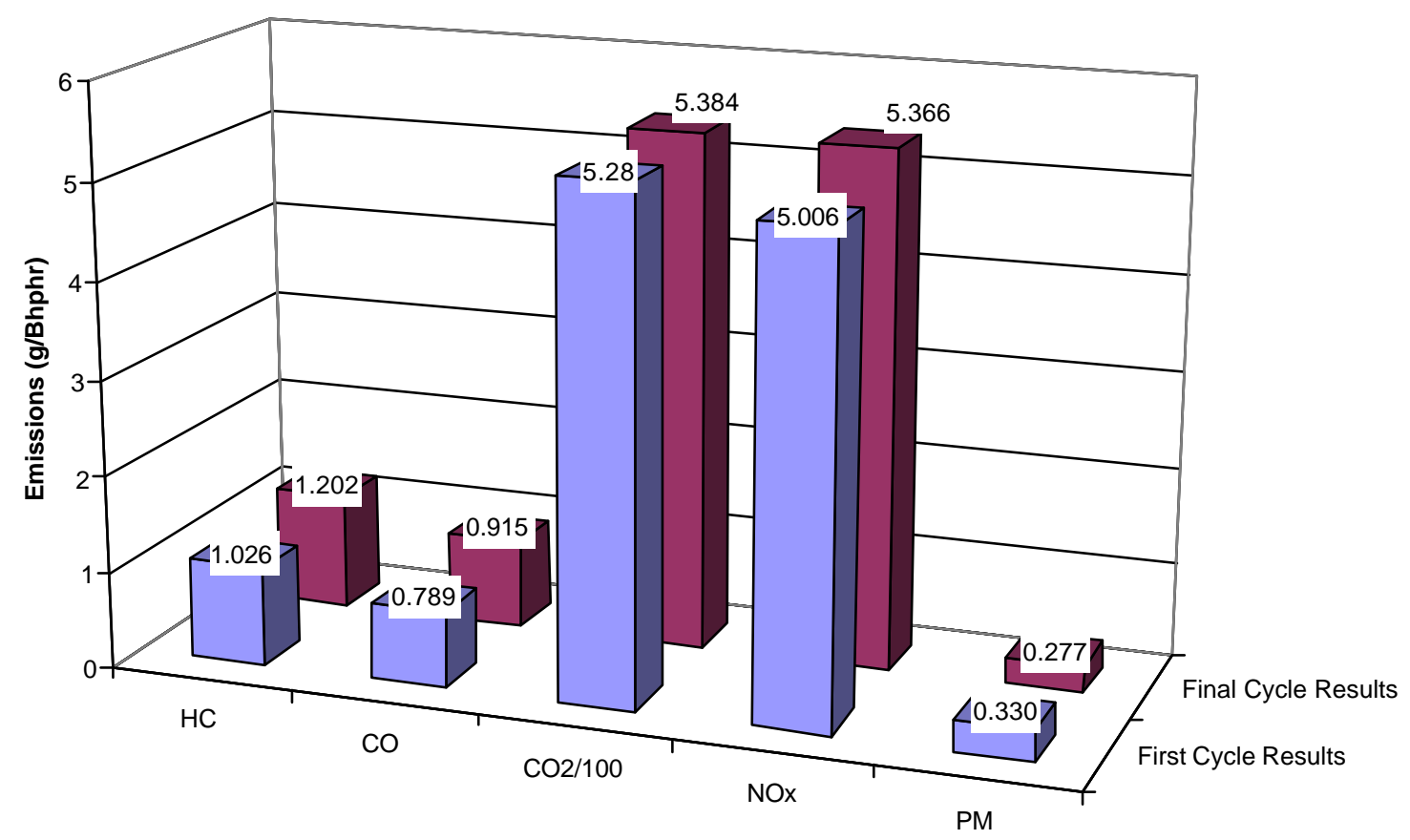

Figure 51 Comparison of Average Brake-specific Emissions Results from the First and Final Cycle 1 Tests

Review of this figure shows that the change in average emissions results did not rely heavily on cycle iteration and smoothing. The data persented herein indicates that the nature of the cycle will tend to affect the averaged emissions more than small changes in the same cycle for purposes of in-field cycle recreation. The first and last comparisons for cycles 2 and 3 demonstrate the same characteristic and are shown in figures Figure 55 and Figure 57. Therefore, should more work be performed in a manner consistent with this study, it is not reccomended that much time be spent on transient cycle iteration as its cost would outweigh its worth to test results. 


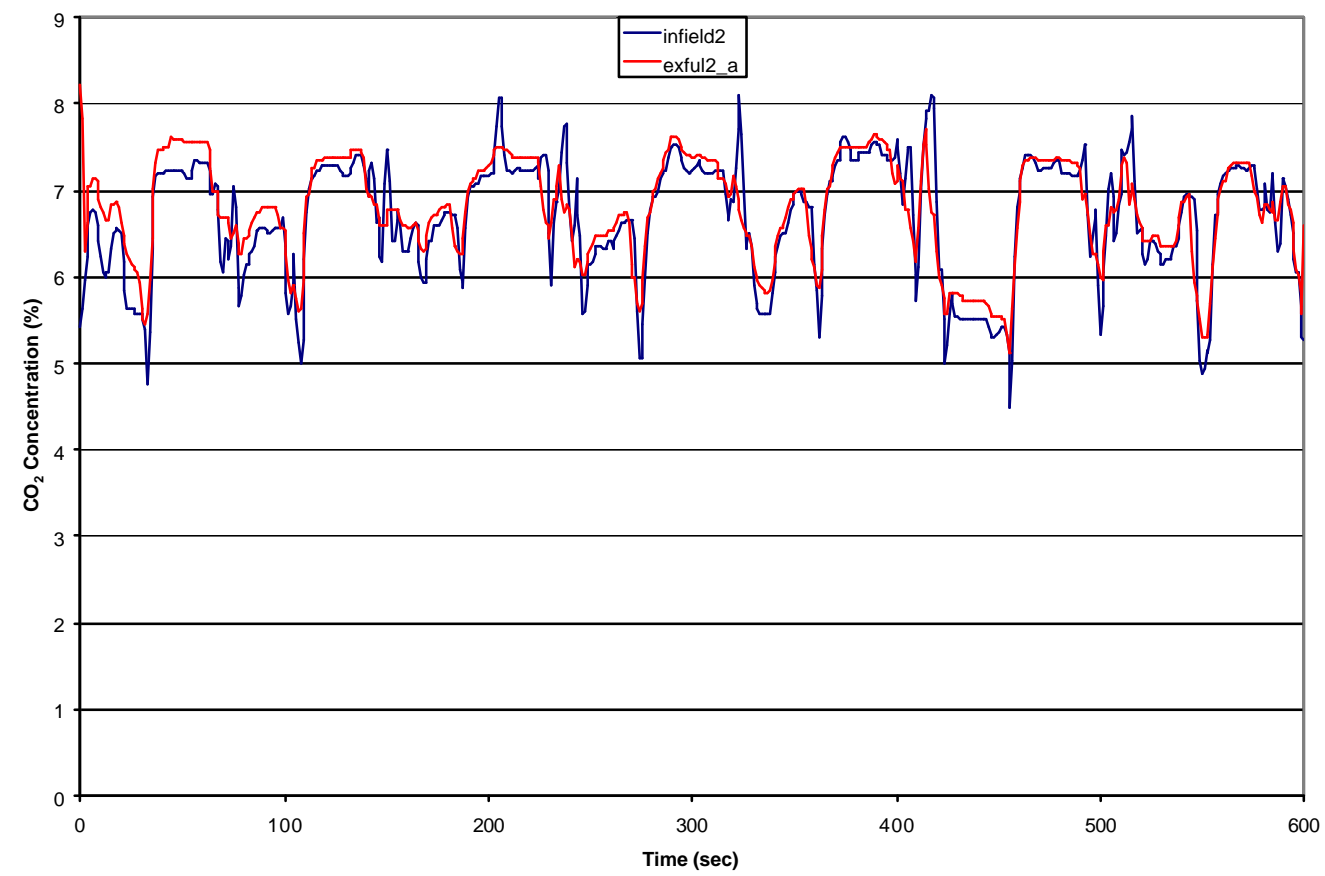

Figure 52 Test Cycle 2 First Approximation Results

Again it is noticeable that the first test cycle follows the general characteristics of the in-field test cycle. The exception is peak values and short duration transient events, which were compensated for by cycle adjustment. The final test cycle raw $\mathrm{CO}_{2}$ results are shown below. 


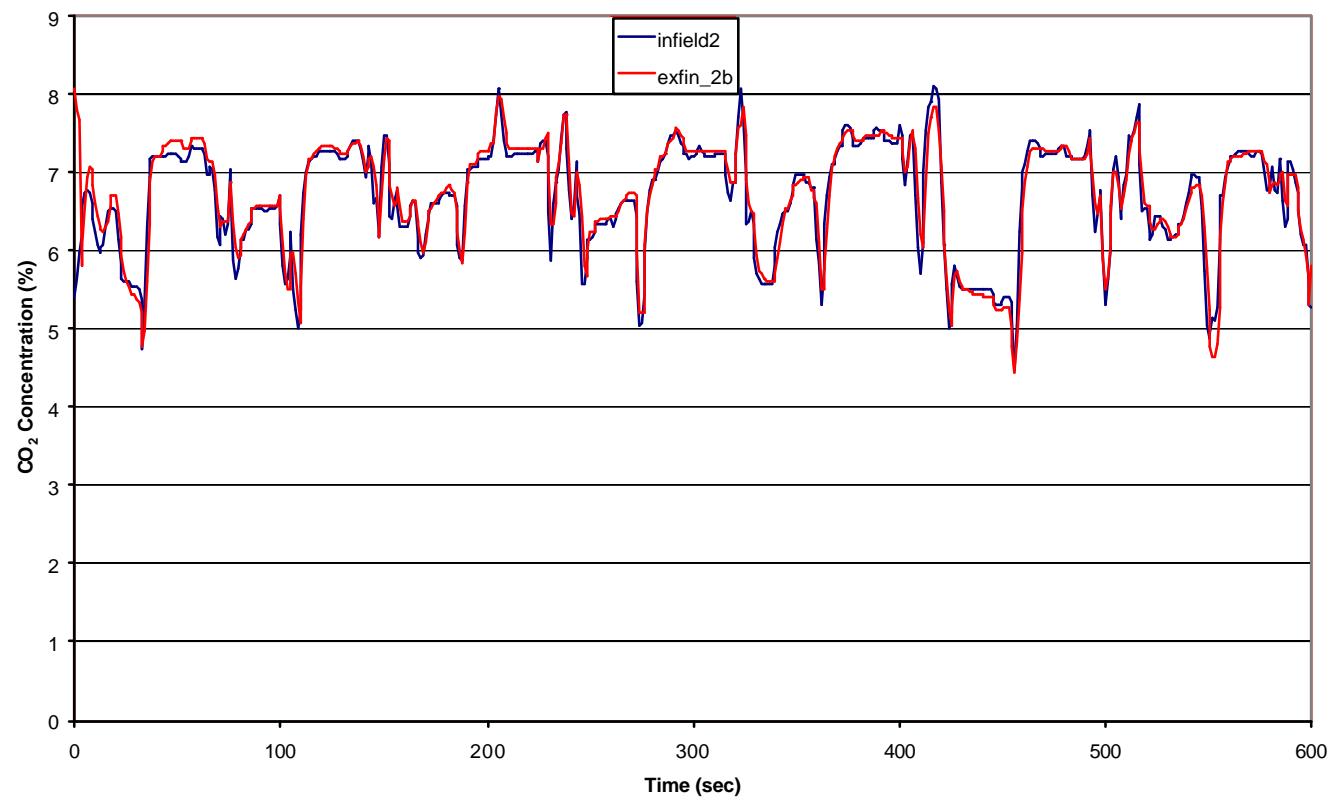

Figure 53 Test Cycle 2 Final Test Results

The results of cycle iteration again made the traces follow one another more closely in peaks and transient events. These cycles tend to show that the operating cycle of the excavator is very repetitive in nature, repeating many cycles of the same characteristic loading. This is largely due to operator tendencies and the nature of the work being performed by the machine. The longer peaks of high emissions rates represent the hauling operation as the excavator moves from one place to another and then returns to the material removal site. Smaller peaks indicate loading and unloading the bucket with material, and the high peaks indicate steering by locking one track and letting the other track turn the machine. 


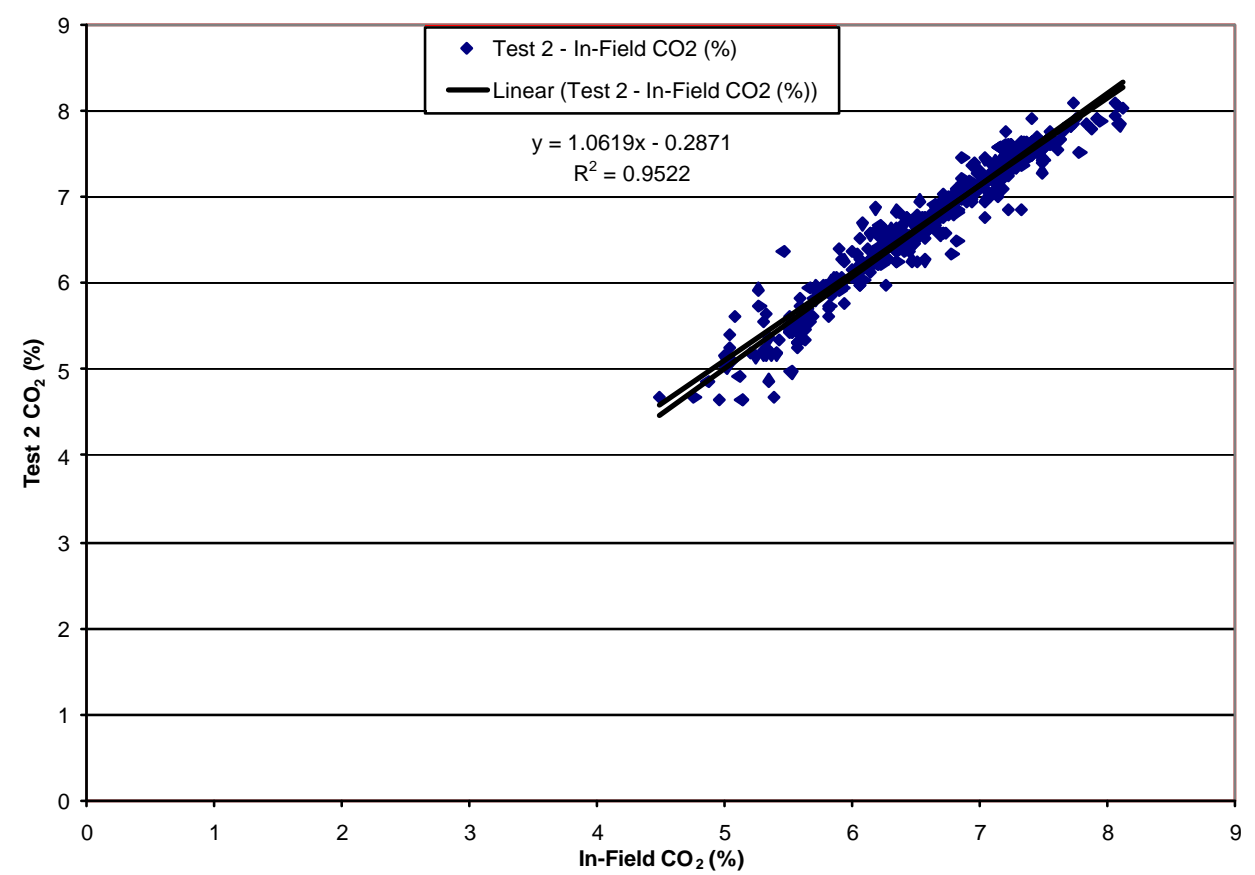

Figure 54 Test Cycle 2 vs. In-field $\mathrm{CO}_{2}$ Correlation

Review of cycle 2 indicated a very close correlation between in-field and in-lab results, with a slope of 1.06 , an intercept of 0.28 , and $\mathrm{R}^{2}$ value of 0.95 . The results of this test cycle showed closer correlation than the results of cycle 1 , largely due to the fact that there are not as many transient events occurring through this cycle. 


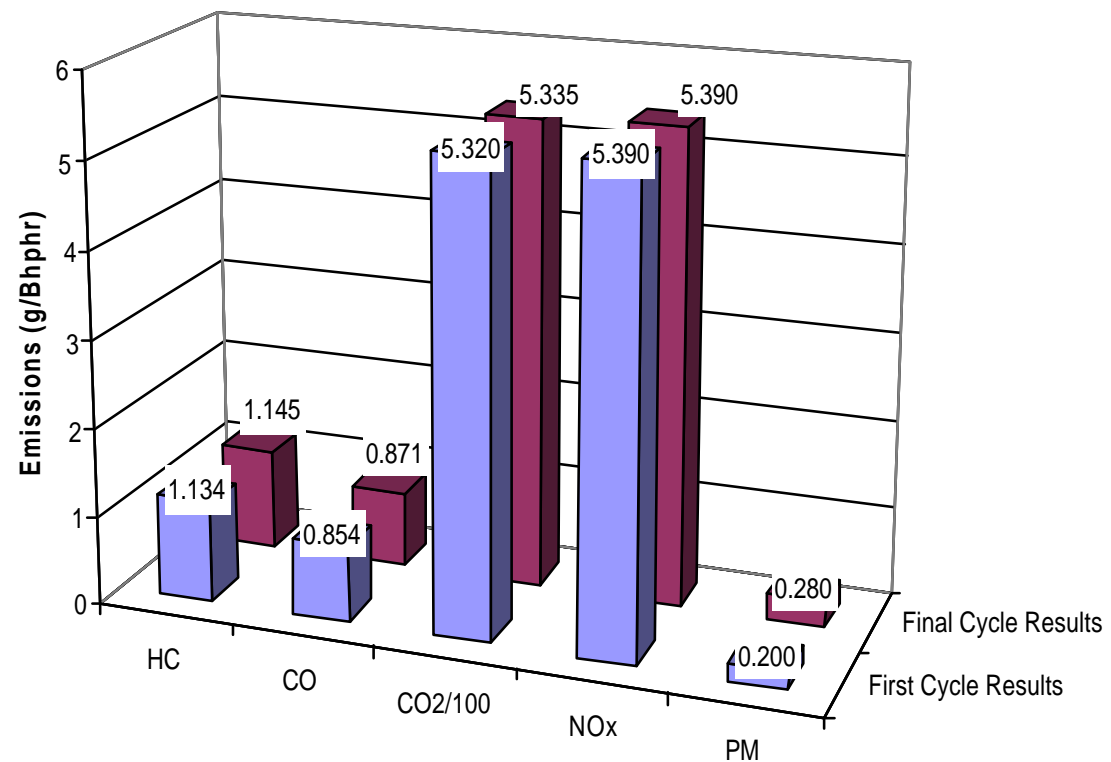

Figure 55 Comparison of Average First and Final Cycle 2 Iteration Brake-specific Emissions

Again it is shown that the iteration of cycles did not have nearly a significant enough impact on brake-specific emissions to warrant the effort involved in manually adjusting the test cycle to achieve the continuous in-field data trace.

Test 3 shows the same trends relative to cycle iteration as the first two cycles. The iterations provided a more accurate recreation of the in-field data, but averaged brake-specific cycle emissions were not changed significantly. Figure 57 shows the general trends of cycle 3 to be relatively close to those of cycle 1 . This is largely due to similarity in the operations. Swells indicate periods of swinging and unloading material, or the period before loading, and peaks indicate periods of digging and/or maneuvering the vehicle. 


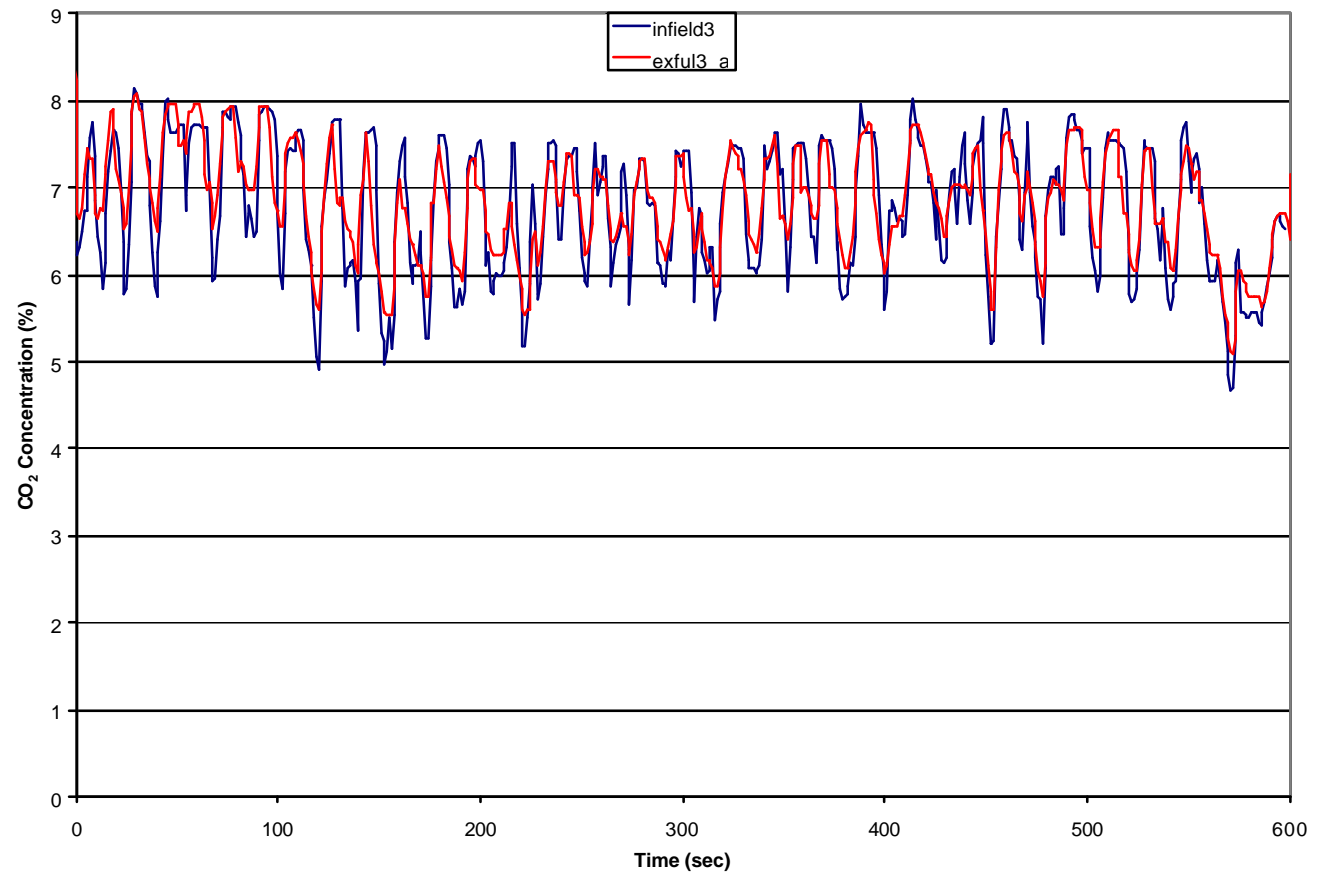

Figure 56 Test Cycle 3 First Approximation Results

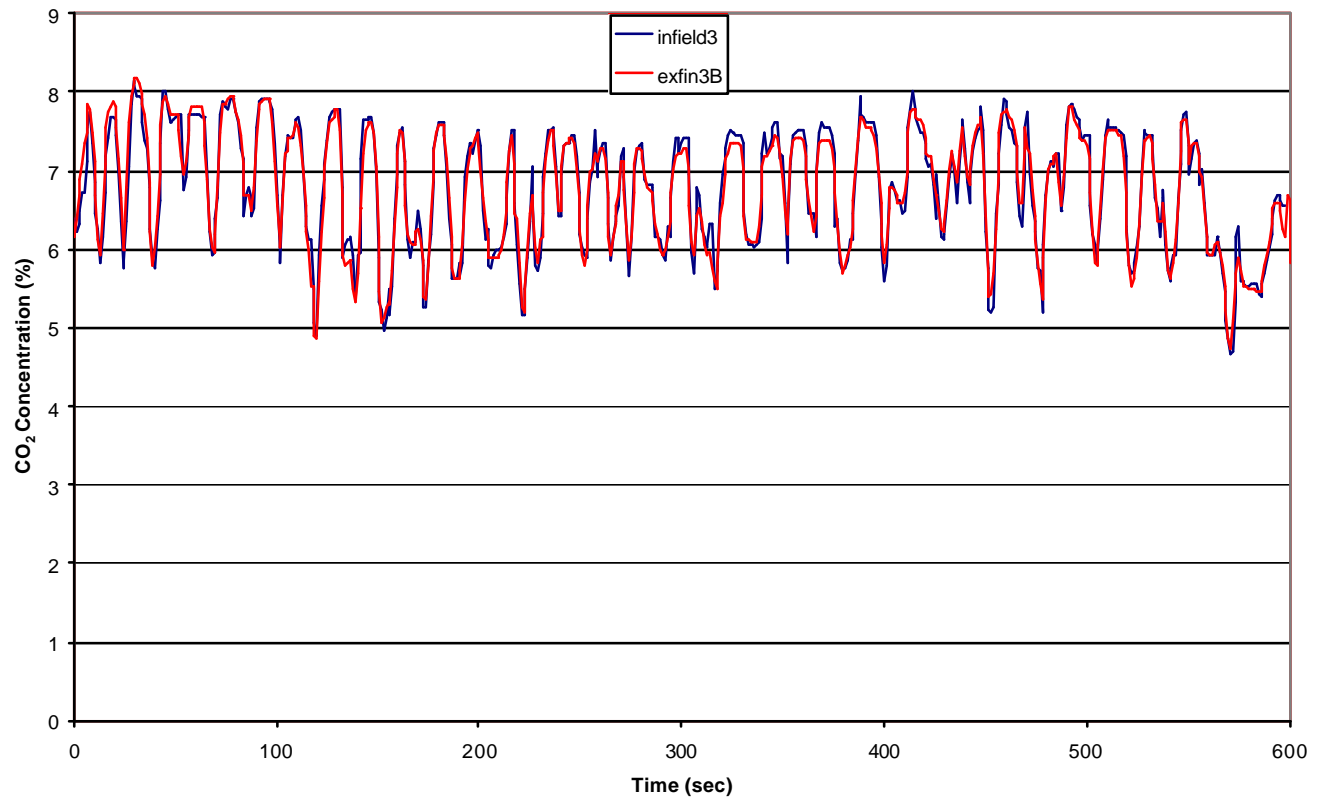

Figure 57 Test Cycle 3 Final Test Results 


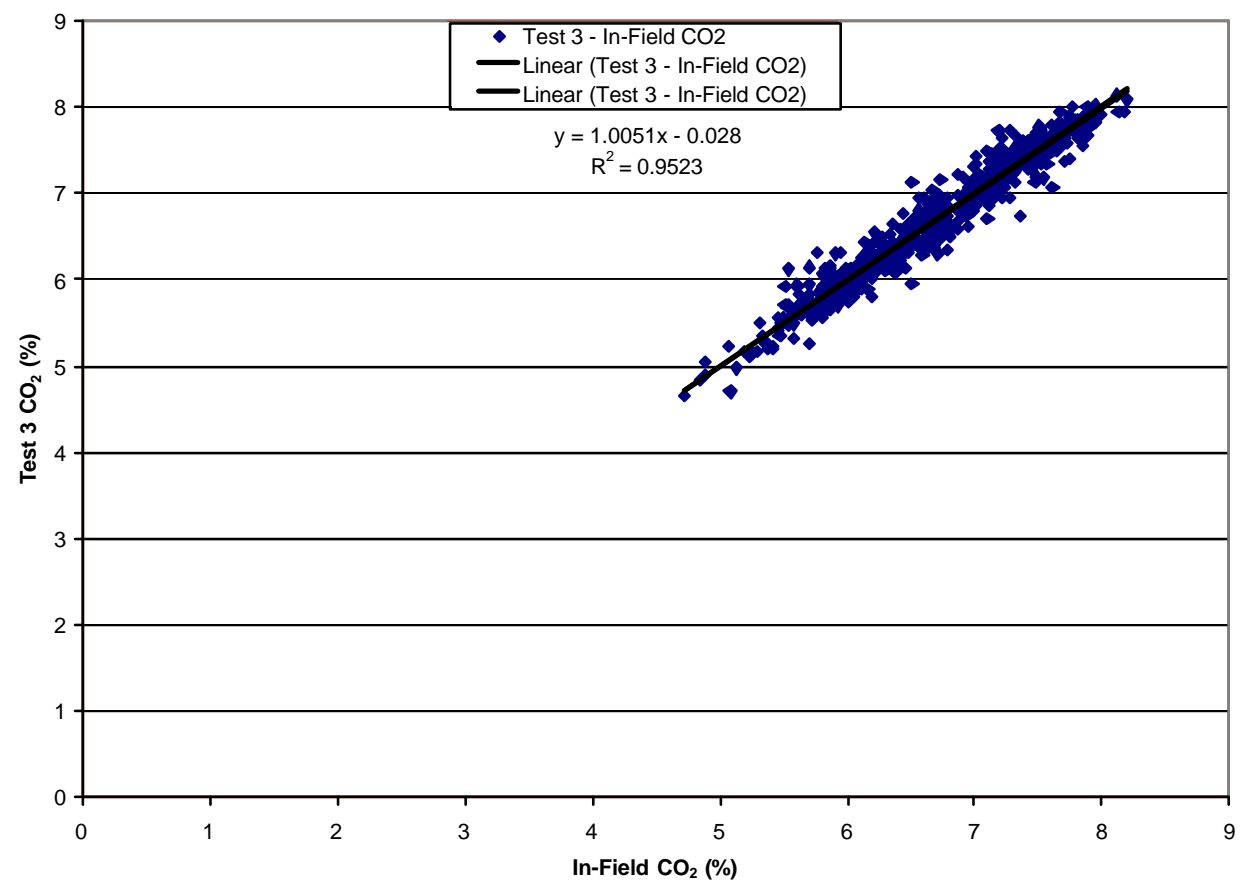

\section{Figure 58 Correlation of $\mathrm{CO}_{2}$ Data from Final Test and Infield Results}

Cycle 3 returned the best correlation results of all three cycles, with a slope of 1.0051, an intercept of 0.028 , and an $\mathrm{R}^{2}$ value of 0.9523 . The results indicate that all cycles returned $\mathrm{CO}_{2}$ traces that were as close to the in-field data as could be expected, as they were within a determined value of test to test repeatability of the same cycle.

Figure 59 shows the averaged brake-specific emissions from the first and last cycle iterations. This again illustrates that the effort put into cycle adjustment produced little effect in brake-specific emissions. 


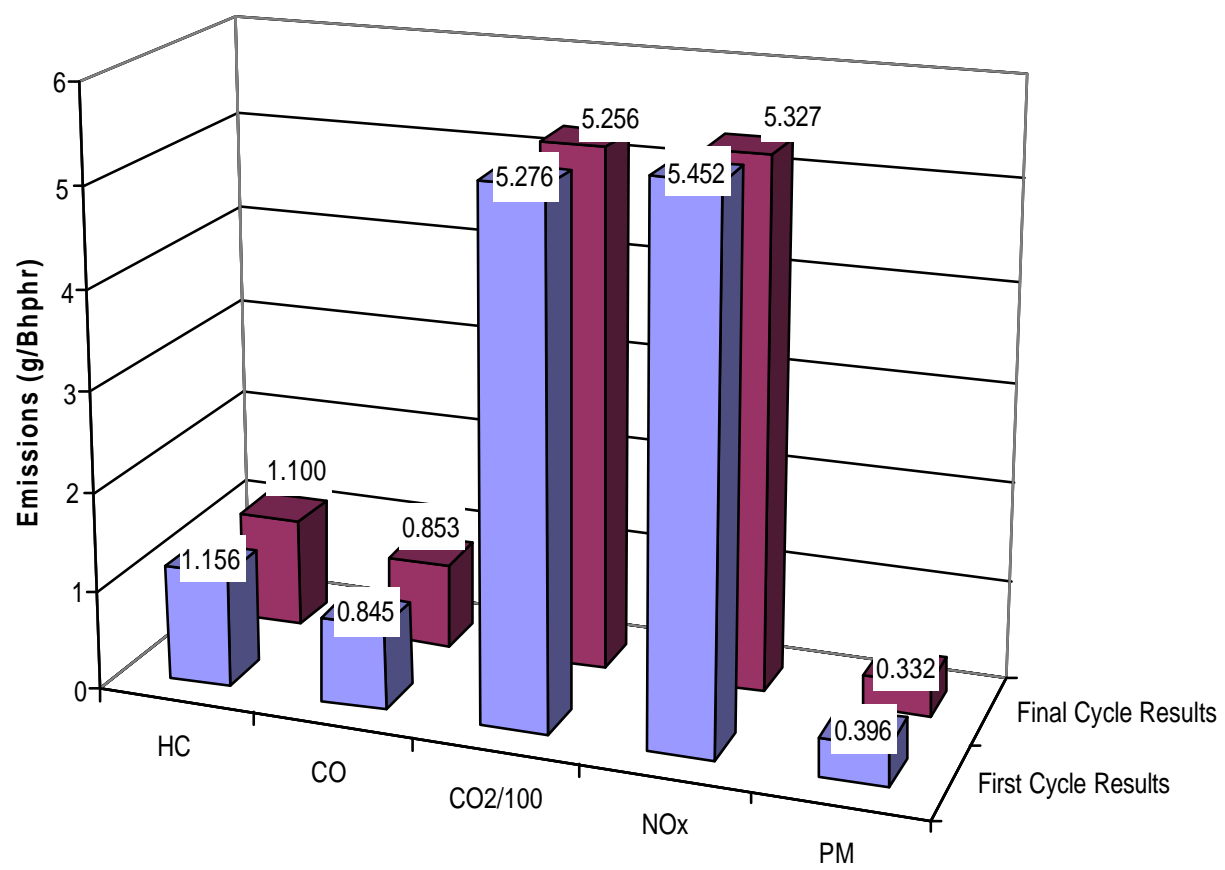

Figure 59 First and Final Cycle 3 Iteration Average Brake-specific Emissions Comparison

\subsubsection{Excavator Transient Cycle Laboratory Emissions Results}

Upon achieving satisfactory correlation between in-field and laboratory-derived test cycles, the engine was operated according to the derived speed-load set points in order to investigate engine exhaust emissions production. Four tests of each cycle were performed to assure repeatability and QC/QA. The following shows the cycle speed and load set points, continuous laboratory results, and the cycle averaged brake-specific emissions results from these cycles. A comparison of average laboratory results from each of the three cycles is shown in Figure 66. 


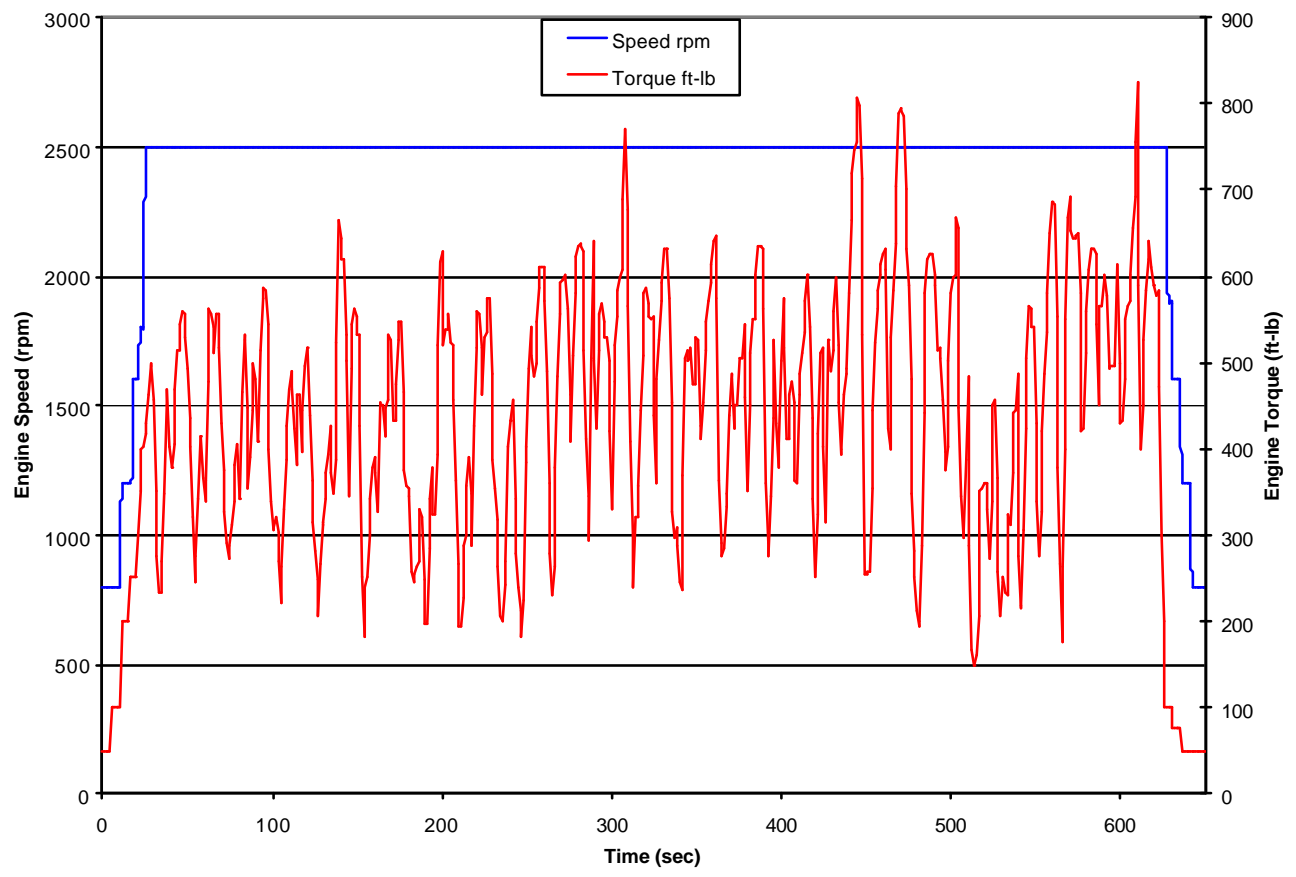

Figure 60 Cycle 1 Set-point Curve

The speed was set at $2500 \mathrm{rpm}$ in order to keep the laboratory fueling control at $100 \%$ by calling for an unattainable engine speed. This was the most reasonable solution to avoiding issues of fueling induced errors. The engine torque sometimes exceeded peak torque, which coincided with periods of the in-field data where the excavator encountered loadings due to embedded large rocks that would have stalled the engine if the operator had not repositioned the bucket and loaded material from another location. Most of the time, the loading tended to be between 50 and $75 \%$ of maximum load. 


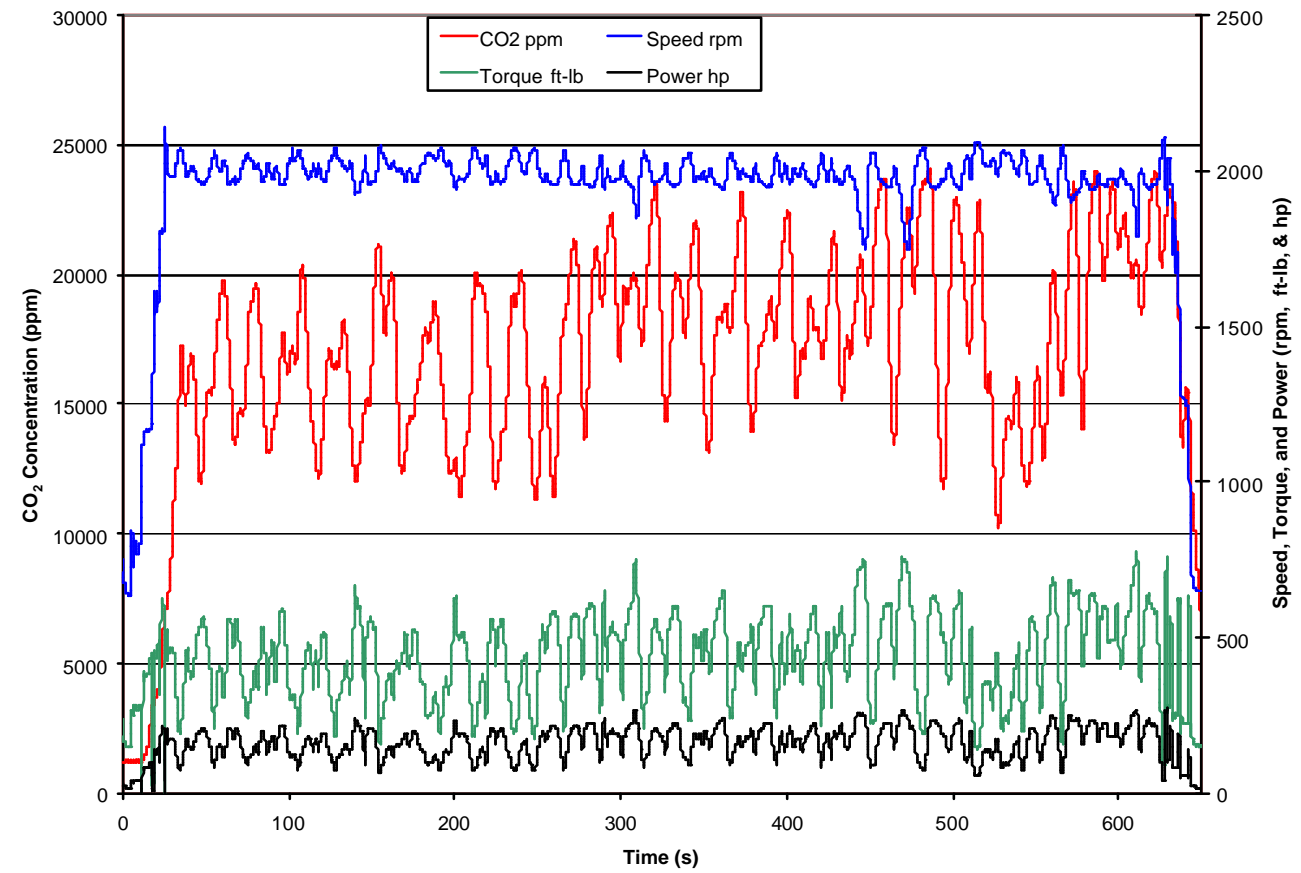

Figure 61 Continuous Cycle 1 Laboratory Results

This figure shows continuous laboratory data as recorded for speed, torque, and $\mathrm{CO}_{2}$. Engine power was calculated from speed and torque data, and it is notable that the power curve shares characteristic similarities with the $\mathrm{CO}_{2}$ curve.

Table 6 Transient Cycle Brake-Specific Exhaust Emissions Results for the Komatsu S6D125-1 Excavator Engine Operating According to the WVU Excavator Test Cycle \#1 (Loading) (g/Bhp-hr)

\begin{tabular}{|c|c|c|c|c|c|}
\hline & Test 1 & Test 2 & Test 3 & Test 4 & Average \\
\hline $\mathbf{H C}$ & 1.212 & 1.252 & 1.159 & 1.183 & 1.202 \\
\hline $\mathbf{C O}$ & 0.883 & 0.946 & 0.923 & 0.909 & 0.915 \\
\hline $\mathbf{C O}_{\mathbf{2}}$ & 536.8 & 539.0 & 539.0 & 538.9 & 538.4 \\
\hline $\mathbf{N O}_{\mathbf{x}}$ & 5.265 & 5.469 & 5.385 & 5.343 & 5.366 \\
\hline PM & 0.267 & 0.297 & 0.260 & 0.283 & 0.277 \\
\hline
\end{tabular}




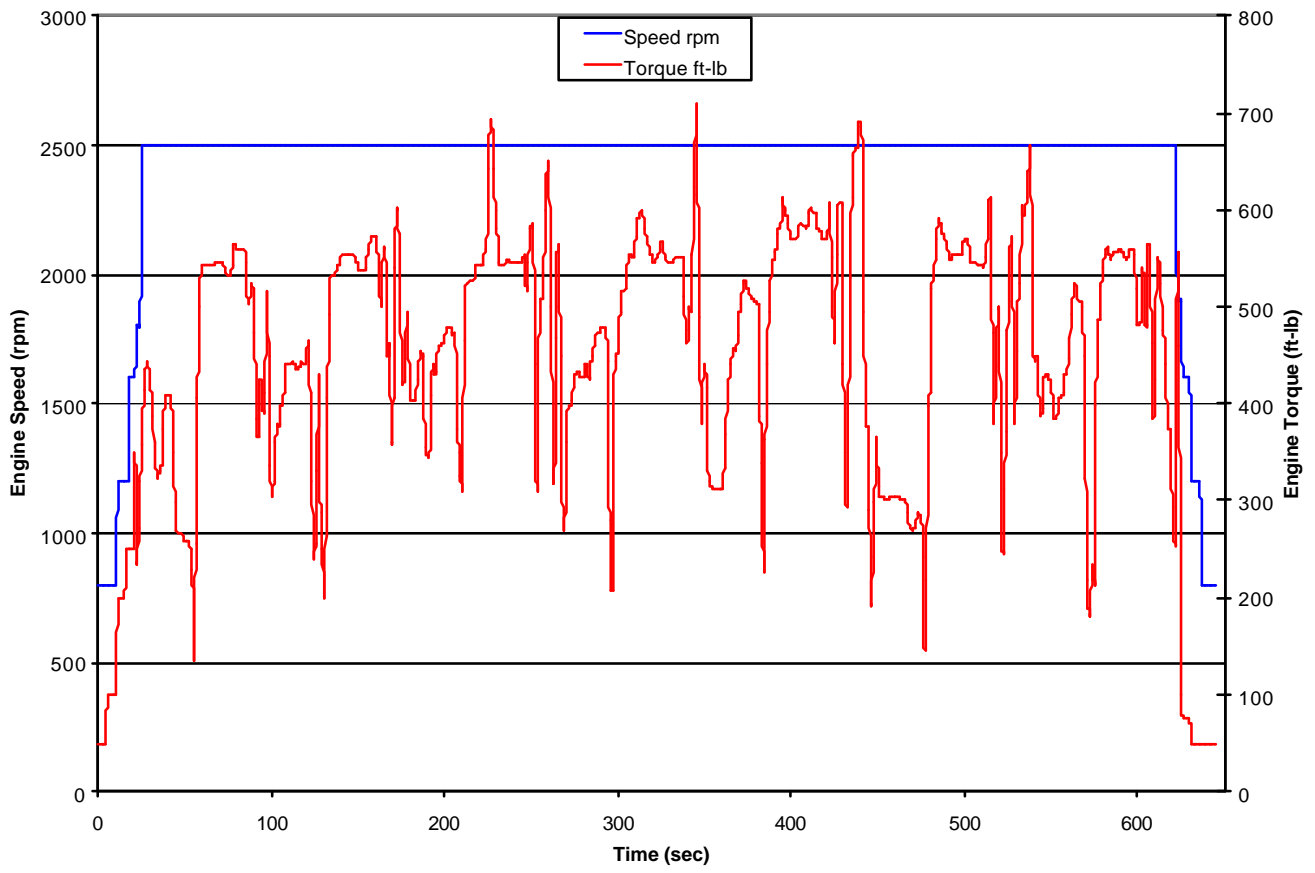

Figure 62 Final Cycle 2 Set-point File

Again, like cycle 1, the engine speed was set to an unattainable value to keep fueling at $100 \%$ and avoid fueling induced error. The long peaks indicate movement of the vehicle while spikes across these peaks indicate steering, the spikes in other areas represent periods of high loads due to filling the bucket with material. Swells indicate areas of unloading the material from the bucket, at times the swing on the excavator was operated during this time to simulate turning to load a truck with the material being hauled by the excavator. 


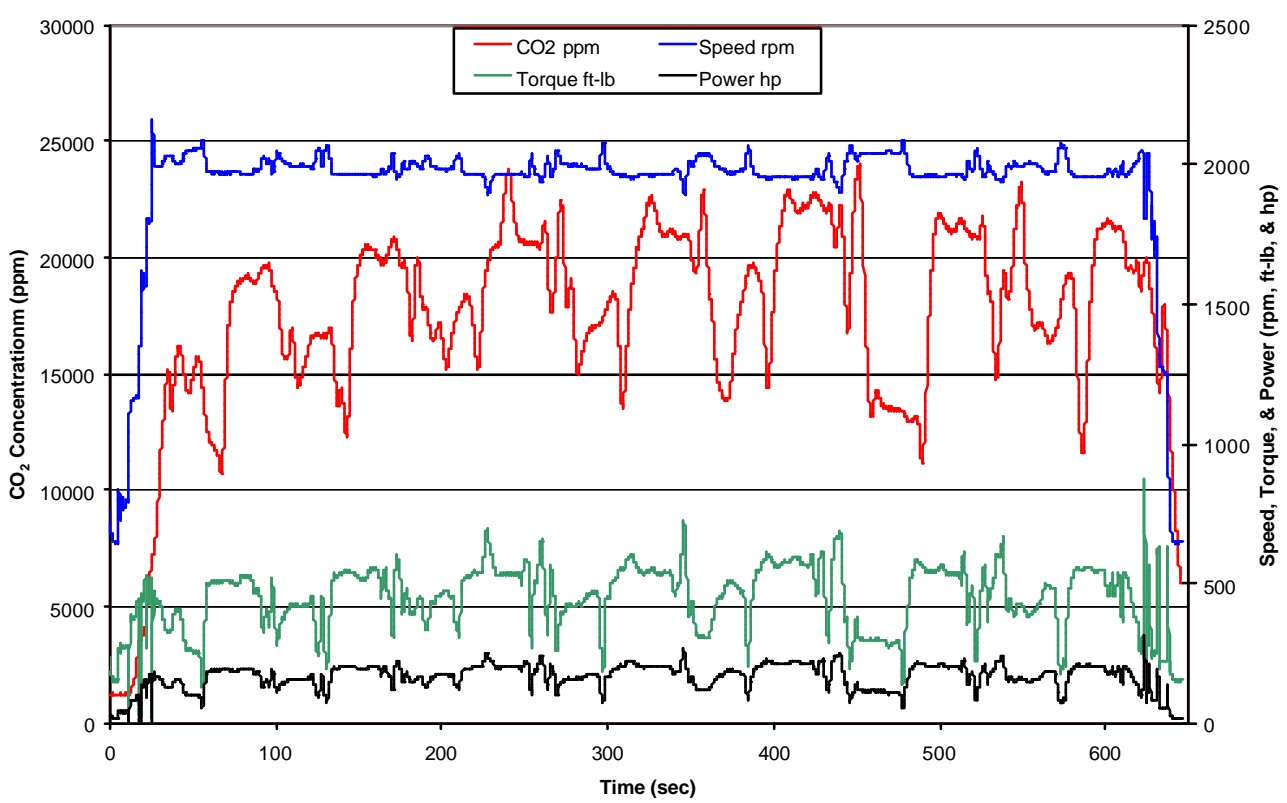

Figure 63 Continuous Cycle 2 Laboratory Results

The engine speed for this cycle did not vary as much as in cycle 1, largely due to the fact that the hauling operation did not usually cause a change in engine speed where as digging imposes variable loads on the engine that cause speed changes. Here, the $\mathrm{CO}_{2}$, engine power, and torque traces are strikingly similar, which is a function of the relatively constant speed. Table 7 shows the averaged cycle brake-specific emissions results and the average value of the four repeat tests of this cycle that were performed. 
Table 7 Brake-Specific Transient Cycle Exhaust Emissions Results for the Komatsu S6D125-1 Excavator Engine Ope rating According to the WVU Excavator Test Cycle \#2 (Transport) (g/Bhp-hr)

\begin{tabular}{|c|c|c|c|c|c|}
\hline & Test 1 & Test 2 & Test 3 & Test 4 & Average \\
\hline HC & 1.156 & 1.158 & 1.169 & 1.095 & 1.145 \\
\hline $\mathbf{C O}$ & 0.886 & 0.861 & 0.861 & 0.875 & 0.871 \\
\hline $\mathbf{C O}_{2}$ & 534.0 & 533.7 & 533.9 & 532.4 & 533.5 \\
\hline $\mathbf{N O}_{\mathbf{x}}$ & 5.415 & 5.391 & 5.381 & 5.372 & 5.390 \\
\hline $\mathbf{P M}$ & 0.305 & 0.274 & 0.290 & 0.251 & 0.280 \\
\hline
\end{tabular}

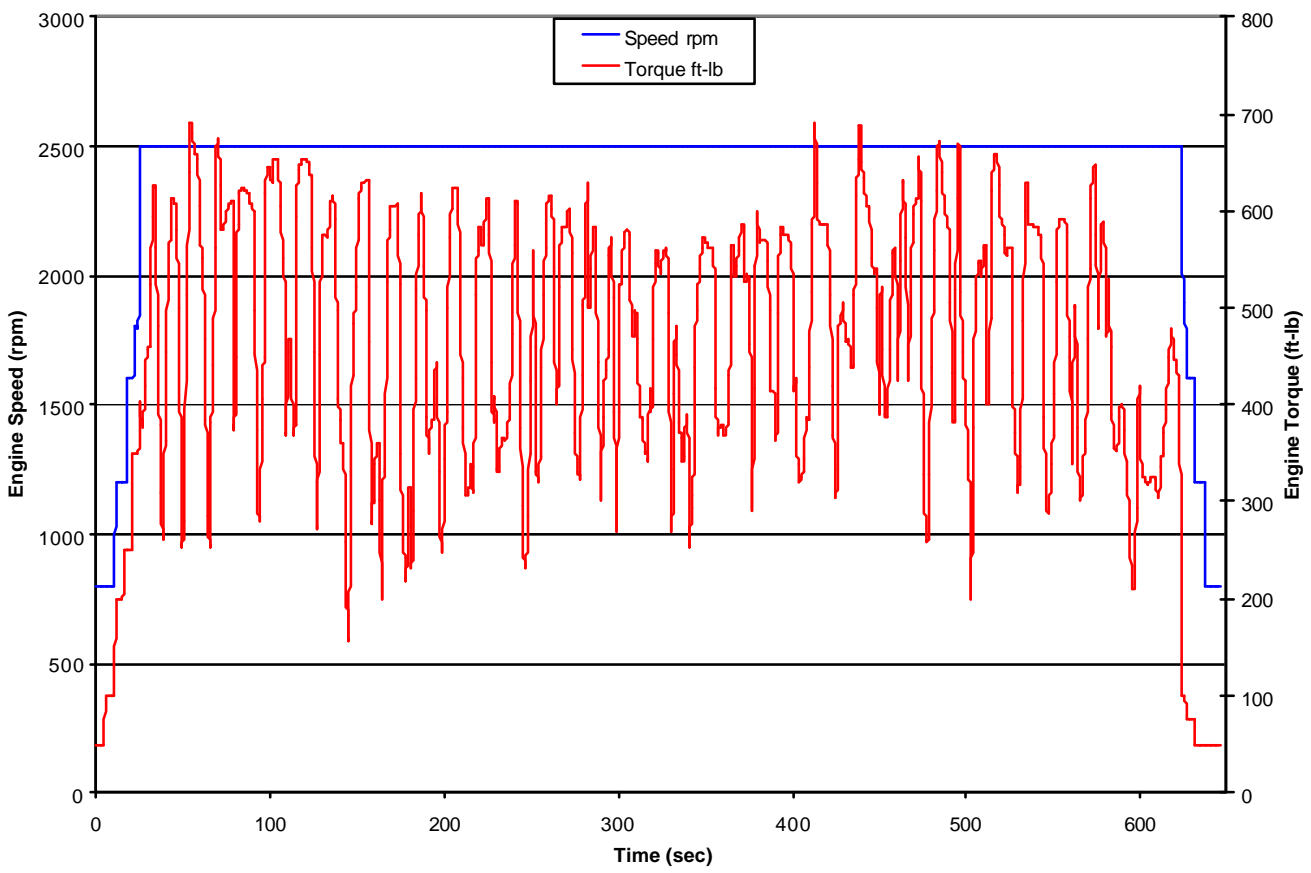

Figure 64 Final Set-point File for Cycle 3

Again the speed is set to an unattainable value, but here the loading takes characteristics from each of the two previous cycles. Short duration peaks ind icate the digging of the trench while longer duration peaks indicate repositioning of the vehicle. 


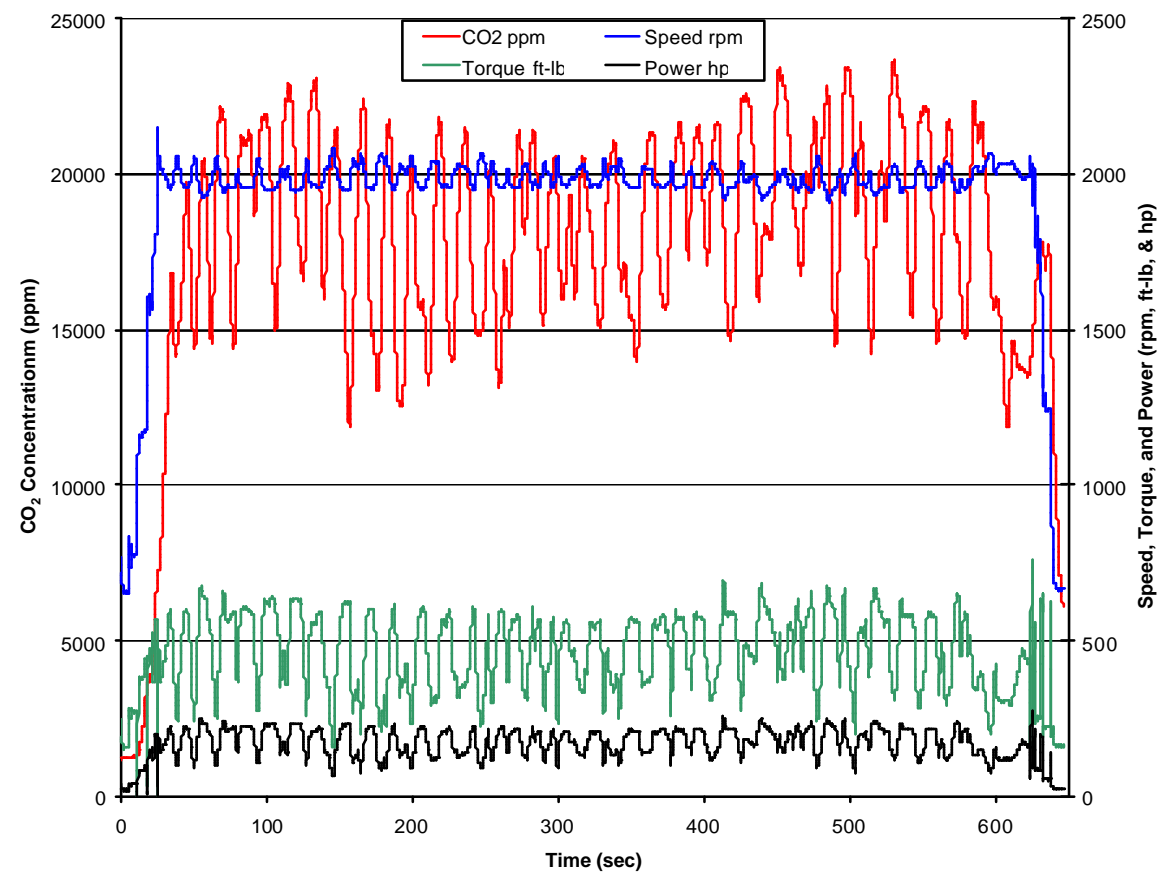

Figure 65 Cycle 3 Final Laboratory Results

Here the engine speed response tends to share more characteristically with cycle one as the trenching operation does not usually involve long periods of vehicle tramming. Thus the continuous power and $\mathrm{CO}_{2}$ traces are characteristic of each other in this case, where torque is not as indicative of $\mathrm{CO}_{2}$ emissions. Like the other cycles, four independent tests of this operation were performed in the laboratory; the average brakespecific results and the four test averages are shown in Table 8. 
Table 8 Transient Cycle Emissions Results for the Komatsu S6D125-1 Excavator Engine Operating According to the WVU Excavator \#3 (Trenching) Test Cycle (g/Bhp-hr)

\begin{tabular}{|c|c|c|c|c|c|}
\hline & Test 1 & Test 2 & Test 3 & Test 4 & Average \\
\hline HC & 1.110 & 1.103 & 1.075 & 1.11 & 1.100 \\
\hline $\mathbf{C O}$ & 0.859 & 0.856 & 0.861 & 0.837 & 0.853 \\
\hline $\mathbf{C O}_{2}$ & 529.9 & 523.4 & 522.8 & 526.2 & 525.6 \\
\hline $\mathbf{N O}_{\mathbf{x}}$ & 5.338 & 5.358 & 5.324 & 5.287 & 5.327 \\
\hline PM & 0.321 & 0.360 & 0.322 & 0.322 & 0.332 \\
\hline \hline
\end{tabular}

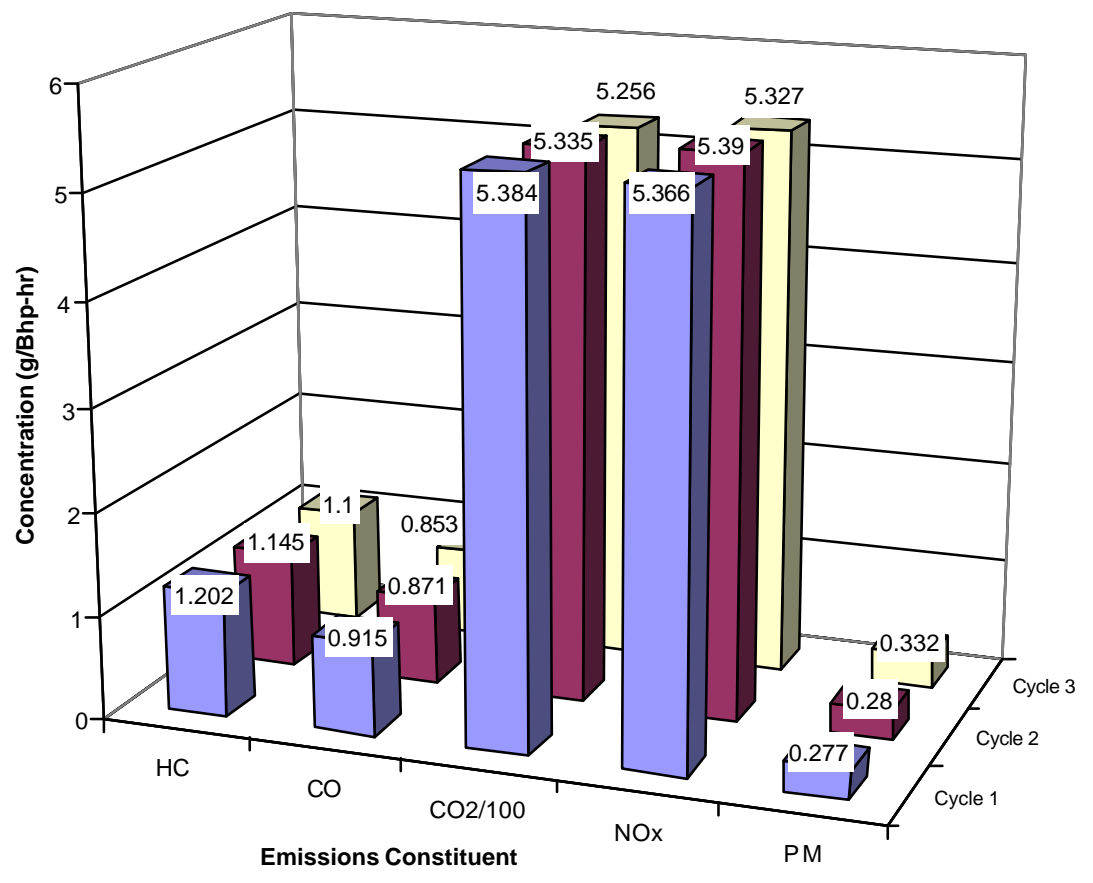

Figure 66 Average Laboratory Results Comparison for the Three Excavator Transient Cycles (g/Bhp-hr)

This figure indicates that the cycles returned similar brake-specific emissions results. This should be expected as the engine speeds and torques shared similar operating ranges throughout the cycles. 


\subsubsection{Steady-state Test Results}

In order that transient test results could be compared to the standard certification test results, two ISO $8178-\mathrm{C}$ steady state tests were performed. The test set points are listed and the results from these tests are tabulated below. At the request of CARB, the eighth or idle mode was performed separately as an extended idle mode at curb idle. Particular attention was given to the idle mode as many machines spend a large amount of time at idle in any given day of operation while an operator may be awaiting instruction or activity completion from the ground crew before the next equipment task, since continually starting and stopping an engine causes excessive wear and thus a shorter life span. The average results of the steady state test data are shown in Table 10, and Figure 67. Weighted 8-Mode results are shown in Figure 68.

Table 9 Excavator 8-Mode Engine Speed/Load Set Points

\begin{tabular}{|c|c|c|c|}
\hline Mode Number & Engine Speed (RPM) & Torque (ft-lbs) & Horsepower (hp) \\
\hline $\mathbf{1}$ & 1800 & 730.0 & 250 \\
\hline $\mathbf{2}$ & 1800 & 547.5 & 188 \\
\hline $\mathbf{3}$ & 1800 & 365.0 & 125 \\
\hline $\mathbf{4}$ & 1800 & 73.0 & 25 \\
\hline $\mathbf{5}$ & 1350 & 745.0 & 192 \\
\hline $\mathbf{6}$ & 1350 & 558.8 & 144 \\
\hline $\mathbf{7}$ & 1350 & 372.5 & 96 \\
\hline $\mathbf{8}$ & $\approx 760$ & - & - \\
\hline
\end{tabular}


Table 10 Average 8-Mode Results for the Komatsu S6D125-1 Excavator Engine (g/Bhp-hr)

\begin{tabular}{|l|c|c|c|c|c|c|c|c|}
\hline & Mode 1 & Mode 2 & Mode 3 & Mode 4 & Mode 5 & Mode 6 & Mode 7 & Mode 8 \\
\hline HC & 0.822 & 0.940 & 1.269 & 7.061 & 0.596 & 0.793 & 1.083 & 7.271 \\
\hline CO & 0.842 & 0.563 & 0.788 & 6.449 & 1.829 & 1.036 & 0.799 & 8.061 \\
\hline CO $_{2}$ & 494.7 & 499.6 & 528.4 & 1036.5 & 488.9 & 489.4 & 507.1 & 862.1 \\
\hline NO $_{\mathbf{x}}$ & 7.328 & 6.396 & 5.257 & 7.854 & 7.664 & 7.469 & 6.867 & 16.166 \\
\hline PM & 0.362 & 0.295 & 0.328 & 1.449 & 0.582 & 0.432 & 0.360 & 1.354 \\
\hline
\end{tabular}

These test results indicate that the engine usually operates at governed speed between $50 \%$ and $75 \%$ of maximum load. This confirms observations made during the collection of the in-field data. More information on cycle characteristics follows in Section 4.6 Discussion.

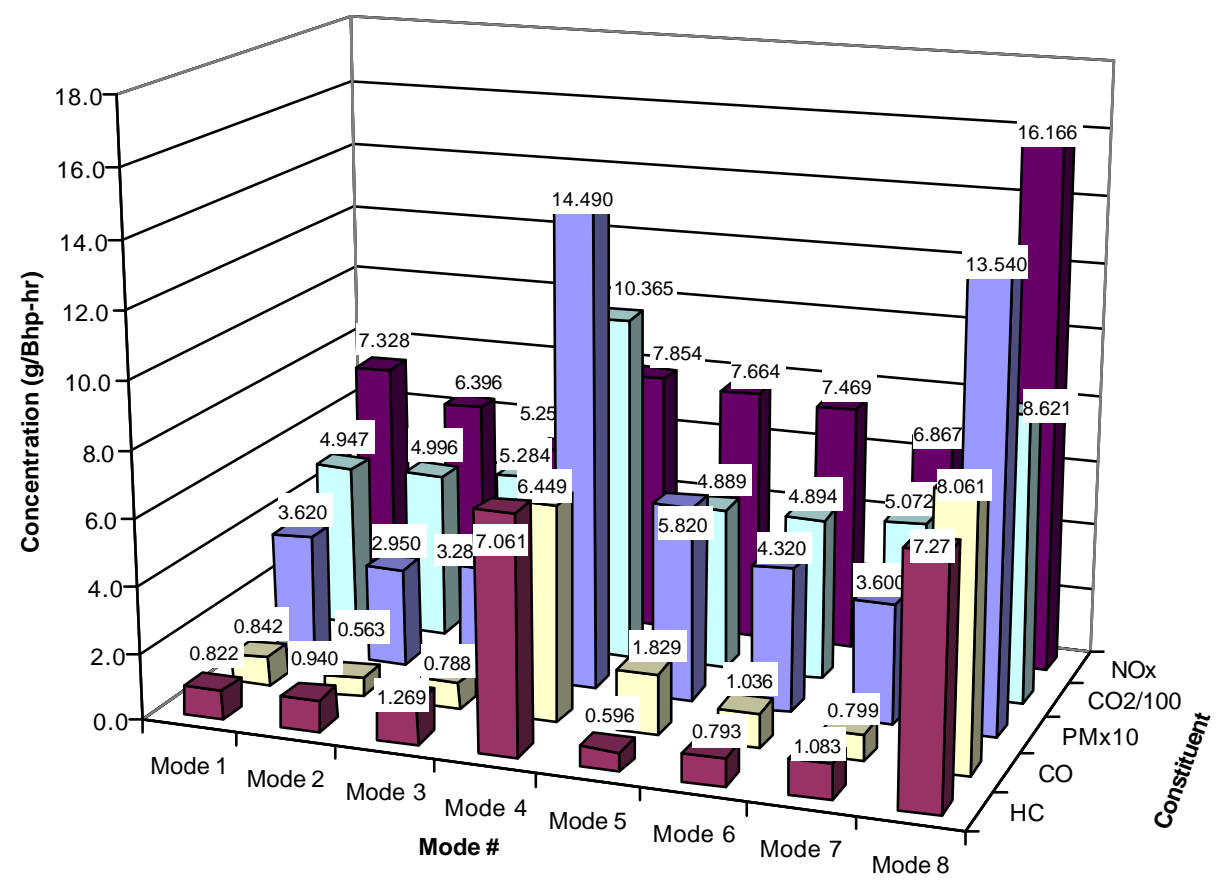

Figure 67 Average of 8-Mode Results for the Komatsu S6D125-1 Engine (g/Bhp-hr) 


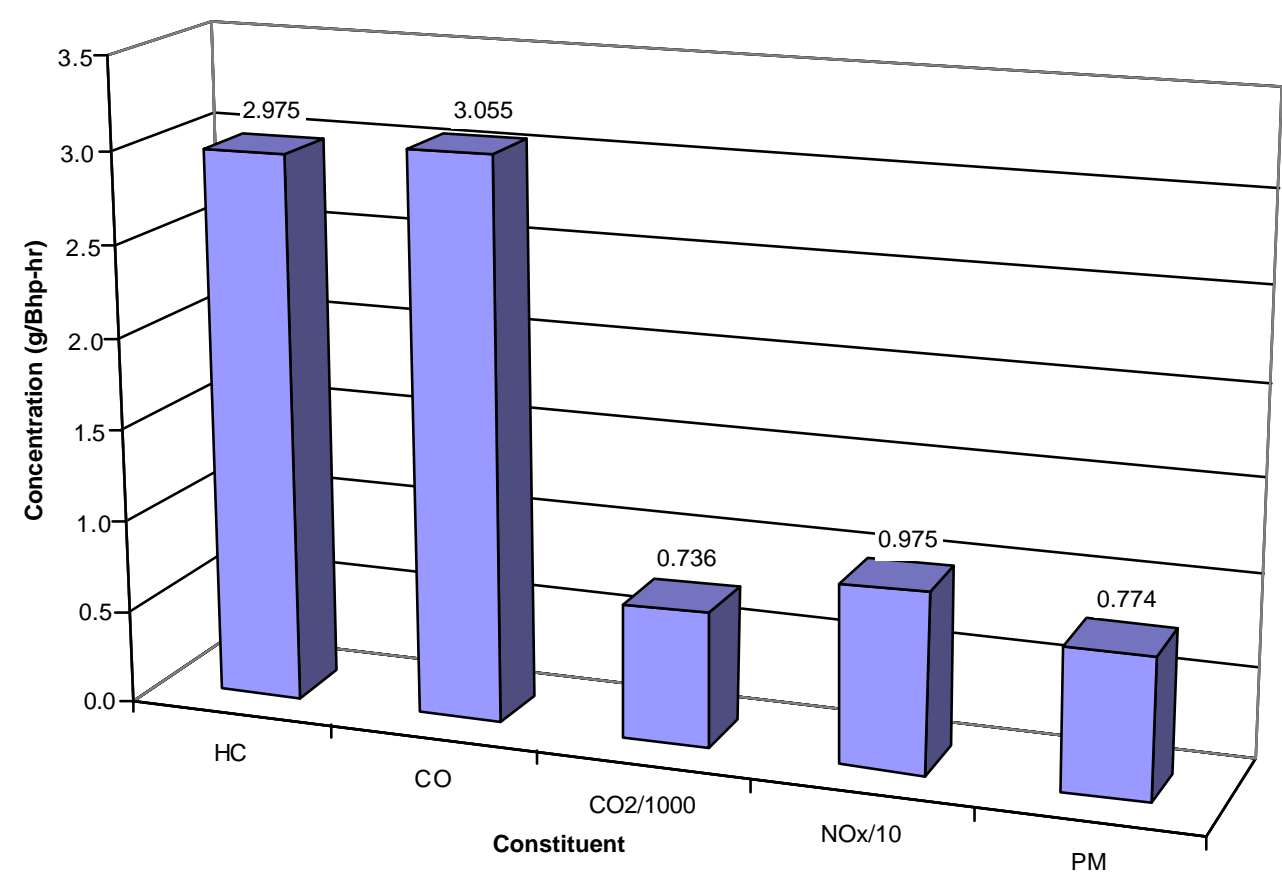

Figure 68 Average Weighted 8-Mode Emissions for the Komatsu S6D125-1 Engine (g/Bhp-hr)

Table 11 Comparison of Weighted 8-Mode Results with Average Transient Test Results for the Komatsu S6D125-1 Excavator Engine (g/Bhp-hr)

\begin{tabular}{|l|c|c|c|c|c|c|c|}
\hline & $\begin{array}{c}\text { Weighted } \\
\text { 8-Mode } \\
\text { Results }\end{array}$ & $\begin{array}{c}\text { Transient } \\
\text { Cycle 1 } \\
\text { Results }\end{array}$ & $\begin{array}{c}\text { Transient } \\
\text { Cycle 2 } \\
\text { Results }\end{array}$ & $\begin{array}{c}\text { Transient } \\
\text { Cycle 3 } \\
\text { Results }\end{array}$ & $\begin{array}{c}\text { \% Diff } \\
\text { Cycle 1 } \\
\text { to 8- } \\
\text { Mode }\end{array}$ & $\begin{array}{c}\text { \% Diff } \\
\text { Cycle 2 } \\
\text { to 8- } \\
\text { Mode }\end{array}$ & $\begin{array}{c}\text { \% Diff } \\
\text { Cycle 3 } \\
\text { to 8- } \\
\text { Mode }\end{array}$ \\
\hline HC & 2.50 & 1.202 & 1.145 & 1.100 & 51.92 & 54.20 & 56.00 \\
\hline CO & 2.55 & 0.915 & 0.871 & 0.853 & 64.12 & 65.84 & 66.55 \\
\hline $\mathbf{C O}_{2}$ & 609.9 & 538.4 & 533.5 & 525.6 & 11.72 & 12.53 & 13.82 \\
\hline NO & 8.26 & 5.366 & 5.390 & 5.327 & 35.04 & 34.75 & 35.51 \\
\hline PM & 0.633 & 0.277 & 0.280 & 0.332 & 56.24 & 55.77 & 47.55 \\
\hline
\end{tabular}

The results of Table 11 were calculated by a simple percent difference, using the following equation. 
It is notable that emissions produced during the transient test cycles are much lower in value than those of the weighted 8-Mode results. This indicates that use of the 8-Mode test for emissions inventory purposes could provide misleading data. However, if weighted 8-Mode results were adjusted by giving more weight to modes that the engine most often operated near on average, the emissions results might more closely resemble one another. Determining appropriate weighting factors would be difficult, as each vehicle would require independent consideration. Other considerations involve the brake-specific approach to emissions reporting. To the untrained eye the emissions of modes 4 and 8 seem outrageously high; however, with near 0 power production in these modes, the results are skewed by a small denominator. The brake-specific approach is traditionally accepted as it provides a means of comparing engines of different power classes, but a fuel-specific approach may be a more meaningful and useful tool for reporting emissions results. In any case, the results of the testing performed on this engine indicate that many considerations still need to be made for the standardization of off-highway emissions testing to provide meaningful data that represents "real-world" operation.

\subsubsection{Comparison of Test Cycle Emissions Results: WVU Off-road Transient Cycle vs. EPA Off-road Transient Cycle}

In order to provide comparative insight into the accuracy of the methods used for the development of the transient dynamometer test cycles for this project, a review of relevant, published engine test cycles was conducted. A test cycle, which was developed by the EPA for excavator engines, was exercised on the Komatsu S6D125-1 engine [24]. These tests were 30 minutes in length and encompassed a range of operations normally 
performed by this class of engine. The results from this testing are listed below as well as compared to the final cycles developed from field data. A problem was encountered during the first operation of this test cycle in that the fueling system failed mid-test for a short time. The subsequent tests did not exhibit this malfunction. With the loss of fueling, engine power was also lost for a short time and thus the overall cycle work was reduced. As the brake-specific results were distorted by this fact, the average EPA cycle results used for comparison to other test cycles are an average of tests 2 and 3.

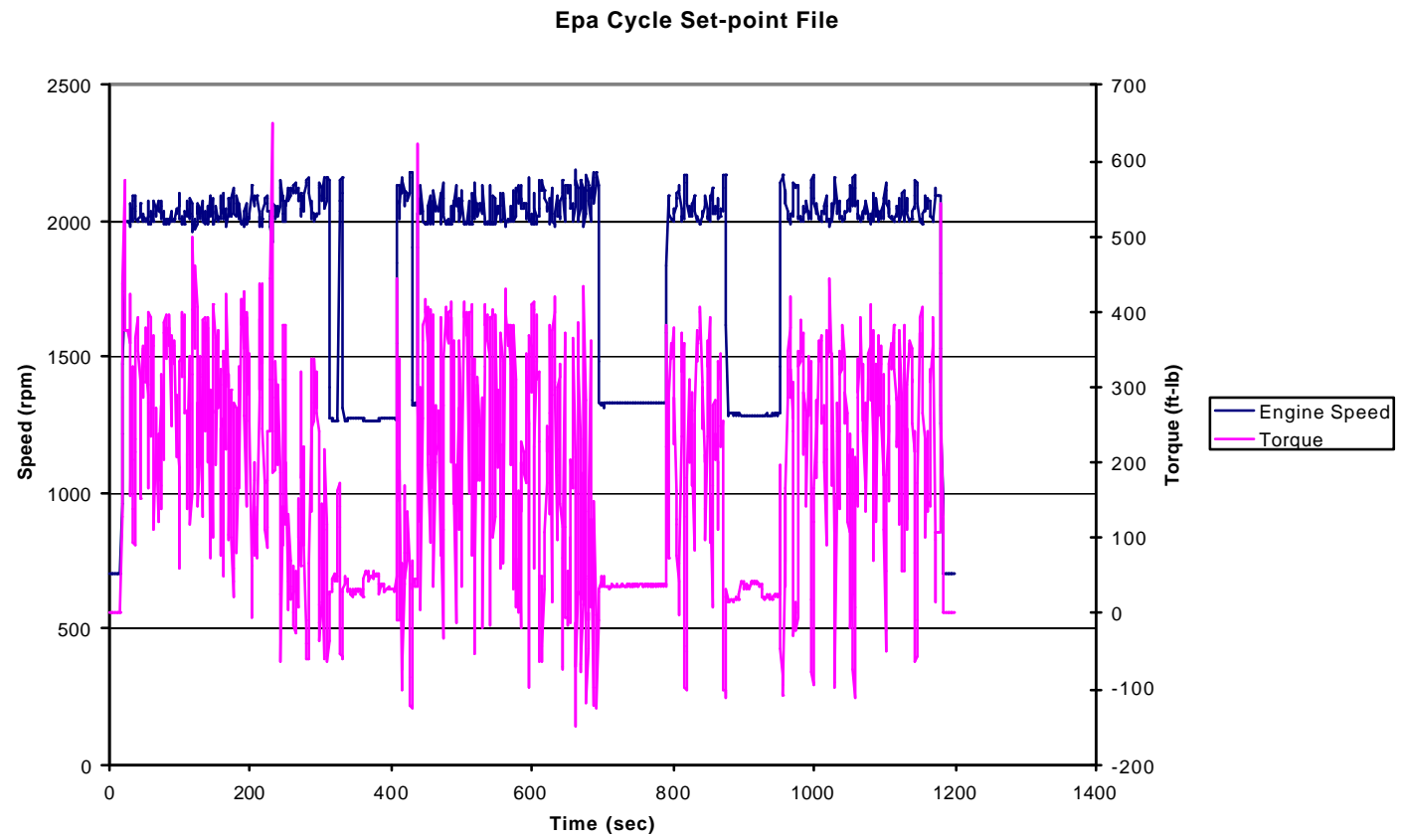

Figure 69 Set-point Torque and Speed for EPA Cycle 


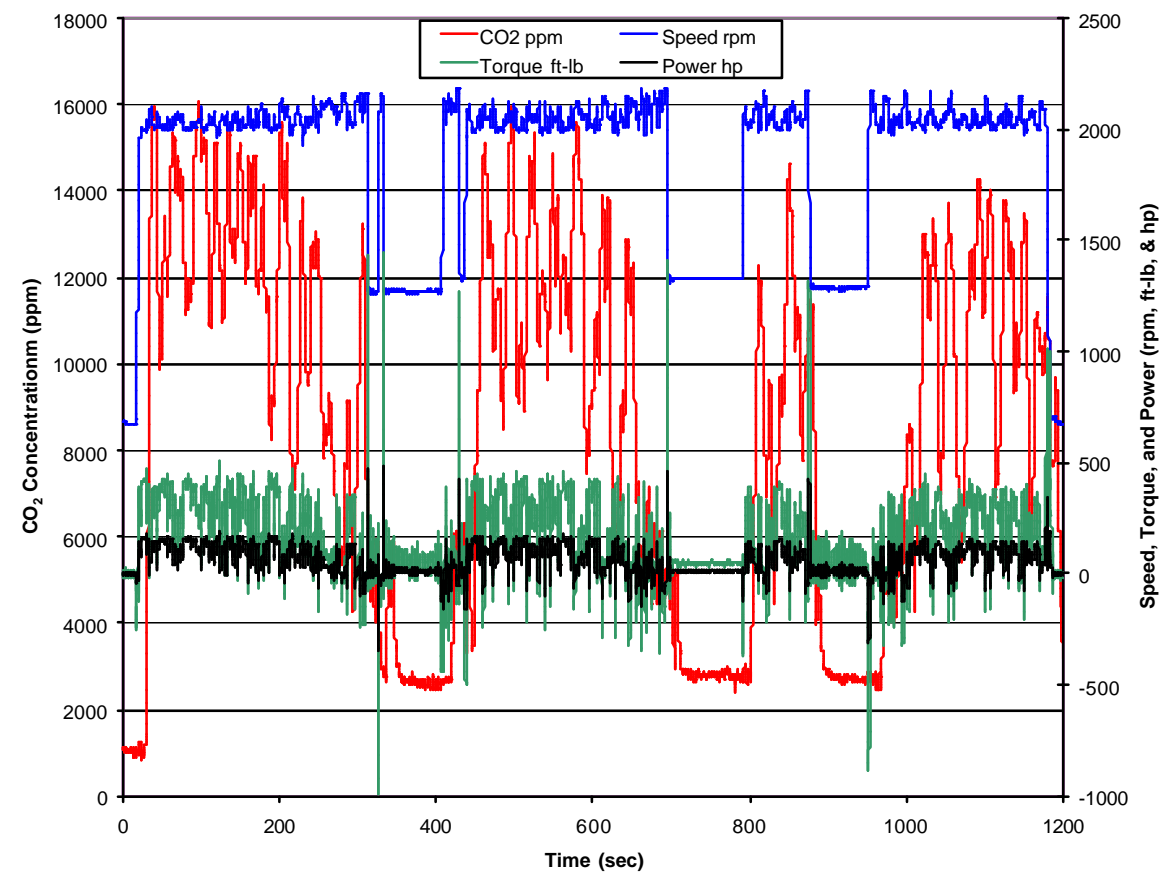

Figure 70 EPA Cycle Continuous Laboratory Results

Table 12 Emissions Results for the Komatsu S6D125-1 Excavator Engine Operating According to the EPA Excavator Test Cycle (g/bhp-hr)

\begin{tabular}{|c|c|c|c|c|}
\hline & $\begin{array}{c}\text { EPA Cycle } \\
\text { Test 1 }\end{array}$ & $\begin{array}{c}\text { EPA Cycle } \\
\text { Test 2 }\end{array}$ & $\begin{array}{c}\text { EPA Cycle } \\
\text { Test 3 }\end{array}$ & $\begin{array}{c}\text { Test 2-3 } \\
\text { Average }\end{array}$ \\
\hline HC & 2.127 & 2.085 & 2.016 & 2.05 \\
\hline $\mathbf{C O}$ & 1.891 & 1.942 & 1.865 & 1.903 \\
\hline $\mathbf{C O}_{2}$ & 631.1 & 628.5 & 636.0 & 632.3 \\
\hline $\mathbf{N O}_{\mathbf{x}}$ & 4.879 & 4.907 & 4.838 & 4.873 \\
\hline $\mathbf{P M}$ & 1.027 & 0.586 & 0.418 & 0.502 \\
\hline
\end{tabular}

The results shown in this table are generally higher than those of the test cycles derived from in-field data, with the exception of $\mathrm{NO}_{\mathrm{x}}$ emissions. This is largely due in part to the idle periods of the EPA cycle which cause the cycle work to be lower when compared to the normalized cycle work of the other transient test cycles. A more detailed 
discussion of this matter is included in Section 4.6. The following shows the results of the in-field derived cycles average brake-specific emisssions with the EPA cycle results.

Table 13 Comparison of Brake-specific Exhaust Emissions Results for the Komatsu S6D125-1 Excavator Engine Operating According to the WVU Excavator Test Cycles and the EPA Excavator Test Cycle (g/Bhp-hr)

\begin{tabular}{|c|c|c|c|c|}
\hline & $\begin{array}{c}\text { Cycle 1 } \\
\text { Average }\end{array}$ & $\begin{array}{c}\text { Cycle 2 } \\
\text { Average }\end{array}$ & $\begin{array}{c}\text { Cycle 3 } \\
\text { Average }\end{array}$ & EPA Cycle \\
\hline $\mathbf{H C}$ & 1.202 & 1.145 & 1.100 & 2.05 \\
\hline $\mathbf{C O}$ & 0.915 & 0.871 & 0.853 & 1.903 \\
\hline $\mathbf{C O}_{\mathbf{2}}$ & 538.4 & 533.5 & 525.6 & 632.3 \\
\hline $\mathbf{N O}$ & 5.366 & 5.390 & 5.327 & 4.873 \\
\hline $\mathbf{P M}$ & 0.277 & 0.280 & 0.332 & 0.502 \\
\hline
\end{tabular}

Table 13 shows that the brake specific emissions will vary significantly with engine duty cycle. Therefore, extensive testing would be required among different operators and machinery to find a realistic representation of a transient test cycle that would accurately represent a broad estimation of the exhaust emissions produced by offroad machinery.

\subsection{Discussion}

The data collected during this study was analyzed so as to compare the differences in emissions produced by an engine due to the nature of the test cycle on which it is operated. The following elaborates on the characteristics of the transient cycles developed and recorded during this study. Data is included from two other engines that were tested by Barnett (2001) [2], as a comparative measure to demonstrate the very different nature of duty cycles for off-highway diesel engines. The results from averaged transient and weighted steady state tests were also compared and found to vary 
significantly. Analysis of this data was performed to evaluate measures that would remove the difference between these test results.

The striking result of this study was that the transient test results produced much lower brake-specific emissions results than the ISO 8178 8-Mode test, which is used for off-highway engine certification.

\subsubsection{Engine Load and Speed Factors}

An analysis of the laboratory produced test cycles was performed for all vehicles tested under this study to determine the average engine load and speed factors. To determine the load factor, the cycle was normalized against the engine map, using a program developed by WVU, to determine the percent load at each data point. This data set was then averaged to produce the average cycle load factor. Engine speed data from the cycle was normalized against governed central speed (GCS, the speed at which the engine produces $1 / 2$ the maximum power once it has passed the maximum power point on the engine map). The following equation was used for normalization:

$$
\text { (Engine Speed - Idle Speed)/(GCS - Idle Speed) * } 100
$$

\section{Equation 13}

The results of this analysis are shown in the following figures. Caterpillar furnished the engine load data for the track-type tractor. 


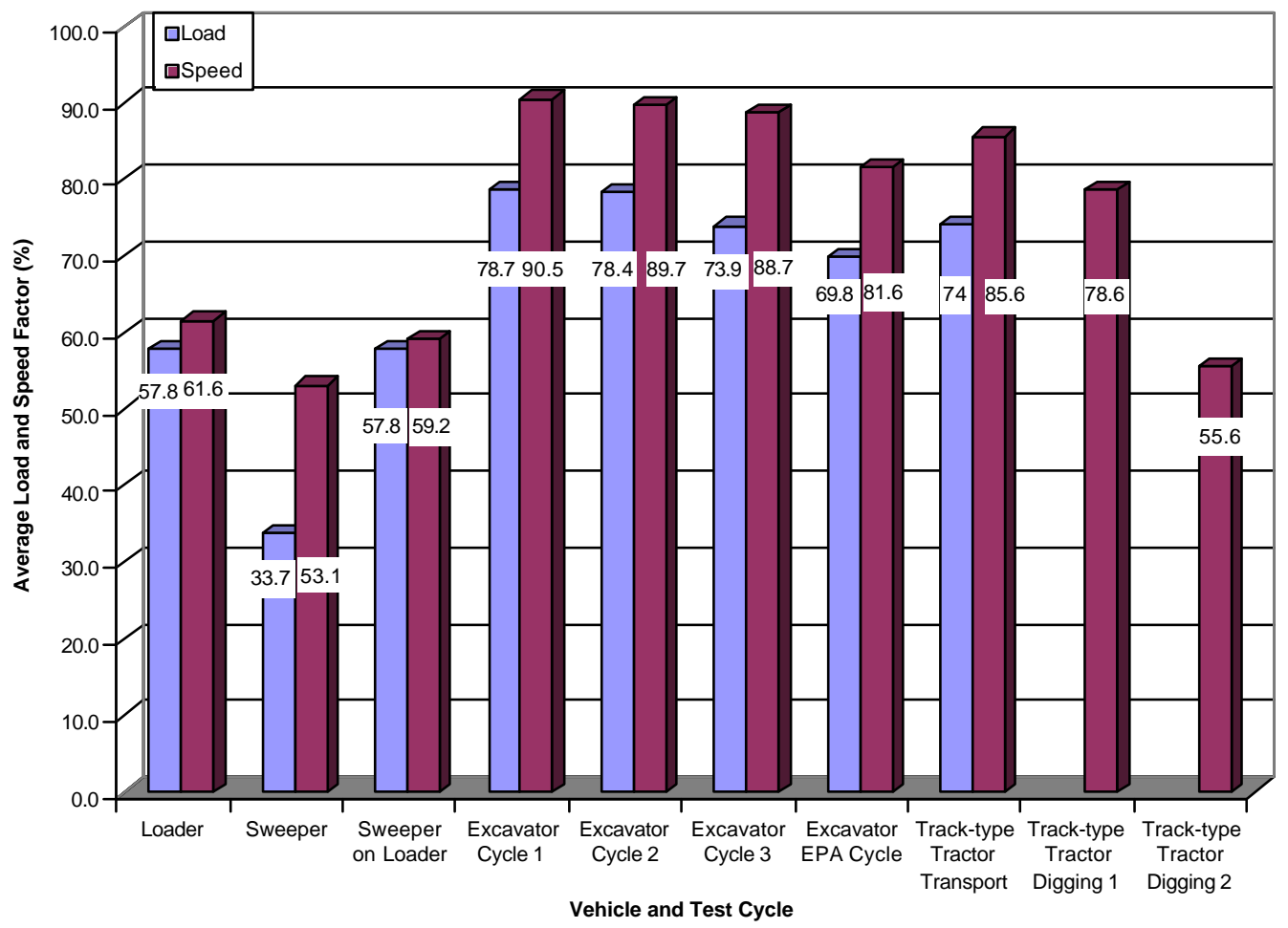

Figure 71 Average Load and Speed Factors for All Vehicles and Test Cycles

Figure 71 displays the averaged load and speed factors for each vehicle and test cycle evaluated under this study. Table 14 shows the cycle lengths with the average load factor for the laboratory transient tests of all engines tested under this study.

Table 14 Average Load Factor and Cycle Time for the Laboratory Transient Test

Cycles

\begin{tabular}{|c|c|c|c|c|c|c|c|}
\hline Cycle & Loader & Sweeper & $\begin{array}{c}\text { Sweeper } \\
\text { on } \\
\text { Loader }\end{array}$ & $\begin{array}{c}\text { Excavator } \\
1\end{array}$ & $\begin{array}{c}\text { Excavator } \\
2\end{array}$ & $\begin{array}{c}\text { Excavator } \\
3\end{array}$ & $\begin{array}{c}\text { Excavator } \\
\text { EPA }\end{array}$ \\
\hline \hline $\begin{array}{c}\text { Load } \\
\text { Factor }\end{array}$ & 57.8 & 33.7 & 57.8 & 78.7 & 78.4 & 73.9 & 74 \\
\hline $\begin{array}{c}\text { Cycle } \\
\text { Length } \\
\text { (s) }\end{array}$ & 1144 & 1226 & 1144 & 650 & 645 & 646 & 1198 \\
\hline
\end{tabular}


Note that since the loader cyc le was normalized for use on the sweeper, the load factors of the two cycles are identical. The load factor for the track-type tractor was derived directly from data that was received from Caterpillar. The speed factors for the track-type tractor are derived from the MEMS speed data files, and the Caterpillar supplied loading data was used for the determination of governed central speed. The next set of figures illustrates the normalized load and speed curves for cycles listed above.

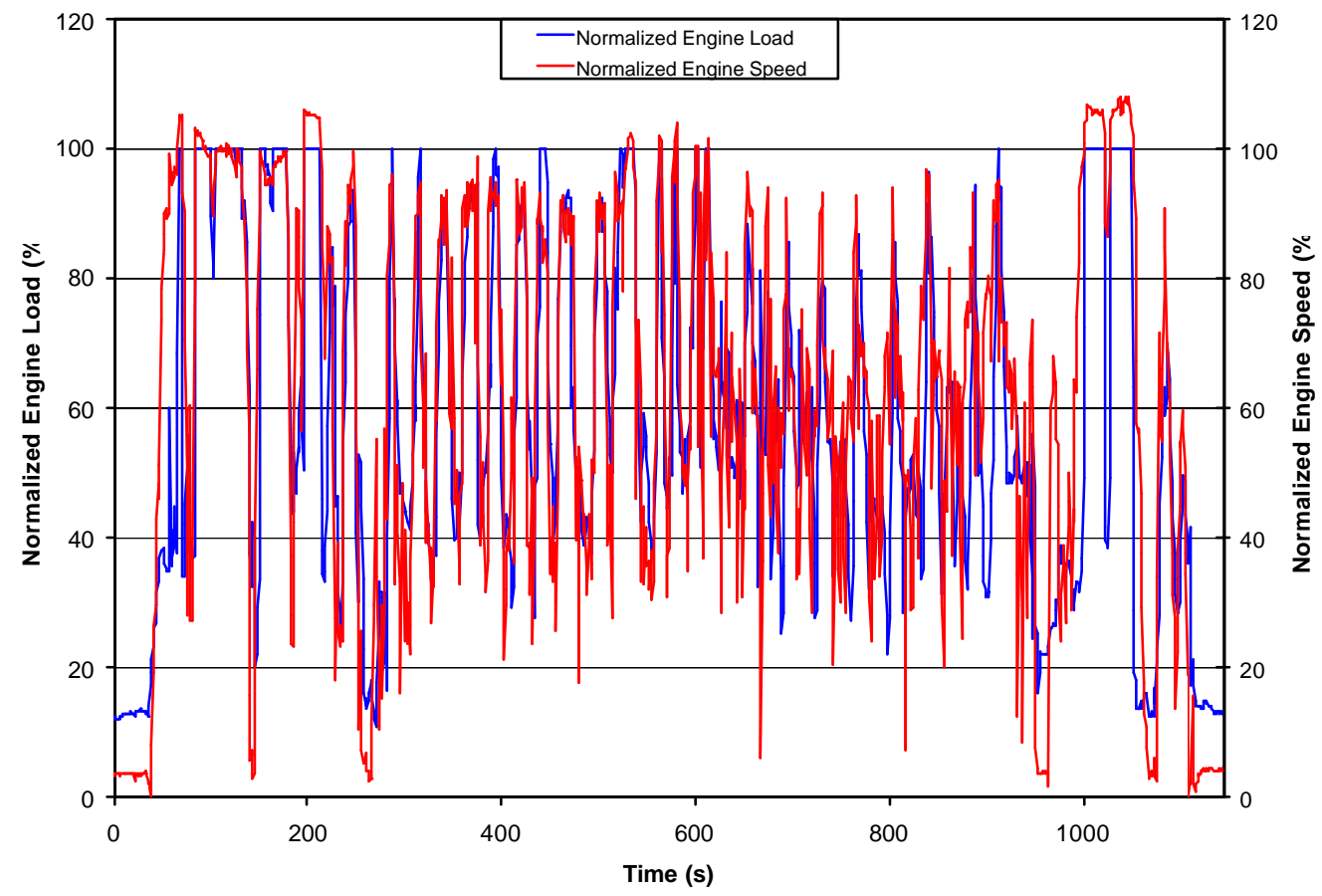

Figure 72 Normalized Load and Speed Curve for the WVU Loader Cycle

Figure 72 shows the normalized speed and load curve from the loader transient cycle that was developed by WVU during earlier testing performed under this study. The loader was a John Deere 444 with a 6059 D engine. For more information on this testing consult the thesis written by Barnett [2]. Values are shown in percentages. Note that as the speed curve was normalized to governed central speed, the curve occasionally exceeds $100 \%$ as the engine does occasionally operate above GCS. 


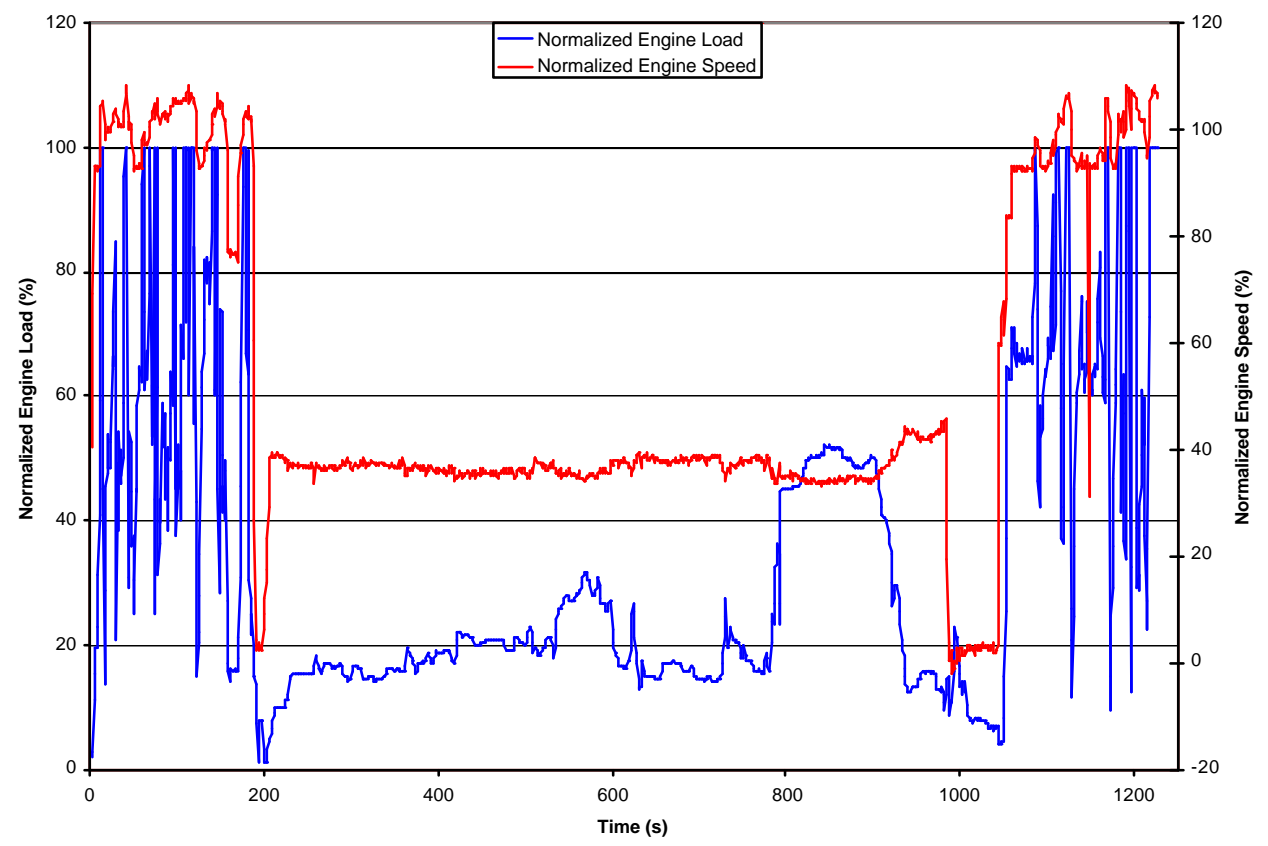

Figure 73 Normalized Load and Speed Curve for the WVU Street Sweeper Cycle

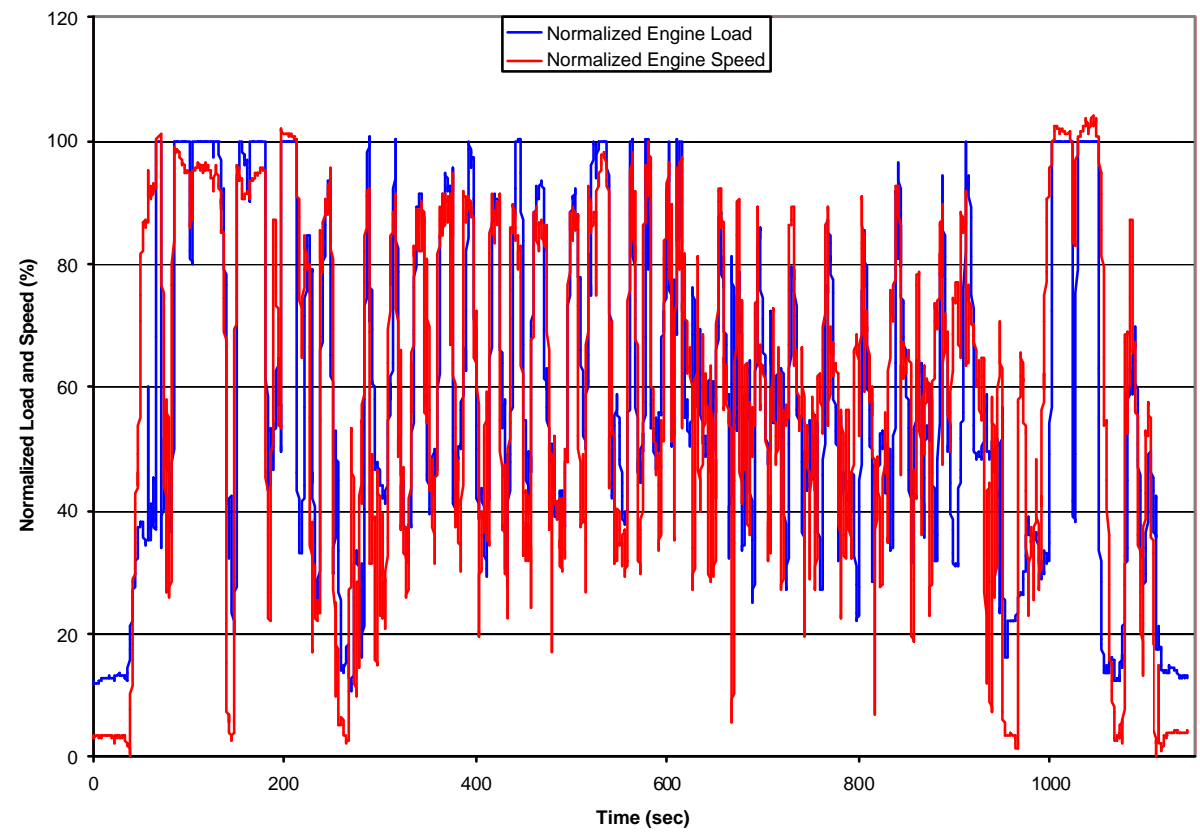

Figure 74 Normalized Load and Speed Curve for the Street Sweeper on Loader Cycle 
Figure 73 displays the normalized load and speed curve from the street sweeper transient cycle that was developed by WVU from the in- field data collected during earlier work performed under this study. The figure shows that the characteristic cycle for this engine does not encounter high loading or high engine speed except during transport operation. In this case the vehicle normally operates on-highway, which leads to the genesis of a classification problem by which some off-highway vehicles do operate onhighway for a considerable period, and thus may be considered subject to on- highway diesel engine emissions standards. Figure 74 shows the normalized load and speed curve for the loader cycle as it was modified for use on the street sweeper engine. Note that the normalized load curve is identical between this cycle and the loader cycle. Differences in the normalized speed curves are accounted for by the difference in governed central speeds between the two engines. 


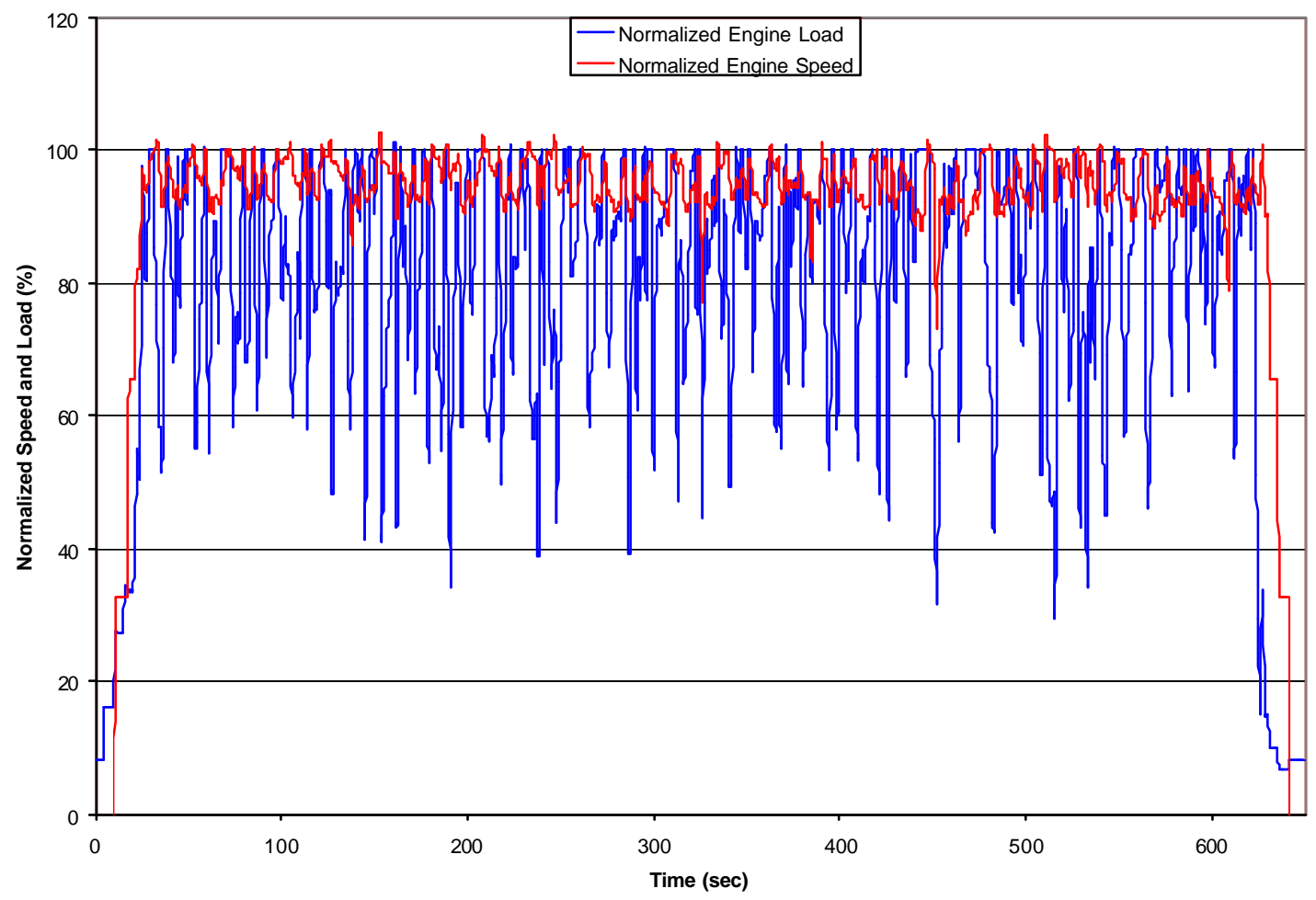

\section{Figure 75 Normalized Load and Speed Curve for the WVU Excavator Cycle 1}

Figure 75 shows the normalized load and speed curve for the excavator digging cycle (cycle 1) developed by WVU from in-field data. This shows a higher characteristic-loading curve than the first two vehicles tested under this study largely due to the fashion in which the vehicle operates. The excavator will remain in one spot and continually move material with the engine operating at high speed, while the other vehicles spend more time in transit to move material and have more variance in engine speed. 


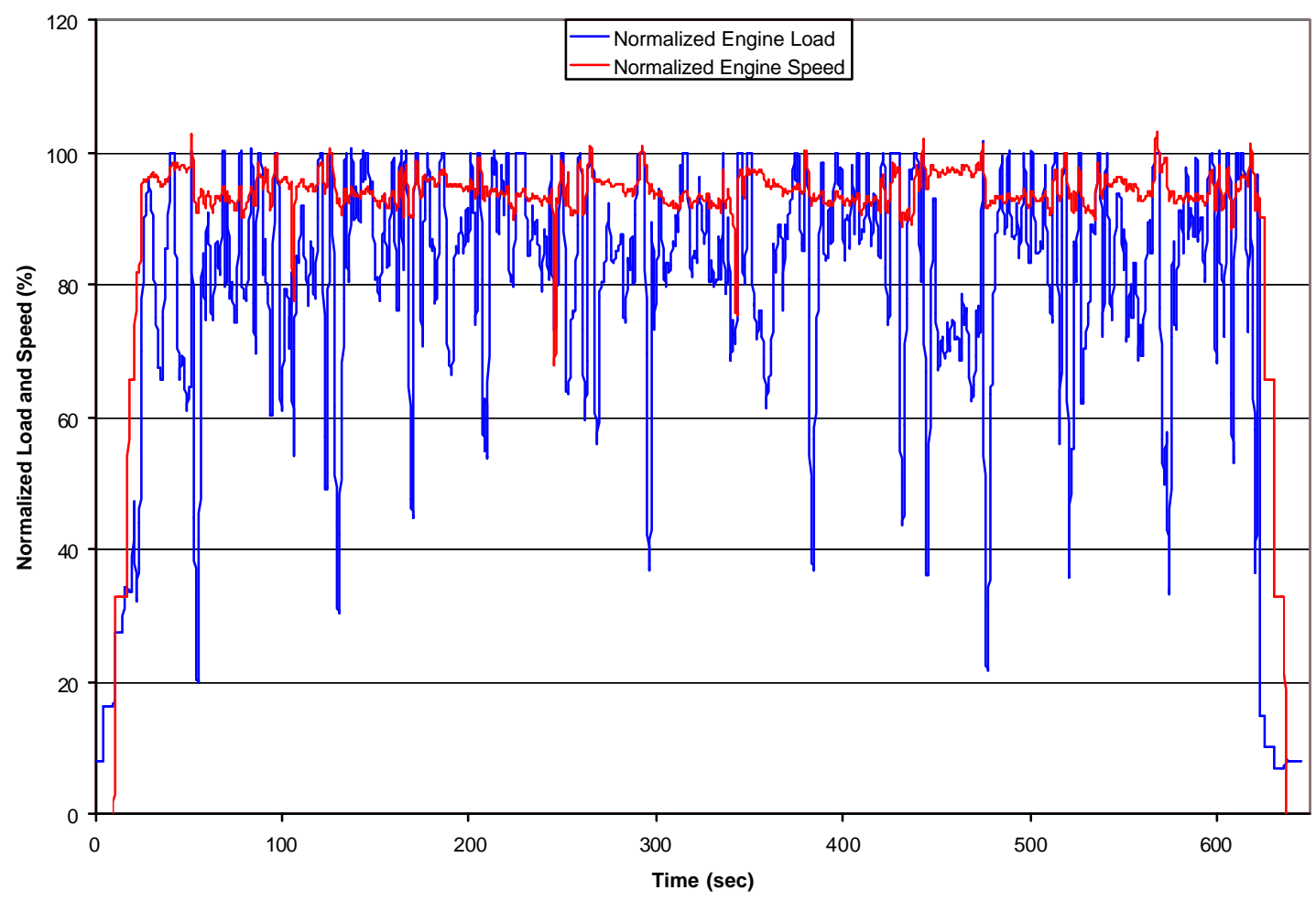

Figure 76 Normalized Load and Speed Curve for the WVU Excavator Cycle 2

Figure 76 shows the normalized engine load and speed curve for the excavator hauling cycle (cycle 2), which was developed by WVU from in-field data. This figure again displays that the excavator tends to operate at higher speed and load factors than the other vehicles. 


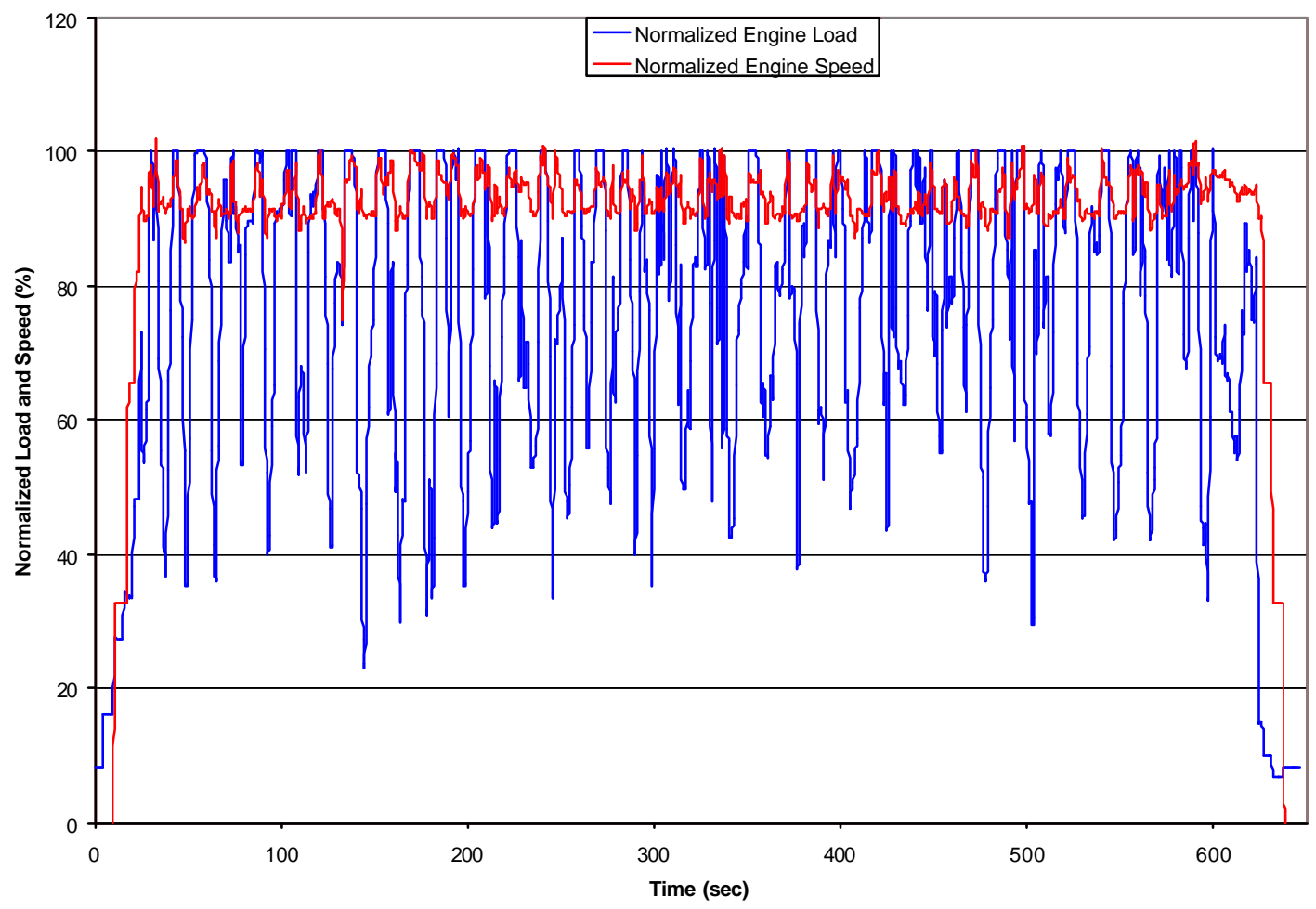

Figure 77 Normalized Load and Speed Curve for the WVU Excavator Cycle 3

Figure 77 shows the normalized engine load and speed curve for the excavator trenching cycle (cycle 3), which was developed by WVU from in-field operation data. The cycle averaged load factors for the three excavator cycles are relatively close, but review of the continuous curves reveals the different characteristics of each cycle. 


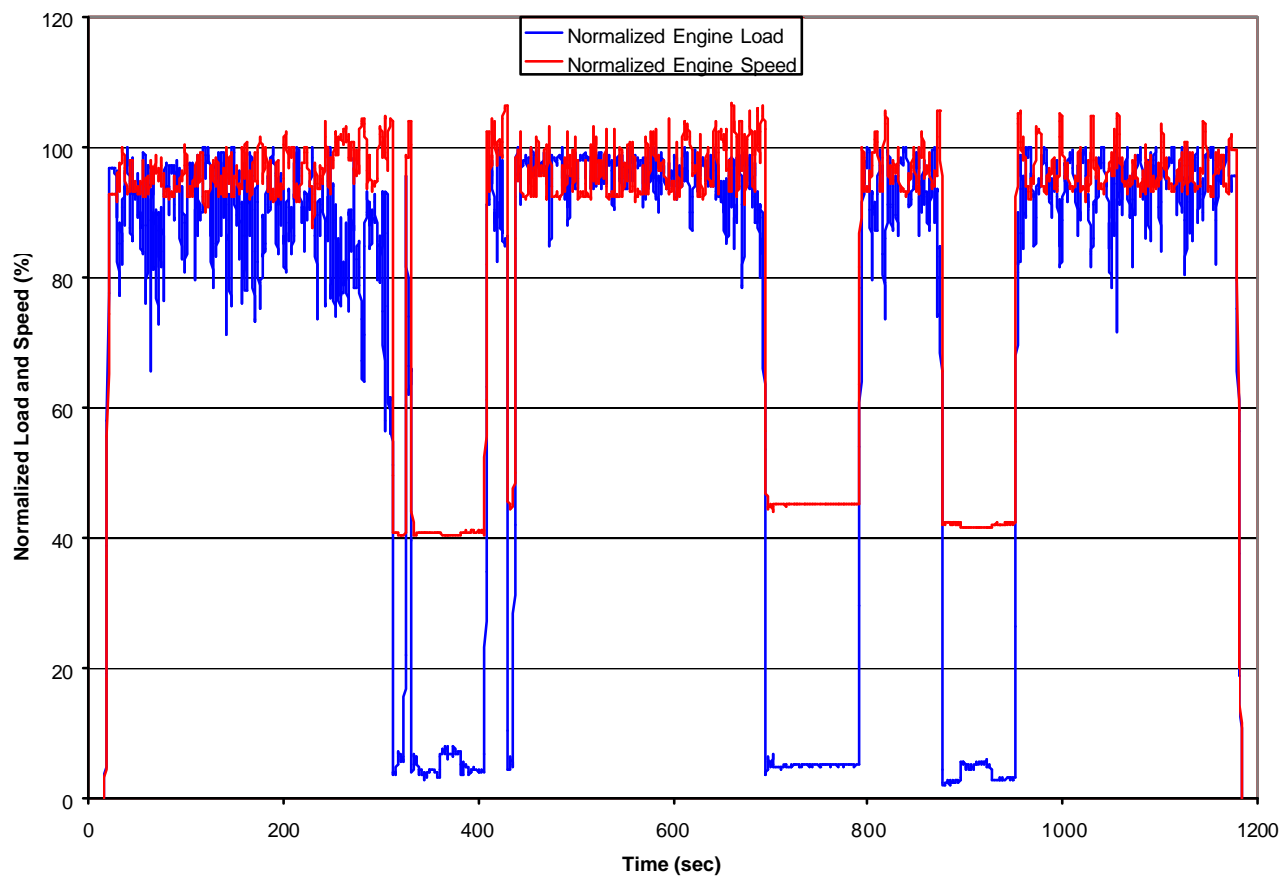

Figure 78 Normalized Load and Speed Curve for the EPA Excavator Cycle

Figure 78 displays the normalized engine load and speed curve for the EPA excavator cycle as tested by WVU. This cycle has lower average load and speed factors than the WVU developed cycles, and a simple review of the continuous curves reveals that this is because of the lengthy low-load, low-speed sections in the EPA cycle. 


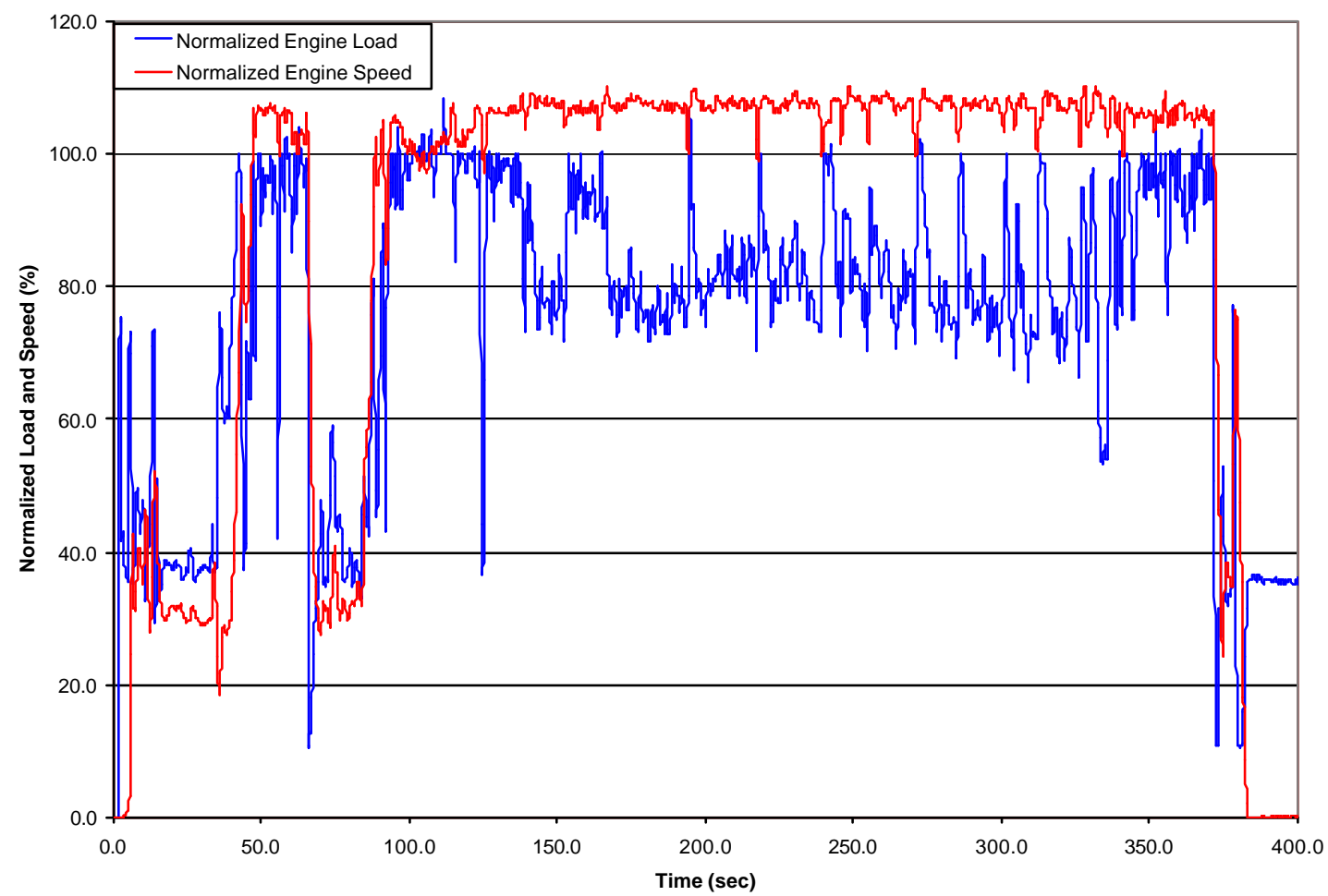

Figure 79 Normalized Load and Speed Curve for the Track-type Tractor Transport Test

Figure 79 shows the continuous engine load and speed data that was provided to WVU by Caterpillar. The cycle exhibits a high engine speed with moderate loading. This is characteristic of the transport operation, as the engine speed tends to high idle to move the tractor faster to the location where production is occurring so as to minimize non-productive operation. 


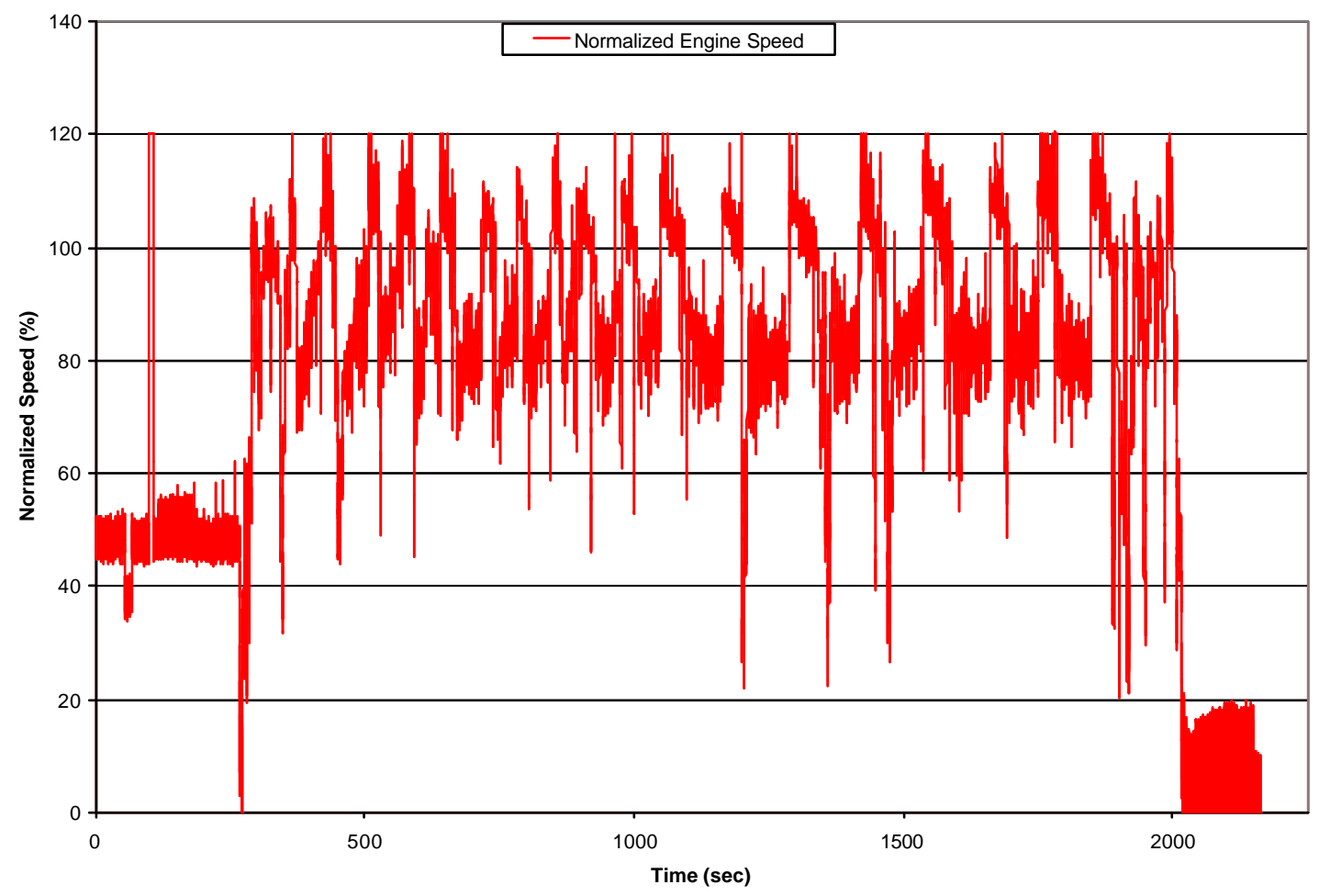

Figure 80 Normalized Engine Speed Data for Track-type Tractor Digging Cycle 1

Figure 80 displays the normalized speed data collected by the MEMS from the first digging test performed with the track type tractor. This figure indicates that the tractor operates at high speed and low load for a significant period, which is due to the transport of the vehicle to the digging start point, after a digging cycle has been completed. Spikes in this and subsequent figures are short durations of noise that can be disregarded. 


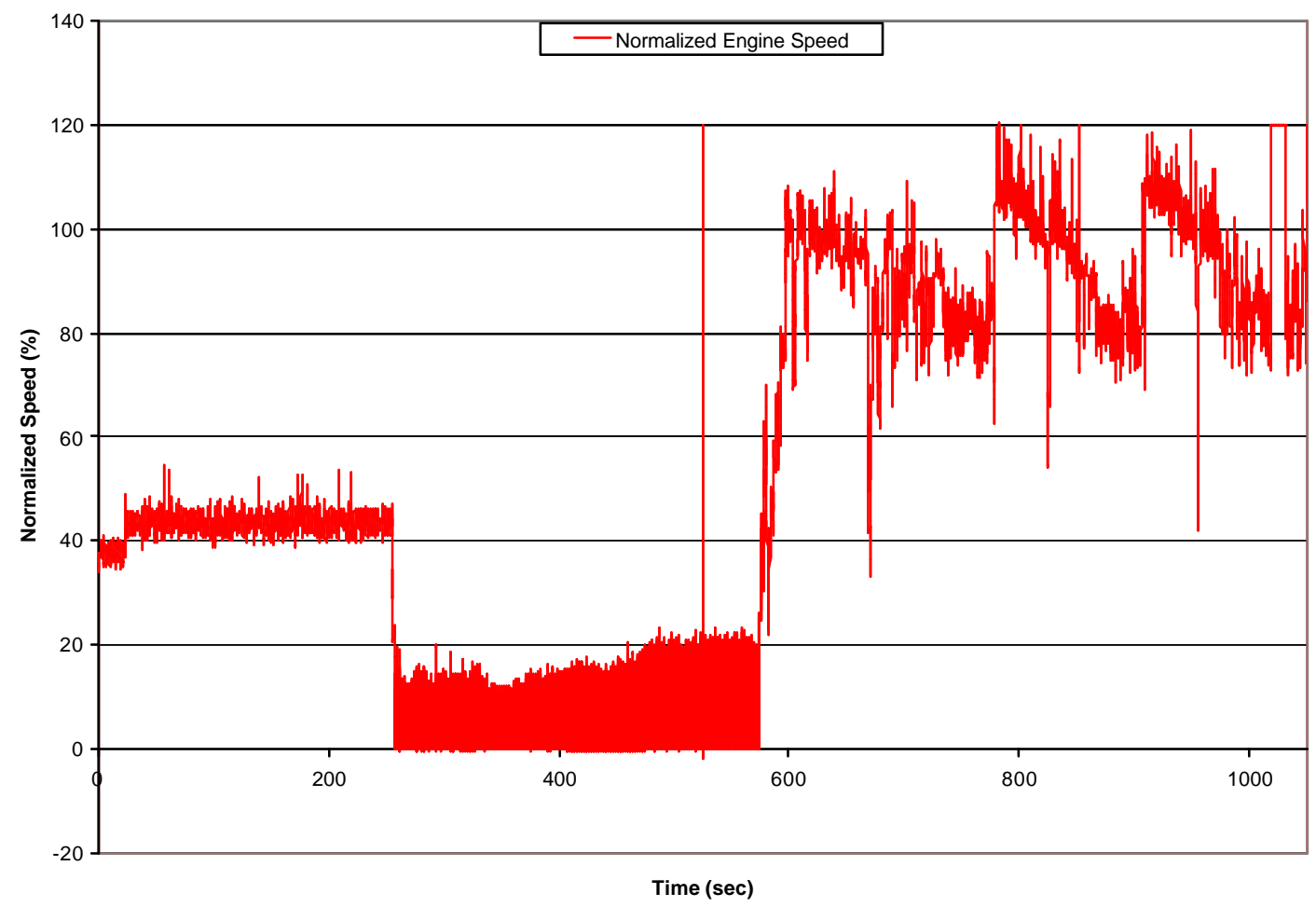

Figure 81 Normalized Engine Speed Data from Track-type Tractor Second Digging Test

Figure 81 shows approximately 1000 seconds of normalized engine speed data from the second track-type tractor digging test. This test exhibits the same characteristics as observed in Test 1 .

The information presented herein provides more proof to the observation that the operating cycles of off-highway equipment are very task and machine specific. When coupled with the results of emissions testing, the evidence leads to the conclusion that in order to understand the emissions produced by off-highway vehicles, each vehicle type will need separate consideration regardless of the given vehicle's engine power rating. 


\subsubsection{Characterization of Transient Test Cycles}

In order that a better understanding and conceptualization of the transient cycles that have been observed and tested under this study, the following gives a characterization of the cycles with respect to the amount of cycle time spent in certain speed ranges and the corresponding loads for the ranges that are most used during the cycle. Speed ranges were separated by units of $100 \mathrm{rpm}$ from either 0 or idle speed to the range of the maximum recorded speed for the cycle. Engine load was also divided into $100 \mathrm{ft}-\mathrm{lb}$ or $10 \%$ increments, depending on the availability of load data. The cycles presented herein are evaluated for characterization and comparison only, this section is meant to neither endorse nor discount any transient test cycle for the off-highway vehicles tested under this study.

\subsubsection{Transient Cycles Used on Komatsu PC400-LC3 Excavator}

The cycles developed from the in-field data are all very similar in nature. They produce relatively similar brake specific emissions results. Although they may differ in instantaneous loading and response, the following figures demonstrate that the cycles are nearly the same when averaged. Figure 82 shows the speed range breakdown for transient cycle 1 , the excavator digging operation. Values are a percentage of the total test cycle time spent in the associated speed range. Review of the figure shows that the significant operating ranges for this cycle are 1900-2000 rpm and 2000-2100 rpm. Using these speed ranges, the cycle was characterized as to the amount of time spent under different loading under the specific speed range. Figure 83 shows the amount of time that was spent at different loading ranges while the engine operated between 1900 and 2000 rpm under test cycle 1. This figure shows that the engine encountered loads between 400 
and $600 \mathrm{ft}-\mathrm{lb}$ for most of this time. This loading correlates with approximately $75 \%$ of max load for this engine speed.

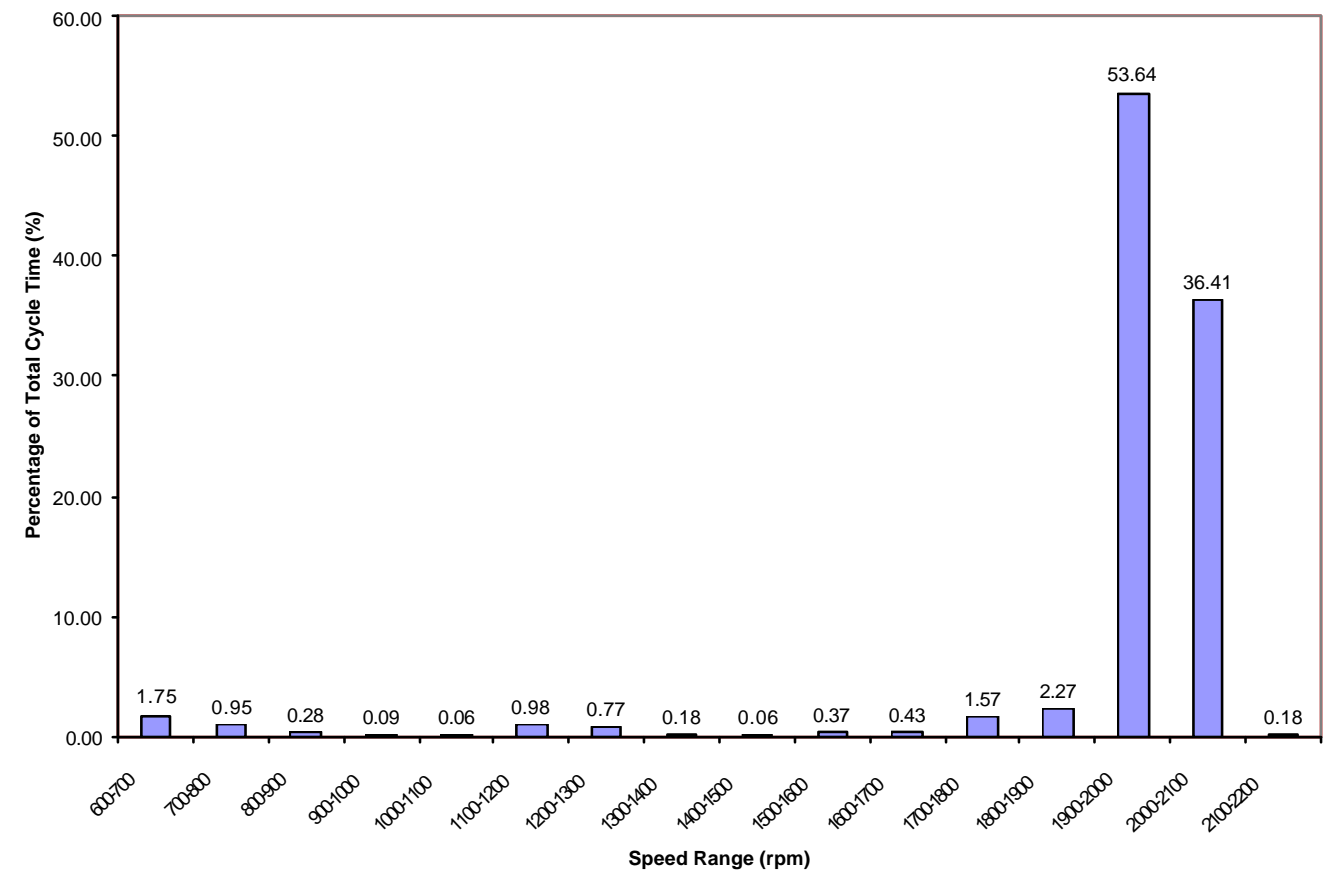

Figure 82 Speed Range Characterization for Excavator Cycle 1 (Digging) 


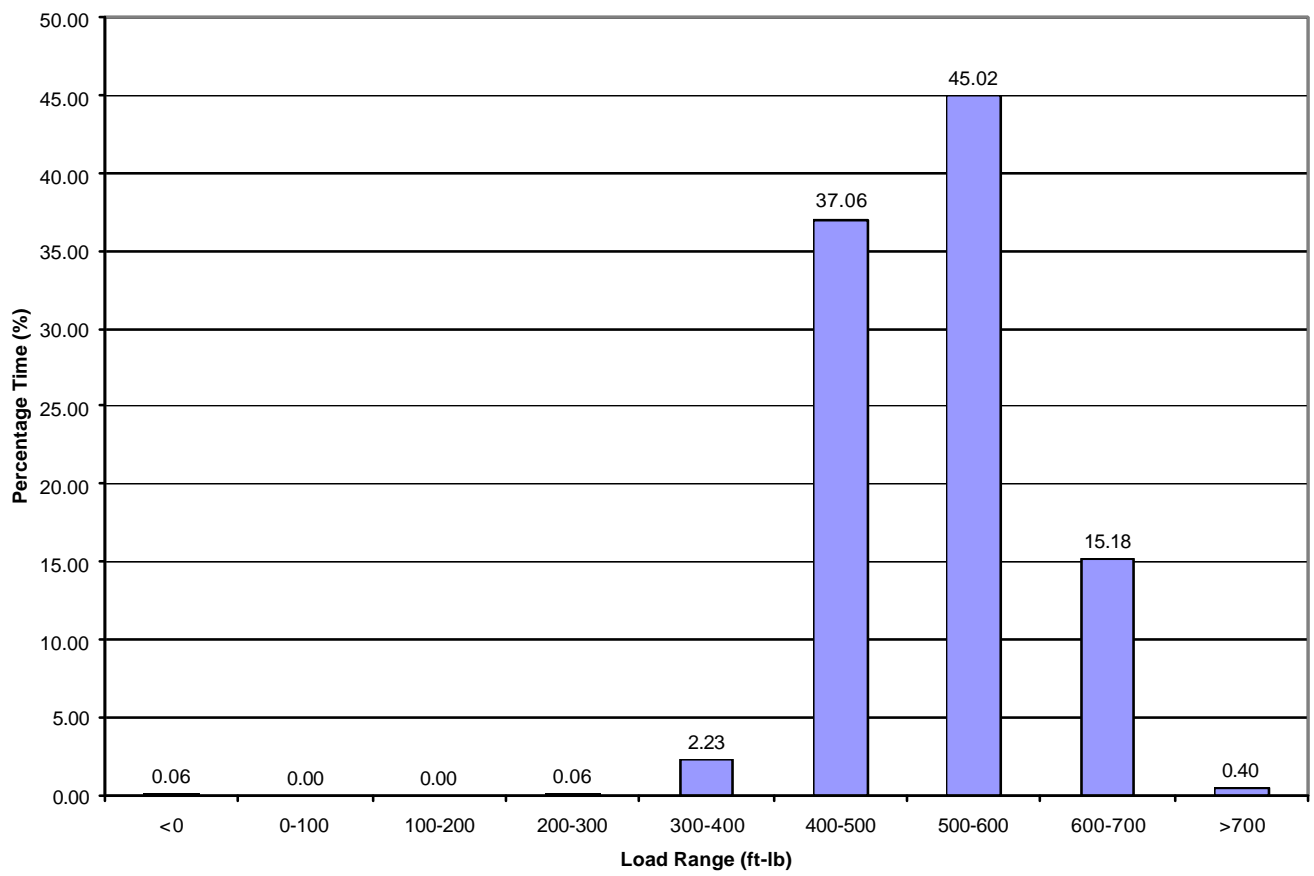

Figure 83 Load Range Characterization for 1900-2000 rpm Speed Range

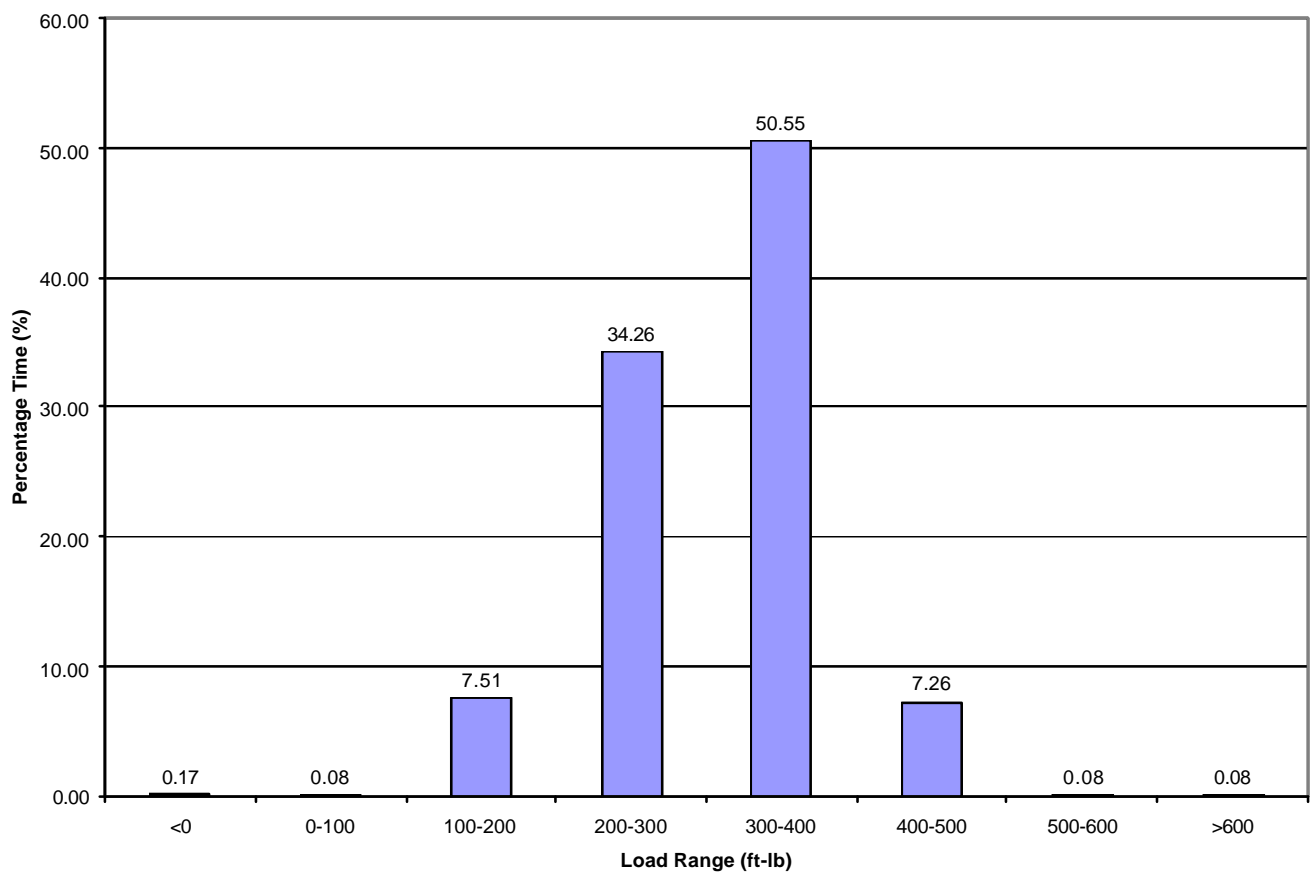

Figure 84 Load Range Characterization for 2000-2100 rpm Speed Range 
Figure 84 shows the load range characterization for the 2000-2100 rpm speed range for excavator test cycle 1 . As the max load significantly drops through this speed range, the $200-400 \mathrm{ft}-\mathrm{lb}$ loads that are most often encountered here represent nearly $100 \%$ loading. This is intuitively correct, as the nature of the operation would be that the engine would be operating at max speed, then speed would be reduced as the excavator digs a load of material to the point where the load introduced to the engine would be compensated by the ability of the engine to produce power.

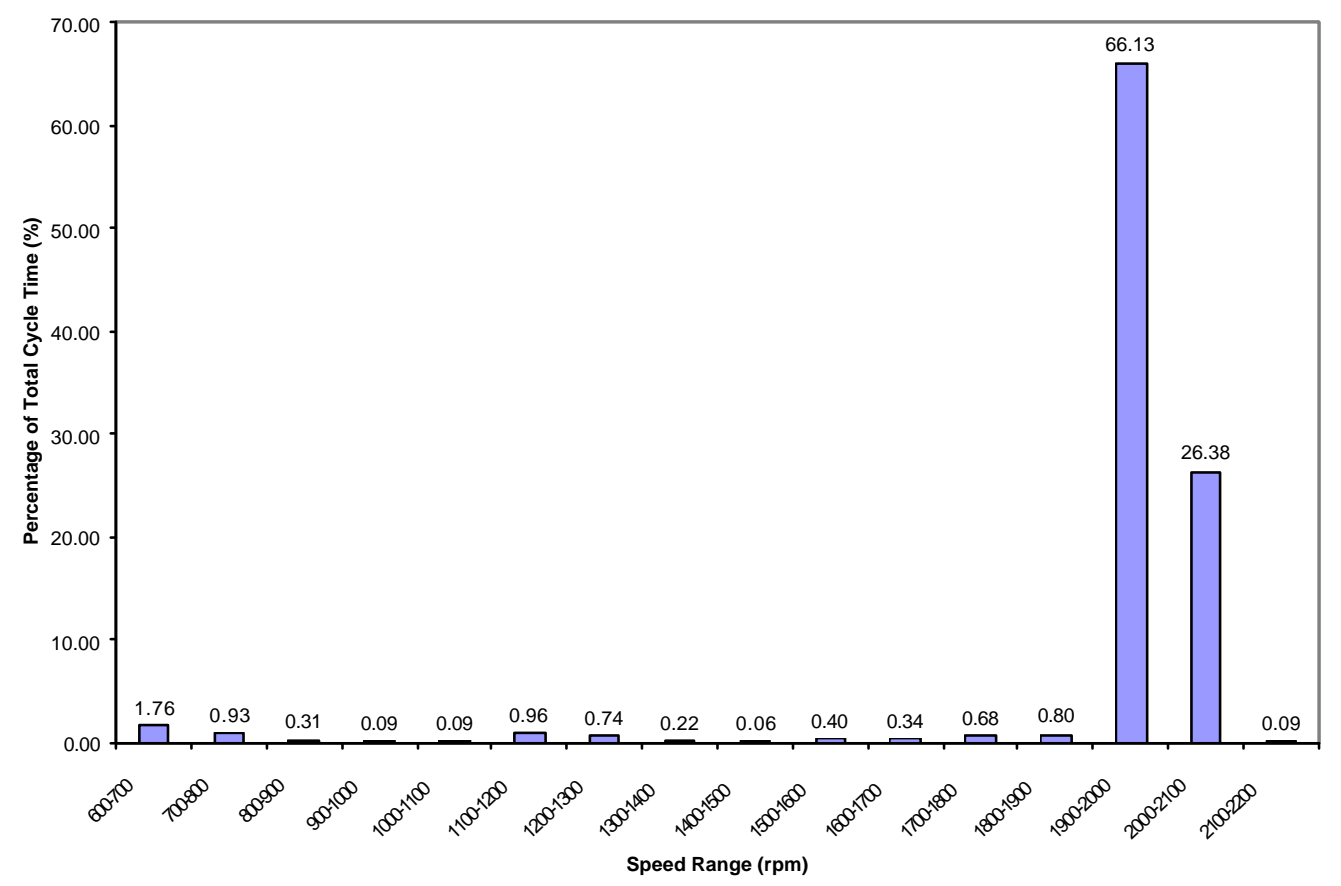

\section{Figure 85 Speed Range Characterization for Excavator Cycle 2 (Hauling)}

Figure 85 shows the speed range characterization for the excavator hauling cycle that was developed from in-field data. Again, like cycle 1, the significant speed ranges are 1900-2000 and 2000-2100. This is largely due to the same reason, as the operation of the excavator tends to start from max speed and then loading causes changes in engine speed. Figure 86 shows the load incurred during the operation of the engine in the 1900- 
$2000 \mathrm{rpm}$ speed range under test cycle 2. This again indicates that the engine incurs nearly $75 \%$ of max load under this speed range for the majority of the time. Figure 87 shows the load ranges seen during operation of the engine in the 2000-2100 rpm speed range under this cycle. The $100-200 \mathrm{ft}-\mathrm{lb}$ range is the vast majority of this portion of the cycle, which is near $100 \%$ loading the higher speeds of this range. Review of the characterizations of cycles 1 and 2 reveals close similarities between the averaged cycles.

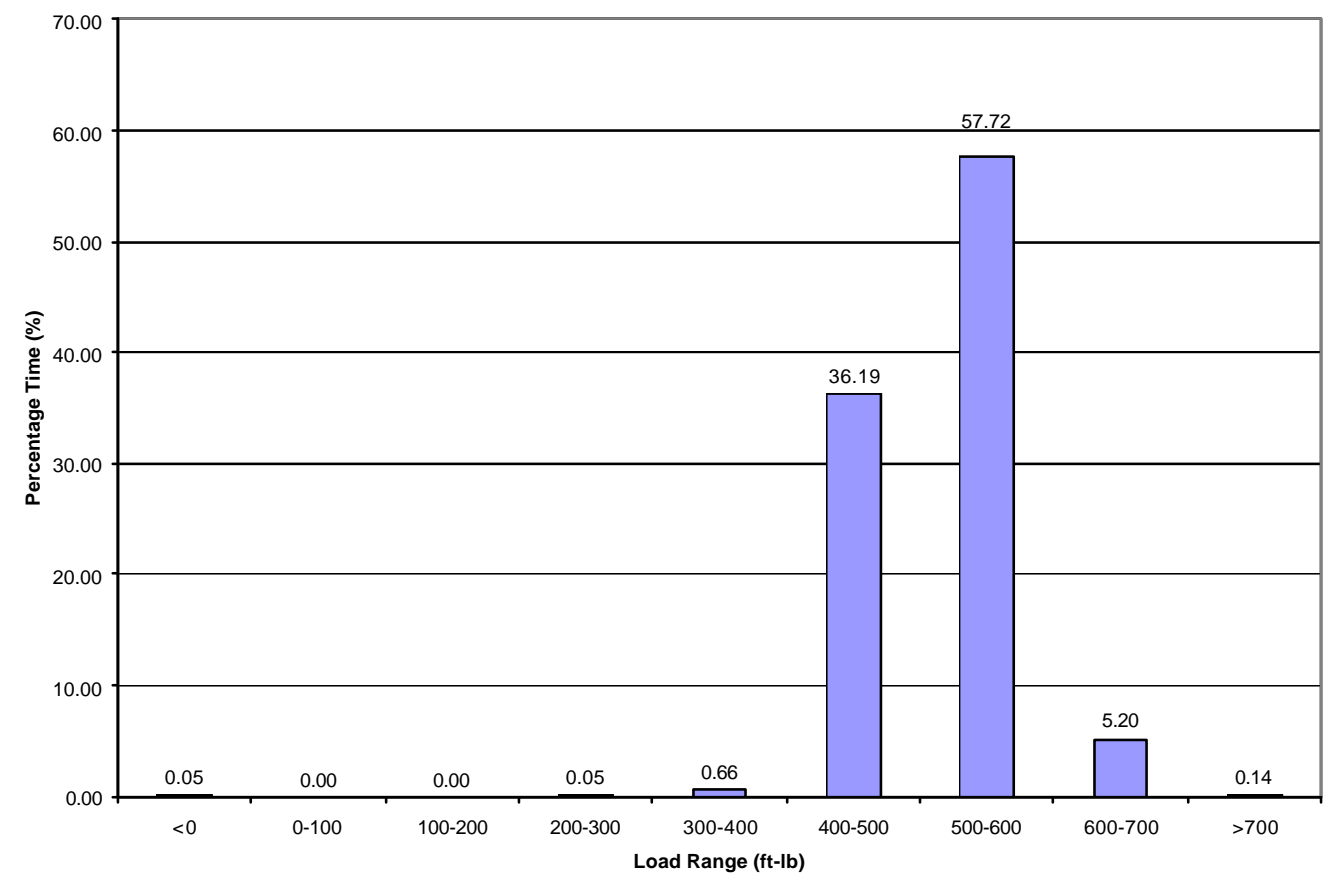

Figure 86 Load Range Characterization for 1900-2000 rpm Speed Range for Excavator Cycle 2 


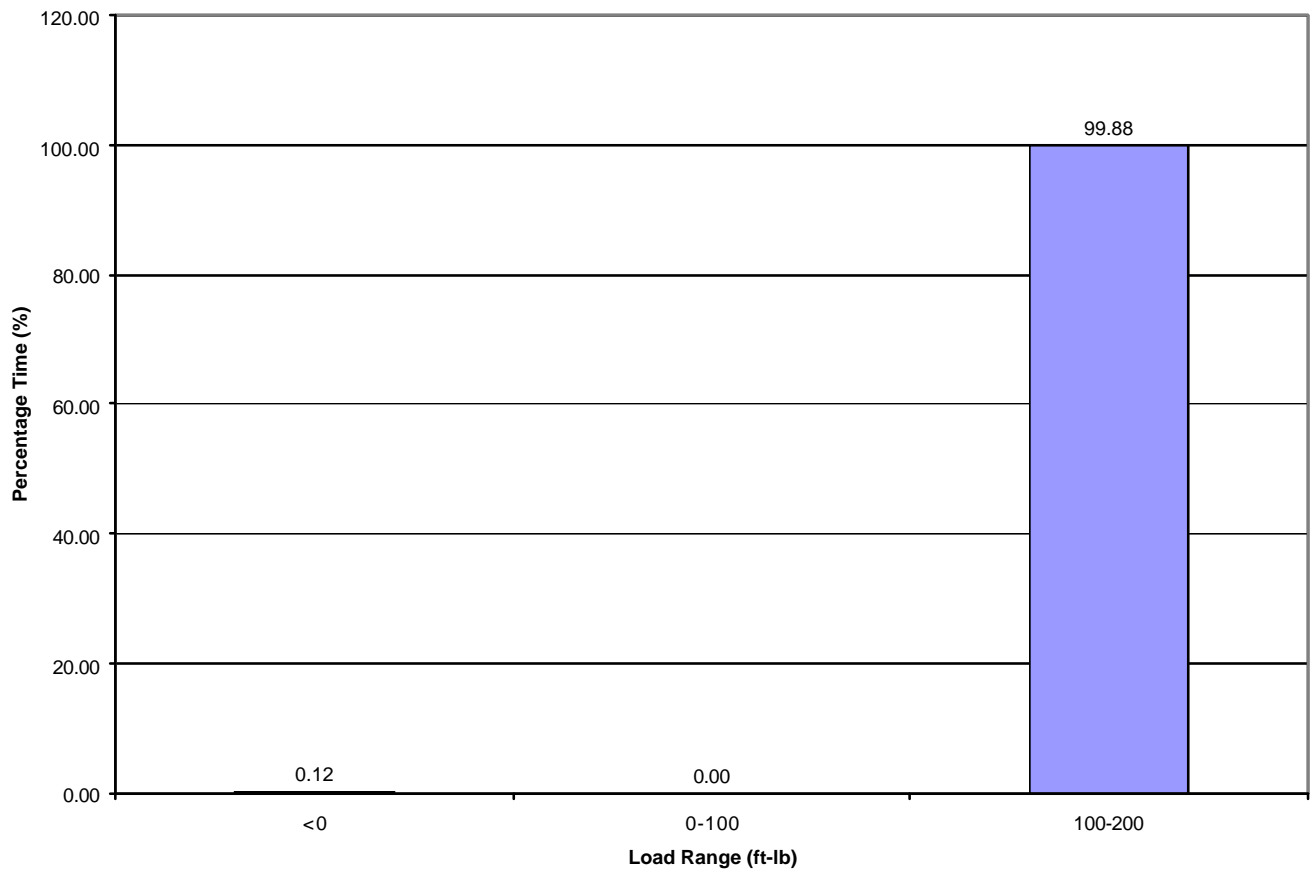

Figure 87 Load Range Characterization for 2000-2100 rpm Speed Range for Excavator Cycle 2

The final excavator cycle derived from in-field test data, the trenching cycle, again shows very similar characteristics to cycles 1 and 2. Again, as indicated in Figure 88, the significant speed ranges are 1900-2000 and 2000-2100 rpm. 


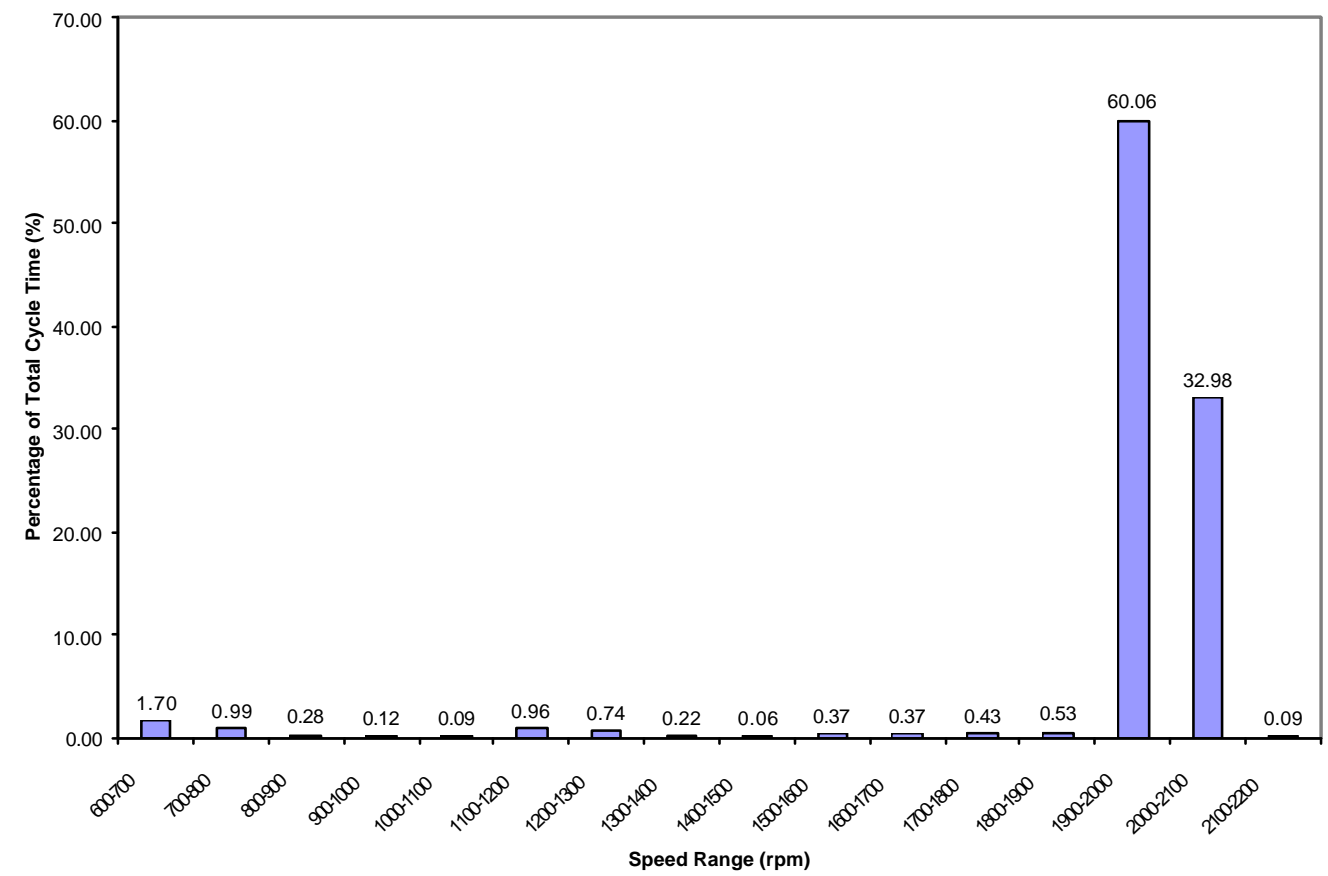

Figure 88 Speed Range Characterization for Excavator Cycle 3 (Trenching)

As the operations in cycle 3 combine those performed in cycles 1 and 2 (i.e. trench digging requires digging and tramming), the load characteristics should tend toward the average of both cycles 1 and 2. Figure 89 tends to agree with this as the percentage of time spent in the 500-600 ft- $\mathrm{lb}$ range is an approximate average of the time percentage values for cycles 1 and 2 in this speed and load range. The results shown in Figure 90 tend to favor the results of cycle 1 for this speed range. This is somewhat logical as the trenching cycle spends more time in digging than moving the machine, therefore, the characteristics of high speed operation will be more often influenced by introducing a digging load. 


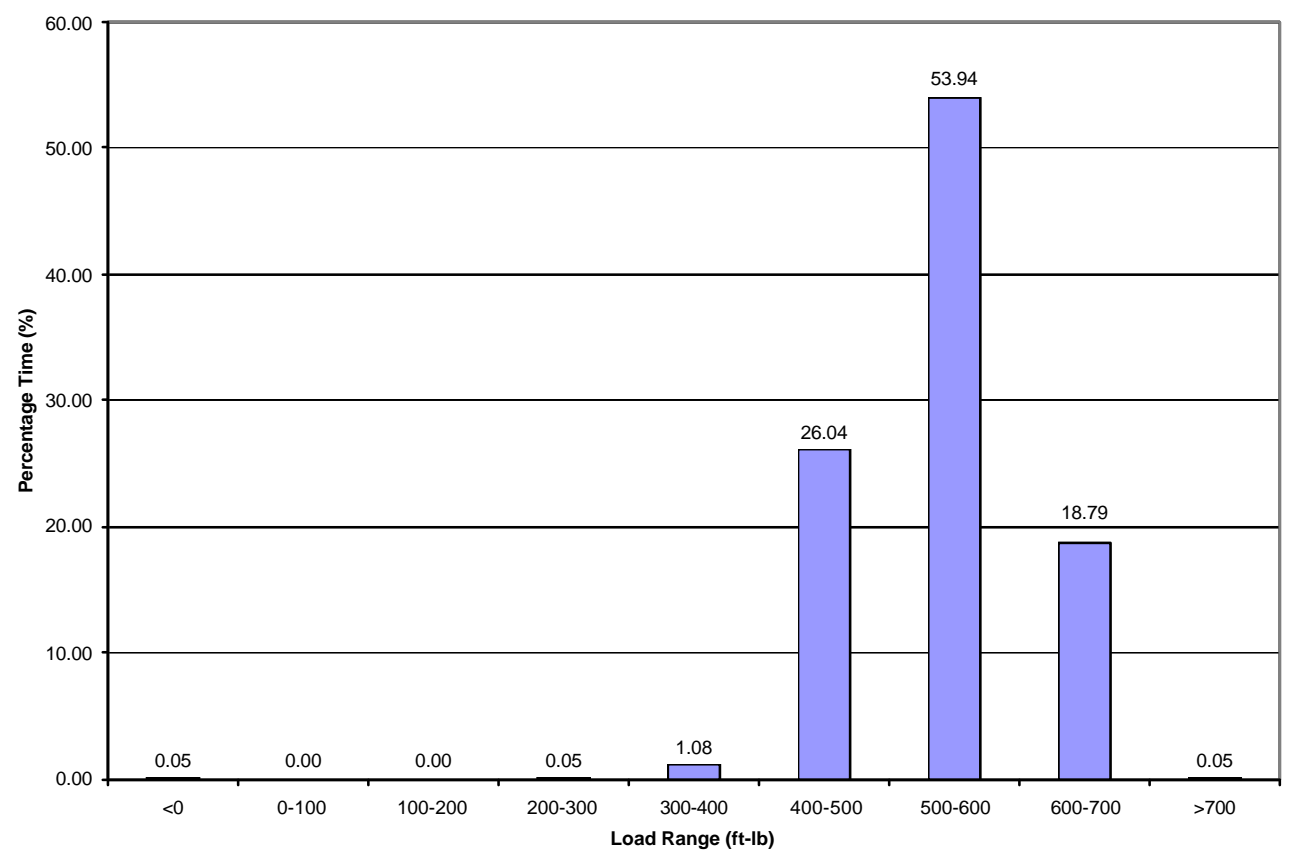

Figure 89 Load Range Characterization for 1900-2000 rpm Speed Range for

Excavator Cycle 3

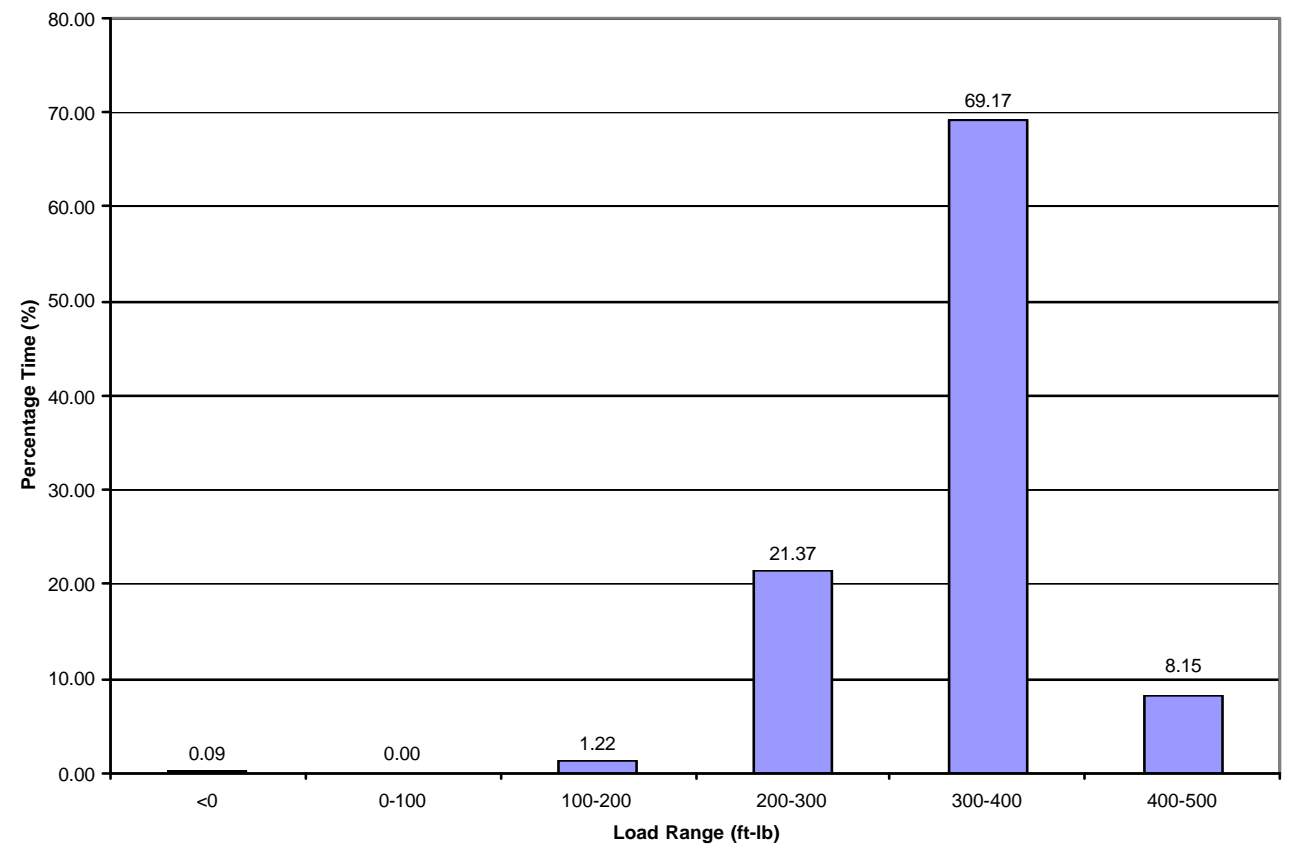

Figure 90 Load Range Characterization for 2000-2100 rpm Speed Range from Excavator Cycle 3 
The EPA transient test designed for excavators was performed for a comparative measure. The results of this test varied widely from the tests derived from in-field test data recorded under this study. The following figures may provide some answers as to why, and what differences in these test cycles may be the root for varying emissions levels.

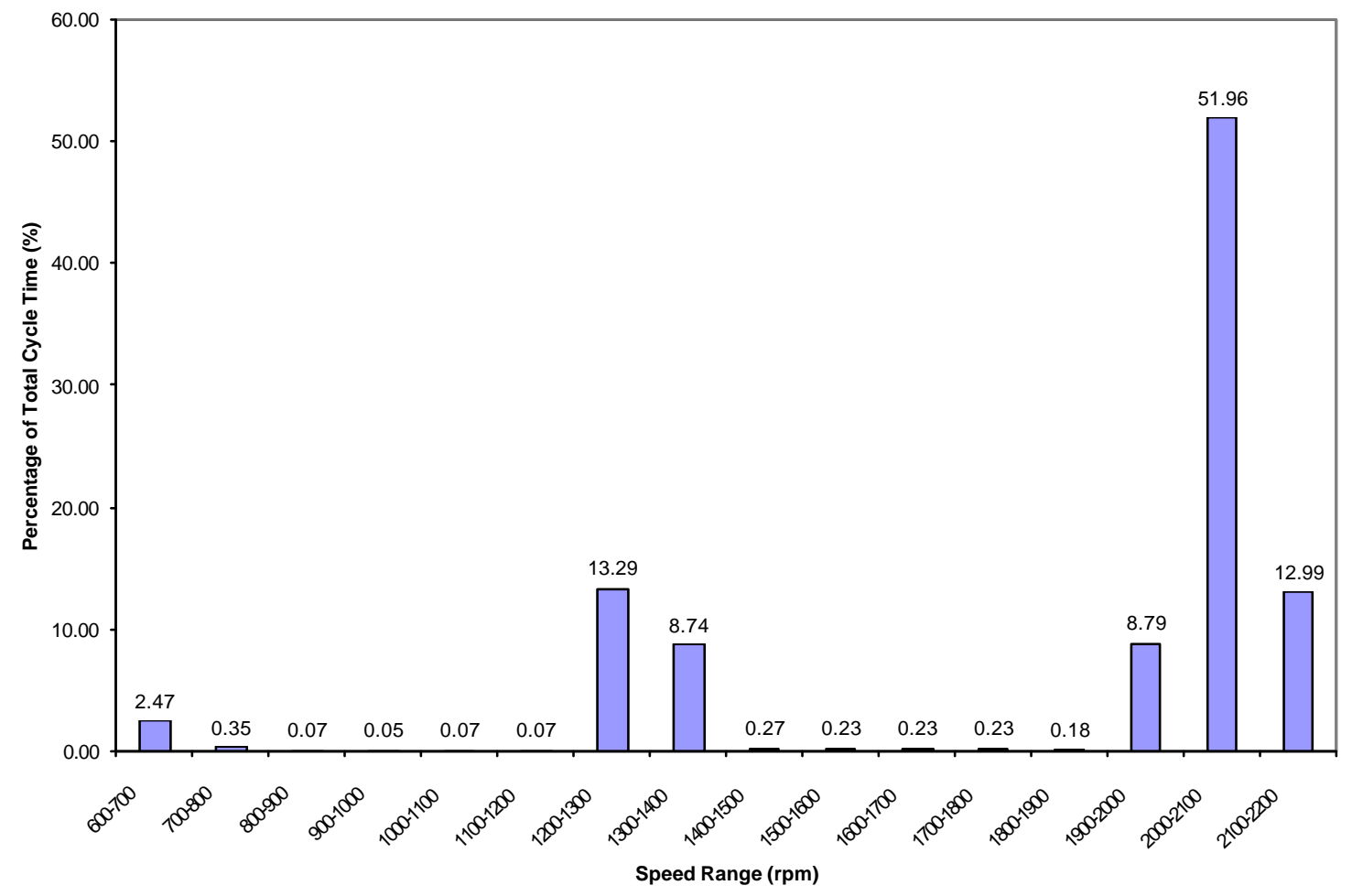

\section{Figure 91 Speed Range Characterization for EPA Transient Excavator Test Cycle}

Figure 91 indicates that there is a significant amount of time spent near the intermediate speed of the excavator engine. This is not the case in the 3 cycles derived from in-field data. This may be due largely in part to the effort to make this cycle more applicable to a wide range of equipment designs. The excavator tested during this study was driven completely by hydraulic systems. The cycle characteristics seen by this engine would vary widely with a machine that may also have direct mechanical drive 
systems in addition to the hydraulic systems, thus this may be a source of difference between the EPA test cycle and the 3 cycles developed under this study. It is rather illogical and unscientific however, to draw conclusions relative to a variety of machines from the testing of only one. The significant speed ranges for this cycle are 1200-1400 rpm and 2000-2100 rpm.

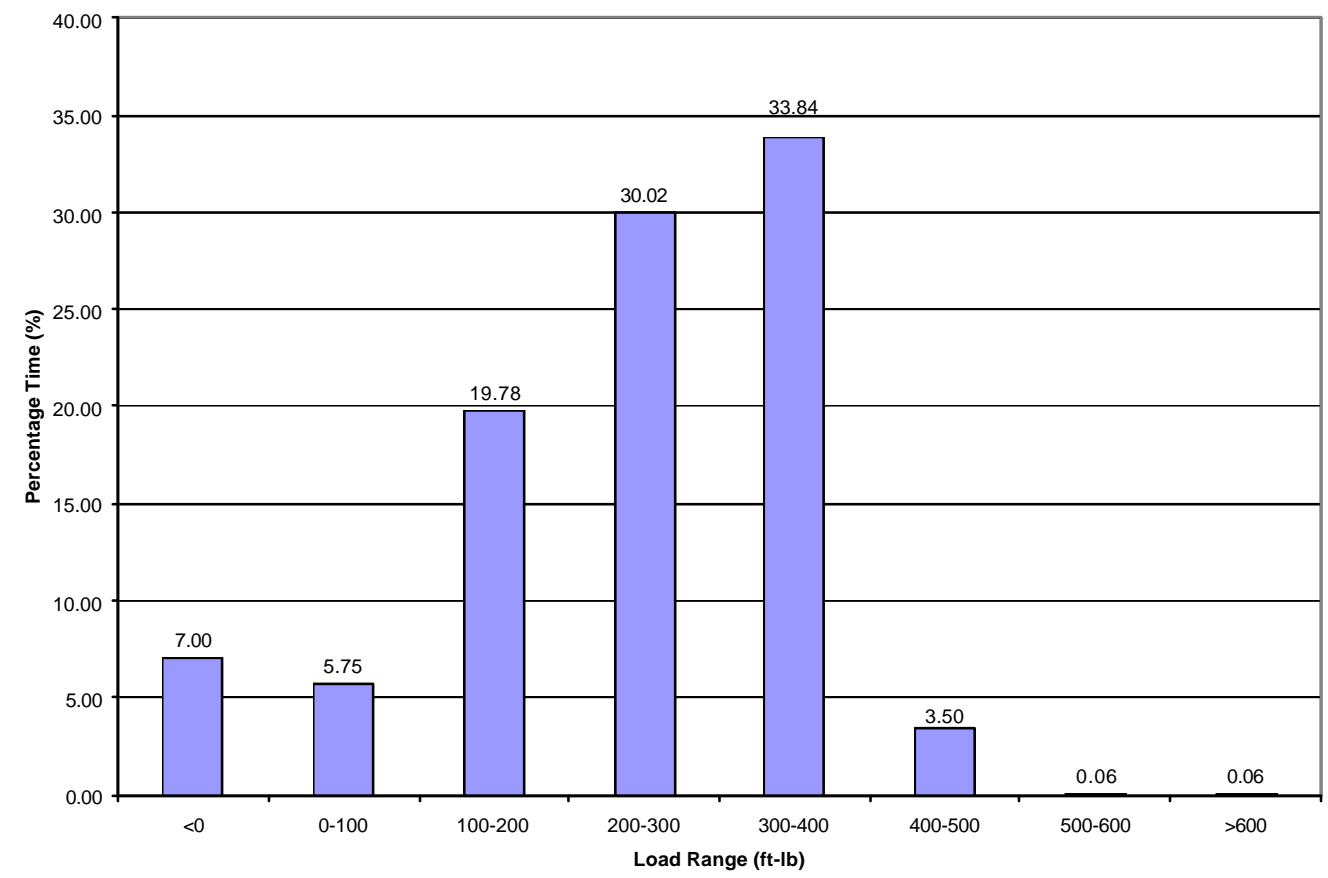

\section{Figure 92 Load Range Characterization for 2000-2100 rpm Speed Range for EPA Excavator Cycle}

Figure 92 displays the load ranges for the 2000-2100 rpm speed range for the EPA transient excavator test cycle. This shows some similarity to the other 3 excavator transient test cycles as a large amount of the time spent in this speed range is at or near $100 \%$ loading for the engine. This may be skewed however as the $2000-2100 \mathrm{rpm}$ range is the most significant speed range in the EPA cycle and the 1900-2000 rpm range is the most significant in the other 3 transient cycles. Due to any number of reasons, the 
calculation of engine speeds from governed central speed may have slightly missed their mark on the intended operating range, and if the cycle spent most of it's time in the 1900$2000 \mathrm{rpm}$ range it is possible that the emissions results from this test would have more closely matched those of the other 3 transient test cycles. A trend identified in the EPA cycle that is not shown in the other cycles is the time spent near intermediate speed.

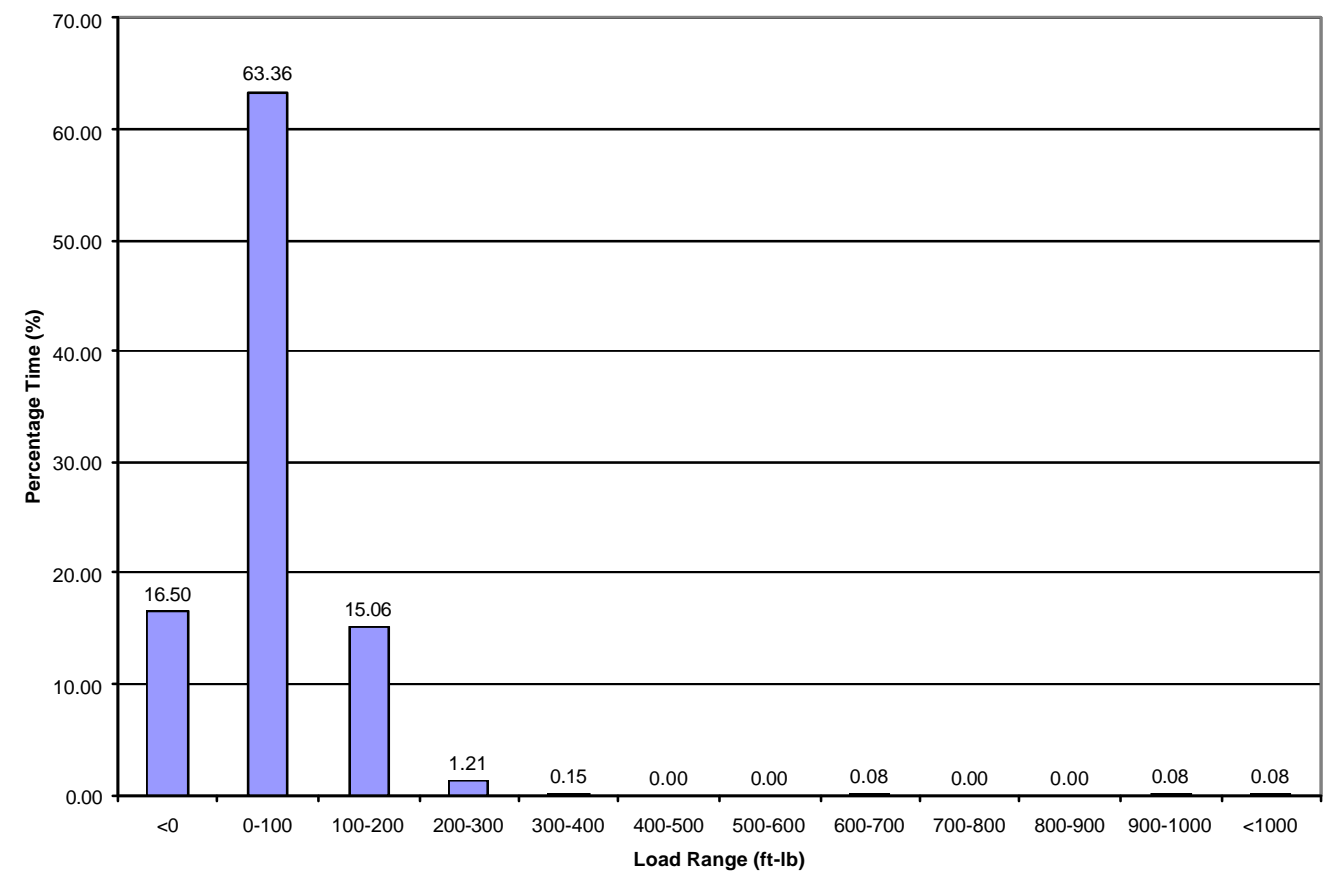

Figure 93 Load Range Characterization for 1200-1400 rpm Speed Range for EPA

\section{Excavator Cycle}

Figure 93 shows the amount of time spent in different load ranges during the 1200-1400 rpm speed range operation of the EPA excavator cycle. Loads are most often in the area of $100 \mathrm{ft}-\mathrm{lb}$, which is nearly $0-10 \%$ of the max load at this speed range. When coupled with the information from the $2000-2100 \mathrm{rpm}$ speed range, this data seems to indicate that the engine speed range characteristics of a cycle may be a very significant factor relative to emissions production. 


\subsubsection{Transient Cycle Characterization Relative to Caterpillar D-11R CD Track-type Tractor}

The limited amount of data collected from the testing of this machine makes it difficult to draw meaningful conclusions relative to emissions production rates from these vehicles. For comparative measures, the EPA crawler tractor cycle and the laboratory cycle used to test emissions measurement equipment for this study have also been characterized. Figure 94 displays the speed ranges observed during the track-type tractor transport test. The data for this cycle was recorded by Caterpillar from the ECU. The most significant speed range is $1900-2000 \mathrm{rpm}$. This is due to the fact that transport is conducted at higher engine speeds for higher vehicle speeds so as to reduce operation of the machine that is considered to be non-productive. Figure 95 shows the loading characterization for the 1900-2000 rpm speed range.

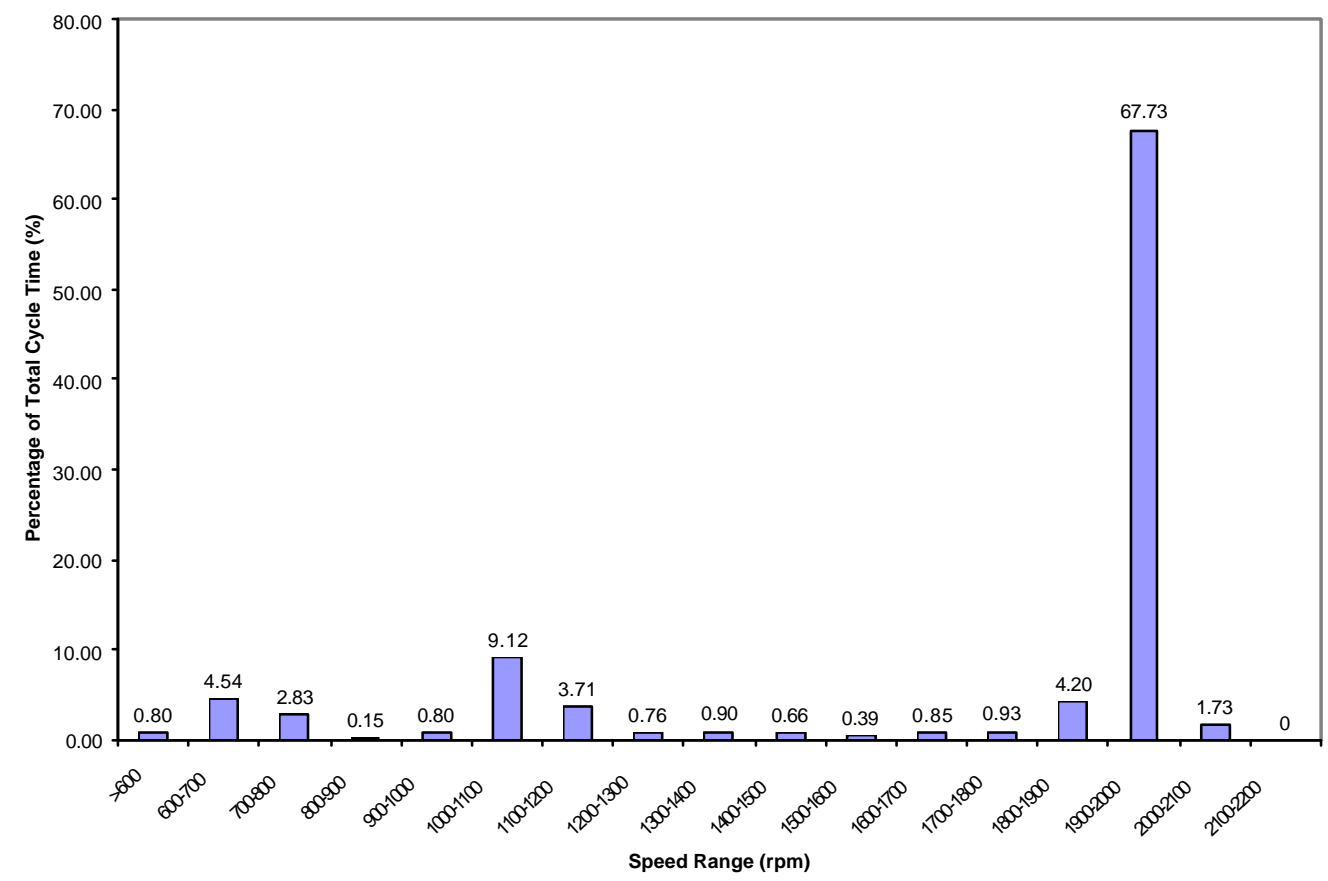

Figure 94 Speed Range Characterization for Track-type Tractor Transport Test 


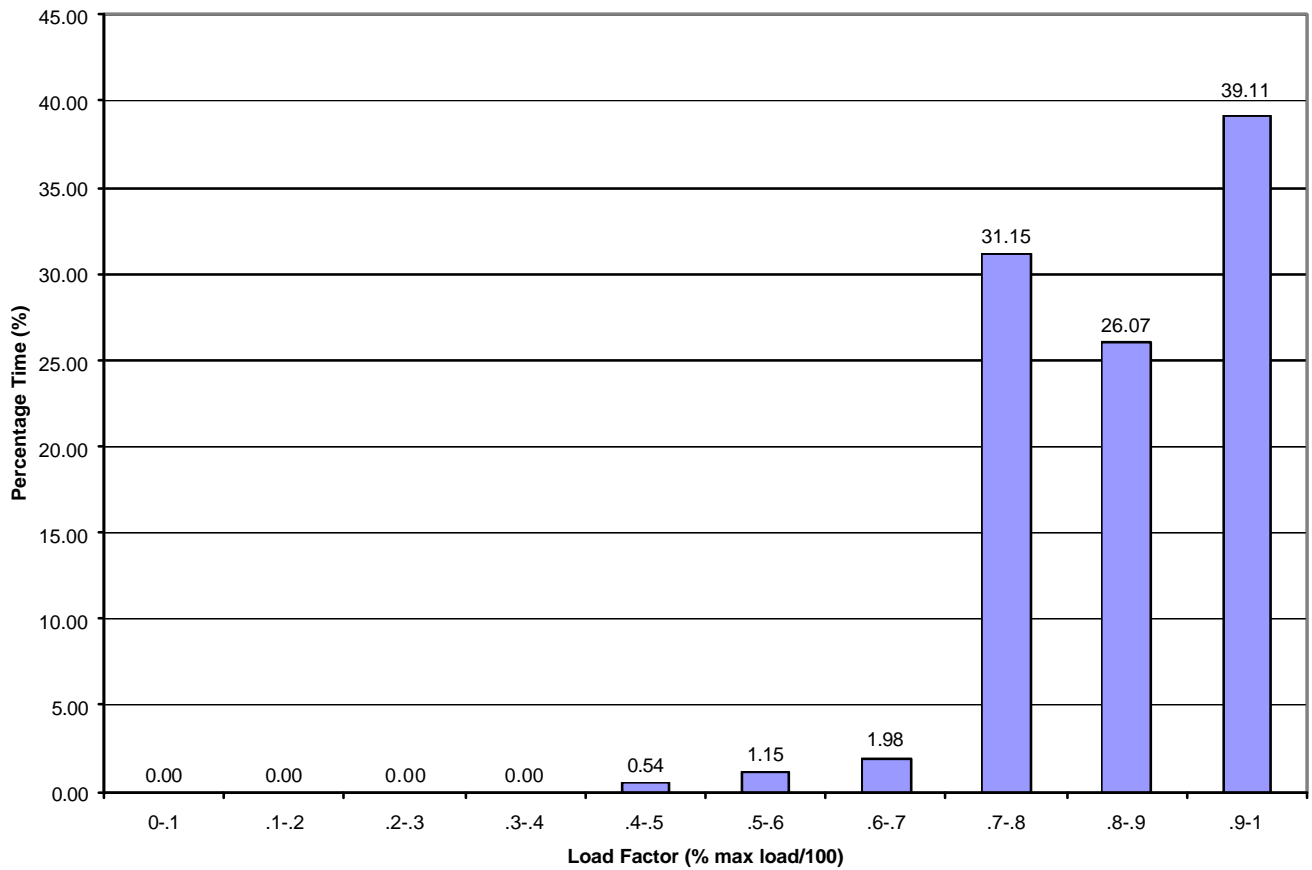

Figure 95 Load Factor Characterization for Track-type Tractor Transport Test in 1900-2000 rpm Speed Range

This figure indicates that the transport cycle was performed near maximum engine loading for this speed range. This again is due to the fact that maximum vehicle speed is desired for non-productive operation. This speed range is slightly past peak power production and seems to be operating in the area where maximum speed is achieved while still having enough power to move such a large machine.

Figure 96 displays the speed characterization for the first in-field track-type tractor digging test. This data was recorded by MEMS test equipment. The data in the figure indicates that the operating range for the engine as the tractor moves material varies from 1600-1900 rpm. The operator attempts to keep the engine speed as close to rated speed as possible during normal operation. The 1900-2000 rpm speed range is larger than any other range because the transport to the starting point is a steady constant 
operation, so the amount of time in transport would fall under this column, as can be witnessed in Figure 94.

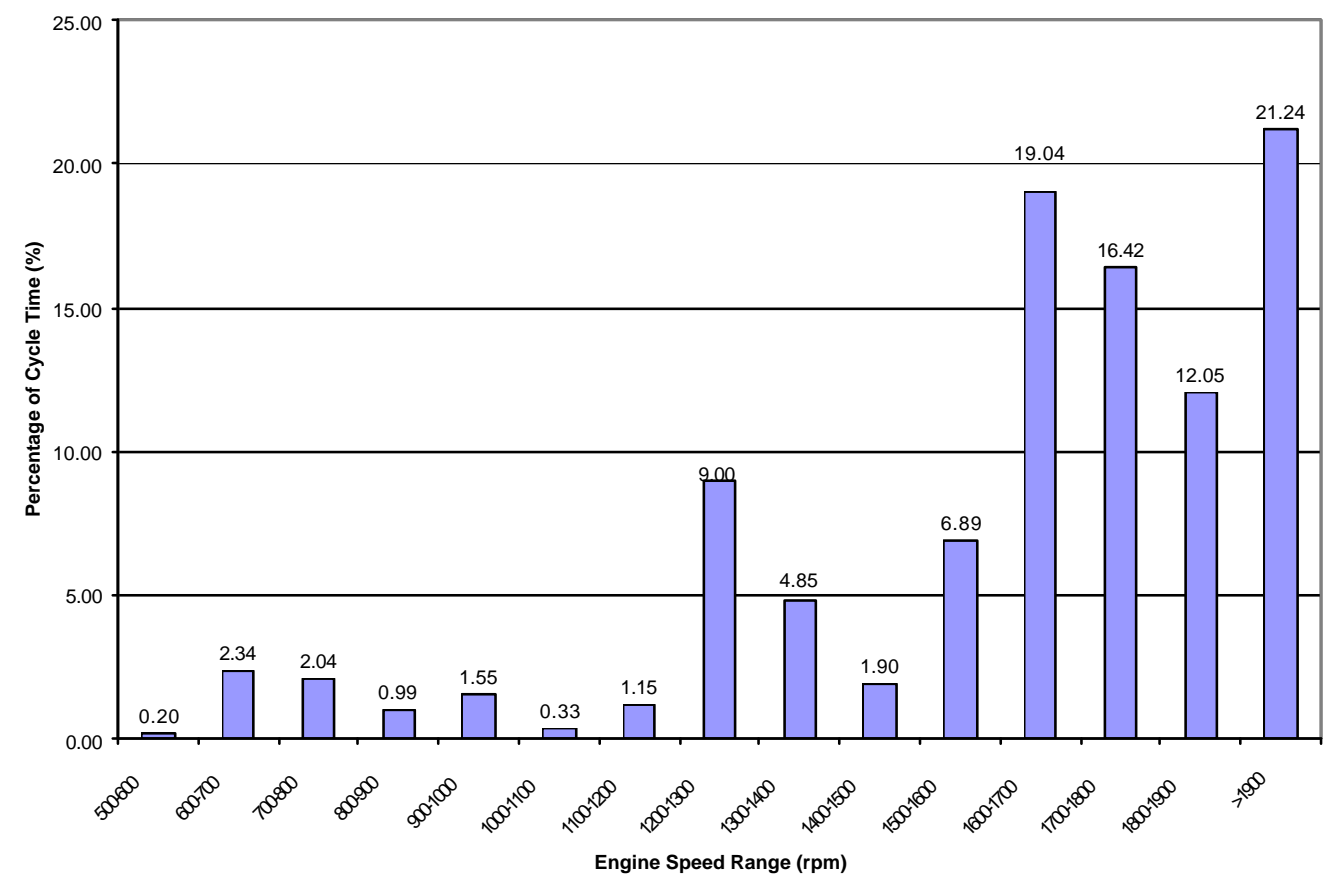

Figure 96 Engine Speed Characterization for In-field Digging Transient Test Cycle \#1

Figure 97 shows the engine speed characterization for the second track-type tractor in-field digging test cycle. This cycle was shortened by equipment failure, and there was a long idle period at the beginning of the test, therefore the characterization does not exactly match the trends shown in Figure 96. Upon close evaluation of the characteristics of this test, one can see that the speed ranges for digging and transport here lie in the same areas as for digging test 1. Both Figure 96 and Figure 97 display operation in the $1200 \mathrm{rpm}$ speed range. This is where the engine tends to idle until it has reached a designed operating temperature. 


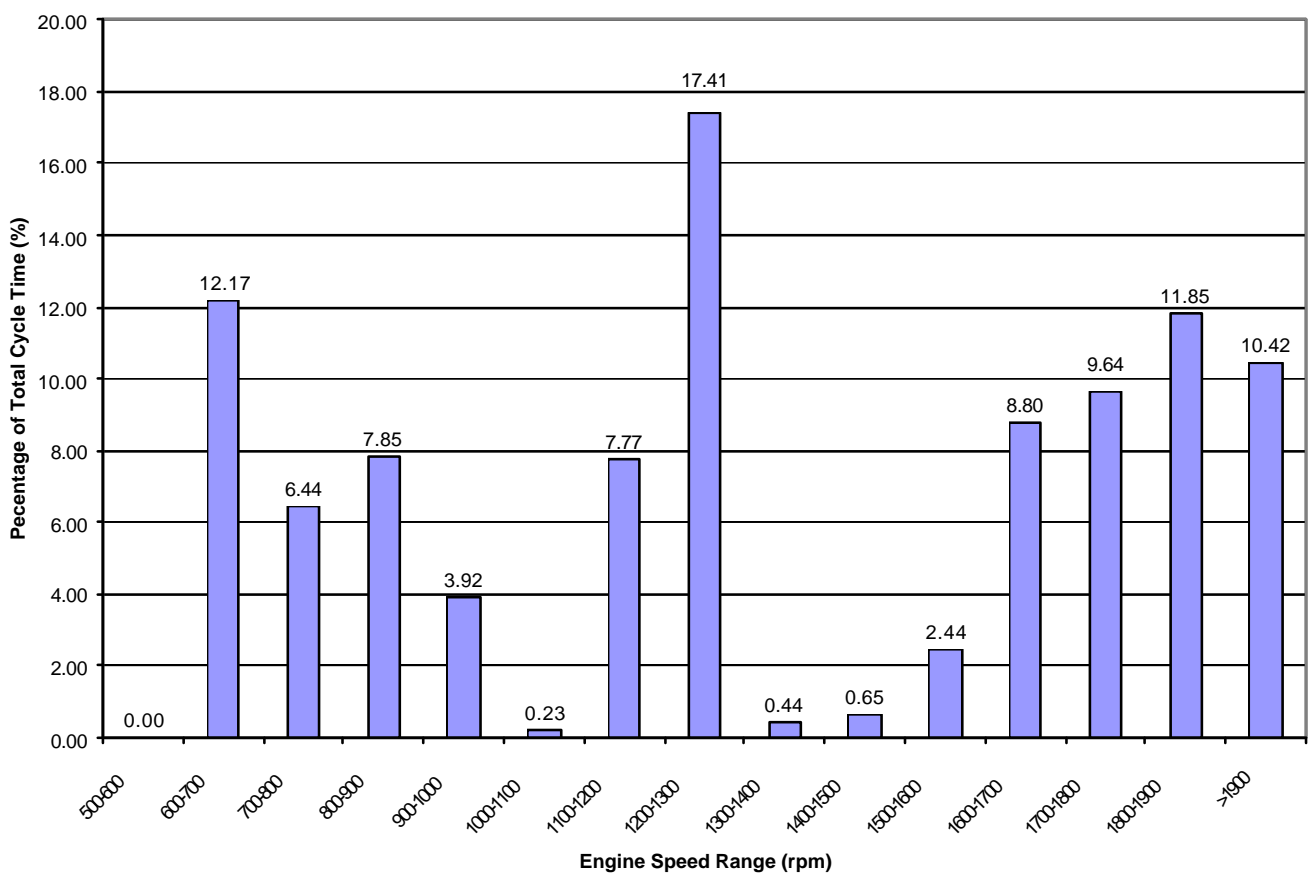

\section{Figure 97 Engine Speed Characterization for Track-type Tractor In-field Digging Transient Test \#2}

For comparative purposes, two other test cycles have been characterized. One is the EPA cycle designed for crawler tractors, which was adjusted to the engine specifications of the Caterpillar 3508 engine, and the other is the laboratory test cycle used to qualify test equipment for the in-field testing of the track-type tractor. Figure 98 shows the speed range characterization for the EPA cycle. This cycle spends significant amounts of time at idle and in the 1300-1600 rpm speed ranges. The cycle is published in percentage speed and load. It was adjusted to the Caterpillar 3508 engine by multiplying the percent speeds by governed central speed as determined from the engine lug curve provided by Caterpillar. Many factors may be causes of differences between cycle trends shown in the transient cycles recorded during in-field testing of the track-type tractor and the EPA crawler tractor test cycle. It is witness to the paramount issue of problems that 
will be encountered if an attempt is made to develop standardized transient testing procedures for off-highway engines.

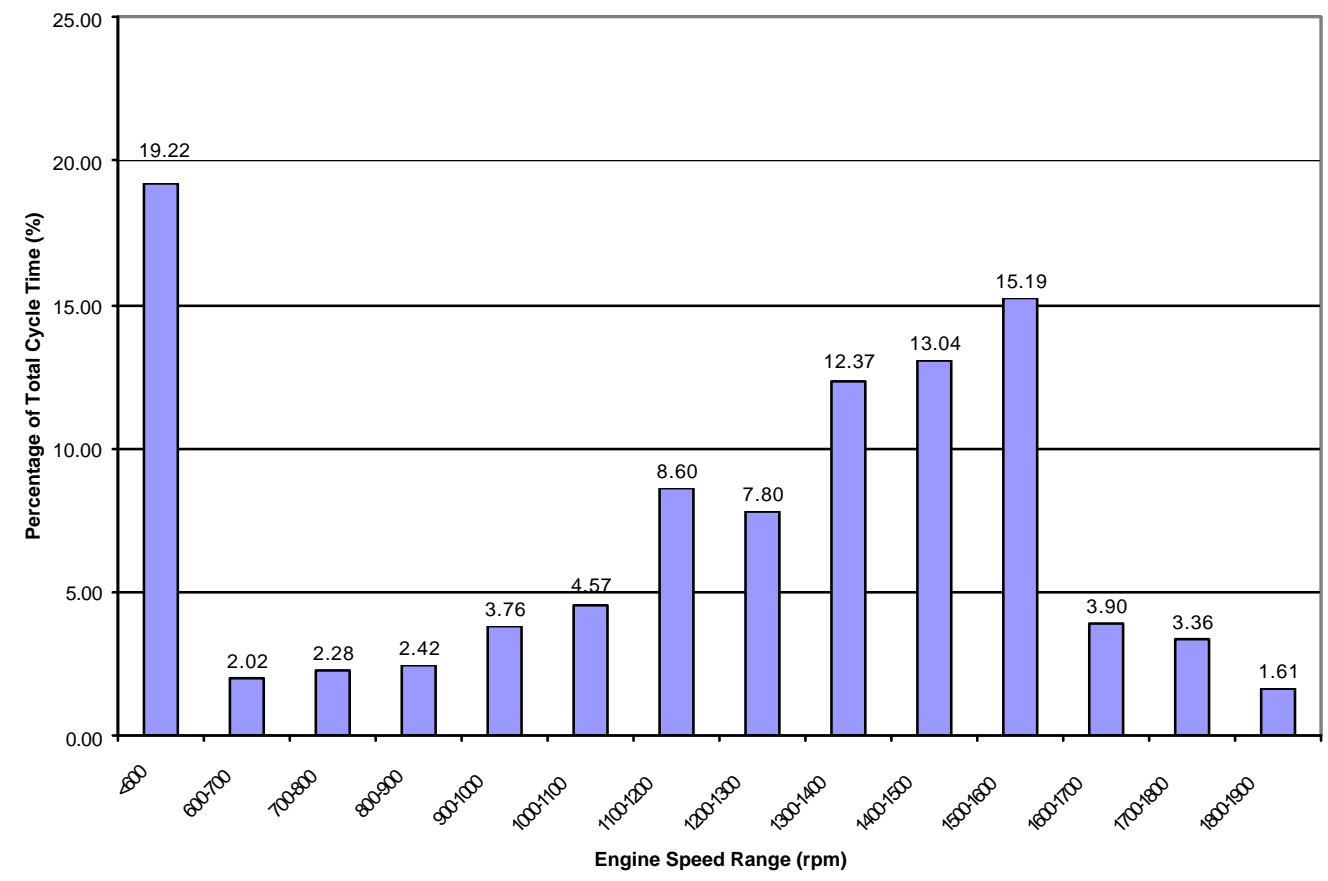

\section{Figure 98 Speed Range Characterization for EPA Crawler Tractor Cycle}

Figure 99 shows the load factors for the 1300-1600 rpm speed range from the

EPA crawler tractor cycle. This indicates that the characteristic operation of this cycle is in the fully loaded state, which logically follows as the design of this type vehicle is to move the maximum amount of material possible in the most efficient, least time consuming manner.

A cycle was developed from estimations of the types of loading that would be encountered during field testing of the track-type tractor, and it was used to qualify test equipment. The cycle was very simple and repetitive in nature, and its characteristics were moving material, then transport, and then moving material again. The speed range characterization for this cycle is shown in Figure 100. 


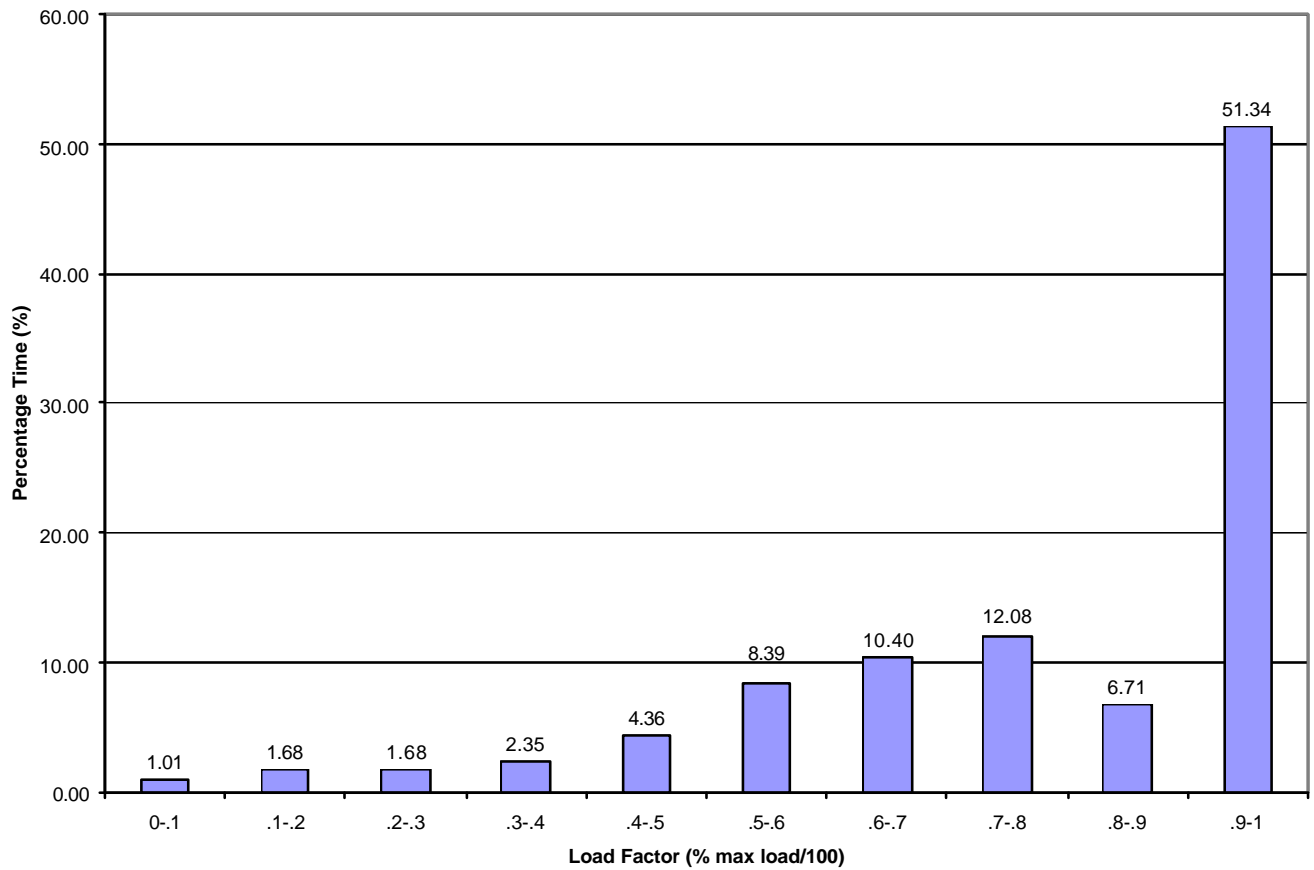

Figure 99 Load Factor Characterization for EPA Crawler Tractor Cycle 1300-1600 rpm Speed Range

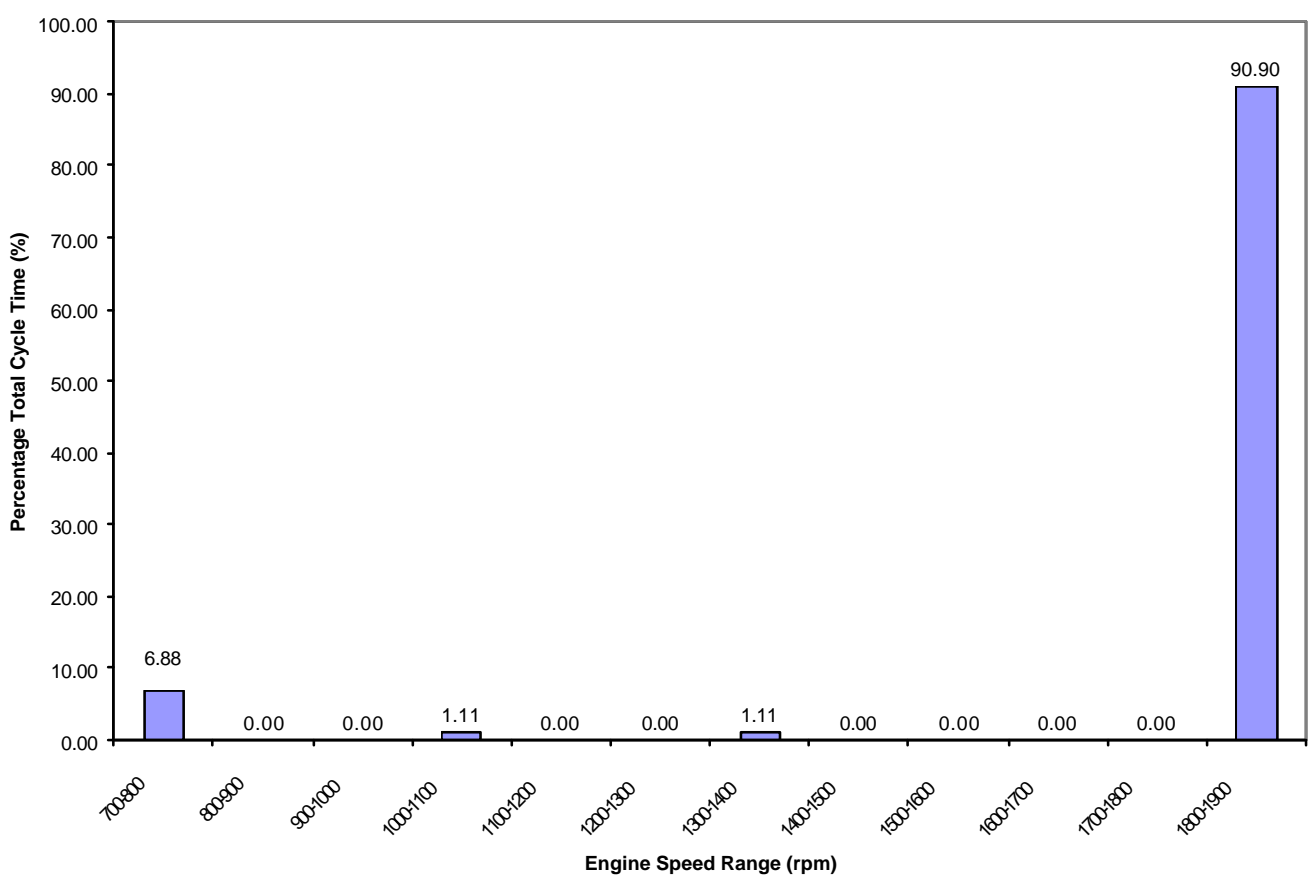

Figure 100 Laboratory Qualification Test Cycle Speed Range Characterization 
The laboratory test cycle was set to maintain a constant speed (1800-1900 rpm, rated) and the torque was varied to simulate the loading that would be encountered infield.

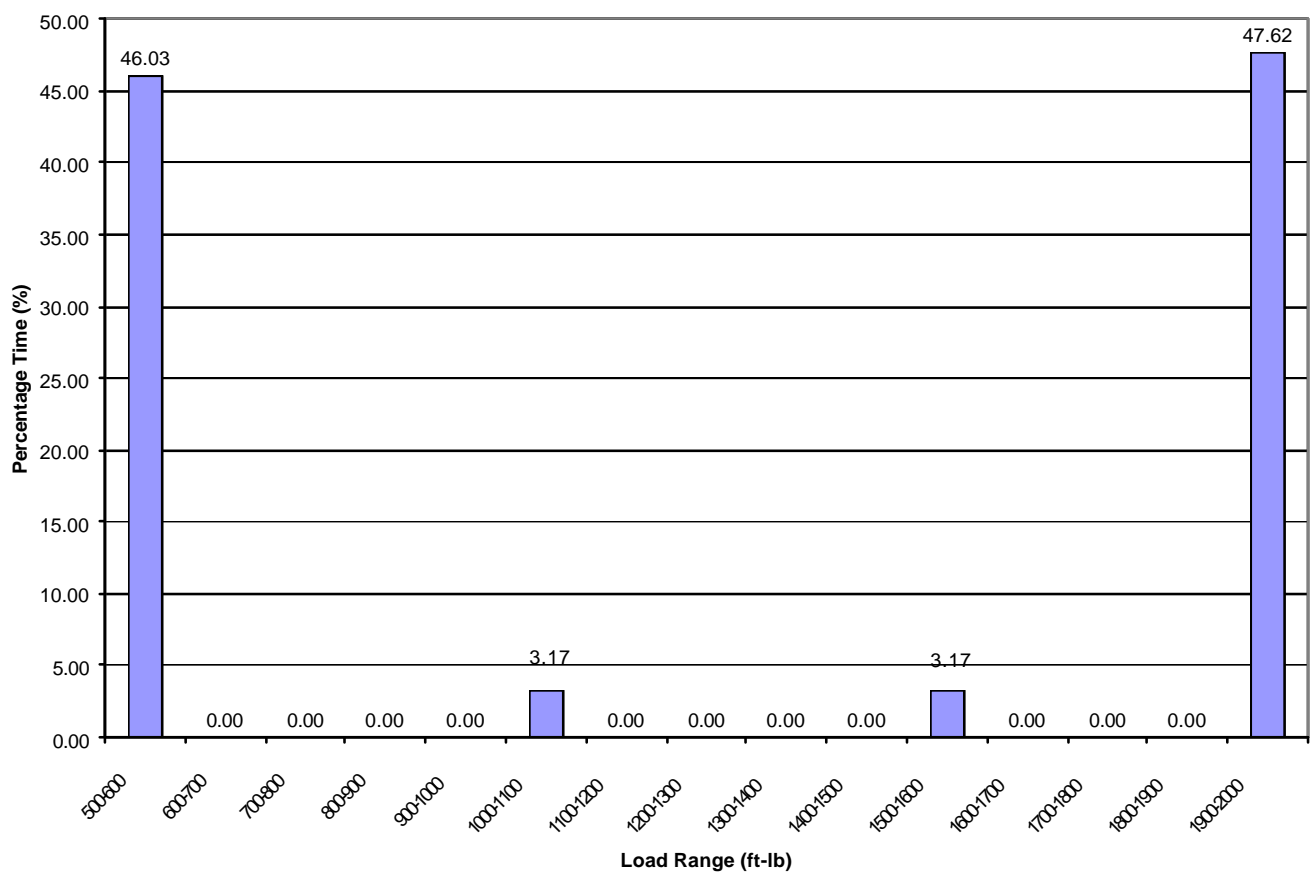

Figure 101 Load Range Characterization for Laboratory Qualification Testing

\section{Cycle}

Figure 101 displays the load ranges for this cycle. The 1900-2000 ft-lb range was used as the loading portion to simulate moving material, and the 500-600 ft- $\mathrm{lb}$ range was used to simulate transport. The loading values were slightly exaggerated in order to avoid problems with fueling control such that the rack position would go to $100 \%$ as the engine tried to reach a loading value greater than $100 \%$ of its max power at the speed it was operating.

While it is difficult to draw conclusions based on limited data, the trends of the cycles performed by this vehicle seem to be operation near full load at rated speed and 
transport at high idle speed. More extensive testing of track-type tractors in different environments would be a more thorough approach to understanding the emissions production of this vehicle class.

\subsubsection{Evaluation of 8-Mode Weighting Factors}

Due to the significant differences that exist between brake-specific averaged transient test and weighted 8-Mode test results, methods were evaluated to more closely match these data. This section uses the excavator results as a means of providing illustration to methods that may be used to make 8-Mode test results agree with transient test results that would simulate in - field operation.

A simple review of the average speed and load factors for the transient excavator cycles indicate that the average load is approximately $80 \%$ of maximum and average speed is $90 \%$ of GCS. Mode 2 of the 8-Mode test is $75 \%$ load at rated speed. The following is a comparison of the Mode 2 results with the transient test results.

Table 15 Comparison of Mode 2 Results with Transient Test Results (g/bhp-hr)

\begin{tabular}{|l|c|c|c|c|c|c|c|}
\hline & $\begin{array}{c}\text { Mode 2 } \\
\text { Results }\end{array}$ & $\begin{array}{c}\text { Transient } \\
\text { Cycle 1 } \\
\text { Results }\end{array}$ & $\begin{array}{c}\text { Transient } \\
\text { Cycle 2 } \\
\text { Results }\end{array}$ & $\begin{array}{c}\text { Transient } \\
\text { Cycle 3 } \\
\text { Results }\end{array}$ & $\begin{array}{c}\text { \% Diff } \\
\text { Cycle 1 to } \\
\text { Mode 2 }\end{array}$ & $\begin{array}{c}\text { \% Diff } \\
\text { Cycle 2 to } \\
\text { Mode 2 }\end{array}$ & $\begin{array}{c}\text { \% Diff } \\
\text { Cycle 3 to } \\
\text { Mode 2 }\end{array}$ \\
\hline $\mathbf{H C}$ & 0.940 & 1.202 & 1.145 & 1.100 & -27.87 & -21.81 & -17.02 \\
\hline $\mathbf{C O}$ & 0.563 & 0.915 & 0.871 & 0.853 & -62.52 & -54.71 & -51.51 \\
\hline $\mathbf{C O}_{2}$ & 499.6 & 538.4 & 533.5 & 525.6 & -7.78 & -6.79 & -5.21 \\
\hline $\mathbf{N O}_{\mathbf{x}}$ & 6.396 & 5.366 & 5.390 & 5.327 & 16.10 & 15.73 & 16.71 \\
\hline PM & 0.295 & 0.277 & 0.280 & 0.332 & 6.10 & 5.08 & -12.54 \\
\hline
\end{tabular}

The results displayed in Table 15 were calculated using equation (12).

With reference to Table 11, the results of Mode 2 more closely represent those of the transient test cycle than the weighted 8-Mode results. However, there is no apparent 
gain in the difference between $\mathrm{CO}$ emissions, and there is still no clear indication that this

is a reasonable method for comparing steady state test results to in-field transient

operation results.

It is notable that results from Modes 4 and 8 can provide high brake specific

emissions results due to the fact that they produce very low amounts of power. The next three tables evaluate the effects by removing Mode 8, Mode 4, and then both Modes 4 and 8 from the weighting process.

Table 16 Comparison of Weighted 8-Mode Results with Transient Cycle Results after the Removal of Mode 8 from the Weighting Process

\begin{tabular}{|l|c|c|c|c|c|c|c||}
\hline & $\begin{array}{c}\text { Weighted } \\
\text { 8-Mode } \\
\text { Results }\end{array}$ & $\begin{array}{c}\text { Transient } \\
\text { Cycle 1 } \\
\text { Results }\end{array}$ & $\begin{array}{c}\text { Transient } \\
\text { Cycle 2 } \\
\text { Results }\end{array}$ & $\begin{array}{c}\text { Transient } \\
\text { Cycle 3 } \\
\text { Results }\end{array}$ & $\begin{array}{c}\text { \% Diff } \\
\text { Cycle 1 to } \\
\text { 8-Mode }\end{array}$ & $\begin{array}{c}\text { \% Diff } \\
\text { Cycle 2 to } \\
\text { 8-Mode }\end{array}$ & $\begin{array}{c}\text { \% Diff } \\
\text { Cycle 3 to } \\
\text { 8-Mode }\end{array}$ \\
\hline HC & 1.41 & 1.202 & 1.145 & 1.100 & 14.75 & 18.79 & 21.99 \\
\hline $\mathbf{C O}$ & 1.34 & 0.915 & 0.871 & 0.853 & 31.72 & 35.00 & 36.34 \\
\hline $\mathbf{C O}_{2}$ & 480.6 & 538.4 & 533.5 & 525.6 & -12.03 & -11.00 & -9.36 \\
\hline $\mathbf{N O}_{\mathbf{x}}$ & 5.83 & 5.366 & 5.390 & 5.327 & 7.96 & 7.55 & 8.63 \\
\hline $\mathbf{P M}$ & 0.43 & 0.277 & 0.280 & 0.332 & 35.58 & 34.88 & 22.79 \\
\hline
\end{tabular}

Table 17 Comparison of Weighted 8-Mode Results with Transient Cycle Results after the Removal of Mode 4 from the Weighting Process

\begin{tabular}{|l|c|c|c|c|c|c|c||}
\hline & $\begin{array}{c}\text { Weighted } \\
\text { 8-Mode } \\
\text { Results }\end{array}$ & $\begin{array}{c}\text { Transient } \\
\text { Cycle 1 } \\
\text { Results }\end{array}$ & $\begin{array}{c}\text { Transient } \\
\text { Cycle 2 } \\
\text { Results }\end{array}$ & $\begin{array}{c}\text { Transient } \\
\text { Cycle 3 } \\
\text { Results }\end{array}$ & $\begin{array}{c}\text { \% Diff } \\
\text { Cycle 1 to } \\
\text { 8-Mode }\end{array}$ & $\begin{array}{c}\text { \% Diff } \\
\text { Cycle 2 to } \\
\text { 8-Mode }\end{array}$ & $\begin{array}{c}\text { \% Diff } \\
\text { Cycle 3 to } \\
\text { 8-Mode }\end{array}$ \\
\hline HC & 1.79 & 1.202 & 1.145 & 1.100 & 32.85 & 36.03 & 38.55 \\
\hline $\mathbf{C O}$ & 1.91 & 0.915 & 0.871 & 0.853 & 52.09 & 54.40 & 55.34 \\
\hline $\mathbf{C O}_{2}$ & 506.3 & 538.4 & 533.5 & 525.6 & -6.35 & -5.38 & -3.82 \\
\hline $\mathbf{N O}_{\mathbf{x}}$ & 7.47 & 5.366 & 5.390 & 5.327 & 28.17 & 27.84 & 28.69 \\
\hline PM & 0.488 & 0.277 & 0.280 & 0.332 & 43.24 & 42.62 & 31.97 \\
\hline
\end{tabular}


Table 18 Comparison of Weighted 8-Mode Results with Transient Cycle Results after the Removal of Modes 4 and 8 from the Weighting Process

\begin{tabular}{||l|c|c|c|c|c|c|c|}
\hline & $\begin{array}{c}\text { Weighted } \\
\text { 8-Mode } \\
\text { Results }\end{array}$ & $\begin{array}{c}\text { Transient } \\
\text { Cycle 1 } \\
\text { Results }\end{array}$ & $\begin{array}{c}\text { Transient } \\
\text { Cycle 2 } \\
\text { Results }\end{array}$ & $\begin{array}{c}\text { Transient } \\
\text { Cycle 3 } \\
\text { Results }\end{array}$ & $\begin{array}{c}\text { \% Diff } \\
\text { Cycle 1 to } \\
\text { 8-Mode }\end{array}$ & $\begin{array}{c}\text { \% Diff } \\
\text { Cycle 2 to } \\
\text { 8-Mode }\end{array}$ & $\begin{array}{c}\text { \% Diff } \\
\text { Cycle 3 to } \\
\text { 8-Mode }\end{array}$ \\
\hline HC & 0.7 & 1.202 & 1.145 & 1.100 & -71.71 & -63.57 & -57.14 \\
\hline CO & 0.69 & 0.915 & 0.871 & 0.853 & -32.61 & -26.23 & -23.62 \\
\hline $\mathbf{C O}_{2}$ & 376.9 & 538.4 & 533.5 & 525.6 & -42.84 & -41.53 & -39.43 \\
\hline $\mathbf{N O}_{\mathbf{x}}$ & 5.05 & 5.366 & 5.390 & 5.327 & -6.26 & -6.73 & -5.49 \\
\hline PM & 0.285 & 0.277 & 0.280 & 0.332 & 2.81 & 1.75 & -16.49 \\
\hline
\end{tabular}

Review of these tables again provides no clear pathway to accurately relate the transient test results and the 8-Mode test results. The removal of Mode 8 alone seems to be the most favorable of these three methods.

After careful consideration of the nature of the duty cycle recorded for this engine, it is found to operate more often at rated speed than intermediate speed. Another effort to modify weighted 8-Mode results took the best of the results achieved and combined them. Mode 8 was eliminated from the weighting process. The modes of rated speed were given weighting factors according to the loading characteristics shown in the load range graphs of the previous section. The engine tends to operate in the rated speed range nearly $80 \%$ of the time with the majority of it experiencing loads consistent with Mode 2. Thus it was given a weighting factor of $50 \%$, which tends to be the average of the three load range graphs. The full load rated speed Mode 1 was given a weighting factor of $10 \%$ and Mode 3 was given a weighting factor of 20\%. The load factors for modes 4-7 were reduced to 5\% to account for the fact that the engine rarely operates in these ranges. Table 19 displays the results of this process. It can be seen that this significantly reduces the amount of difference between weighted 8-Mode results and 
transient test results. These numbers were produced intuitively from results of testing performed on this specific engine. It is highly unlikely that a method can be developed to relate steady state test emissions results to in-use transient emissions without testing each engine as it operates in-vehicle so as to understand the nature of the in-field duty cycle.

Table 19 Comparison of Weighted 8-Mode Results with Transient Cycle Results after the Removal of Mode-8 and the Adjustment of Weighting Factors

\begin{tabular}{|l|c|c|c|c|c|c|c||}
\hline & $\begin{array}{c}\text { Weighted } \\
\text { 8-Mode } \\
\text { Results }\end{array}$ & $\begin{array}{c}\text { Transient } \\
\text { Cycle 1 } \\
\text { Results }\end{array}$ & $\begin{array}{c}\text { Transient } \\
\text { Cycle 2 } \\
\text { Results }\end{array}$ & $\begin{array}{c}\text { Transient } \\
\text { Cycle 3 } \\
\text { Results }\end{array}$ & $\begin{array}{c}\text { \% Diff } \\
\text { Cycle 1 to } \\
\text { 8-Mode }\end{array}$ & $\begin{array}{c}\text { \% Diff } \\
\text { Cycle 2 to } \\
\text { 8-Mode }\end{array}$ & $\begin{array}{c}\text { \% Diff } \\
\text { Cycle 3 to } \\
\text { 8-Mode }\end{array}$ \\
\hline HC & 1.28 & 1.202 & 1.145 & 1.100 & 6.09 & 10.55 & 14.06 \\
\hline CO & 1.03 & 0.915 & 0.871 & 0.853 & 11.17 & 15.44 & 17.18 \\
\hline $\mathbf{C O}_{2}$ & 531.0 & 538.4 & 533.5 & 525.6 & -1.39 & -0.46 & 1.03 \\
\hline $\mathbf{N O}_{\mathbf{x}}$ & 6.47 & 5.366 & 5.390 & 5.327 & 17.06 & 16.69 & 17.67 \\
\hline PM & 0.390 & 0.277 & 0.280 & 0.332 & 28.97 & 28.21 & 14.87 \\
\hline
\end{tabular}




\section{CHAPTER 5 - CONCLUSIONS AND RECOMMENDATIONS}

\subsection{Overview}

The objective of this study was to collect "real-world" exhaust emissions data from off-highway diesel powered vehicles. This information is being used to assist the updating of emissions inventories models, such that with new models, appropriate measures may be taken to maintain air quality standards. Emissions regulations for these non-road engines have not been scrutinized until recently, which is disturbing as the equipment often operates in areas where people work in close proximity and are directly exposed to the vehicle's exhaust. The driving force in efficiency for these engines was fuel economy, but new regulations significantly reduce the allowable exhaust emissions for non-road engines. In order to provide an accurate estimation of the duty-cycles seen by the test engines as they operated in-field; methods were devised such that pertinent information used for the estimation of loading could be gathered from the engine during vehicle operation. Results from transient and steady-state tests were compared and found to differ significantly for these engines. Another significant objective of this study was realized as in-field emissions tests were performed on an off-highway vehicle using laboratory grade analyzers and collecting mass emission rates of gaseous exhaust emissions and particulate matter. Limitations in equipment, funding, and time prohibited the laboratory emissions testing of this engine.

The data collected under this study shows that exhaust emissions are very vehicle and task specific in nature, and therefore cannot be used as a generalization for all offhighway engines. However, the need for creating new testing protocols for off-highway 
diesel engines has been realized. The information collected during this study may be useful in the development of requirements and standards for the emissions testing of diesel-powered off-road vehicles.

\subsection{Conclusions}

The results from testing performed under this study provide a start to the understanding of "real-world" emissions from off-highway diesel-powered vehicles. Results from the testing of the Komatsu S6D125-1 Excavator engine indicated that the weighted brake-specific emissions from an 8-Mode test are substantially higher than those generated by a transient cycle derived from in-field operation testing. This shows that the use of results from 8-Mode testing, currently used for off-highway engine certification, may provide misleading estimates for emissions inventory modeling. The removal of mode 8 from the weighting procedure was performed, and found that results more closely matched brake-specific transient test results. This is most likely due to the fact that the work produced during mode 8 is small in value and skews brake-specific emissions results. Further reduction in the difference between steady state and transient test results was achieved by intuitively adjusting the weighting factors for the steady state tests to apply more weight to the modes that the engine operated in more often and reduce the amount of weighting applied to modes in which the engine rarely operated. The weighted 8-Mode emissions were further compared to the 1996 standard set forth between EPA, CARB, and off-highway engine manufacturers. These results are shown in Table 20. 


\section{Table 20 Comparison of Steady -state Dynamometer Test Results with the Current Off-road Diesel Emissions Standards}

\begin{tabular}{|c|c|c|c|c|}
\hline & $\begin{array}{c}\text { PM } \\
\text { (g/bhp-hr) }\end{array}$ & $\begin{array}{c}\text { CO } \\
\text { (g/bhp-hr) }\end{array}$ & $\begin{array}{c}\text { HC } \\
(\mathbf{g} / \mathbf{b h p}-\mathbf{h r})\end{array}$ & $\begin{array}{c}\mathbf{N O}_{\mathbf{x}} \\
(\mathbf{g} / \mathbf{b h p}-\mathbf{h r})\end{array}$ \\
\hline 1996 Std. & 0.40 & 8.5 & 1.0 & 6.9 \\
\hline Excavator & 0.63 & 2.55 & 2.50 & 8.26 \\
\hline
\end{tabular}

Review of this table indicates that the excavator engine emissions would not pass the 1996 standard. This is most likely characteristic of many older off-highway diesel powered machines, which account for a large portion of the off-highway equipment owned by small business. However, this is not to say that a comparable engine built after this standard was enacted would not meet this standard or that the engine could not have passed this standard when it was new, as age effects could quite possibly account for higher emissions levels.

Characterization of the transient engine cycles for the excavator revealed that the engine most often operates near rated speed with $75 \%$ of full loading. The limited nature of the results collected from the track-type tractor indicates that it has similar operation characteristics.

It is difficult to draw conclusions from the limited amount of data that was collected from the track-type tractor. Review of the available data suggests that the cycle is very repetitive in nature and that the machine operates most often in two modes, full load at rated speed as it moves material, and rated speed and intermediate load as it relocates for the next material removal sequence. 


\subsection{Recommendations}

When one considers the fact that air quality standards must be maintained and overall air quality should be improved, the determination of significant contributors to air pollution becomes ever more important. Off-highway diesel-powered equipment has been identified as one such significant contributor and will therefore become more closely regulated. Continued emissions testing and improved testing procedures will be enacted in the future to more accurately quantify and understand exhaust emissions from this equipment. Future emissions testing would benefit from building upon methods developed for this study. Also alternate approaches to the reporting of emissions test results may in fact provide for a better means of collecting and understanding "real world" vehicle emissions.

\subsubsection{Future Testing}

In order that accurate estimations can be made for the updating of emissions inventories models, further testing is paramount. This study classed vehicles by engine power ratings. It has been shown that the nature of emissions from this type equipment is more vehicle and task specific in nature than power dependant. The task performed by a given vehicle determines the design for engine operation and the mechanisms used to transmit power from the flywheel to the attachments performing the work.

A method for estimating the fuel consumed by an engine from the measured exhaust emissions is outlined in the CFR 40, Part 89 [20]. This would provide a means of relating fuel consumption to manufacturer fueling curves such that brake specific emissions could be determined with relative certainty when emissions measurement 
equipment capable of determining mass emission rates is used to monitor exhaust emissions during in-field use.

As mechanically injected engines are phased out and replaced by electronically controlled engines, the determination of duty cycles and in-use emissions will require less effort as torque would be able to be inferred by reading data from the ECU. A problem encountered in this project was that the engine data is not publicly broadcast, which is unlike many newer on-highway engines. For the sake of future testing, it would be advantageous to make engine data accessible through industry standard protocols.

In the event of future off-highway vehicle testing, emissions measurement devices will need to be designed to withstand the rigors of the environment in which these vehicles operate. The MEMS system used for the in- field emissions testing of the tracktype tractor was designed for on-highway use. Though it proved to be a useful tool for collecting emissions data, it eventually failed due to the demands of the off-highway environment. The system would also benefit from design changes to reduce the size and amount of equipment used as such simplification would reduce setup time and effort.

\subsubsection{Engine Design Improvement}

Tier 1 standards have been implemented on off-highway engines since 1996. Tier 2 standards phase in from 2001 to 2006, and the even more stringent Tier 3 standards come into effect from 2006 through 2008. These standards were reached by an agreement with EPA, CARB, and various off-highway diesel engine manufacturers [1]. They represent a significant reduction of exha ust emissions from these vehicles.

Vast improvements have been made in on- highway diesel engines with respect to emissions reduction. As the demand for lower emissions vehicles increases, engine 
designs are ever more efficient. The driving force for engine efficiency in the offhighway sector has been reduced fuel consumption for lower operating cost. This, along with prolonged engine life, has led to large volume engines that operate with lower fueling rates, producing conservative power to displacement ratios. Take for example the two engines tested for this study and compare them to the on-highway engine that was used to qualify the MEMS testing equipment. The Detroit D-60 is a 12.7 liter engine that produces $500 \mathrm{hp}$, while the Caterpillar 3508 engine produces $850 \mathrm{hp}$ with 35 liters and the S6D125-1 Komatsu engine produces $250 \mathrm{hp}$ with 11 liters. A simple comparison shows that the power production per displacement of the on-highway engine is nearly twice those of the off-highway engines. Off- highway engines are often conservative in power to displacement ratios for durability and engine life. While the demands placed on off-highway engines are quite different and many times more severe than those faced by on-highway engines, it is reasonable to expect improvements in off-highway engine designs to improve engine efficiency and exhaust emission rates.

Ultimately, the goal of all facets of this research and design work should be to reduce the production of harmful emissions from diesel powered vehicles. 


\section{References}

1. Emissions Standards: USA-Heavy Duty Truck and Bus Engines/Off-Road Diesel Engines. www.dieselnet.com., EcoPoint Inc., April 2000.

2. Barnett, R.A., "Characterization of Infield Vehicle Activity Data and Exhaust Emissions from Diesel Powered Off-Road Vehicles," M.S. Thesis, Department of Mechanical and Aerospace Engineering, West Virginia University, Morgantown, WV, 2001.

3. Howes, P., "Final Report for the City of Houston Concerning the Municiple Waste Truck running on PuriNO ${ }_{x}$ Fuel, "Environmental Research and Measurement Division, Gloucester, Ontario, 2000.

4. Technical Report: "VERT: Curtailing Emissions of Diesel Engines in Tunnel Sites". www.dieselnet.com., EcoPoint Inc., April 1998.

5. Baumgard, K.J. (1995), "Effect of Fuel and Engine Design on Diesel Exhaust Particle Size Distributions", Ph.D. Dissertation, Michigan Technological University, Houghton, MI.

6. Summary Report: "Construction Equipment Retrofit Project", Northeast States for Coordinated Air Use Management, Boston, Mass., 1997.

7. Bentz, A. P., "Final Summary Report on Project 3310, Marine Diesel Exhaust Emissions (Alternative Fuels)," United States Department of Transportation United States Coast Guard Systems, Report No. CG-D-08-98, 1997.

8. Bentz, A. P. and Weaver, E., "Marine Diesel Exhaust Emissions Measured by Portable Instruments," SAE Technical Paper No. 941784, 1994.

9. Carder, D. K., "Performance Evaluation of Exhaust Aftertreatment Devices Used for Emissions Control On Diesel Engines Employed in Underground Coal Mines," M.S. Thesis, Department of Mechanical and Aerospace Engineering, West Virginia University, Morgantown, WV, 1999.

10. Englund, M.S., "Field Compatible $\mathrm{NO}_{\mathrm{x}}$ Emission Measurement Technique," SAE Technical Paper No. 820647, 1982.

11. Human, D. M. and Ullman, T. L., "Development of an I/M Short Emissions Test for Buses," SAE Technical Paper No. 920727, 1992.

12. Kelly, N.A. and Groblicki, P. J., "Real-world emissions from a modern production vehicle driven in Los Angeles," Journal of Air and Waste Management Association, Vol. 43, No. 10, 1993. 
13. Butler, J. W., Gierczac, C. A., Jesion, G., Stedman, D. H., and Lesko, J. M., “OnRoad $\mathrm{NO}_{\mathrm{x}}$ Emissions Intercomparison of On-Board Measurement and Remote Sensing," Final Report, Coordinating Research Council, Inc., Atlanta, GA, CRC Report No. VE-11-6, 1994.

14. Gierczac, C. A., Jesion, G., Piatak, J. W., and Butler, J. W., "On-Board Vehicle Emissions Measurement Program,” Final Report, Coordinating Research Council, Inc., Atlanta, GA, CRC Report No. VE-11-1, 1994.

15. Mackay, G. I., Nadler, S. D., Karecki, D. R., Schiff, H. I., Butler, J. W., Gierczac, C. A., and Jesion, G., "Dynamometer Intercomparison of Automobile Exhaust Gas $\mathrm{CO} / \mathrm{CO}_{2}$ Ratios and Temperature Between On-Board Measurements and a Remote Sensing Near Infrared Diode Laser System, "Phase 1b Report to the Coordinating Council and National Renewable Energy Laboratory, 1994.

16. Mackay, G. I., Nadler, S. D., Karecki, D. R., Schiff, H. I., Butler, J. W., Gierczac, C. A., and Jesion, G., "Dynamometer Intercomparison of Automobile Exhaust Gas $\mathrm{CO} / \mathrm{CO}_{2}$ Ratios and Temperature Between On-Board Measurements and a Remote Sensing Near Infrared Diode Laser System, "Phase 1c Report to the Coordinating Council and National Renewable Energy Laboratory, 1994.

17. Vojtisek-Lom, M. and Cobb, Jr., J. T., "On-Road Light-Duty Vehicle Mass Emission Measurements Using a Novel Inexpensive On-Board Portable System, "Proceedings of the Eighth CRC On-Road Vehicle Workshop, San Diego, CA, April 20-22, 1998.

18. Butler, J. W., Korniski, T. J., Reading, A. R., and Kotenko, T. L., "Dynamometer Quality Data On-Board Vehicles for Real-World Emission Measurements," Proceedings of the Ninth CRC On-Road Vehicle Workshop, April 19-21, San Diego, CA, 1999.

19. Shade, B. C., " A Performance Evaluation of the MEMS - An On-Road Emissions Measurement System Study," M.S. Thesis, Department of Mechanical and Aerospace Engineering, West Virginia University, Morgantown, WV, 2000.

20. “Code of Federal Regulations," CFR 40 Parts 86 to 99, Washington, D.C., 1994

21. Gautam, M., (2001) Personal Correspondence.

22. Brockmann, J.E., Liu, B.Y.H and McMurry, P.H., "A Sample Extraction Diluter for Ultrafine Aerosol Sampling”, Aerosol Science \& Technology, 441-451 (1984).

23. Schlicting, "Boundary Layer Theory”, McGraw-Hiill, New York, 1955.

24. Comments on EPA's NPRM for the Control of Emissions of Air Pollution from Nonroad Diesel Engines 
APPENDIX A - ADDITIONAL BRAKE-SPECIFIC LABORATORY TRANSIENT CYCLE TESTING DATA FOR KOMATSU S6D125-1 (g/Bhp-Hr) 
Table 21 Comparison of Brake-Specific Emissions from First and Final Iterations of Excavator Cycle 1 (Digging Cycle)

\begin{tabular}{|c|c|c|c|c|c|c|c|c|c|c|}
\hline Cycle 1 & \multicolumn{3}{|c|}{ First Cycle } & \multicolumn{9}{c|}{ Final Cycle } & Comparison \\
\hline Test & $\mathbf{1}$ & $\mathbf{2}$ & Average & $\mathbf{1}$ & $\mathbf{2}$ & $\mathbf{3}$ & $\mathbf{4}$ & Average & Ave - Ave \\
\hline Emissions & $\mathbf{g} / \mathbf{B h p H r}$ & $\mathbf{g} / \mathbf{B h p H r}$ & $\mathbf{g} / \mathbf{B h p H r}$ & $\mathbf{g} / \mathbf{B h p H r}$ & $\mathbf{g} / \mathbf{B h p H r}$ & $\mathbf{g} / \mathbf{B h p H r}$ & $\mathbf{g} / \mathbf{B h p H r}$ & $\mathbf{g} / \mathbf{B h p H r}$ & \% Diff \\
\hline HC & 0.844 & 1.208 & 1.026 & 1.212 & 1.252 & 1.159 & 1.183 & 1.202 & -14.6 \\
\hline CO & 0.643 & 0.934 & 0.789 & 0.883 & 0.946 & 0.923 & 0.909 & 0.915 & -13.8 \\
\hline CO2/100 & 5.131 & 5.426 & 5.28 & 5.368 & 5.390 & 5.390 & 5.389 & 5.384 & -2.0 \\
\hline NOx & 4.786 & 5.226 & 5.006 & 5.265 & 5.469 & 5.385 & 5.343 & 5.366 & -6.7 \\
\hline PM & 0.343 & 0.316 & 0.330 & 0.267 & 0.297 & 0.260 & 0.283 & 0.277 & 19.2 \\
\hline
\end{tabular}

Table 22 Comparison of Brake-Specific Emissions from First and Final Iterations of Excavator Cycle 2 (Hauling Cycle)

\begin{tabular}{|c|c|c|c|c|c|c|c|c|c|c|}
\hline Cycle 2 & \multicolumn{4}{|c|}{ First Cycle } & \multicolumn{4}{c|}{ Final Cycle } & Comparison \\
\hline Test & $\mathbf{1}$ & $\mathbf{2}$ & $\mathbf{3}$ & Averaqe & $\mathbf{1}$ & $\mathbf{2}$ & $\mathbf{3}$ & $\mathbf{4}$ & Average & Ave - Ave \\
\hline Emissions & $\mathbf{g} / \mathbf{B h p H r}$ & $\mathbf{g} / \mathbf{B h p H r}$ & $\mathbf{g} / \mathbf{B h p H r}$ & $\mathbf{g} / \mathbf{B h p H r}$ & $\mathbf{g} / \mathbf{B h p H r}$ & $\mathbf{g} / \mathbf{B h p H r}$ & $\mathbf{g} / \mathbf{B h p H r}$ & $\mathbf{g} / \mathbf{B h p H r}$ & $\mathbf{g} / \mathbf{B h p H r}$ & $\% \mathbf{D i f f}$ \\
\hline HC & 1.149 & 1.175 & 1.078 & 1.134 & 1.156 & 1.158 & 1.169 & 1.095 & 1.145 & -0.9 \\
\hline CO & 0.836 & 0.872 & 0.853 & 0.854 & 0.886 & 0.861 & 0.861 & 0.875 & 0.871 & -2.0 \\
\hline CO2/100 & 5.316 & 5.310 & 5.334 & 5.320 & 5.340 & 5.337 & 5.339 & 5.324 & 5.335 & -0.3 \\
\hline NOx & 5.371 & 5.434 & 5.364 & 5.390 & 5.415 & 5.391 & 5.381 & 5.372 & 5.390 & 0.0 \\
\hline PM & 0.226 & 0.297 & 0.076 & 0.261 & 0.305 & 0.274 & 0.290 & 0.251 & 0.280 & -6.7 \\
\hline
\end{tabular}

Table 23 Comparison of Brake-Specific Emissions from First and Final Iterations of Excavator Cycle 3 (Trenching Cycle)

\begin{tabular}{|c|c|c|c|c|c|c|c|c|c|}
\hline Cycle 3 & \multicolumn{3}{|c|}{ First Cycle } & \multicolumn{3}{c|}{ Final Cycle } & Comparison \\
\hline Test & $\mathbf{1}$ & $\mathbf{2}$ & Average & $\mathbf{1}$ & $\mathbf{2}$ & $\mathbf{3}$ & $\mathbf{4}$ & Average & Ave - Ave \\
\hline Emissions & $\mathbf{g} / \mathbf{B h p H r}$ & $\mathbf{g} / \mathbf{B h p H r}$ & $\mathbf{g} / \mathbf{B h p H r}$ & $\mathbf{g} / \mathbf{B h p H r}$ & $\mathbf{g} / \mathbf{B h p H r}$ & $\mathbf{g} / \mathbf{B h p H r}$ & $\mathbf{g} / \mathbf{B h p H r}$ & $\mathbf{g} / \mathbf{B h p H r}$ & \% Diff \\
\hline HC & 1.154 & 1.157 & 1.156 & 1.110 & 1.103 & 1.075 & 1.11 & 1.100 & 5.1 \\
\hline CO & 0.835 & 0.854 & 0.845 & 0.859 & 0.856 & 0.861 & 0.837 & 0.853 & -1.0 \\
\hline CO2/100 & 5.307 & 5.245 & 5.276 & 5.300 & 5.234 & 5.228 & 5.262 & 5.256 & 0.4 \\
\hline NOx & 5.436 & 5.467 & 5.452 & 5.338 & 5.358 & 5.324 & 5.287 & 5.327 & 2.3 \\
\hline PM & 0.386 & 0.406 & 0.396 & 0.321 & 0.360 & 0.322 & 0.322 & 0.332 & 19.4 \\
\hline
\end{tabular}

